Giovanni Chaves Penner

\title{
"ESTUDO DE CASO DA CONTAMINAÇÃO DO SOLO E DA ÁGUA SUBTERRÂNEA POR DESCARTE DE RESÍDUOS VINCULADOS A ÓLEOS LUBRIFICANTES"
}

Tese apresentada à Escola de Engenharia de São Carlos da Universidade de São Paulo, como parte dos requisitos para a obtenção do Título de Doutor em Hidráulica e Saneamento.

Orientador: Prof. Tit. Harry Edmar Schulz 



\section{FOLHA DF HUGAMERT}

\section{Candidato Engerheiro GIONA V VI CAVES PENNER}

Tese defendida e julgada em 2 -06-2005 pennte a Comisto Julgadon:
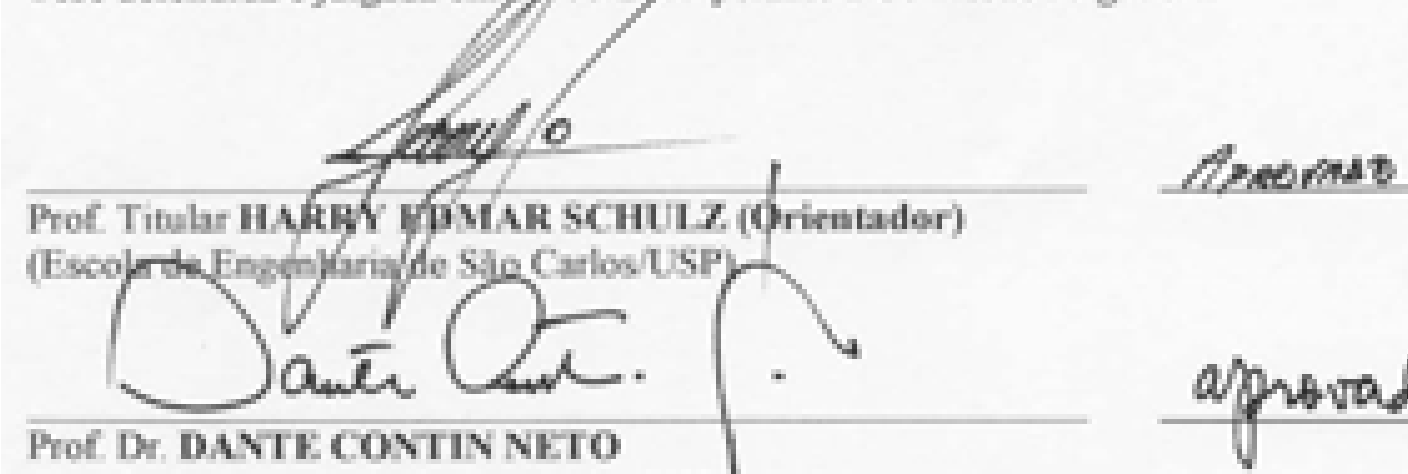

(Fseola de Engcehara de Sio CarlosusP)

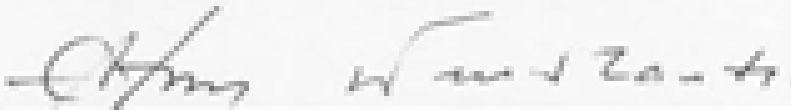

Prof Dr EDSON CRZAR WR VDLAND

(Kroola de Engenharia de sio Carlos/LSP)

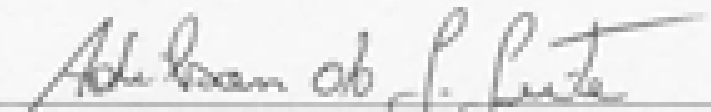

Pot Dr ADII S0\% DO haO I.FTT.

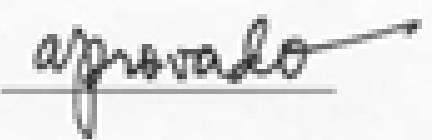

(Universidade Fedenal de Ouro ProtoLFOP)

\section{PIOf DN VAGVER ROHERTO EI.IS}

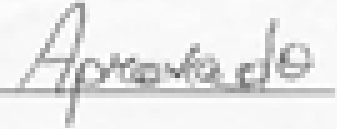

(Instituto Astronbmico e Gooffico-LSP)

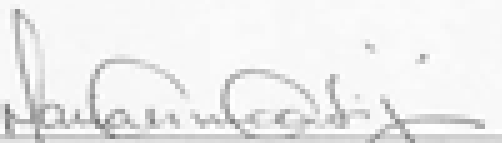

Profi Titula MARL DO CARMO CALDURI

Coondenadora do Programa de Pos-Ginduaglio em

Eingesharia (Hidraliea e Saneamento) e

Presidente da Comisulo de Pos-Ginductio 

Dedico este trabalho as duas mulheres que ao longo destes últimos anos foram exemplo de garra, determinação e companheirismo, minha mãe Gilda e minha esposa Josiele. 



\section{Agradecimentos}

A Deus Pai, sem ele nada teria conseguido.

Aos meus irmãos Gustavo, Gilvandro, Gisele e Gerson, ao meu pai Guilherme (in memoriam) e em especial a minha mãe Gilda, por todo o apóio, incentivo e participação. Também agradeço aos meus parentes de Belém do Pará por toda a motivação ao longo desta árdua caminhada.

A minha esposa Josiele de Souza Araújo pelos ótimos momentos que já vivemos e pelos que ainda virão, te amo.

Ao meu orientador professor Harry Edmar Schulz pela confiança, colaboração, amizade e contribuição.

À Secretaria de Planejamento e Gestão Ambiental do Município de Ribeirão Preto na pessoa do Geólogo Maurício de Melo Figueiredo Junior que contribuiu sobremaneira no fornecimento de dados, referências e informações.

Ao Centro de Monitoramento e Pesquisa da Qualidade de Combustíveis (CEMPEQC) do Instituto de Química de Araraquara da Universidade Estadual Paulista, nas pessoas do professor José Eduardo de Oliveira, Maria Luiza, Marco, Carlos Eduardo (Baiano), Juliano, Danilo, Graziele e Fabrício, por toda a amizade e ajuda nas análises de HPAs e EDX.

Aos colegas e amigos; do Pará: André Coelho, Neyson Mendonça, Márcio Nemer, Natache Arrifano, Hélio Almeida, Aurélio Picanço, Newton, Raimundo França, Alexandre, André e Celso Gurjão; do SHS: Leonardo Soares, Sergio 
Brasil, Sérgio Siebras, Renato Siman, Alisson Borges, João Moreira, Alexandre Silveira e família, Romeu Gadotti, Carlos Alberto Perdigão, Tibério Magalhães, Fábio Lavor, Fernando Passig, Karina Querne, João Rodrigo e família, André de Oliveira, José Eduardo Alamy, José Eduardo Quaresma, José Anderson Batista, Jorge Rabelo; da geotécnia: Paulo, Sandra, Cleber (Baiano), Holden, Domingos, Leonardo.

Ao professor Dante Contin Neto pela enorme contribuição no início desta pesquisa, pelo incentivo no planejamento da vigem ao exterior e pela excelente amizade.

Aos professores Edson Wendland e Bohdan Matvienko pelas contribuições ao longo desta tese.

Aos funcionários do Departamento de Hidráulica e Saneamento, em especial a Paulo Fragiacomo, Roberto Bergamo, Valdecir e Rose.

Ao Departamento de Hidráulica e Saneamento e ao Programa de PósGraduação em Hidráulica e Saneamento pela estrutura disponibilizada.

Aos professores Ruth e Luiz Duarte pelos bons momentos.

À Agência de Proteção Ambiental dos Estados Unidos (United State Environmental Protection Agency), aos pesquisadores Jack Hwang e Freddy Tilman, e em especial ao pesquisador James W. Weaver pela amizade, acolhida em Athens, GA, USA e orientação nos trabalhos de simulação numérica.

Ao professor Lázaro Valentin Zuquette pelas grandes contribuições na caracterização do solo e pela disponibilização dos laboratórios do Departamento de Geotecnia para a realização de vários ensaios.

Ao professor Vagner Roberto Elis pela amizade e pela participação ímpar em todas as etapas do levantamento geofísico. 
Ao professor Evaldo Luiz Gaeta Espíndola e a colega Mariana Masutti pela grande contribuição nas análises de metais.

A professora Maria Olímpia e ao colega Claudemir pela grande contribuição nas análises de carbono orgânico.

Ao senhor Sérgio Barbieri pela autorização de acesso a área pesquisada.

Aos funcionários do Departamento de Geotecnia: José Luis e Antônio pelo auxílio nos experimentos.

Agradeço à Fundação de Amparo a Pesquisa do Estado de São Paulo (FAPESP) pela bolsa (00/09933-0) e auxílio pesquisa (01/10302-7) concedidos, sem estes recursos esta pesquisa não seria possível.

Finalmente a todos aqueles que contribuíram de forma material e humana para a realização desta tese. 

"Ésgua du curno. Disque num sabe u que é pajurá". Comentário de Catifoló, um tapuio do Tapajós, diante de um turista que pedia informações, sobre as frutas da regiaão.

(Paulo André e Ruy Barata)

"Todas as coisas complexas estão condenadas à decadência". 



\section{Resumo}

PENNER, G. C. (2005). Estudo de caso da contaminação do solo e da água subterrânea por descarte de resíduos vinculados a óleos lubrificantes. Tese (Doutorado) - Escola de Engenharia de São Carlos, Universidade de São Paulo, São Carlos, 2005.

O presente trabalho apresenta resultados de medidas de campo, laboratório e simulações numéricas para o diagnóstico de um sítio de descarte de resíduos de rerefino de óleo lubrificante, localizado no Município de Ribeirão Preto, no Estado de São Paulo. A metodologia laboratorial utilizada mostrou-se viável, sendo descritos também casos nos quais a primeira proposta de trabalho não foi adequada. Adicionalmente, o programa numérico comercial escolhido para simular a situação do sítio mostrou-se suficientemente manuseável e adequado para estudos expeditos. Os dados de contaminação da água subterrânea por metais mostram que os principais contaminantes são o chumbo e o alumínio. Em termos de contaminação do solo por HPAs, verificou-se, de forma geral, baixa concentração (em alguns casos não detectáveis), ficando o fenantreno como o composto com a concentração mais elevada, porém sem padrão de comparação. O naftaleno, que possui esse padrão, mostrou concentração muito inferior àquela considerada como referência. Os resultados da simulação numérica são apresentados em sete camadas ao longo da profundidade, sendo sua resolução, no plano, efetuada com malhas de 50,0 $\mathrm{m}$ por $50,0 \mathrm{~m}$. Simulou-se uma pluma poluente de chumbo, com evolução para um tempo de 10 anos, com concentração inicial e de contorno compatível com as medidas efetuadas nos poços de monitoramento $(25 \mu \mathrm{g} / \mathrm{L})$. Os resultados apontam para contaminação efetiva da área utilizada para disposição do resíduo, bem como alteração nas circunvizinhanças. O presente trabalho representa uma contribuição para a sistematização da metodologia de estudo de áreas similares.

Palavras-chave: água subterrânea; contaminação; solo; metais; HPAs; simulação numérica. 



\section{Abstract}

PENNER, G. C. (2005). Case study of soil and groundwater contamination related to oil waste disposal on the soil. Ph.D. Thesis - Escola de Engenharia de São Carlos, Universidade de São Paulo, São Carlos, 2005.

This research introduces results of field and laboratory applications and numerical simulation to assess a site of oil waste disposal, in Ribeirão Preto, São Paulo, Brazil. The laboratorial methodology applied was useful, but there were also cases where the first try was not adequate. Additionally, the commercial numeric software selected to simulate site conditions was properly handled and applicable to expedited site assessment. The results of metals concentration in ground water highlight lead and aluminum as the main contaminants. In terms of PAHs in soil, in general, low concentrations (in some cases not detectible) were observed, where phenanthrene was the compound with the highest concentration, however without reference level. The naphthalene, has reference level, present concentrations much lower than the reference level. The numerical simulation results are presented in seven subsurface layers, which in a plan view the grid was divided in 50,0 $\mathrm{m}$ per 50,0 $\mathrm{m}$. A lead contamination was simulated in the transport model, with 10 years of temporal discretization, and with initial and boundary concentrations compatible with measures in monitoring wells $(25 \mu \mathrm{g} / \mathrm{L})$. The results show contamination in the disposal area, and alteration in the neighboring areas. The present research represents a contribution to the methodology for similar site assessment.

Keywords: groundwater; contamination; soil; metals; PAHs; numerical simulation. 



\section{Lista de Figuras}

Figura 3.1 - Espalhamento de um soluto provocado por difusão ao longo do tempo........17 Figura 3.2 - Transporte e espalhamento de um pulso de soluto com o tempo devido

a advecção e a dispersão.

Figura 3.3 - Isoterma de sorção linear............................................................................................. 24

Figura 3.4 - Linearização da isoterma de sorção de Freundlich. ..........................................2

Figura 3.5 - Linearização da isoterma de Langmuir. ................................................................ 28

Figura 3.6 - Equilíbrio das tensões em linha de contato entre três líquidos imiscíveis. .38

Figura 3.7 - Tensões interfaciais entre uma superfície sólida, a água (fluido molhante) e um líquido imiscível em fase não aquosa (fluido não molhante)..... 39

Figura 3.8 - Molhabilidade variando com o ângulo de contato..............................................40

Figura 3.9 - Elevação capilar em um tubo............................................................................................ 41

Figura 3.10 - Pressões atuantes em um tubo capilar. ............................................................... 42

Figura 3.11 - Curva de pressão capilar - curva de saturação do fluido molhante para escoamento bifásico.

Figura 3.12 - Retenção de blob e ganglion pelo solo.

Figura 3.13 - Escoamento de uma gota de água por uma superfície inclinada. Percebe-se que os ângulos de contato nas extremidades da gota são diferentes (histerese).

Figura 3.14 - Efeito da variação da condutividade hidráulica na curva de pressão capilar versus saturação.

Figura 3.15 - Efeitos da variação da formação na curva de pressão capilar versus saturação.

Figura 3.16 - Curva de permeabilidade relativa para um sistema NAPL-água em uma matriz porosa.

Figura 3.17 - Representação esquemática do comportamento de LNAPLs em subsuperfície. As fases são: (1) vapor, (2) adsorvida, (3) residual, (4), livre ou separada e (5) dissolvida.

Figura 3.18 - Representação esquemática do comportamento de DNAPLs em subsuperfície. As fases são: (1) vapor, (2) adsorvida, (3) residual, (4), livre ou separada e (5) dissolvida.

Figura 4.1 - Fotografia panorâmica do sítio estudado...................................................................... 79

Figura 4.2 - Localização da área de estudo...............................................................................................8 80

Figura 4.3 - Representação do croqui inicial do sítio.....................................................................83

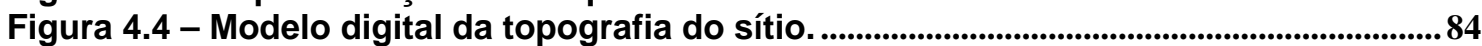

Figura 4.5 - Técnica de caminhamento elétrico, arranjo dipolo-dipolo (DD). (Fonte: Elis, 2001)

Figura 4.6 - Disposição em campo do arranjo Schlumberger. (Fonte: Elis, 2001).....89

Figura 4.7 - Amostra não deformada obtida na perfuração do PM - 08. .........................103

Figura 4.8 - Perfuração do poço de monitoramento PM - 05. ....................................................106

Figura 4.9 - Realização de slug test no PM - 02 A. Percebe-se que todos os equipamentos (carretel do transdutor, armazenador de dados "datalogger" $\mathrm{e}$ indicador) foram mantidos no porta-mala do automóvel.

Figura 4.10 - Geometria e simbologia para slug tests em um poço parcialmente penetrante para aqüíferos não confinados (modificado de BOUWER, 1989). ..............113

Figura 4.11 - Parâmetros adimensionais $A$, B e C em função do $\ln \left(L_{e} / R\right)$. .............................113

Figura 4.12 - Uma ilustração do procedimento de coleta. .....................................................117 
Figura 4.13 - Representação esquemática da distribuição das camadas no modelo numérico.

Figura 4.14 - Esquematização das condições impostas as modelo de transporte. Nota-se a ação da dispersividade vertical $\left(\alpha_{v}\right)$ na mistura vertical, da condição de recarga com $\mathrm{C}_{\mathrm{c}}=25 \mu \mathrm{g} / \mathrm{L}$ (área das cavas) e o efeito de transporte entre as diferentes camadas pela drenança.

Figura 5.2 - Seção 1 interpretada com o programa RES2DINV.

Figura 5.3 - Seção 2 interpretada com o programa SURFER 6.0.

Figura 5.4 - Seção 2 interpretada com o programa RES2DINV.................................................132

Figura 5.5 - Seção 3 interpretada com o programa SURFER 6.0. ..........................................132

Figura 5.6 - Seção 3 interpretada com o programa RES2DINV.................................................133

Figura 5.7 - Seção 4 interpretada com o programa SURFER 6.0. .............................................133

Figura 5.8 - Seção 4 interpretada com o programa RES2DINV.................................................134

Figura 5.9 - Seção 5 interpretada com o programa SURFER 6.0. ............................................134

Figura 5.10 - Seção 5 interpretada com o programa RES2DINV. ...........................................135

Figura 5.11 - Seção 6 interpretada com o programa SURFER 6.0. ........................................135

Figura 5.12 - Seção 6 interpretada com o programa RES2DINV. ...........................................136

Figura 5.13 - Seção 7 interpretada com o programa SURFER 6.0. ........................................136

Figura 5.14 - Seção 7 interpretada com o programa RES2DINV. ...........................................137

Figura 5.15 - Seção 8 interpretada com o programa SURFER 6.0. ........................................137

Figura 5.16 - Seção 8 interpretada com o programa RES2DINV. ...........................................137

Figura 5.17 - Seção 9 interpretada com o programa SURFER 6.0. .........................................138

Figura 5.18 - Seção 9 interpretada com o programa RES2DINV. ...........................................138

Figura 5.19 - Seção 10 interpretada com o programa SURFER 6.0. ......................................139

Figura 5.20 - Seção 10 interpretada com o programa RES2DINV. .............................................139

Figura 5.21 - Mapa de resistividade aparente - Nível 1 (profundidade teórica 10 metros) Interpretado com o programa SURFER 6.0.................................................................140

Figura 5.22 - Mapa de resistividade aparente - Nível 2 (profundidade teórica 15 metros) Interpretado com o programa SURFER 6.0..................................................................141

Figura 5.23 - Mapa de resistividade aparente - Nível 3 (profundidade teórica 20 metros) Interpretado com o programa SURFER 6.0..................................................................141

Figura 5.24 - Mapa de resistividade aparente - Nível 4 (profundidade teórica 25 metros) Interpretado com o programa SURFER 6.0.................................................................142

Figura 5.25 - Mapa de resistividade aparente - Nível 5 (profundidade teórica 30 metros) Interpretado com o programa SURFER 6.0.................................................................143

Figura 5.26 - Sondagem elétrica vertical 1 - Curva de campo e perfil geológico interpretado.

Figura 5.27 - Sondagem elétrica vertical 2. Curva de campo e perfil geológico interpretado.

Figura 5.28 - Variações na direção do escoamento subterrâneo com base nos PMs

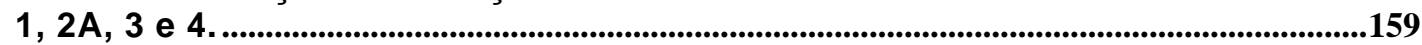

Figura 5.29 - Variações na direção do escoamento subterrâneo com base nos PMs

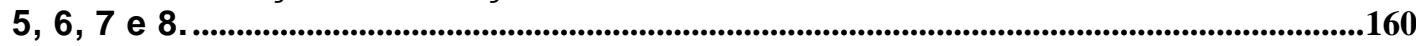

Figura 5.30 - Variações na direção do escoamento subterrâneo com base nos PMs 1, 2A, 6, 7 e 8.

Figura 5.31 - Mapa potenciométrico mostrando a comunicação entre o aqüífero suspenso e o localizado na formação arenito. .................................................................162

Figura 5.32 - Rebaixamento adimensional versus tempo de ensaio, para os PMs 1 e $2 A$

Figura 5.33 - Rebaixamento adimensional versus tempo de ensaio, para os PMs 2B

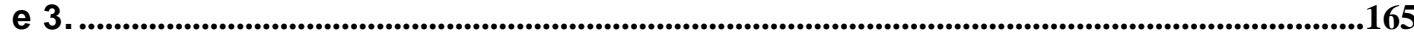

Figura 5.34 - Rebaixamento adimensional versus tempo de ensaio, para os PMs 4 e 5.

Figura 5.35 - Rebaixamento adimensional versus tempo de ensaio, para os PMs 6 e

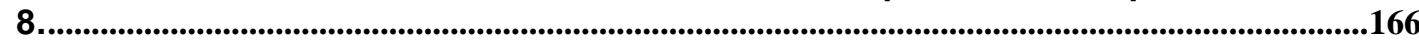

Figura 5.36 - Mapa definindo as condutividades hidráulicas (K) das camadas 2, 3 e 4 do modelo numérico. A região em vermelho refere-se à zona de maior " $K$ ". Foram definidas apenas dois valores de "K" diferentes nas camadas 2, 3 e 4, sendo que nas demais camadas restringiu-se o uso a só um valor de " $\mathrm{K}$ ". 
Figura 5.37 - Condutividades hidráulicas usadas no modelo de transporte. 173

Figura 5.38 - Mapa definindo as condições de contorno, cargas hidráulicas e vetores de direção do escoamento. As flechas indicam as direções dos escoamentos para a camada superficial de solo. A cota dos rios e a topografia definem as condições de contorno. As linhas em vermelho definem as cargas hidráulicas, considerando a primeira camada de solo na simulação efetuada. 174

Figura 5.39 - Mapa das cargas hidráulicas na primeira camada do modelo para a região do sítio estudado e imediações.

Figura 5.40 - Mapa das cargas hidráulicas na segunda camada do modelo para a região do sítio estudado e imediações.

Figura 5.41 - Mapa das cargas hidráulicas na terceira camada do modelo para a região do sítio estudado e imediações.

Figura 5.42 - Mapa das cargas hidráulicas na quarta camada do modelo para a região do sítio estudado e imediações.

Figura 5.43 - Mapa das cargas hidráulicas na quinta camada do modelo para a região do sítio estudado e imediações.

Figura 5.44 - Mapa das cargas hidráulicas na sexta camada do modelo para a região do sítio estudado e imediações.

Figura 5.45 - Mapa das cargas hidráulicas na sétima camada do modelo para a região do sítio estudado e imediações.

Figura 5.46 - Mapa de propagação de chumbo simulada para o um período de 10 anos. Observa-se a primeira camada do modelo para a região do sítio estudado e imediações.

Figura 5.47 - Mapa de propagação de chumbo simulada para o um período de 10 anos. Observa-se a segunda camada do modelo para a região do sítio estudado e imediações.

Figura 5.48 - Mapa de propagação de chumbo simulada para o um período de 10 anos. Observa-se a terceira camada do modelo para a região do sítio estudado e imediações.

Figura 5.49 - Mapa de propagação de chumbo simulada para o um período de 10 anos. Observa-se a quarta camada do modelo para a região do sítio estudado e imediações.

Figura 5.50 - Mapa de propagação de chumbo simulada para o um período de 10 anos. Observa-se a quinta camada do modelo para a região do sítio estudado e imediações...

Figura 5.51 - Mapa de propagação de chumbo simulada para o um período de 10 anos. Observa-se a sexta camada do modelo para a região do sítio estudado e imediações.

Figura 5.52 - Mapa de propagação de chumbo simulada para o um período de 10 anos. Observa-se a sétima camada do modelo para a região do sítio estudado e imediações. 



\section{Lista de Tabelas}

Tabela 3.1 - Contaminantes encontrados no solo e na água subterrânea no Estado de São Paulo.

Tabela 3.2 - Padrões de aceitação para os contaminantes de interesse desta pesquisa (Adaptado de CETESB, 2001b).

Tabela 3.3 - Coeficientes de difusão para algumas espécies em soluções diluídas a $25^{\circ} \mathrm{C}$ (Fonte: Lerman, 1979).

Tabela 3.4 - Valores de $K_{d}$ para alguns contaminantes freqüentemente encontrado......... 25

Tabela 3.5 - Equações para a estimativa de $\mathrm{K}_{\mathrm{oc}}$ por dados de $\mathrm{K}_{\mathrm{ow}}$ (Fonte: Compilação de Cleary, 1991 e Fetter, 1998).

Tabela 3.6 - Estimativa empírica do $K_{o c}$ por dados de $S$ (Adaptado de FETTER, 1998). 33

Tabela 3.7 - Distribuição das Fases do Contaminante (Adaptado de EPA, 1996a)..............61

Tabela 3.8 - Valores Típicos da Concentração de Destilados Médios Residuais na Zona Não Saturada (Adaptado de API, 1993).

Tabela 4.1 - Procedência e tipo de informações a respeito da área investigada.

Tabela 4.2 - Dados de níveis de água durante a primeira campanha de desenvolvimento.

Tabela 4.3 - Condições utilizadas na espectrometria de absorção atômica por chama. 120

Tabela 5.1 - Parâmetros de qualidade da água do poço vizinho ao sítio em estudo, medidos em campo.

Tabela 5.2 - Parâmetros de qualidade da água do poço vizinho ao sítio em estudo, medidos em laboratório.

Tabela 5.3 - Metais presentes na água do poço vizinho a área de estudo.

Tabela 5.4 - Concentrações de orgânicos voláteis medidas com detector de fotoionização.

Tabela 5.5 - Densidade absoluta das amostras do resíduo coletado nas cavas.................149

Tabela 5.6 - Densidade aparente das amostras de resíduo. ........................................................150

Tabela 5.7 - Composição mineralógica identificada na fração fina (menor que $0,037 \mathrm{~mm}$ ) das amostras analisadas.

Tabela 5.8 - Resultados de direção e gradiente para os poços de monitoramento 1, 2A, 3 e 4.

Tabela 5.9 - Resultados de direção e gradiente para os poços de monitoramento 5, 6, 7 e 8.

Tabela 5.10 - Resultados de direção e gradiente para os poços de monitoramento 1, 2A, 6,7 e 8.

Tabela 5.11 - Condutividades hidráulicas dos poços de monitoramento, determinadas por slug tests.

Tabela 5.12 - Resultados de parâmetros de qualidade de água, medidos em campo..... 168

Tabela 5.13 - Resultados das concentrações de metais em água subterrânea em $\mu$ g/L. 170 



\section{Lista de Siglas e Abreviaturas}

ABNT - Associação Brasileira de Normas Técnicas

API - American Petroleum Institute

CE - Condutividade Elétrica

CETESB - Companhia de Tecnologia de Saneamento Ambiental

CONAMA - Conselho Nacional do Meio Ambiente

CTC - Capacidade de Troca Catiônica

DD - Dipolo-Dipolo

DDT - Diclorodifeniltricloroetano

DNAPL - Líquido Imiscível em Fase Não Aquosa mais Denso que a Água DP - Desvio Padrão

EAAC - Espectrometria de Absorção Atômica por Chama

EAAFG - Espectrometria de Absorção Atômica por Forno de Grafite

Eh - Potencial Redox

ETE - Estação de Tratamento de Esgoto

GV - Groundwater Vistas

$\mathrm{HCH}$ - Hexaclorociclohexano

HPAs - Hidrocarbonetos Policíclicos Aromáticos

LD - Limite de Detecção

LNAPL - Líquido Imiscível em Fase Não Aquosa mais Leve que a Água

LQ - Limite de Quantificação

NAPL - Líquido Imiscível em Fase Não Aquosa

NBR - Norma Brasileira

NIOSH - National Institute for Occupational Safety Health

OD - Oxigênio Dissolvido

PCE - Tetracloroetileno

PM - Poço de Monitoramento 
SE - Superfície Específica

SD - Sondagem a Trado Mecanizado

SEV - Sondagem Elétrica Vertical

SMA - Secretaria de Meio Ambiente

USEPA - United State Environmental Protection Agency

USGS - United State Geological Survey

WHO - World Health Organization 


\section{Lista de Símbolos}

\section{Arábicos}

$A$ - área atingida pelo vazamento $\left(\mathrm{L}^{2}\right)$.

$a$ - teor volumétrico de $\operatorname{ar}\left(\mathrm{M} / \mathrm{L}^{3}\right)$.

$C$ - concentração do soluto $\left(\mathrm{M} / \mathrm{L}^{3}\right)$.

$C^{*}$ - quantidade de soluto sorvido por peso unitário de sólido $\left(M / L^{3}\right)$.

$C_{i}^{w}$ - concentração do soluto na fase aquosa em equilíbrio com a fase orgânica $\left(\mathrm{M} / \mathrm{L}^{3}\right)$.

$C_{a_{i}}$ - concentração do composto "i" em água $\left(\mathrm{M} / \mathrm{L}^{3}\right)$.

$\frac{d C}{d x}-$ gradiente de concentração $\left(M / L^{3} / L\right)$.

$\frac{\partial C}{\partial t}-$ variação de concentração com o tempo $\left(M / L^{3} / T\right)$.

$D_{d}$ - coeficiente de difusão $\left(\mathrm{L}^{2} / \mathrm{T}\right)$.

$D_{T}$ - coeficiente de dispersão hidrodinâmica perpendicular à direção principal do escoamento (transversal) $\left(\mathrm{L}^{2} / \mathrm{T}\right)$.

$D_{L}$ - coeficiente de dispersão hidrodinâmica paralelo à direção principal do escoamento (longitudinal) ( $\left.\mathrm{L}^{2} / \mathrm{T}\right)$.

$d$ - distância vertical percorrida pelo produto até atingir o nível da água (L).

$F_{A_{X}}$ - fluxo de massa advectivo unidimensional $\left(\mathrm{M} / \mathrm{L}^{2} / \mathrm{T}\right)$.

$F_{D_{X}}$ - fluxo de massa difusivo unidimensional $\left(\mathrm{M} / \mathrm{L}^{2} / \mathrm{T}\right)$.

$f_{L}$ e $f_{S}$ - fugacidade dos componente "i" puro nas fases de sub-congelamento líquida e sólida (adimensional).

$f_{o c}$ - fração de carbono orgânico (adimensional). 
$g$ - aceleração da gravidade $\left(\mathrm{L} / \mathrm{T}^{2}\right)$.

$H_{0}$ - variação inicial do nível de água (L).

$H_{t}$ - variação do nível de água em um tempo qualquer (L).

$H_{p c}$ - constante de Henry $\left(\mathrm{L}^{2} / \mathrm{T}^{2}\right)$.

$h_{c}-$ altura capilar (L).

$\frac{d h}{d l}$ - gradiente hidráulico (L/L).

$\frac{d h}{d x}$ - gradiente hidráulico (L/L).

$K$ - condutividade hidráulica (L/T).

$K_{d}$ - coeficiente de distribuição $\left(\mathrm{L}^{3} / \mathrm{M}\right)$.

$K_{O C}$ - coeficiente de partição vinculado ao carbono (adimensional).

$K_{\text {ow }}$ - coeficiente de partição octanol-água (adimensional).

$k$ - permeabilidade do meio $\left(\mathrm{L}^{2}\right)$.

$k_{m}$ - permeabilidade efetiva para o fluido molhante $\left(L^{2}\right)$.

$k_{n m}$ - permeabilidade efetiva para o fluido não molhante $\left(\mathrm{L}^{2}\right)$.

$k_{r_{m}}$ - permeabilidade relativa para o fluido molhante $\left(\mathrm{L}^{2}\right)$.

$k_{r_{m}}$ - permeabilidade relativa para o fluido não molhante $\left(L^{2}\right)$.

$k_{r n m m}^{*}$ - permeabilidade relativa do NAPL na saturação residual de água num sistema água-NAPL $\left(\mathrm{L}^{2}\right)$.

$k_{r n m m}$ - permeabilidade relativa do NAPL em função da $S_{m}\left(L^{2}\right)$.

$k_{r n m a}-$ permeabilidade relativa do NAPL em função da $S_{a}\left(\mathrm{~L}^{2}\right)$.

$L_{e}$ - comprimento do filtro (L).

$n_{e}$ - porosidade efetiva (adimensional).

$P$ - pressão $\left(\mathrm{M} / \mathrm{LT}^{2}\right)$.

$P_{c}-$ pressão capilar $\left(\mathrm{M} / \mathrm{LT}^{2}\right)$.

$P_{m}$ - pressão exercida pelo fluido molhante $\left(\mathrm{M} / \mathrm{LT}^{2}\right)$.

$P_{n m}$ - pressão exercida pelo fluido não molhante $\left(M / L T^{2}\right)$.

$p_{i}-$ pressão parcial do composto "i" na fase de vapor $\left(\mathrm{M} / \mathrm{LT}^{2}\right)$.

$p_{i}^{o}-$ pressão de vapor do composto "i" puro $\left(\mathrm{M} / \mathrm{LT}^{2}\right)$. 
$q$ - fluxo de Darcy $\left(\mathrm{L}^{3} / \mathrm{L}^{2} / \mathrm{T}\right)$.

$R$ - raio da região preenchida com pré-filtro (L).

$R_{v}$ - Quantidade de NAPL retida na zona saturada (litros de NAPL/ $\mathrm{m}^{3}$ de solo).

$R_{e}$ - raio de interferência da variação na carga hidráulica $(\mathrm{L})$.

$r$ - raio dos poros $(\mathrm{L})$.

$r_{c}$ - raio interno do revestimento do poço $(\mathrm{L})$.

$r_{c v}$ - raio de curvatura formado na interface entre os dois fluidos imiscíveis (L).

$r_{t}$ - raio do tubo $(\mathrm{L})$.

$r_{f}$ - fator de retardamento (adimensional).

rxn - indicação de reações biológicas ou químicas do soluto.

$S_{i}^{w}$ - solubilidade do componente puro em água $\left(M / L^{3}\right)$.

$S_{R}$ - retenção específica do material geológico para o produto (adimensional).

$T$ - tortuosidade (adimensional).

$t$ - tempo $(\mathrm{T})$.

$V_{R}-$ volume de produto retido pelos poros $\left(\mathrm{L}^{3}\right)$.

$X_{i}$ - fração molar do composto "i" em mistura (adimensional).

$z_{n}$ - espessura crítica de DNAPL (L).

\section{Gregos}

$\alpha$ - constante relacionada à energia de ligação $\left(\mathrm{L}^{3} / \mathrm{M}\right)$.

$\alpha_{L}-$ dispersividade na direção " $x$ " (L).

$\alpha_{T}-$ dispersividade na direção " $y$ " (L).

$\beta$ - quantidade máxima de soluto que pode ser absorvido por um sólido (adimensional).

$\gamma_{i}$ - coeficiente de atividade do soluto "i" na fase orgânica (adimensional).

$\sigma_{L}^{2}-$ variância do espalhamento longitudinal da pluma (adimensional).

$\sigma_{T}^{2}-$ variância do espalhamento transversal da pluma (adimensional). 
$\sigma_{B A}$ - tensão entre o líquido $B$ e líquido $\mathrm{A}\left(\mathrm{ML} / \mathrm{T}^{2}\right)$.

$\eta$ - porosidade (adimensional).

$\Theta$ - conteúdo volumétrico de água $\left(\mathrm{M} / \mathrm{L}^{3}\right)$.

$\theta$ - ângulo de contato (adimensional).

$\mu$ - viscosidade absoluta ou viscosidade dinâmica (M/LT).

$v_{x}$ - velocidade linear média (L/T).

$\rho_{b}$ - massa específica dos sólidos $\left(\mathrm{M} / \mathrm{L}^{3}\right)$.

$\rho_{\text {agua }}$ - densidade ou massa específica da água $\left(\mathrm{M} / \mathrm{L}^{3}\right)$.

$\rho_{n}$ - densidade ou massa específica do NAPL $\left(\mathrm{M} / \mathrm{L}^{3}\right)$.

$w$ - coeficiente relacionado à tortuosidade do meio (adimensional). 


\section{Sumário}

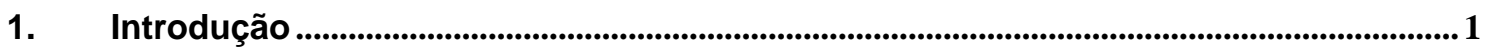

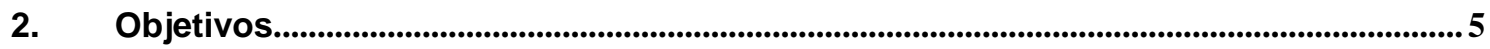

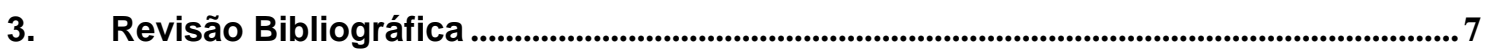

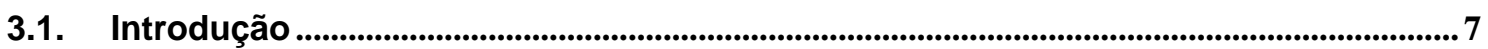

3.1.1. Contaminantes de Importância Ambiental ..............................................................................

3.1.2. Padrões de Qualidade de Água e Solo .........................................................................

3.1.3. Fontes de Contaminação do Solo e das Águas Subterrâneas....................................... 9

3.1.4. Histórico de Contaminações Relevantes ..................................................................................10

3.2. Transporte de Massa em Meio Poroso Saturado ...........................................................12

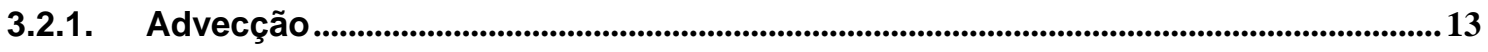

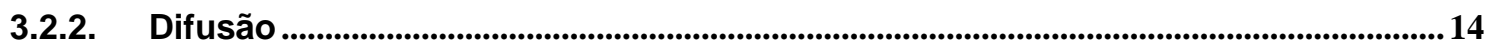

3.2.3. Dispersão Mecânica ..................................................................................................................... 18

3.2.4. Dispersão Hidrodinâmica............................................................................................................. 19

3.3. Transformações, Retardamento e Atenuação do Soluto................................................... 21

3.3.1. Processos de Sorção ………………………........................................................................ 22

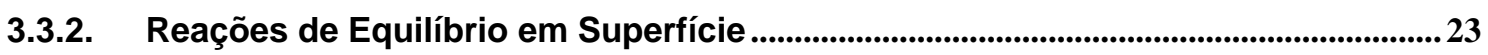

3.3.2.1. Isoterma de Sorção Linear .....................................................................................................23

3.3.2.2. Isoterma de Sorção de Freundlich....................................................................................... 25

3.3.2.3. Isoterma de Sorção de Langmuir ......................................................................................... 27

3.3.2.4. Sorção de Compostos Orgânicos Hidrofóbicos ............................................................. 29

3.3.2.4.1. Partição Controlada pelo Carbono Orgânico ................................................................. 29

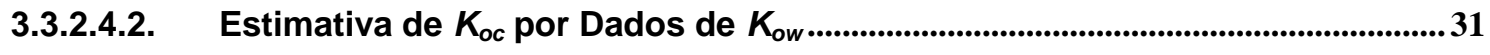

3.3.2.4.3. Estimativa de $K_{o c}$ por Dados de Solubilidade ........................................................33 
3.3.2.4.4. Efeitos na Mistura de Solutos: Lei de Raoult ......................................................34

3.4. Escoamento Multfásico e Conceituação Básica .........................................................35

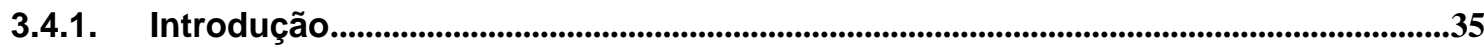

3.4.2. Saturação

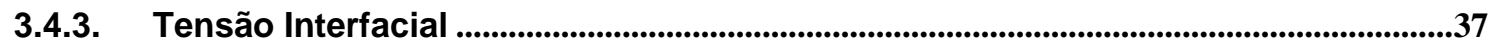

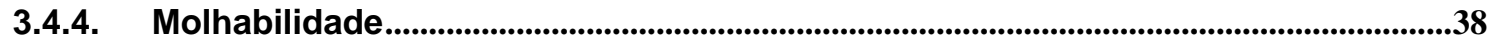

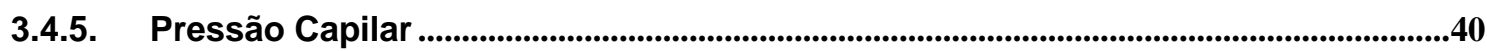

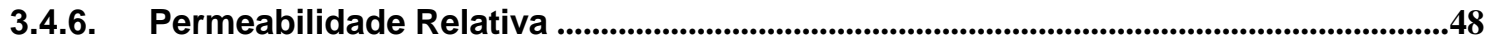

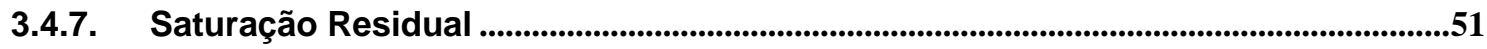

3.4.8. Equação de Darcy para Escoamentos Bifásicos.....................................................52

3.4.9. Migração de Líquidos em Fase Não Aquosa ............................................................53

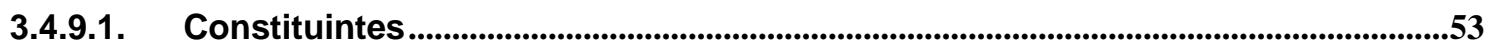

3.4.9.2. Propriedades Físico-Químicas dos NAPLs......................................................55

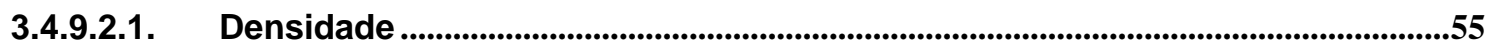

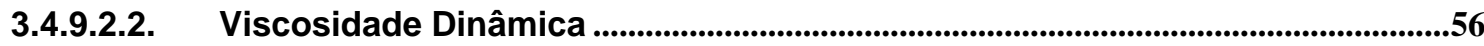

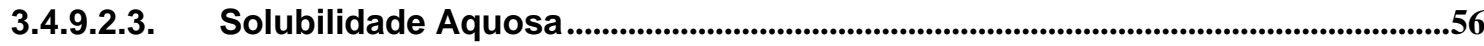

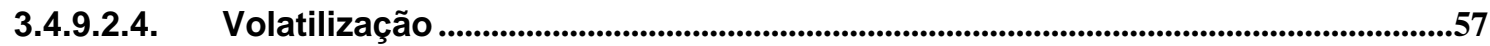

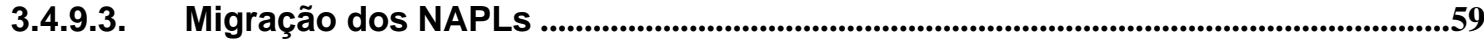

3.4.9.4. Comportamento das Fases dos NAPLs ................................................................61

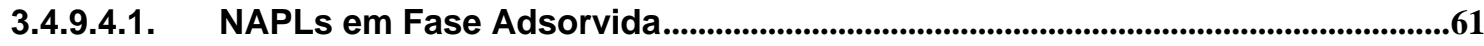

3.4.9.4.2. NAPLs em Fase Dissolvida .................................................................................64

3.4.9.4.3. NAPLs em Fase Livre ou Separada......................................................................66

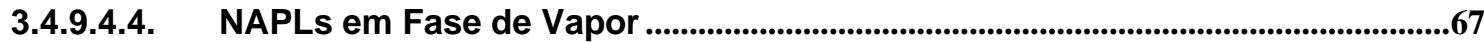

3.5. Geofísica Aplicada à Avaliação de Áreas Contaminadas ................................................70

3.5.1. Geofísica Aplicada a Contaminação por Hidrocarbonetos..........................................71

3.6. Determinação da Condutividade Hidráulica por Slug Test...........................................73

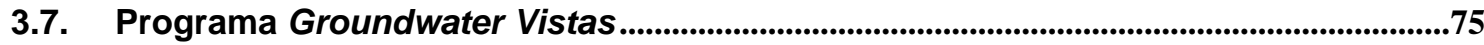

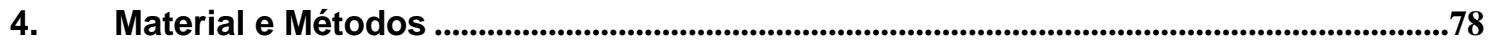

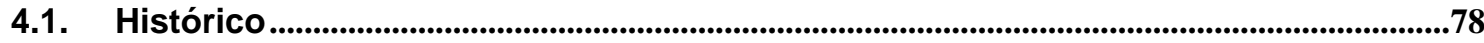

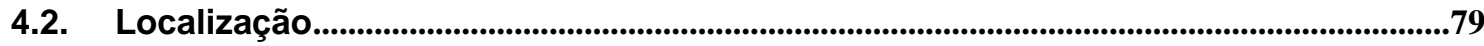


4.3. Revisão das Informações Existentes................................................................................

4.4. Desenvolvimento do Modelo Conceitual Inicial .................................................................

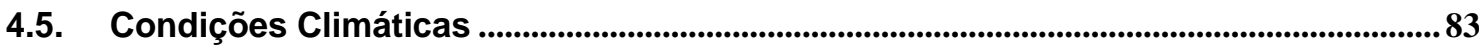

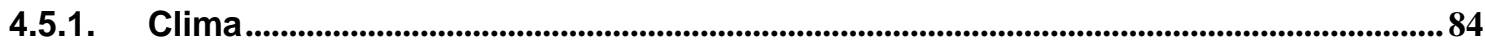

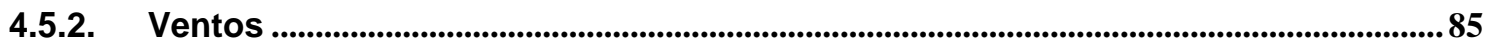

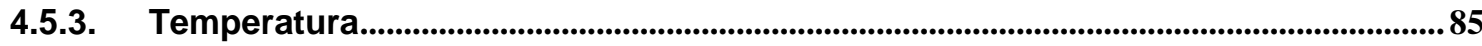

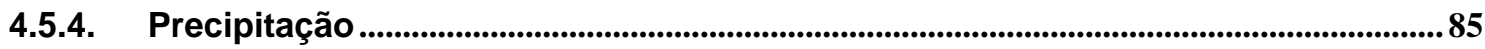

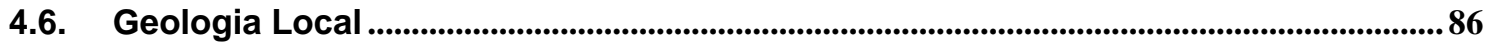

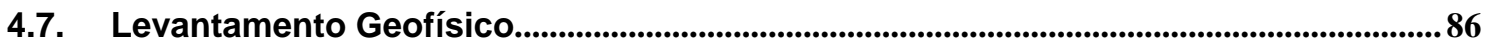

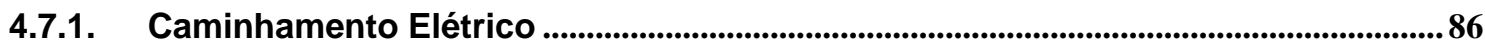

4.7.2. Sondagem Elétrica Vertical ......................................................................................................... 88

4.8. Caracterização do Resíduo de Re-refino de Óleo................................................................90

4.8.1. Medidas com Detector de Fotoionização................................................................................ 91

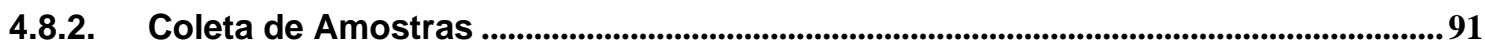

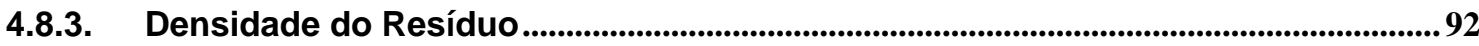

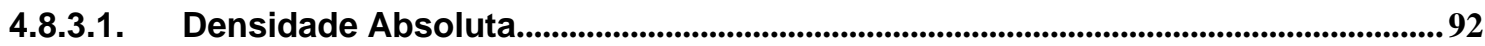

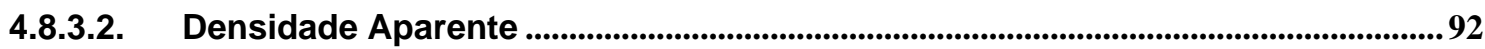

4.8.4. Caracterização da Fração Orgânica ......................................................................................93

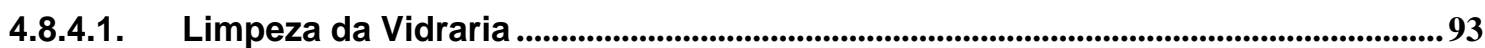

4.8.4.2. Tratamento das Fases Sólidas............................................................................................... 93

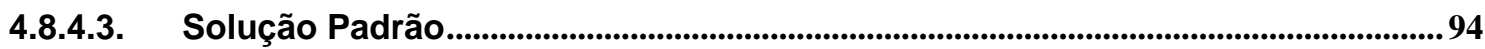

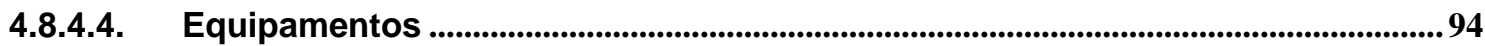

4.8.4.5. Curvas de Calibração ...........................................................................................................94

4.8.4.6. Avaliação da Sensibilidade: Limites de Detecção e Quantificação .......................95

4.8.4.7. Extração ................................................................................................................................. 95

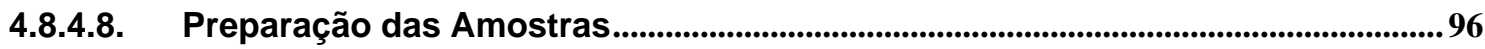

4.8.5. Caracterização da Fração Inorgânica ………………………..................................................96

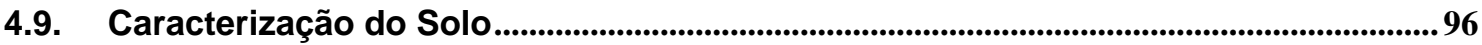

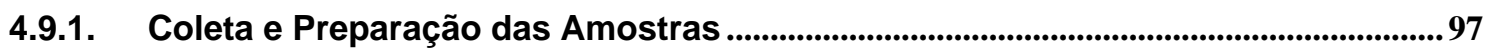

4.9.2. Caracterização Física .............................................................................................................97 
4.9.2.1. Análise Granulométrica Conjunta ............................................................................97

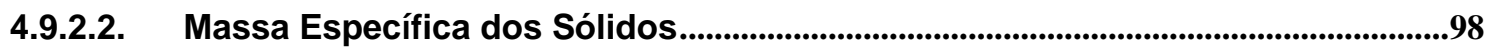

4.9.3. Caracterização Físico-Química ..............................................................................................98

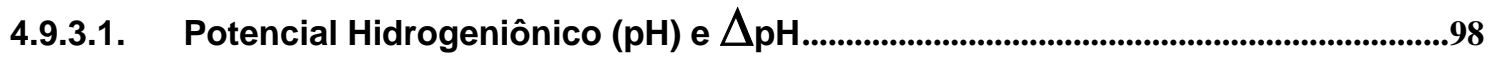

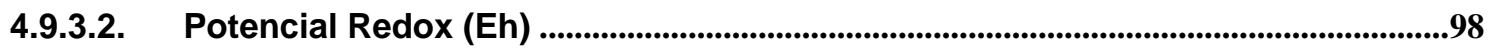

4.9.3.3. Condutividade Elétrica do Extrato Aquoso.....................................................................99

4.9.3.4. Estimativa da Capacidade de Troca Catiônica e Superfície Específica ................99

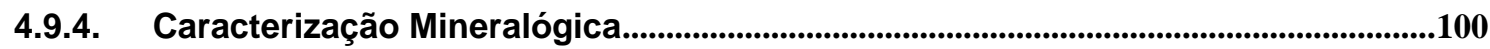

4.9.4.1. Preparação das Lâminas ...................................................................................................100

4.9.4.2. Condições do Ensaio ..................................................................................................101

4.9.5. Caracterização Química ................................................................................................101

4.9.5.1. Teor de Carbono Orgânico Total ……....................................................................101

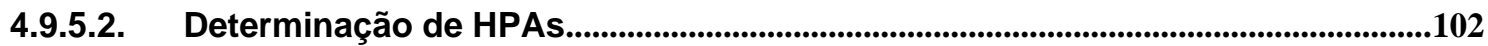

4.9.5.3. Determinação da Fração Inorgânica.................................................................................103

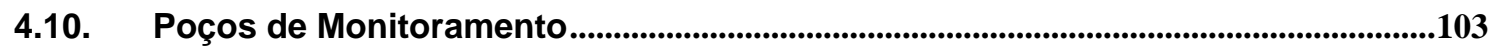

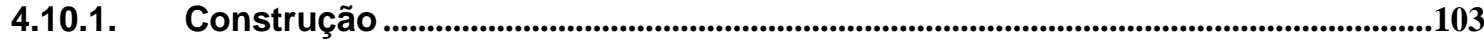

4.10.2. Características dos Poços de Monitoramento .................................................................105

4.10.3. Desenvolvimento dos Poços de Monitoramento............................................................106

4.10.4. Direção do Escoamento, Gradiente Hidráulico e Superfície Potenciométrica 107

4.10.5. Determinação da Condutividade Hidráulica por Slug Tests.....................................108

4.10.5.1. Método de Bouwer e Rice ...................................................................................................111

4.11. Qualidade da Água Subterrânea ...............................................................................114

4.11.1. Determinação de Metais em Amostras de Água Subterrânea....................................114

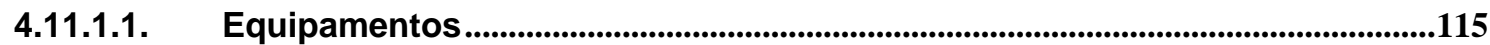

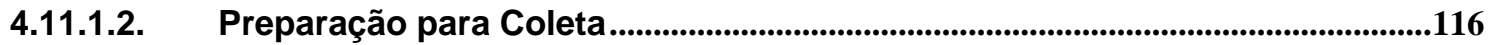

4.11.1.3. Pontos de Amostragem...........................................................................................116

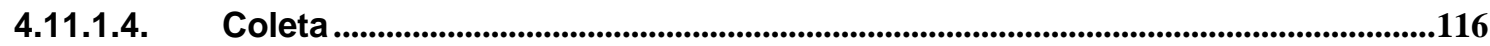

4.11.1.5. Filtração para Metais Dissolvidos ...............................................................................118

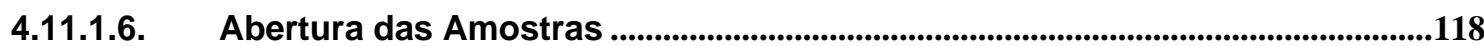


4.11.1.7. Curvas de Calibração

4.11.1.8. Avaliação da Sensibilidade: Limites de Detecção e Quantificação ................ 119

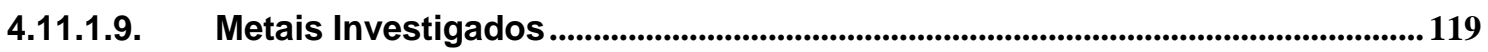

4.12. Simulação Numérica com o Programa Groundwater Vistas......................................120

4.12.1. Definição dos Objetivos da Simulação...................................................................120

4.12.2. Coleta de Dados e Desenvolvimento do Modelo Conceitual ................................. 121

4.12.3. Escolha do Programa de Escoamento e Transporte ............................................ 122

4.12.4. Construção do Modelo de Escoamento …...........................................................123

4.12.5. Construção do Modelo de Transporte ......................................................................125

4.12.6. Calibração por Pontos de Referência (Targets) ..................................................126

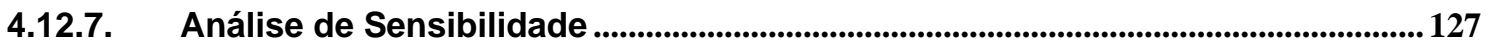

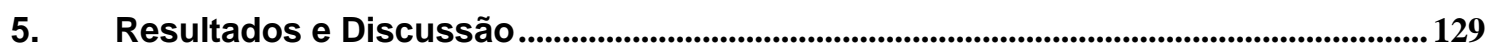

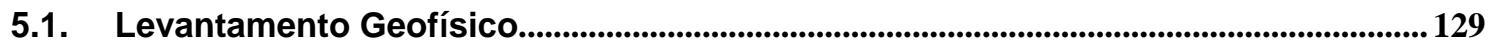

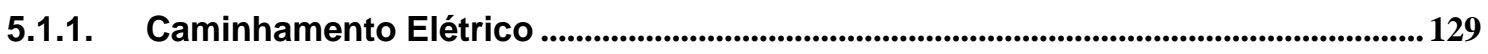

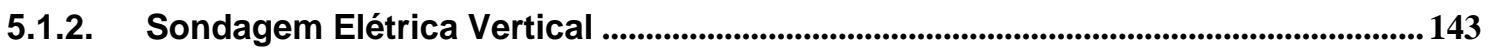

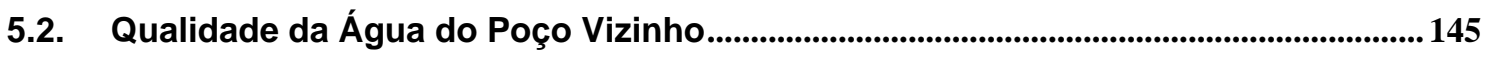

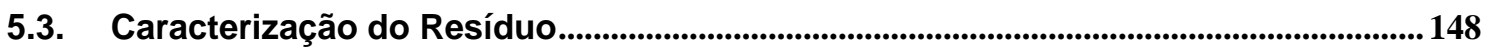

5.3.1. Medidas com Detector de Fotoionização.........................................................................148

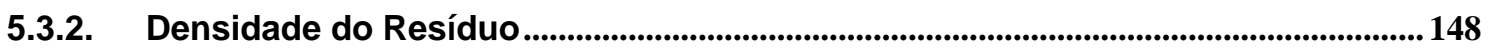

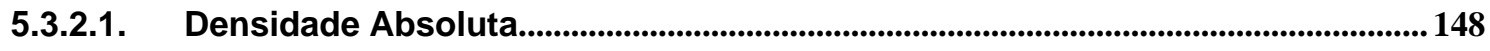

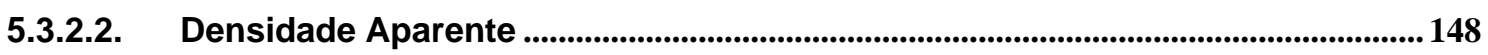

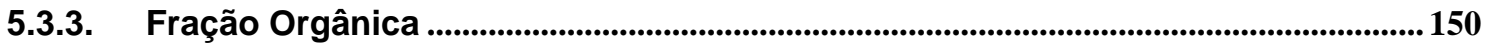

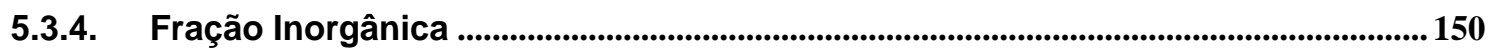

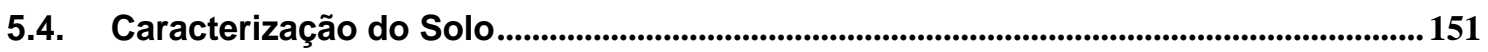

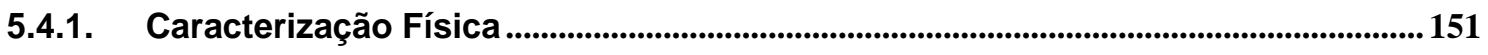

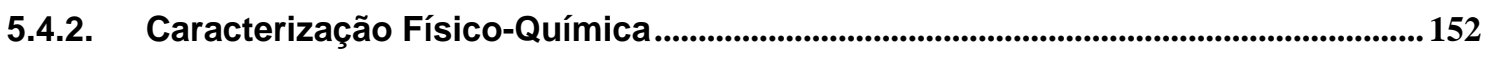

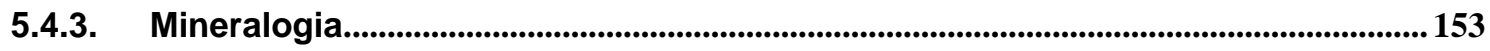

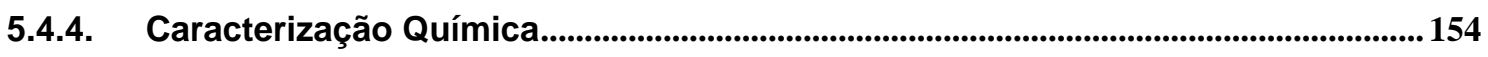

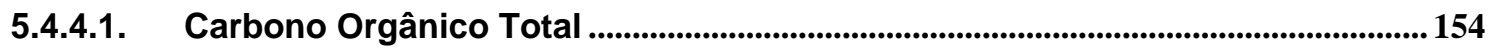

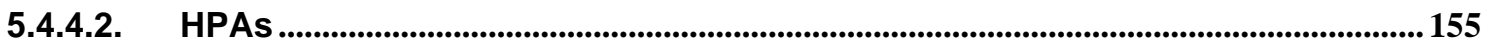




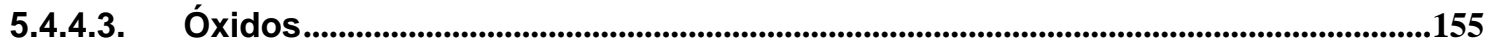

5.4.5. Interpretação dos Perfis das Sondagens e dos Poços de Monitoramento ...........156

5.5. Direção do Escoamento, Gradiente Hidráulico e Superfície Potenciométrica .........157

5.6. Interpretação dos Resultados de Slug Test...........................................................................162

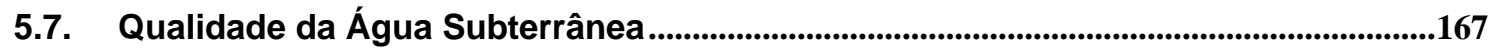

5.8. Simulação Numérica ...................................................................................................................171

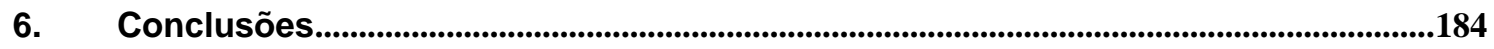

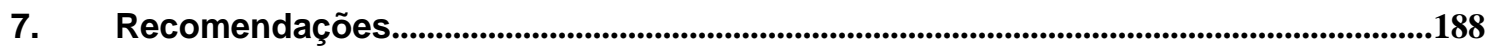

8. Referências Bibliográficas .......................................................................................190 


\section{Introdução}

A contaminação do solo e água subterrânea, hoje em dia, é motivo de preocupação para a sociedade e autoridades responsáveis, devido aos impactos provocados à saúde publica e ao meio ambiente. Em termos de divulgação, que por vezes coloca em evidência algum aspecto de desleixo por parte do poder público, observa-se que a atenção despendida pela mídia aos acidentes, como por exemplo, os relatos vinculados ao descarte descontrolado de resíduos industriais no "aterro" Mantovani, caso Shell no município de Paulínia-SP, etc., têm aumentado ao longo das últimas décadas. Não obstante, a contaminação de forma geral e do solo em particular continua em discussão e, ainda, sem consenso geral de quais são as melhores formas de abordagem do assunto entre os pesquisadores e profissionais da área. Se por um lado existem dificuldades técnicas, por outro lado, a questão política é relevante, pois não sendo adequadamente orientada, os resultados em termos de controle e recuperação serão nulos.

Desde tempos remotos, o solo é utilizado como receptor de resíduos resultantes das diversas atividades humanas. Com o início da utilização de processos industriais em grande escala, principalmente a partir da Revolução Industrial, as descargas não controladas de resíduos no ambiente e as conseqüências das acumulações no solo sofreram mudanças impressionantes de intensidade e forma. Mais e mais observa-se o uso excessivo dos recursos naturais, uma conseqüência decorrente do crescimento exacerbado, principalmente das atividades industriais e agrícolas.

O solo é encarado como um receptor de resíduos, que pode ocorrer das seguintes formas: como um depósito local de resíduos propriamente dito, como uma área de estocagem ou processamento de produtos químicos, como resultado de algum vazamento ou derramamento, ou ainda assumindo escala regional, através de deposição na atmosfera, por inundação ou mesmo por 
práticas agrícolas inadequadas. Em todos os casos pode ocorrer um deslocamento descendente de contaminantes do solo para a água subterrânea, o que evidentemente passa a compor um problema para as populações que usam tal recurso hídrico. As conseqüências geradas pela contaminação do meio ambiente e, em especial, do solo, só atualmente têm despertado a atenção de uma maior massa de pessoas leigas e especialistas no Brasil. $O$ solo, cada vez mais, está sendo considerado como parte importante do ambiente, e sendo reconhecido como um recurso limitado. Como conseqüência, o conceito de proteção do solo está sendo objeto de discussões e pode se tornar parte integrante das decisões no contexto político. Esta é uma questão delicada e complexa do ponto de vista gerencial, pelas muitas funções que o solo desempenha, além do valor econômico intrínseco que possui. De forma geral, o proprietário possui o direito legal do solo (que constitui a sua propriedade) e o transaciona como mercadoria (CETESB, 2001a).

Em um derramamento, vazamento e/ou descarte no solo de derivados do petróleo, uma das principais preocupações é a contaminação dos aqüíferos que são usados como fonte de abastecimento de água para consumo humano. Por serem muito pouco solúveis em água, os derivados do petróleo derramados, contendo geralmente mais de uma centena de componentes distintos, inicialmente estão presentes no subsolo como líquido em fase não aquosa (NAPL), comportando-se como uma fonte contínua de contaminação, além de apresentarem risco de explosões e incêndios. Posteriormente, quando em contato com a água subterrânea, o contaminante se solubiliza parcialmente. Os hidrocarbonetos monoaromáticos são os constituintes dos derivados de petróleo que têm maior solubilidade em água e, portanto, são os contaminantes que primeiro afetam o lençol freático. Dentre os monoaromáticos, o benzeno é considerado o mais tóxico, comprovadamente cancerígeno, com padrão de potabilidade de $5 \mu \mathrm{g} / \mathrm{L}$ (BRASIL, LEIS, etc. 2000).

O presente estudo se insere no contexto da disposição de derivados de petróleo em solo, procedimento seguido por uma indústria de re-refino. O sítio no qual se desenvolveram os trabalhos compõe-se de cavas abertas em solo nu, nos quais os resíduos foram lançados sem tratamento ou preocupações relativas à proteção da área. Esses procedimentos foram considerados, segundo informações, adequados quando de sua implantação. Evidentemente 
o momento atual da consciência ambiental e da legislação brasileira não permite mais o convívio com essa forma de disposição final.

Como os procedimentos tomados numa avaliação são demorados e onerosos, pois se necessita de mão-de-obra especializada e equipamentos modernos, uma passagem inoportuna para uma etapa seguinte, de recuperação ou remediação, pode acarretar em um gasto de recursos e tempo desnecessários. Assim, percebe-se que um roteiro para avaliação de meio físico alterado deve ser desenvolvido, para uma caracterização efetiva da área em questão. O presente projeto de pesquisa foi desenvolvido com esse intuito, sendo os resultados apresentados no presente texto. Espera-se que a contribuição possa ser inserida no contexto brasileiro de avaliação de sítios de descarte de resíduos. 


\section{Objetivos}

Dividem-se os objetivos deste projeto em Objetivo Geral e Objetivos Específicos.

Objetivo Geral:

A partir de um caso real de contaminação do solo por resíduo oriundo de

óleo lubrificante, aplicar, adaptar e desenvolver formas de obtenção e tratamento de dados relacionados ao transporte deste contaminante.

Como Objetivos Específicos desta pesquisa sobressaem-se os seguintes tópicos:

- O caso da Indústria a ser estudada representa uma oportunidade para verificar a adequação de medidas e modelos previstos em estudos do movimento de contaminantes em solo e água subterrânea;

- Estabelecer a evolução da concentração ao longo da profundidade do solo a partir de análises comparativas (fotoionização, métodos extrativos e cromatografia);

- Buscar a otimização da rede de poços de monitoramento para estudos de casos similares;

- A partir da quantificação das diversas fases do caso específico, explicar sua inter-relação e avançar na quantificação prevista do avanço da pluma de contaminação e cálculo da zona afetada;

- Sugerir medidas adequadas para este caso e casos similares. 


\section{Revisão Bibliográfica}

\subsection{Introdução}

\subsubsection{Contaminantes de Importância Ambiental}

Uma grande variedade de substâncias pode ser considerada como contaminante para o solo e a água subterrânea. Entende-se por contaminante qualquer substância que exceda os padrões de qualidade estabelecidos pela legislação momentaneamente em vigor em uma região do globo, quais sejam, limite de potabilidade, valores de referência, valores orientadores, etc. Furtamonos de argumentar em favor de uma definição absoluta, uma vez que a destinação (o uso) é o fator que estabelece se uma substância é ou não indesejável, constituindo-se, por conseguinte, em um contaminante. Basta talvez mencionar as substâncias que mais comumente são associadas com efeitos deletérios ao homem. Nesse grupo estão inseridos: compostos orgânicos sintéticos, hidrocarbonetos, íons (cátions e ânions), organismos patogênicos e substâncias radioativas. Muitos destes se solubilizam ou se dissociam em várias ordens de magnitude. Alguns dos compostos orgânicos são parcialmente solúveis, sendo encontrados nas fases dissolvida e insolúvel (fase insolúvel é, também, usualmente denominada de fase separada ou fase livre), as quais podem migrar pelo subsolo. A ocorrência de cátions e ânions pode advir de forma natural, bem como, de fontes antropogênicas.

$\mathrm{Na}$ Tabela 3.1 são apresentados os contaminantes encontrados em solos e águas subterrâneas no Estado de São Paulo, segundo a lista intitulada "Áreas Contaminadas no Estado de São Paulo", divulgada pela CETESB em novembro de 2004. De um total de 1.336 sítios diagnosticados como contaminados, 931 são postos de combustíveis. Este número elevado de 
contaminações provocadas por postos de combustíveis decorre das atuais exigências para o licenciamento ambiental, como determina a Resolução CONAMA no 273 e a Resolução SMA n 5. Muito provavelmente, outros casos de contaminação, que não por postos, podem estar presentes, porém ainda não foram diagnosticados.

Tabela 3.1 - Contaminantes encontrados no solo e na água subterrânea no Estado de São Paulo.

\begin{tabular}{lr}
\hline \multicolumn{1}{c}{ Contaminante } & Número de Casos \\
\hline Combustíveis Líquidos & 881 \\
\hline Solventes Aromáticos & 818 \\
\hline PAHs & 467 \\
\hline Metais & 197 \\
\hline Solventes Halogenados & 94 \\
\hline Outros Contaminantes & 64 \\
\hline Outros Inorgânicos & 47 \\
\hline Fenóis Halogenados & 42 \\
\hline Biocidas & 30 \\
\hline PCBs & 15 \\
\hline Solventes Aromáticos Halogenados & 14 \\
\hline Ftalatos & 12 \\
\hline Dioxinas e Furanos & 2 \\
\hline Anilinas & 2 \\
\hline Radionuclídeos & 1 \\
\hline Microbiológicos & 1 \\
\hline \hline
\end{tabular}

\subsubsection{Padrões de Qualidade de Água e Solo}

Os padrões de qualidade para solo e água subterrânea utilizados como referência nesta pesquisa foram: resolução CONAMA 357/05 (atualização do CONAMA 20/86), que estabelece valores aceitáveis de qualidade de água para cada classe de uso; portaria 518/04, editada pelo Ministério da Saúde estabelece valores aceitáveis para água potável; além dos valores orientadores para solos e águas subterrâneas publicados pela Companhia de Tecnologia de Saneamento Ambiental - CETESB. Na Tabela 3.2 são apresentadas algumas das substâncias de interesse para essa pesquisa, com seus respectivos padrões de aceitação. 
Tabela 3.2 - Padrões de aceitação para os contaminantes de interesse desta pesquisa (Adaptado de CETESB, 2001b).

\begin{tabular}{|c|c|c|c|c|c|c|}
\hline \multirow{3}{*}{ Substância } & \multicolumn{5}{|c|}{ Solo $(\mathrm{mg} / \mathrm{kg})$} & \multirow{3}{*}{$\begin{array}{l}\text { Água }(\mu g / L) \\
\text { Intervenção }\end{array}$} \\
\hline & \multirow{2}{*}{ Referência } & \multirow{2}{*}{ Alerta } & \multicolumn{3}{|c|}{ Intervenção } & \\
\hline & & & Agrícola & Residencial & Industrial & \\
\hline Alumínio & - & - & - & - & - & 200,0 \\
\hline Cobre & 35,0 & 60,0 & 100,0 & 500,0 & 700,0 & $2.000,0$ \\
\hline Chumbo & 17,0 & 100,0 & 200,0 & 350,0 & $1.200,0$ & 10,0 \\
\hline Ferro & - & - & - & - & - & 300,0 \\
\hline Manganês & - & - & - & - & - & 100,0 \\
\hline Zinco & 60,0 & 300,0 & 500,0 & $1.000,0$ & $1.500,0$ & $5.000,0$ \\
\hline Naftaleno & 0,20 & - & 15,0 & 60,0 & 90,0 & 100,0 \\
\hline
\end{tabular}

\subsubsection{Fontes de Contaminação do Solo e das Águas Subterrâneas}

A contaminação de solos e águas subterrâneas pode acontecer de diversas maneiras e podem ser criados diversos esquemas para classificar os tipos de contaminação. Por exemplo, os contaminantes podem ser classificados de acordo com a afinidade ao solo e a água. Fetter (1998) dividiu as fontes de contaminação em seis categorias, baseando-se num relatório apresentado ao Congresso dos Estados Unidos, são elas:

- Descarga de substâncias no solo - tanques sépticos e fossas, poços de injeção de efluentes, disposição no solo de efluentes domésticos ou industriais;

- Armazenamento - tratamento e/ou disposição de substâncias sólidas no solo, lagoas de armazenamento e tratamento de efluentes industriais; resíduos de mineração, tanques aéreo ou subterrâneo de armazenamento de substâncias;

- Contenção de substâncias durante o transporte - oleodutos, rede de esgoto e efluentes industriais, transporte de produtos químicos; 
- Descarga de substâncias como conseqüência de outras atividades - irrigação, aplicação de pesticidas e fertilizantes, emissões atmosféricas;

- Facilitam o contato de águas contaminadas com os aqüíferos - poços de extração de água, petróleo e poços de monitoramento com falhas no projeto ou construção;

- Criadas elou exacerbadas pela atividade do homem interação entra as águas superfícies e subterrâneas, infiltração natural e intrusão salina.

\subsubsection{Histórico de Contaminações Relevantes}

Na opinião de muitos, o caso de contaminação de maior notoriedade para o mundo ocidental foi o evento ocorrido no Love Canal em Niagara Falls, no Estado de Nova Iorque, Estados Unidos. A escavação inicialmente projetada para desviar parte do curso do rio Niagara foi utilizada para descarte de resíduos industriais. Esgotada a capacidade de disposição de resíduos, por volta de 1953, o sítio foi "vendido" (o valor da negociação foi de um dólar) para o município para a construção de uma escola, seguida da construção de casas. Em 1978 a Secretaria Estadual de Saúde decretou estado de emergência para esta área, sendo ela interditada e cercada. Foram identificados mais de 200 contaminantes na mistura solo/resíduo e mais de 80 nas amostras de água subterrânea, dentre os quais pelo menos 11 são comprovadamente cancerígenas. Evidentemente as análises foram efetuadas em decorrência de problemas detectados entre a população local. Outro caso de proporções semelhantes ocorreu no continente europeu, na região de Lekkerkirk na Holanda. Em 1978 as casas construídas sobre uma área de descarte de resíduos industriais tiveram que ser abandonadas. Paulatinamente novas situações surgiram, sendo que Sánchez (2001) cita casos de semelhante impacto, ocorridos em vários paises da Europa e no Canadá entre o final da década de 1970 e início da década de 1980. 
No Brasil, talvez, o primeiro caso de repercussão ocorreu na baixada santista nos anos da década de 1980, quando foram identificados descartes de resíduos organoclorados nos municípios de Cubatão e São Vicente, SP (SÁNCHEZ, 2001). Neste caso os resíduos foram gerados pelas atividades da empresa Clorogil, que foi comprada pela Rhodia S.A. em 1976, a qual foi responsabilizada pelo passivo ambiental gerado no passado. Outro caso de certa repercussão foi identificado na localidade conhecida como Cidade dos Meninos, Município de Duque de Caxias, Baixada Fluminense. Uma indústria inaugurada em 1950 para produzir o pesticida hexaclorociclohexano $(\mathrm{HCH})$, também conhecido como BHC ou "pó de broca", foi desativada após cinco anos de produção, sendo que os estoques e a matéria-prima foram abandonados em um terreno, ao ar livre e sem qualquer espécie de proteção (BARRETO, 1998). Este evento permaneceu desapercebido até 1989, quando denúncias da comercialização do referido pesticida foram apresentadas nos meios de comunicação. Ainda no mesmo ano, 40 toneladas de $\mathrm{HCH}$ foram removidas e incineradas, contudo o montante que permaneceu no local era desconhecido. Uma tentativa de remediação do sítio iniciada em 1995 agravou ainda mais a situação pela reação resultante da mistura do contaminante com cal (BARRETO, 1998). Esses eventos são alguns exemplos de casos de repercussão no Brasil e no mundo que desencadearam mudanças drásticas na legislação ambiental voltada à questão de resíduos industriais. Eles representam o "ponta-pé inicial" para a busca e descoberta de muitos sítios contaminados, tanto em paises industrializados desde mais longa data até, em menor proporção, no Brasil. Para ter uma idéia quantitativa, pode-se tomar como base uma visão numérica mais pessimista, sugerida por Sánchez (2001), que aponta algo em torno de 100 mil sítios contaminados no Reino Unido, 110 mil na Holanda, 300 mil na França, 500 mil nos Estados Unidos e 190 mil na Alemanha. Ainda sobre os Estados Unidos, segundo dados disponíveis na página da Agência de Proteção Ambiental, até 2004 foram gastos entorno de US $\$ 17,6$ bilhões com avaliação e remediação de sítios contaminados, sendo este valor equivale a 2,4 \% do Produto Interno Bruto do Brasil.

O único caso documentado encontrado na literatura ao longo do presente estudo, que se atinha especificamente à contaminação de solos e águas subterrâneas por óleo usado e resíduo de re-refino de óleo lubrificante 
foi o caso da empresa Petrochem/Ekotek, em Salt Lake City, no Estado de Utah, nos Estados Unidos da América. Segundo USEPA (1996b), numa ação de limpeza do sítio em questão, realizada em 1989, para a remoção das fontes de contaminação, foram removidos aproximadamente 60 tanques superficiais, 1.200 tambores, 1.500 pequenos contêineres, três lagoas superficiais, uma área de drenagem sub-superficial, numerosas pilhas e cavas de resíduos, fornos incineradores e solos contaminados. No sítio, tanto no solo como na água subterrânea, foram encontradas elevadas concentrações de metais, hidrocarbonetos, organoclorados e pesticidas. Os custos totais de investigação, limpeza e remediação ficaram na ordem de 69 milhões de dólares, sendo 12 milhões gastos na investigação e estudo de viabilidade, 43 milhões na remediação e 14 milhões na operação e manutenção da área por 30 anos. Vale acrescentar que, neste caso, os usos do sítio ao longo do tempo e as empresas usuárias foram investigados para definir quais os responsáveis pelos danos e qual a parcela do custo referente a cada um.

Já para o Brasil, como um todo, não se tem idéia do número aproximado de sítios contaminados. Entretanto, para o Estado de São Paulo, segundo dados publicados na página eletrônica da CETESB, em novembro de 2004 existiam oficialmente 1.336 áreas contaminadas cadastradas. Se considerarmos as áreas potencialmente contaminadas e em estudo, provavelmente o resultado seria muito superior e segundo informações não oficiais da CETESB, estima-se que o número de sítios contaminados no Estado de São Paulo gire em torno de 10.000 .

\subsection{Transporte de Massa em Meio Poroso Saturado}

Nesta seção são introduzidos os principais mecanismos que governam o transporte de solutos (contaminantes) dissolvidos em água subterrânea. Esta seção poderia, também, ser iniciada com o título de "transporte de soluto", considerando o aspecto básico dos conceitos aqui descritos. 


\subsubsection{Advecção}

O transporte advectivo ocorre quando espécies químicas são transportadas devido ao movimento preferencial de um fluido, ao longo de um escoamento. A quantidade de soluto transportado depende da concentração do soluto em água e da quantidade de água que está escoando. Para um escoamento que passa através de uma área de seção unitária de um aqüífero, a quantidade de água escoando é igual à velocidade linear média multiplicada pela porosidade efetiva. A velocidade linear média, $v_{x}$, é a taxa na qual o escoamento de água atravessa a seção de área unitária considerando os espaços porosos interconectados. Assim, a velocidade linear média não se refere às moléculas de água que se movem nos caminhos individuais, onde a velocidade é maior devido à tortuosidade. A porosidade efetiva, $n_{e}$, se refere aos vazios através dos quais um escoamento pode ocorrer. Poros não interconectados e bloqueados "dead-end" não são considerados como porosidade efetiva. A velocidade linear média segue a lei de Darcy, na forma da eq. (1):

$$
v_{x}=\frac{K}{n_{e}} \cdot \frac{d h}{d l}
$$

Onde:

$v_{x}$ - velocidade linear média (L/T);

$K$ - condutividade hidráulica (L/T);

$n_{e}$ - porosidade efetiva (adimensional);

$\frac{d h}{d l}$ - gradiente hidráulico (L/L).

Considerando o transporte advectivo de uma espécie química (contaminante, por exemplo), o fluxo de massa unidimensional por advecção (neste caso direção " $x$ "), $F_{A_{X}}$, é igual à quantidade de água que escoa multiplicada pela concentração dos compostos nela dissolvidos, sendo representado pela eq. (2):

$$
F_{A_{X}}=v_{x} \cdot n_{e} \cdot C
$$


Considerando o balanço de massa em um elemento infinitesimal, no qual se permite haver variação temporal de concentração e transporte advectivo, a eq. unidimensional (3) pode ser deduzida:

$$
\frac{\partial C}{\partial t}=-v_{x} \cdot \frac{\partial C}{\partial x}
$$

Devido à heterogeneidade das formações geológicas, o transporte advectivo em estratos diferentes acarreta um espalhamento da frente de propagação a diferentes taxas em cada estrato. Esse fato traz implicações práticas de razoável magnitude. Por exemplo, caso se necessite de uma amostra de água com o propósito de monitorar o avanço de um contaminante dissolvido, o uso de um poço de monitoramento ou de um piezômetro que adentre diferentes formações (gerando o que se denomina de "amostra composta") pode envolver a mistura de águas com diferentes graus de contaminação, oriundas de diferentes formações, que permitem diferentes velocidades de escoamento. A concentração de contaminantes em amostra composta deve, portanto, ser vista com cuidado. Ilustrando uma solução para este problema, menciona-se o uso de filtro curto (1,0 a 3,0 metros) e poço multinível quando na construção de poços de monitoramento. A denominação filtro curto e poço multinível advém da norma ABNT NBR 13.895 referente à "Construção de poços de monitoramento e amostragem". Adicionalmente, completando esse exemplo, é sugerida a utilização da menor dimensão, qual seja, 1 metro, quando as condições geológicas forem favoráveis.

\subsubsection{Difusão}

Em água, um soluto se move de uma região de maior concentração para uma região de menor concentração. Esse fenômeno é denominado de difusão molecular ou simplesmente difusão. Todas as vezes que ocorre um gradiente de concentração também ocorre difusão, mesmo quando o solvente (água) não está em movimento. O fluxo de massa difundida é proporcional ao gradiente de concentração, sendo expresso pela primeira lei de Fick, que, em uma dimensão, é dada por (FETTER, 1998): 


$$
F_{D_{X}}=-D_{d}\left(\frac{d C}{d x}\right)
$$

Onde:

$F_{D_{X}}$ - fluxo de massa do soluto por unidade de área e por unidade de tempo. Fluxo difusivo na direção " $x$ ";

$D_{d}-$ coeficiente de difusão em soluções livres $\left(\mathrm{L}^{2} / \mathrm{T}\right)$;

$C$ - concentração do soluto $\left(\mathrm{M} / \mathrm{L}^{3}\right)$;

$\frac{d C}{d x}-$ gradiente de concentração $\left(M / L^{3} / L\right)$.

O sinal negativo indica que o movimento ocorre de regiões de maior concentração para regiões de menor concentração.

Valores de referência para o coeficiente de difusão $\left(D_{d}\right)$ são determinados em laboratório, pelo uso de solução diluída da espécie química desejada e água ultrapura. Lerman (1979) determinou valores de “ $D_{d}$ ”, a $25^{\circ} \mathrm{C}$, para vários cátions e ânions presentes em casos de contaminação. Na Tabela 3.3 são apresentados alguns dos valores medidos por Lerman (1979).

Tabela 3.3 - Coeficientes de difusão para algumas espécies em soluções diluídas a $25^{\circ} \mathrm{C}$ (Fonte: Lerman, 1979).

\begin{tabular}{lllr}
\hline \hline Espécie Química & $D_{d} \cdot 10^{10} \mathrm{~m}^{2} / \mathrm{s}$ & Espécie Química & $D_{d} \cdot 10^{10} \mathrm{~m}^{2} / \mathrm{s}$ \\
\hline Cátions & & Ânions & \\
\hline $\mathrm{H}^{+}$ & 93,1 & $\mathrm{OH}^{-}$ & 527 \\
\hline $\mathrm{Li}^{+}$ & 10,3 & $\mathrm{Cl}^{-}$ & 20,3 \\
\hline $\mathrm{Na}^{+}$ & 13,3 & $\mathrm{HS}^{-}$ & 17,3 \\
\hline $\mathrm{K}^{+}$ & 19,6 & $\mathrm{NO}_{2}^{-}$ & 19,1 \\
\hline $\mathrm{NH}_{4}^{+}$ & 19,8 & $\mathrm{NO}_{3}{ }^{-}$ & 19,0 \\
\hline $\mathrm{Mg}^{+2}$ & 7,05 & $\mathrm{HCO}_{3}^{-}$ & 11,8 \\
\hline $\mathrm{Ca}^{+2}$ & 7,93 & $\mathrm{SO}_{4}^{-2}$ & 10,7 \\
\hline $\mathrm{Mn}^{+2}$ & 6,88 & $\mathrm{CO}_{3}{ }^{-2}$ & 9,55 \\
\hline $\mathrm{Fe}^{+2}$ & 7,19 & $\mathrm{PO}_{4}^{-3}$ & 6,12 \\
\hline $\mathrm{Cu}^{+2}$ & 7,33 & $\mathrm{CrO}_{4}^{-2}$ & 11,2 \\
\hline $\mathrm{Zn}^{+2}$ & 7,15 & & \\
\hline $\mathrm{Cd}^{+2}$ & 7,17 & & \\
\hline $\mathrm{Pb}^{+2}$ & 9,45 & & \\
\hline \hline
\end{tabular}

Para sistemas onde ocorrem variações de concentração com o tempo aplica-se a segunda lei de Fick. Para uma dimensão a eq. é expressa por: 


$$
\frac{\partial C}{\partial t}=D_{d} \frac{\partial^{2} C}{\partial x^{2}}
$$

Onde:

$\frac{\partial C}{\partial t}$ - variação de concentração com o tempo $\left(\mathrm{M} / \mathrm{L}^{3} / \mathrm{T}\right)$.

Em meios porosos a difusão não se processa tão rápido quanto em água, porque os íons e moléculas percorrem caminhos mais longos quando se movimentam ao redor dos minerais. Como correção se utiliza um coeficiente de difusão efetiva.

$$
D^{*}=w \cdot D_{d}
$$

Onde:

$w$ - coeficiente relacionado à tortuosidade do meio.

Tortuosidade é a medida da forma de escoamento seguido pelas moléculas de água em um meio poroso específico. Por exemplo, considerandose $L$ a distância em linha reta entre as extremidades de um escoamento tortuoso de comprimento $L_{e}$, a tortuosidade $(T)$ é definida por $T=L_{e} / L$. Em meios porosos a tortuosidade é uma grandeza com valor sempre superior a um, pois o caminho que as moléculas seguem sempre diverge ao redor das partículas sólidas. O caminho percorrido através de uma amostra com grãos uniformes é menor do que o caminho percorrido através de uma amostra com grãos variados, na qual os menores grãos preenchem os vazios dos grãos maiores. Assim os sedimentos melhor sortidos (uniformes) possuem um valor para tortuosidade menor do que sedimentos pouco sortidos (FETTER, 1998). Comumente $w=1 / T$, de forma que o valor de " $w$ " é sempre menor do que um. Freeze e Cherry (1979) sugerem que $w$ varia entre 0,5 a 0,01 para estudos em laboratório usando diferentes solos.

Como já foi mencionado, a difusão acarreta um lento espalhamento do soluto a partir da região onde ele foi introduzido, mesmo na ausência de escoamento. Na Figura 3.1 pode ser observado o comportamento de um soluto introduzido com uma concentração inicial $\mathrm{C}_{0}$, tempo inicial $t_{0}$, em um intervalo de $(x-a)$ a $(x+a)$. A intervalos de tempo sucessivos $t_{1}$ e $t_{2}$, o soluto se espalhou, resultando numa redução de concentração no local de injeção ao 
longo do tempo, bem como um aumento da concentração nas regiões para as quais o soluto difundiu.

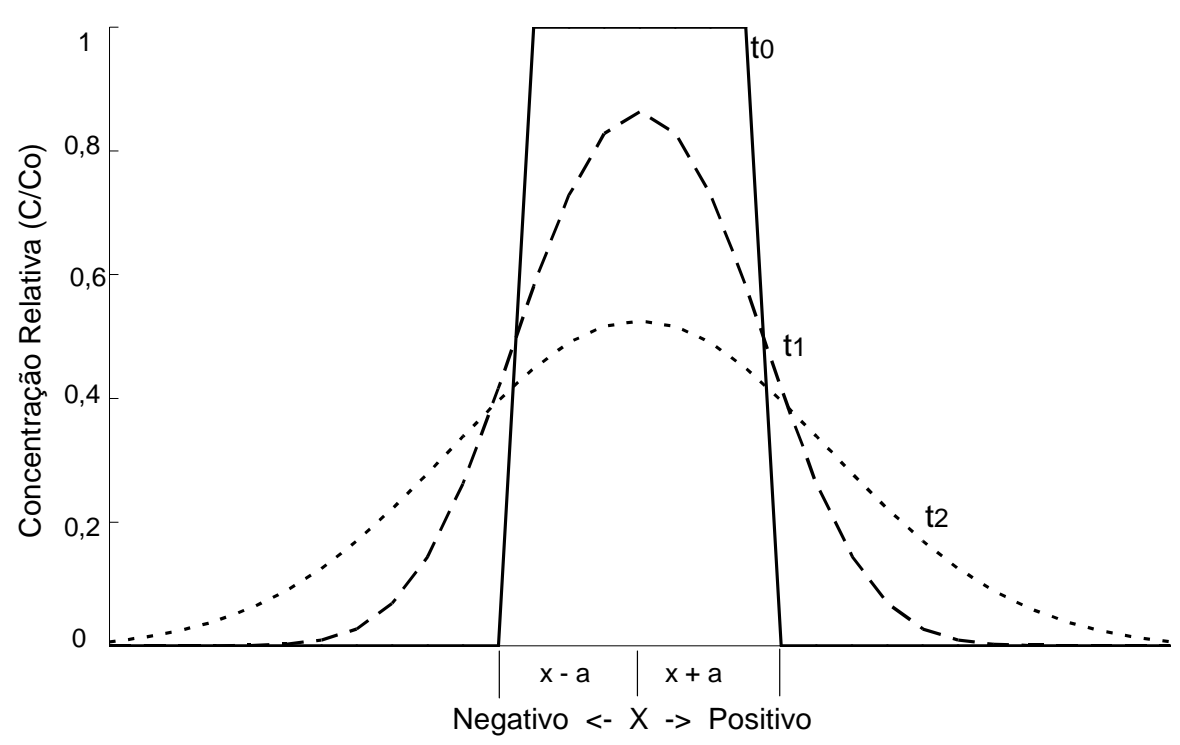

Figura 3.1 - Espalhamento de um soluto provocado por difusão ao longo do tempo.

Nota-se que a concentração do soluto tem uma forma que se aproxima de uma distribuição normal, ou Gaussiana. Quando a fonte é pontual a descrição matemática é precisamente uma Gaussiana e, assim, pode ser descrita por duas propriedades estatísticas, quais sejam, a média, $\bar{C}$, e a variância, $\sigma_{C}^{2}$.

Com base nas propriedades das funções Gaussianas, o coeficiente de difusão efetivo, $D^{*}$, pode ser definido como:

$$
D^{*}=\frac{\sigma_{C}^{2}}{2 \cdot t}
$$

Onde:

$t-$ tempo.

Esta é uma definição alternativa, fundamentada em argumentos matemáticos, para o coeficiente de difusão efetivo apresentado na eq. (6). De fato, a eq. (6) define o coeficiente, porém não o relaciona com grandezas vinculadas à concentração de massa, como é o caso da eq. (7). Em solos, a difusão ocorre quando a concentração de uma espécie química é muito maior em um estrato do que no estrato adjacente. Um exemplo no qual se busca 
suprimir o transporte de qualquer natureza, inclusive o difusivo, é a impermeabilização de aterros sanitários ou industriais, onde são utilizadas mantas sintéticas e camadas de argila.

\subsubsection{Dispersão Mecânica}

O escoamento subterrâneo ocorre a taxas maiores ou menores que a velocidade linear média. Em escala macroscópica - isto é, sobre um domínio com volume suficiente onde os efeitos de cada poro passam a ser representado por valores médios - existem três causas básicas para este fenômeno: a) com o escoamento de fluido através dos poros, prevalecerá maior velocidades no centro dos poros do que nas extremidades; b) para uma mesma distância linear, as partículas percorrerão caminhos diferentes na matriz porosa; c) como os poros apresentam diferentes espaçamentos ocorrem diferenças na velocidade de escoamento.

Se toda a água subterrânea que contém um soluto pudesse se mover com uma mesma velocidade, isto criaria, na ausência de efeitos difusivos, uma interface entre águas contaminadas e não contaminadas. Contudo, o que se observa é que ocorrem misturas ao longo do escoamento provocadas pelas diferentes velocidades. Esta mistura é denominada de dispersão mecânica, sendo esta a primeira causa da diluição do soluto nas extremidades do escoamento. Sendo denomina dispersão longitudinal a mistura que ocorre ao longo da direção principal de deslocamento.

Uma frente de avanço de soluto também se expande na direção normal ao escoamento devido aos detalhes do escoamento que ocorrem na escala de poros. Denomina-se dispersão transversal à mistura ocorrida na direção normal ao deslocamento principal do escoamento.

Assumindo-se que a dispersão mecânica pode ser descrita pelas leis de Fick e que a parcela da dispersão mecânica é uma função da velocidade linear média, coeficientes de dispersão mecânica podem ser introduzidos. Esses coeficiente são definidos como "uma propriedade do meio", recebendo nomes 
de "dispersividade dinâmica" ou simplesmente dispersividade, $\alpha$, que passa a ser multiplicada pela velocidade linear média. Assim resulta:

Coeficiente de dispersão mecânica longitudinal $=\alpha_{L} \cdot v_{x}$

Onde:

$\alpha_{L}-$ dispersividade na direção " $x$ " (L).

Coeficiente de dispersão mecânica transversal $=\alpha_{T} \cdot v_{x}$

Onde:

$\alpha_{T}-$ dispersividade na direção " $y$ " (L).

\subsubsection{Dispersão Hidrodinâmica}

O processo de difusão molecular não pode ser analisado separadamente da dispersão mecânica em escoamento de água subterrânea. Pela fusão destes dois fenômenos se origina um parâmetro denominado de coeficiente de dispersão hidrodinâmica, $D$. Sendo definido pelo seguinte equacionamento:

$$
\begin{aligned}
& D_{L}=\alpha_{L} \cdot v_{x}+D^{*} \\
& D_{T}=\alpha_{T} \cdot v_{x}+D^{*}
\end{aligned}
$$

Onde:

$D_{L}$ - coeficiente de dispersão hidrodinâmica paralelo à direção principal do escoamento (longitudinal) $\left(\mathrm{L}^{2} / \mathrm{T}\right)$;

$D_{T}$ - coeficiente de dispersão hidrodinâmica perpendicular à direção principal do escoamento (transversal) $\left(\mathrm{L}^{2} / \mathrm{T}\right)$.

A Figura 3.2 ilustra o processo de dispersão hidrodinâmica. Uma massa de soluto é, instantaneamente, introduzida em um aqüífero no instante $t_{0} \mathrm{e}$ sobre o intervalo $x=0+a$, sendo a concentração inicial resultante $C_{0}$. A massa de soluto é deslocada com o avanço da água subterrânea (nesse caso, um fenômeno advectivo). Ao longo do percurso o pulso de soluto é espalhado e a 
máxima concentração decresce com o tempo, como pode ser observado para os tempos $t_{1}$ e $t_{2}$. O modelo para dispersão hidrodinâmica assume que as curvas de concentração têm distribuições Gaussianas, podendo as suas propriedades básicas ser descritas pelas média e variância.

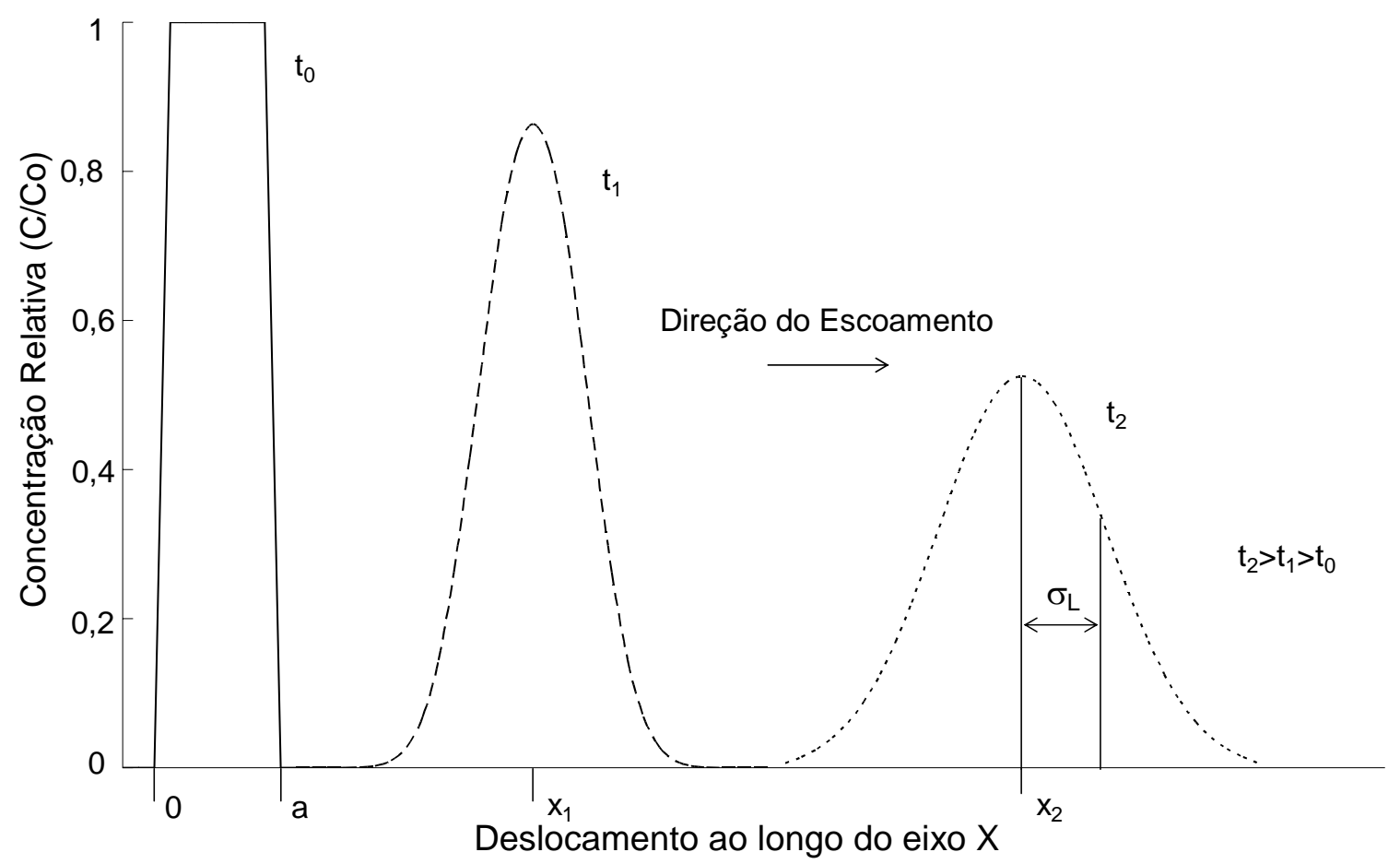

Figura 3.2 - Transporte e espalhamento de um pulso de soluto com o tempo devido a advecção e a dispersão.

Com esta distribuição os coeficientes de dispersão hidrodinâmica longitudinal e transversal podem ser definidos como:

$$
D_{L}=\frac{\sigma_{L}^{2}}{2 \cdot t}
$$

Onde:

$\sigma_{L}^{2}-$ variância do espalhamento longitudinal da pluma.

$$
D_{T}=\frac{\sigma_{T}^{2}}{2 \cdot t}
$$

Onde:

$\sigma_{T}^{2}$ - variância do espalhamento transversal da pluma. 
Para um meio homogêneo, com campo de velocidade uniforme, difusão bidimensional e direção do escoamento principal paralela ao eixo " $x$ ", tem-se a eq. (14) como eq. governante do transporte:

$$
D_{L} \frac{\partial^{2} C}{\partial x^{2}}+D_{T} \frac{\partial^{2} C}{\partial y^{2}}-v_{x} \frac{\partial C}{\partial x}=\frac{\partial C}{\partial t}
$$

Anderson (1992), Gelhar et al. (1992) e Zeng e Bennett (1995) sugerem que na ausência de dados de dispersividade para um sítio em particular, o valor da dispersividade transversal pode ser adotado com uma ordem de magnitude menor do que a dispersividade longitudinal, enquanto que a dispersividade vertical pode ser assumida com duas ordens de magnitude menor.

\subsection{Transformações, Retardamento e Atenuação do Soluto}

Diferentes processos regem o comportamento de solutos dissolvidos em água subterrânea. O soluto pode ser sorvido pela superfície dos grãos minerais do aqüífero, sorvido pelo carbono orgânico presente no aqüífero, sofrer precipitação química, ser substrato para microorganismos sofrendo biodegradação e fazer parte de reações de oxidação-redução. Adicionalmente, compostos radioativos podem apresentar decaimento de massa. Como resultado do processo sorcivo, alguns solutos deslocam-se mais lentamente do que a água subterrânea que os está transportando através do aqüífero, sendo este efeito denominado de retardamento. Alguns processos como a biodegradação, o decaimento radioativo e a precipitação acarretam redução na concentração do soluto, mas não necessariamente provocam a redução na velocidade de propagação da pluma. Fetter (1998) apresenta uma forma de representação da equação unidimensional da advecção-dispersão para a sorção e o decaimento, conforme apresentado na eq. (15):

$$
\frac{\partial C}{\partial t}=D_{L} \frac{\partial^{2} C}{\partial x^{2}}-v_{x} \frac{\partial C}{\partial x}-\frac{\rho_{b}}{\eta} \cdot \frac{\partial C^{*}}{\partial t}+\left(\frac{\partial C}{\partial t}\right)_{r x n}
$$


Onde:

$C$ - concentração de soluto em fase líquida;

$t$ - tempo;

$D_{L}$ - coeficiente de dispersão longitudinal;

$v_{x}$ - velocidade linear média da água subterrânea;

$\rho_{b}$ - massa específica dos sólidos;

$\eta$-porosidade;

$C^{*}$ - quantidade de soluto sorvido por peso unitário de sólido;

rxn - código que indicando reações biológicas ou químicas do soluto.

O primeiro termo do lado direito da eq. (15) representa a dispersão do soluto, o segundo é a advecção, o terceiro é a transferência de soluto da fase líquida para as partículas sólidas por sorção e o último termo indica variação da concentração do soluto com o tempo provocada por reações química ou biológica ou decaimento radioativo.

\subsubsection{Processos de Sorção}

O processo sorcivo é um conjunto de quatro processos separados, que interagem. São eles: adsorção, sorção química, absorção e troca iônica. A adsorção inclui os processos nos quais um soluto se adere a uma superfície sólida. A troca iônica ocorre, por exemplo, quando cátions (neste caso troca catiônica) são atraídos para regiões próximas com cargas negativas e os retém por forças eletrostáticas. Um exemplo é a superfície de argilo-minerais. A sorção química ocorre quando o soluto é incorporado à superfície de sedimento, solo ou rocha por reações químicas. A absorção acontece quando os grãos que formam o aqüífero são porosos o bastante para que o soluto possa difundir-se nos grãos e ser sorvido na superfície interior. O processo pelo qual um contaminante, que originalmente estava em solução, distribui-se entre a solução e fase sólida é conhecido como partição.

Esta tese não usa os fenômenos supracitados de forma separada, usando simplesmente o termo sorção para indicar o resultado dos vários 
processos em conjunto. Em muitos casos, o mais importante é a remoção do soluto presente na água subterrânea. A sorção é determinada experimentalmente pela medição de quanto de um soluto pode ser sorvido por um sedimento, solo, ou rocha. Alíquotas de soluto em várias concentrações são homogeneizadas com os sólidos e em seguida é determinada a quantidade de soluto removida da solução. Os resultados dos experimentos são lançados em diagrama cartesiano, na forma de concentração de equilíbrio de soluto versus a quantidade de soluto sorvida pelos sólidos. Sendo o gráfico resultante denominado de isoterma de sorção. O termo "isoterma" deriva das condições de temperatura constante dos ensaios.

\subsubsection{Reações de Equilíbrio em Superfície}

\subsubsection{Isoterma de Sorção Linear}

Se existir uma relação linear direta entre a quantidade de soluto sorvida nos sólidos, $C^{*}$, e a concentração de soluto, $C$, o gráfico da isoterma de adsorção de $C$ como uma função de $C^{*}$ é, evidentemente, uma linha reta (ver Figura 3.3), seguindo a eq. (16):

$$
C^{*}=K_{d} \cdot C
$$

Onde:

$\mathrm{C}^{\star}$ - massa de soluto sorvida por massa de solo seco $(\mathrm{mg} / \mathrm{kg})$;

$C$ - concentração de soluto na solução em equilíbrio com a massa de soluto sorvida $(\mathrm{mg} / \mathrm{L})$;

$K_{d}$ - coeficiente de distribuição $(L / k g)$.

O coeficiente de proporcionalidade $K_{d}$, alcunhado de coeficiente de distribuição, é o coeficiente angular da isoterma linear de sorção.

A isoterma de sorção linear é muito atraente sob o ponto de vista matemático. Se a eq. (16) for substituída na eq. (15), obtemos a seguinte equação de advecção-dispersão (na qual a parcela de reações químicas foi desconsiderada): 


$$
\frac{\partial C}{\partial t}=D_{L} \frac{\partial^{2} C}{\partial x^{2}}-v_{x} \frac{\partial C}{\partial x}-\frac{\rho_{b}}{\eta} \cdot \frac{\partial\left(K_{d} \cdot C\right)}{\partial t}
$$

Reorganizado os termos encontramos:

$$
\frac{\partial C}{\partial t}\left(1+\frac{\rho_{b}}{\eta} K_{d}\right)=D_{L} \frac{\partial^{2} C}{\partial x^{2}}-v_{x} \frac{\partial C}{\partial x}
$$

Onde se define o fator de retardamento, $r_{f}$, dado por:

$$
r_{f}=1+\frac{\rho_{b}}{\eta} K_{d}
$$

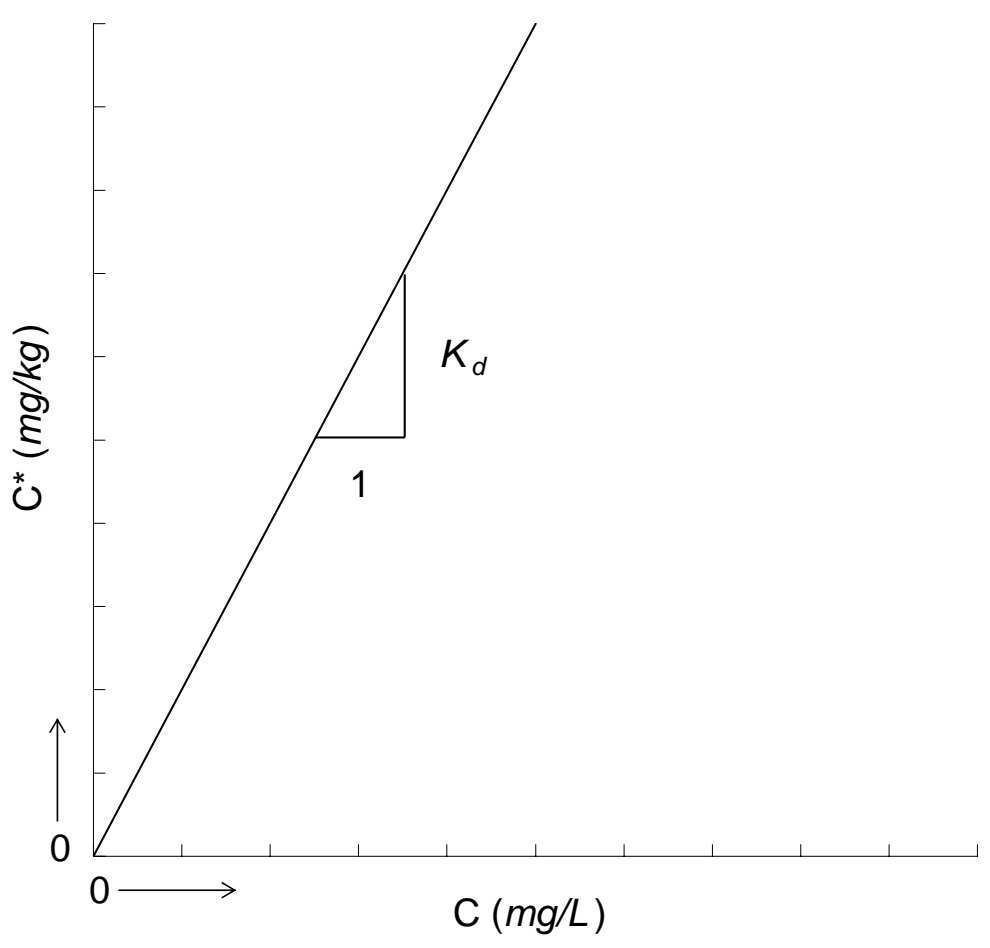

Figura 3.3 - Isoterma de sorção linear.

A velocidade média da frente de propagação (também denominada de centróide da pluma ou centro de massa), $v_{C}$, é obtida para a situação na qual a concentração é metade da original. $v_{C}$ é dada pela relação:

$$
v_{C}=\frac{v_{x}}{r_{f}}
$$

Existem duas limitações no uso da isoterma de sorção linear. A primeira é que não há um limite teórico da quantidade de soluto que pode ser sorvido pelos sólidos, o que não corresponde à realidade, uma vez que deve haver um limite superior da massa de soluto que pode ser sorvida. A segunda é, na 
verdade, uma decorrência de interpretação de dados. Quando existem poucos dados, pode ocorrer que comportamentos curvilíneos de $C$ versus $C^{\star}$ podem ser interpretados incorretamente como lineares. Não obstante as restrições, o modelo de isoterma de sorção linear foi amplamente usado no final da década de 70 e década de 80 por facilidades numéricas. Acrescenta-se que em baixas concentrações a relação linear normalmente acontece.

Valores típicos de $K_{d}$ podem ser observados na Tabela 3.4. Para metais o $K_{d}$ é fortemente influenciado pelo $\mathrm{pH}$ e Capacidade de Troca Catiônica (CTC), já para compostos orgânicos o $K_{d}$ está vinculado ao percentual de carbono orgânico $\left(f_{o c}\right)$.

Tabela 3.4 - Valores de $K_{d}$ para alguns contaminantes freqüentemente encontrado.

\begin{tabular}{|c|c|c|c|}
\hline Substância & $\begin{array}{c}K_{d}(\mathrm{~L} / \mathrm{kg}) \\
\text { CETESB, 2001b }\end{array}$ & $\begin{array}{c}K_{d}(\mathrm{~L} / \mathrm{kg}) \text { Rowe } \\
\text { et al., } 1995\end{array}$ & $\begin{array}{c}K_{d}(\mathrm{~L} / \mathrm{kg}) \text { USEPA } \\
\text { 1999a e b }\end{array}$ \\
\hline Alumínio & 1.000 & - & - \\
\hline Chumbo & 2.400 & 1.900 & 900 \\
\hline Cobre & 540 & 400 & 22 \\
\hline Zinco & 250 & - & $16-530$ \\
\hline Benzeno & - & $2 ; 13-60 ; 35$ & - \\
\hline Tetracloroetileno & - & 0,56 & - \\
\hline Tolueno & - & 0,$58 ; 3$ & - \\
\hline
\end{tabular}

\subsubsection{Isoterma de Sorção de Freundlich}

Uma isoterma de equilíbrio mais geral é a isoterma de sorção de Freundlich, definida por uma relação não linear da seguinte forma:

$$
C^{*}=K \cdot C^{N}
$$

Onde $K$ e $N$ são constantes.

A isoterma de Freundlich pode ser ajustada diretamente a um conjunto de dados, com $C$ lançado em função de $C^{*}$, apresentando um comportamento 
curvilíneo. Todavia, o logaritmo da eq. (21) permite linearizar os dados da seguinte forma:

$$
\log C^{*}=\log K+N \cdot \log C
$$

Se $\log C$ é lançado em gráfico contra $\log C^{*}$, o resultado é uma função linear com $N$ dado pelo coeficiente angular da reta formada $\log K$ representando o ponto de intersecção dessa reta com o eixo das ordenadas. Isto pode ser observado na Figura 3.4.

Se a eq. (21) for substituída na eq. (15), sem a parcela de reação química, obtém-se:

$$
\frac{\partial C}{\partial t}=D_{L} \frac{\partial^{2} C}{\partial x^{2}}-v_{x} \frac{\partial C}{\partial x}-\frac{\rho_{b}}{\eta} \cdot \frac{\partial\left(K \cdot C^{N}\right)}{\partial t}
$$

Reorganizado a eq. 23 resulta:

$$
\frac{\partial C}{\partial t}\left(1+\frac{\rho_{b} \cdot K \cdot N \cdot C^{N-1}}{\eta}\right)=D_{L} \frac{\partial^{2} C}{\partial x^{2}}-v_{x} \frac{\partial C}{\partial x}
$$

O fator de retardamento para isoterma de sorção de Freundlich, $r_{f f}$, é dado por:

$$
r_{f f}=1+\frac{\rho_{b} \cdot K \cdot N \cdot C^{N-1}}{\eta}
$$

Se $N$ for maior do que 1 a eq. (24) tenderá a um espalhamento da frente de propagação, enquanto que se $N$ for menor do que 1 , tenderá a uma retração da frente de propagação. Por fim, se $N$ for igual a 1 , a isoterma de sorção de Freundlich torna-se uma isoterma de sorção linear.

A isoterma de sorção de Freundlich vem sendo extensamente aplicada em estudos de sorção de solo para vários metais e compostos orgânicos. A isoterma de sorção de Freundlich apresenta as mesmas limitações atribuídas à isoterma de sorção linear, ou seja, teoricamente não existe limite superior da quantidade de soluto que pode ser sorvida. Deve-se ser bastante cuidadoso para não extrapolar a equação além dos limites de concentração definidos pelos dados experimentais. A isoterma de sorção de Freundlich é comumente obtida pelo ajuste empírico de dados experimentais. 


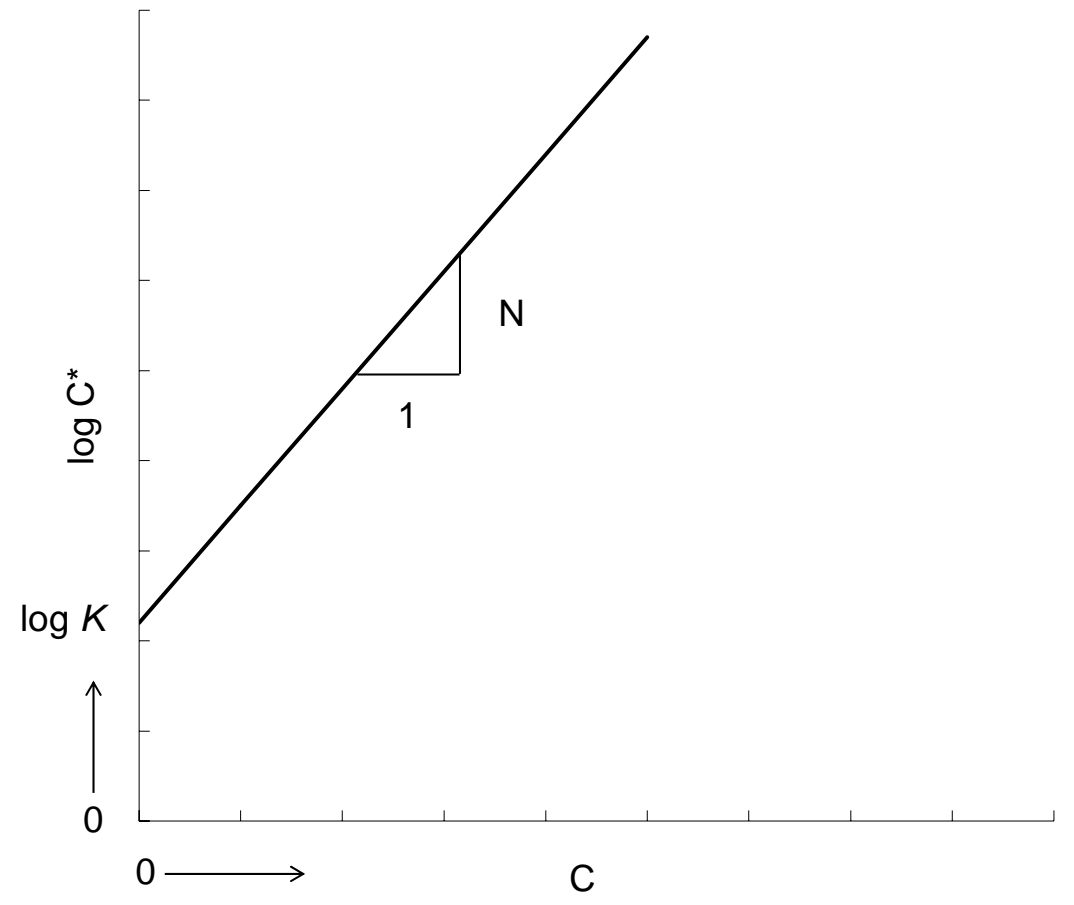

Figura 3.4 - Linearização da isoterma de sorção de Freundlich.

\subsubsection{Isoterma de Sorção de Langmuir}

A isoterma de sorção de Langmuir foi concebida com o conceito de que um sólido possui em sua superfície um número finito de áreas disponíveis para sorção. Quando todos os espaços disponíveis para sorção estiverem preenchidos, a superfície não será capaz de sorver soluto da solução. A isoterma de Langmuir apresenta a seguinte forma:

$$
\frac{C}{C^{*}}=\frac{1}{\alpha \cdot \beta}+\frac{C}{\beta}
$$

Onde:

$\alpha$ - constante relacionada à energia de ligação $(L / m g)$;

$\beta$ - quantidade máxima de soluto que pode ser absorvido por um sólido $(m g / k g)$.

Pode-se, também, expressar a isoterma de sorção de Langmuir como:

$$
C^{*}=\frac{\alpha \cdot \beta \cdot C}{1+\alpha \cdot C}
$$


Substituindo a eq. (27) na eq. (15), obtém-se:

$$
\frac{\partial C}{\partial t}=D_{L} \frac{\partial^{2} C}{\partial x^{2}}-v_{x} \frac{\partial C}{\partial x}-\frac{\rho_{b}}{\eta} \cdot \frac{\partial\left(\frac{\alpha \cdot \beta \cdot C}{1+\alpha \cdot C}\right)}{\partial t}
$$

Diferenciado e reorganizado a eq. (28) tem-se:

$$
\frac{\partial C}{\partial t}\left[1+\frac{\rho_{b}}{\eta}\left(\frac{\alpha \cdot \beta}{(1+\alpha \cdot C)^{2}}\right)\right]=D_{L} \frac{\partial^{2} C}{\partial x^{2}}-v_{x} \frac{\partial C}{\partial x}
$$

O fator de retardamento para a isoterma de sorção de Langmuir, $r_{f l}$, é dado por:

$$
r_{f l}=1+\frac{\rho_{b}}{\eta}\left(\frac{\alpha \cdot \beta}{(1+\alpha \cdot C)^{2}}\right)
$$

Se dados experimentais de $C^{*}$ versus $C$ são lançados em gráfico e seguem uma isoterma de sorção de Langmuir, observa-se uma forma curvilínea que tende a um valor máximo. Contudo se $C / C$ * é lançado em gráfico como função de $C$, os dados apresentam comportamento retilíneo. A máxima sorção iônica, $\beta$, é inversamente proporcional ao coeficiente angular, e a constante vinculada à energia de ligação, $\alpha$, é o coeficiente angular dividido pela intersecção da função linear com o eixo das ordenadas, ver Figura 3.5.

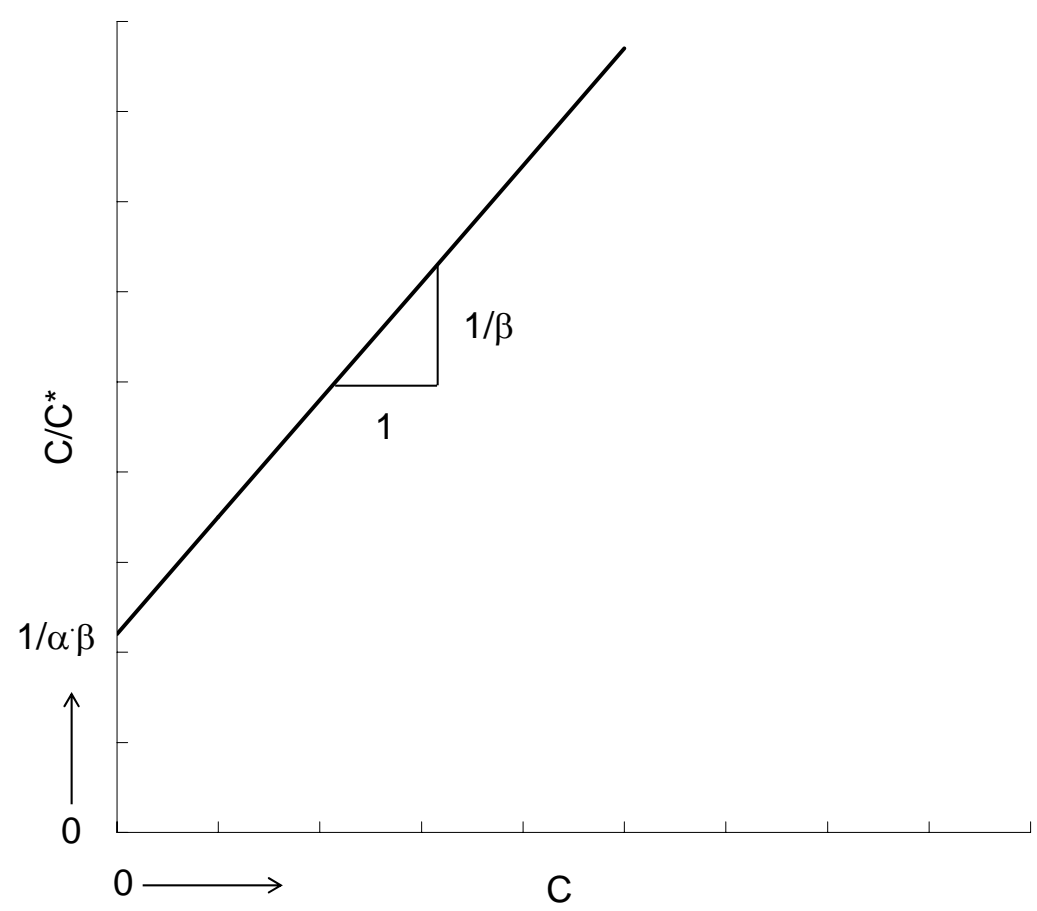

Figura 3.5 - Linearização da isoterma de Langmuir. 


\subsubsection{Sorção de Compostos Orgânicos Hidrofóbicos}

Muitos dos compostos orgânicos dissolvidos em água subterrânea podem ser adsorvidos na superfície dos sólidos pelo que denominamos de efeito hidrofóbico (FETTER, 1998). Estes compostos existem como espécies eletricamente neutras com diferentes graus de polaridade. A solubilidade dos compostos orgânicos em água é uma função do grau de atração exercido pelas moléculas polares da água. Esta atração depende da polaridade das moléculas orgânicas. Compostos hidrofóbicos podem ser solubilizados em muitos solventes orgânicos apolares, mas podem apresentar baixa solubilidade em água. Quando dissolvidas em água, essas moléculas tendem a ser atraídas por superfícies que são menos polares que a água. Segundo Fetter (1998), há uma pequena e limitada adsorção de compostos orgânicos na superfície dos minerais. Entretanto, a principal superfície adsorvente é o carbono orgânico presente no solo ou aqüífero (CLEARY, 1991; SCHWARZENBACH et al., 1993; FETTER, 1998; OLIVEIRA, 2002). De uma maneira geral podemos considerar que polar dissolve polar e apolar dissolve apolar.

\subsection{Partição Controlada pelo Carbono Orgânico}

A partição de um soluto para o solo ou aqüífero é quase que exclusivamente controlada pela fração de carbono orgânico, $f_{o c}$, caso o teor de carbono orgânico contido seja superior a 0,1\% em relação ao peso seco (CLEARY, 1991). Nessas condições o coeficiente de partição vinculado ao carbono orgânico, $K_{O C}$, pode ser definido como:

$$
K_{o c}=\frac{K_{d}}{f_{o c}}
$$

Cleary (1991) expressa que "embora não seja estritamente correto, na prática, a eq. (31) é muitas vezes aplicada mesmo quando o carbono orgânico é menor que 0,1\%". Todavia, se a fração de carbono orgânico for menor que 0,1\%, não podemos considerar de imediato que o carbono orgânico presente na matriz irá controlar a partição dos compostos orgânicos. Há níveis críticos 
de carbono orgânico nos quais a sorção deixa de ser controlada somente pela fração orgânica, sendo controlada também pelos minerais (SCHWARZENBACH et al., 1993; FETTER, 1998). Percebe-se a existência de um nível crítico, conhecido como $f_{o c}^{*}$, abaixo do qual as moléculas orgânicas são sorvidas primeiramente pela superfície dos minerais. Fetter (1998) afirma que este nível crítico de carbono orgânico depende de duas variáveis: a área de superfície da matriz, $S_{a}$, a qual está relacionada ao conteúdo de argila, e ao coeficiente de partição octanol-água.

O coeficiente de partição octanol-água, $K_{o w}$, é uma medida da hidrofobicidade de um composto. O composto orgânico de interesse é agitado em mistura de n-octanol e água, seguido da determinação da concentração dissolvida em cada fase. O coeficiente de partição octanol-água é a razão entre a concentração em n-octanol e a concentração em água. O $K_{o w}$ é comumente expresso no livro de referência sob a forma logarítmica. Comumente, o $\log K_{\text {ow }}$ varia entre $-3,0$ e 7,0, sendo que os compostos que apresentam $\log K_{\text {ow }}$ superior a 4,0 são considerados hidrofóbicos e os compostos que apresentam $\log K_{o w}$ inferior 1,0 são considerados hidrofílicos. Por exemplo, o DDT possui $K_{o w}=10^{6}$ e $\log K_{o w}=6,0$, portanto é considerado hidrofóbico.

Fetter (1998) sugere ainda que os valores de $f_{o c}^{*}$ sejam determinados pela eq.:

$$
f_{o c}^{*}=\frac{S_{a}}{200 \cdot\left(K_{o w}\right)^{0,84}}
$$

Pela observação da eq. (32) percebe-se que matrizes com baixos teores de carbono orgânico estão aptas a reter compostos orgânicos com elevados valores de $K_{o w}$, mas podem não estar aptas a reter compostos com baixos $K_{o w}$. 


\subsection{Estimativa de $K_{o c}$ por Dados de $K_{o w}$}

O uso de uma relação entre o coeficiente de partição octanol-água $\left(K_{o w}\right)$ e o coeficiente de partição vinculado ao carbono orgânico $\left(K_{o c}\right)$ parte de três premissas básicas: a) a sorção é controlada pelo carbono orgânico presente na matriz; b) a sorção é basicamente hidrofóbica, quando comparada a outros processos; c) há uma relação linear entre sorção e a concentração do soluto.

Cleary (1991) e Fetter (1998) apresentam várias equações diferentes encontradas na literatura internacional, que correlacionam o coeficiente de partição octanol-água de diferentes compostos orgânicos, ou grupos de compostos orgânicos, com o coeficiente de partição baseado no carbono orgânico. Na Tabela 3.5 apresenta-se uma compilação das equações listadas em Cleary (1991) e Fetter (1998). Frisa-se que somente em alguns casos foi publicado o coeficiente de correlação $\left(r^{2}\right)$ do ajuste aplicado na construção da equação.

Fetter (1998) afirma que embora existam várias equações (ver Tabela 3.5), a maioria dos valores de $\log K_{\text {ow }}$ computados para diversos compostos de referência localizam-se próximos à média dos valores das equações ou no "espaço" de um desvio padrão (quando usadas as equações da Tabela 3.5). Ainda segundo o mesmo autor, existe na literatura uma quantidade razoável de dados de $K_{o c}$ ou $\log K_{o c}$ determinados experimentalmente, que, quando comparados com os valores fornecidos pelas equações da Tabela 3.5, apresentam-se também próximos à média. Já Cleary (1991) afirma que "existem muitos valores de $K_{o c}$ publicados na literatura e, como este parâmetro é considerado uma propriedade do composto químico, era de se esperar que todos os valores fossem iguais. Infelizmente, eles não são iguais...". Assim, conclui-se que tanto as equações fornecidas pela literatura para a determinação do $\log K_{o c}$, como os valores determinados experimentalmente e relatados na literatura devem ser usado com bastante cautela, observando-se como os mesmos foram obtidos, para minorar os erros na estimativa do fator de retardamento ou qualquer outro parâmetro correlato. 
Tabela 3.5 - Equações para a estimativa de $\mathrm{K}_{\mathrm{oc}}$ por dados de $\mathrm{K}_{\mathrm{ow}}$ (Fonte: Compilação de Cleary, 1991 e Fetter, 1998).

\begin{tabular}{|c|c|c|}
\hline Equação & Compostos Usados & Autor e Ano \\
\hline $\log K_{\text {om }}=0,52 \cdot K_{o w}+0,62$ & 72 Pesticidas & Briggs, 1981 \\
\hline $\log K_{o c}=1,00 \cdot \log K_{o w}-0,21$ & $\begin{array}{l}10 \text { Hidrocarbonetos } \\
\text { Poliaromáticos }\end{array}$ & $\begin{array}{l}\text { Karickhoff, Brown e Scott, } \\
1979\end{array}$ \\
\hline$K_{o c}=0,63 \cdot K_{o w}$ & $\begin{array}{l}\text { Hidrocarbonetos } \\
\text { Aromáticos Polinucleares }\end{array}$ & $\begin{array}{l}\text { Karickhoff, Brown e Scott, } \\
1979\end{array}$ \\
\hline $\log K_{o c}=0,544 \cdot \log K_{o w}+1,377$ & $\begin{array}{l}45 \text { Compostos Orgânicos, } \\
\text { Principalmente Pesticidas }\end{array}$ & Kenaga e Goring, 1980 \\
\hline $\begin{array}{l}\log K_{o c}=1,029 \cdot \log K_{o w}-0,18 \\
r^{2}=0,91\end{array}$ & 13 Pesticidas & Rao e Davidson, 1980 \\
\hline $\log K_{o c}=0,94 \cdot \log K_{o w}+0,22$ & S-Trizinas e Dinitroanalinas & Rao e Davidson, 1980 \\
\hline $\begin{array}{l}\log K_{o c}=0,989 \cdot \log K_{o w}-0,346 \\
r^{2}=0,991\end{array}$ & $\begin{array}{l}5 \text { Hidrocarbonetos } \\
\text { Poliaromáticos }\end{array}$ & Karickhoff, 1981 \\
\hline $\log K_{o c}=0,937 \cdot \log K_{o w}-0,006$ & $\begin{array}{l}\text { Aromáticos, Poliaromáticos } \\
\text { e Triazinas }\end{array}$ & Lyman, 1982 \\
\hline $\ln K_{o c}=\ln K_{o w}-0,7301$ & $\begin{array}{l}\text { DDT, Tetraclorobifenil, } \\
\text { Lindano, 2,4-D e } \\
\text { Dicloropropano }\end{array}$ & $\begin{array}{l}\text { McCall, Swann e } \\
\text { Laskowski, } 1983\end{array}$ \\
\hline $\begin{array}{l}\log K_{o m}=0,904 \cdot \log K_{o w}-0,779 \\
r^{2}=0,989\end{array}$ & $\begin{array}{l}\text { Benzeno, Hidrocarbonetos } \\
\text { Clorados e PCBs }\end{array}$ & $\begin{array}{l}\text { Chiou, Porter e } \\
\text { Schmedding, } 1983\end{array}$ \\
\hline $\begin{array}{l}\log K_{o c}=0,72 \cdot \log K_{o w}+0,49 \\
r^{2}=0,95\end{array}$ & $\begin{array}{l}\text { Hidrocarbonetos Clorados } \\
\text { e Alquibenzenos }\end{array}$ & $\begin{array}{l}\text { Schwarzenbach e Westall, } \\
1981\end{array}$ \\
\hline $\begin{array}{l}\log K_{o c}=1,00 \cdot \log K_{o w}-0,317 \\
r^{2}=0,98\end{array}$ & $\begin{array}{l}22 \text { Compostos Aromáticos } \\
\text { Polinucleares }\end{array}$ & Hassett e outros, 1980 \\
\hline $\log K_{o c}=0,94 \cdot \log K_{o w}+0,02$ & $\begin{array}{l}\text { S-Triazinas e Dintroanalina } \\
\text { (Herbicidas) }\end{array}$ & USEPA, 1988 \\
\hline $\begin{array}{l}\quad K_{o m} \text { é o coeficiente } \\
\text { aqüífero. Por meio de estuda } \\
\text { (Fetter, 1998). }\end{array}$ & de partição baseado & $\begin{array}{l}\text { matéria orgânica do } \\
\text { que } K_{o c}=1,724 \cdot K_{o m}\end{array}$ \\
\hline
\end{tabular}




\subsection{Estimativa de $K_{o c}$ por Dados de Solubilidade}

Valores para $K_{\text {oc }}$ podem ser também estimados a partir de dados de solubilidade. Como para o coeficiente de partição octanol-água, há na literatura várias equações que descrevem a relação entre a solubilidade, $S$, e o coeficiente de partição baseado no carbono orgânico, $K_{o c}$.

Na Tabela 3.6 são apresentadas cinco equações que correlacionam $K_{o c}$ e $S$. O " $r$ " representa o coeficiente de correlação do ajuste aplicado quando na obtenção da equação. Ainda com relação à Tabela 3.6, deve-se observar os valores das unidades de entrada da solubilidade em cada equação para evitar estimativas errôneas dos valores de $K_{o c}$.

Tabela 3.6 - Estimativa empírica do $K_{o c}$ por dados de $S$ (Adaptado de FETTER, 1998).

\begin{tabular}{lcl}
\hline \multicolumn{1}{c}{ Equação } & Unidade de Solubilidade & \multicolumn{1}{c}{ Autor e Ano } \\
\hline $\log K_{o c}=0,44-0,54 \cdot \log S$ & Fração Molar & $\begin{array}{l}\text { Karickhoff, Brown e Scott, } \\
1979\end{array}$ \\
$r^{2}=0,94$ & & Kenaga, 1980 \\
\hline $\log K_{o c}=3,64-0,55 \cdot \log S$ & $m g / L$ & Means e outros, 1980 \\
\hline $\log K_{o c}=4,273-0,686 \cdot \log S$ & $m g / L$ & Hassett e outros, 1983 \\
\hline $\log K_{o c}=3,95-0,62 \cdot \log S$ & $m g / L$ & Chiou, Poter e Schmedding, \\
\hline $\log K_{o m}=0,001-0,729 \cdot \log S$ & & 1983 \\
$r^{2}=0,996$ & $m o l e s / L$ & \\
\hline \hline
\end{tabular}

Fetter (1998) aplicou as equações da Tabela 3.6 a dados experimentais de solubilidade e os resultados obtidos apresentam uma variação de cerca de uma ordem de magnitude em torno dos resultados experimentais.

A temperatura e a força de atração iônica interferem na determinação da solubilidade. Muitas vezes a literatura não apresenta quais as condições de experimento para a obtenção da solubilidade. Pode, ainda, haver uma série de resultados diferentes de solubilidade por várias razões: a pureza da espécie química, força iônica da água, temperatura e procedimentos experimentais. Por 
razões similares pode haver uma série de valores para o coeficiente de partição octanol-água para uma mesma espécie química. Assim, deve-se ter em mente que os valores de $K_{\text {oc }}$ obtidos por dados de $K_{\text {ow }}$ ou $S$ são apenas estimativas.

\subsection{Efeitos na Mistura de Solutos: Lei de Raoult}

Grande parte dos casos de contaminação ambiental que contém espécies orgânicas apresenta mistura de compostos. Assim, há uma distribuição de solubilidades nesses casos. A solubilidade dos hidrocarbonetos decresce com o aumento do tamanho das moléculas (NADIM et al. 2000). Sabe-se que a solubilidade de espécies orgânicas líquidas hidrofóbicas de estruturas moleculares similares, em solução aquosa, é controlada pelo percentual dos solutos presentes em mistura (BANERJEE, 1984; FETTER, 1998; NADIM et al. 2000). Para espécies orgânicas que são líquidas à temperatura ambiente, a solubilidade aquosa pode ser estimada pela eq.:

$$
C_{i}^{w}=X_{i} \cdot \gamma_{i} \cdot S_{i}^{w}
$$

Onde:

$C_{i}^{w}$ - concentração do soluto na fase aquosa em equilíbrio com a fase orgânica;

$X_{i}$ - fração molar do composto "i" em mistura;

$\gamma_{i}$ - coeficiente de atividade do soluto "i" na fase orgânica;

$S_{i}^{w}$ - solubilidade do componente puro em água.

Em muitos subprodutos do petróleo tais como: gasolina, óleo diesel e óleos lubrificantes, a mistura pode ser considerada como solução ideal e o coeficiente de atividade, $\gamma_{i}$, de cada componente pode ser considerado igual a 1,0 (NADIM et al., 2000 e FERREIRA, 2000).

Para hidrocarbonetos pesados tais como naftaleno e isoparafinas, que são sólidos à temperatura ambiente, Peters e Luthy (1993) usaram a seguinte equação para estimar a solubilidade aquosa de hidrocarbonetos de moléculas pesadas: 


$$
C_{i}^{w}=X_{i} \cdot S_{i}^{w} \cdot\left(\frac{f_{L}}{f_{S}}\right)_{\text {pure }(i)}
$$

Onde:

$f_{L}$ e $f_{S}$ - fugacidade do componente " $i$ " puro nas fases de subcongelamento líquida e sólida.

O termo do lado direito da eq. 34 representa a razão da fugacidade do componente puro nas fases de sub-congelamento líquida e sólida.

Se uma análise química indicar que uma amostra aquosa apresenta compostos orgânicos hidrofóbicos excedendo o limite de solubilidade, pode ser que haja a formação de fase livre ou fase separada. Nestas condições, deve-se considerar a teoria do transporte de fase líquida não aquosa ou NAPL (FETTER, 1998).

\subsection{Escoamento Multfásico e Conceituação Básica}

\subsubsection{Introdução}

O escoamento multifásico caracteriza-se pelo escoamento conjunto de dois ou mais fluidos imiscíveis em um meio sólido. O escoamento de líquidos imiscíveis concomitantemente com água, passando pelas zonas saturada e não saturada do solo, ilustra um exemplo claro de aplicação do escoamento multifásico no estudo da contaminação de solos e águas subterrâneas, ou hidrogeologia de contaminação. Na maioria dos textos, estes líquidos imiscíveis são denominados de "líquidos imiscíveis em fase não aquosa" ou NAPL (do inglês, nonaqueous phase liquids). Conforme a densidade, os NAPLs podem ser classificados como "Iíquido imiscível em fase não aquosa mais leve que a água" ou LNAPL (do inglês, light nonaqueous phase liquids) ou "líquido imiscível em fase não aquosa mais denso que a água" ou DNAPL (do inglês, dense nonaqueous phase liquids). Desconsiderando-se o rigor da classificação, estes líquidos podem apresentar solubilidade parcial em água e, assim, ocorre uma fase dissolvida, bem como a fase imiscível. 
Os conceitos básicos do escoamento multifásico estão muito ligados aos trabalhos desenvolvidos pela engenharia do petróleo, onde é estudado o movimento do petróleo dentro do reservatório subterrâneo, que na maioria das vezes contém gás e água. Esses conceitos foram, também, estendidos à zona não saturada, para facilitar a compreensão dos derrames superficiais, bem como dos vazamentos nos tanques de armazenamento subterrâneo.

Os LNAPLs mais comumente encontrados em problemas ambientais são a gasolina e o óleo diesel. Já DNAPLs freqüentemente observados em ocorrências ambientais são os hidrocarbonetos clorados, como por exemplo, o tricloroetano e o pentaclorofenol.

\subsubsection{Saturação}

A saturação de um meio poroso pode ser definida como a relação entre o volume que o fluido ocupa nos poros e o volume total de poros (USEPA, 1994b; COHEN e MERCER, 1993; USEPA, 1996a; FETTER, 1998). O nível de saturação para cada fluido varia de zero (o fluido não está presente nos vazios dos poros e a saturação é 0\%) a um (o fluido ocupa completamente os vazios dos poros e a saturação é 100\%).

A mobilidade de um líquido em meio poroso está diretamente relacionada à saturação do meio poroso pelo fluido em questão. Para haver escoamento de um líquido em um meio poroso, este líquido deve estar continuamente interconectado aos poros da região onde o escoamento ocorre. Quando um líquido é drenado de um meio poroso, ocorre a formação de fase líquida descontínua. O ponto no qual um líquido não aquoso que se apresentava em fase contínua se torna descontínuo é denominado de saturação residual (ver item 2.4.2.6) (USEPA, 1994b; COHEN e MERCER, 1993; USEPA, 1996a), sendo que o nível de saturação de água correspondente é conhecido como água irredutível (USEPA, 1996a). Ressaltase ainda que nos pontos de baixa saturação as pressões capilares são muito elevadas. 


\subsubsection{Tensão Interfacial}

O fenômeno da tensão interfacial ocorre quando um líquido entra em contato com uma superfície sólida ou com um fluido imiscível, surgindo uma energia interfacial. Esta energia é o resultado da diferença do grau de atração entre as moléculas do líquido com as moléculas da outra substância (FETTER, 1998). A tensão interfacial é definida como a quantidade de trabalho exercida por uma substância para "empurrar" uma área unitária de outra substância. A tensão interfacial também é a medida da deformabilidade do contato interfacial, quantificada em unidades de força por comprimento (GRUBB e PALOMINO, 1998). É importante ressaltar que a tensão superficial, um caso especial da tensão interfacial, é a tensão gerada entre um líquido e o seu próprio vapor.

Na Figura 3.6 pode ser observado o contato entre três líquidos imiscíveis e as tensões interfaciais geradas pelo contato entre eles. O líquido no lado côncavo da interface está sob maior pressão do que o líquido do lado convexo e a diferença de pressão é proporcional ao grau de curvatura da interface.

A tensão interfacial é o fator primário que controla a molhabilidade. Quanto maior a tensão interfacial, maior a estabilidade da interface entre os dois fluidos. A tensão interfacial para líquidos completamente miscíveis é 0 dina/cm. A água (a $25^{\circ} \mathrm{C}$ ) tem uma tensão de superfície de $72 \mathrm{dina} / \mathrm{cm}$. Valores de tensão interfacial para DNAPLs giram em torno 15 a 50 dina/cm (COHEN e MERCER, 1993). A tensão interfacial decresce com a elevação da temperatura e pode ser afetada por mudanças no $\mathrm{pH}$, agentes superfície-ativos (surfactantes), e gases em solução (COHEN e MERCER, 1993; USEPA, 1996a). Valores de tensão interfacial são dados de entrada em métodos teóricos para cálculo do volume de produto livre em sub-superfície e em modelos de escoamento multifásico (COHEN e MERCER, 1993). A obtenção de um valor preciso é difícil por duas razões: em primeiro lugar, a medida de tensão interfacial em campo geralmente não é viável ou possível; em segundo lugar, embora possam ser obtidos valores na literatura para alguns hidrocarbonetos de petróleo, esses valores tendem a ser para compostos puros sob condições ideais e podem não ser representativos para os compostos presentes numa pluma em fase livre (COHEN e MERCER, 1993). 
Quando as forças ou tensões atuantes no sistema trifásico apresentado na Figura 3.6 estão em equilíbrio, podemos utilizar a Lei do Triângulo de Neumann:

$$
\sigma_{B A}+\sigma_{B C}+\sigma_{A C}=0
$$

Onde:

$\sigma_{B A}-$ tensão entre o líquido $B$ e líquido $A$;

$\sigma_{B C}-$ tensão entre o líquido B e líquido C;

$\sigma_{A C}-$ tensão entre o líquido A e líquido C.

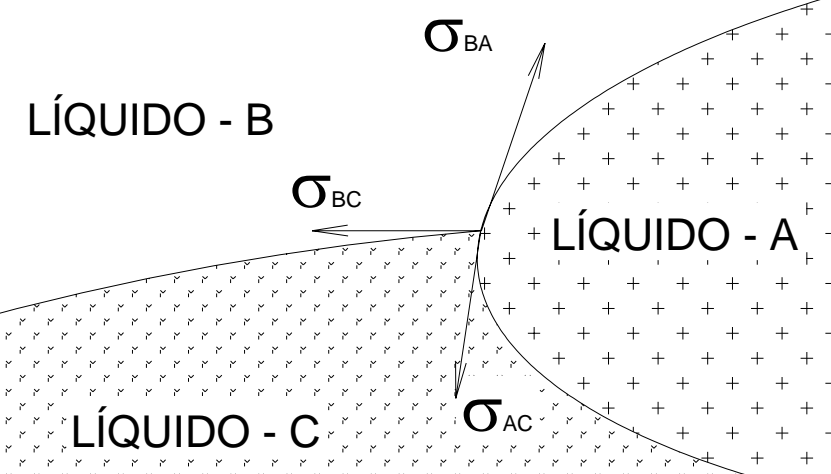

Figura 3.6 - Equilíbrio das tensões em linha de contato entre três líquidos imiscíveis.

\subsubsection{Molhabilidade}

O conceito de molhabilidade refere-se ao espalhamento preferencial de fluido sobre uma superfície sólida, num sistema composto por dois fluidos imiscíveis e uma superfície sólida. Percebe-se que a molhabilidade está diretamente ligada à tensão interfacial chegando a ser abordada como um único item em vários livros texto.

Na Figura 3.7 podem ser observadas as tensões interfaciais formadas entre uma superfície sólida, a água e um NAPL. Pela equação de Young o equilíbrio das tensões pode ser descrito:

$$
\cos \theta=\frac{\sigma_{N S}-\sigma_{A S}}{\sigma_{N A}}
$$


Onde:

$\theta$ - ângulo de contato entre o NAPL e a água (por convenção, $\theta$ é medido em relação ao fluido mais denso);

$\sigma_{N S}$ - tensão entre o NAPL e a superfície sólida;

$\sigma_{A S}$ - tensão entre a água e a superfície sólida;

$\sigma_{N A}-$ tensão entre o NAPL e a água.

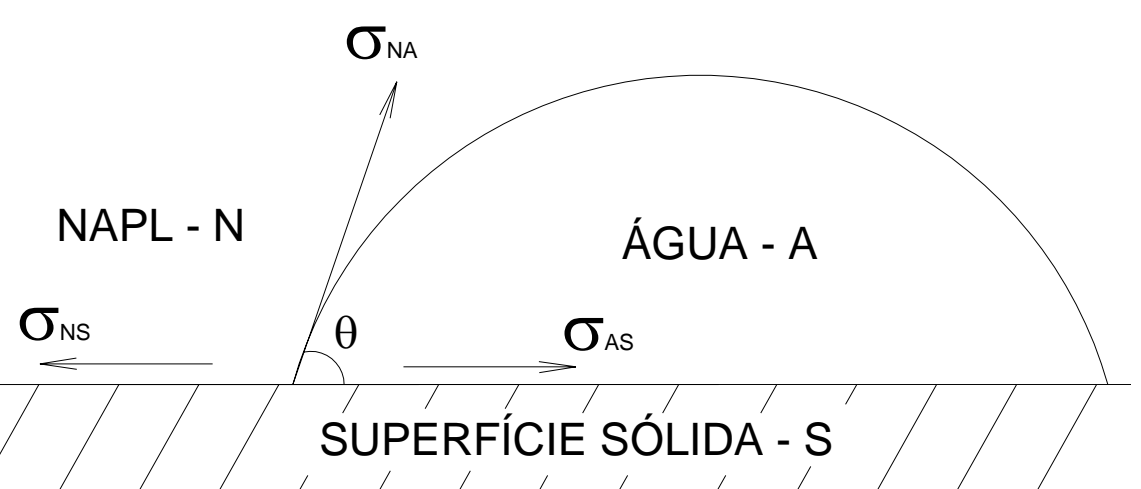

Figura 3.7 - Tensões interfaciais entre uma superfície sólida, a água (fluido molhante) e um líquido imiscível em fase não aquosa (fluido não molhante).

Em geral, um dos fluidos irá se espalhar (ser o fluido molhante) sobre a superfície sólida. Se $\theta$ for menor do que $90^{\circ}$, para a Figura 3.8, a água será o fluido molhante para a superfície sólida. Se $\theta$ for maior do que $90^{\circ}$, então 0 NAPL passará a ser o fluido molhante. Isto significa que na presença de dois fluidos imiscíveis em uma matriz porosa, um dos fluidos envolverá a superfície dos grãos do solo. Podem haver casos onde $\theta$ é $0^{\circ}$, o que indica o início do espalhamento do fluido molhante. Também podem ocorrer casos em que $\theta$ é $90^{\circ}$ e indica o equilíbrio entre os dois fluidos, e, finalmente, casos em que $\theta$ menor do que $90^{\circ}$ e indica o início do espalhamento do fluido não molhante.

Em sistemas água-NAPL-solo, a água tende a ser preferencialmente 0 fluido molhante. Entretanto, se o solo estiver seco e for envolvido primeiramente pelo NAPL, então o NAPL passa a ser o fluido molhante, porque a água não contatará os grãos. Todavia, mesmo a zona não saturada apresenta um pequeno percentual de água envolvendo os grãos e assim, mesmo na zona não saturada a água pode ser considerada o fluido molhante. Um exemplo clássico, citado nos livros texto, é o caso de um automóvel 
encerado onde um NAPL é fluido molhante. Neste exemplo, a água forma gotas e pequenos bolsões e escoa de forma não uniforme.

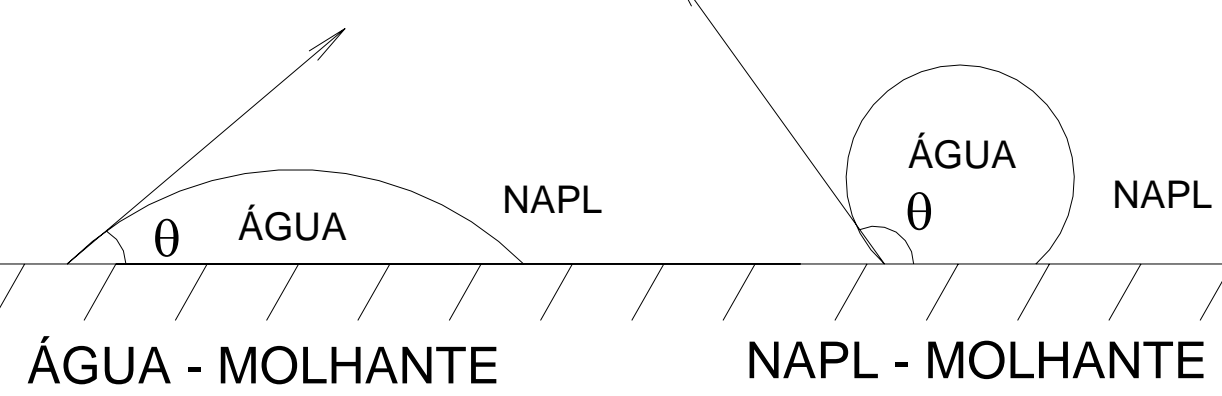

Figura 3.8 - Molhabilidade variando com o ângulo de contato.

Um fluido " $X$ " pode ser molhante em relação a um fluido "Y" e a uma superfície "Z", mas se consideramos outra superfície, por exemplo, "W" esta constatação pode deixar de ser verdadeira. Molhabilidade é uma função de vários fatores como: mineralogia, característica química dos fluidos em contato, presença de matéria orgânica ou surfactantes e histórico de saturação do meio (COHEN e MERCER, 1993).

\subsubsection{Pressão Capilar}

Quando dois fluidos imiscíveis estão em contato, na interface ocorre a formação de uma superfície curva. A diferença entre as pressões exercidas pelos dois fluidos é denominada de pressão capilar (ver Figura 3.9) (CHATZIS, 1983; COHEN e MERCER, 1993; USEPA, 1994b; USEPA, 1996a). Na zona não saturada a pressão capilar é negativa (isto é, menor que a atmosférica) e é muitas vezes denominada de sucção ou tensão (USEPA, 1996a).

$$
P_{c}=P_{m}-P_{n m}
$$

Onde:

$P_{c}$ - pressão capilar;

$P_{m}$ - pressão exercida pelo fluido molhante;

$P_{n m}$ - pressão exercida pelo fluido não molhante. 
O AR É O FLUIDO NÃO MOLHANTE

$\mathrm{Pa}$

SUPERFÍCIE LIVRE

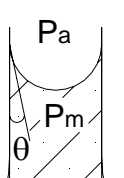

$\theta$

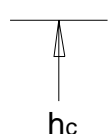

hc

$\mathrm{Pa}=\mathrm{Pnm}$

$\mathrm{Pm} \ll \mathrm{Pnm}$

\section{LÍQUIDO MOLHANTE}

Figura 3.9 - Elevação capilar em um tubo.

Na Figura 3.10 pode ser observado o raio de curvatura, $r_{c v}$, para interface NAPL-água esférica. A relação entre a pressão capilar, $P_{c}$, a tensão interfacial NAPL-água, $\sigma_{N A}$, e o raio de curvatura, $r_{c v}$, ou o raio do tubo, $r_{t}$, é dada por:

$$
P_{c}=\frac{2 \cdot \sigma_{N A}}{r_{c v}}=\frac{2 \cdot \sigma_{N A} \cdot \cos \theta}{r_{t}}
$$

Onde:

$r_{c v}$ - raio de curvatura formado na interface entre os dois fluidos imiscíveis;

$r_{t}$ - raio do tubo.

Para que o NAPL, considerando fluido não molhante, neste caso, consiga deslocar a água, a pressão exercida pelo NAPL deve ser superior à soma das pressões capilar e exercida pela água, $P_{N}>P_{A}+P_{C}$. Quando a pressão exercida pelo fluido não molhante provoca o deslocamento do fluido molhante diz-se que houve "drenagem" (CHATZIS, 1983). A drenagem está vinculada ao escoamento resultante da redução da saturação do fluido molhante (ver Figura 3.10). Por outro lado, quando a pressão exercida pelo fluido não molhante é inferior à soma das pressões capilar e exercida pelo fluido molhante, $P_{n m}<P_{m}+P_{C}$, ocorre o processo inverso, ou seja, a "embebição" pelo fluido molhante e o conseqüente deslocamento do fluido não molhante. A embebição está vinculada ao escoamento resultante do aumento da saturação do fluido molhante (CHATZIS, 1983). 


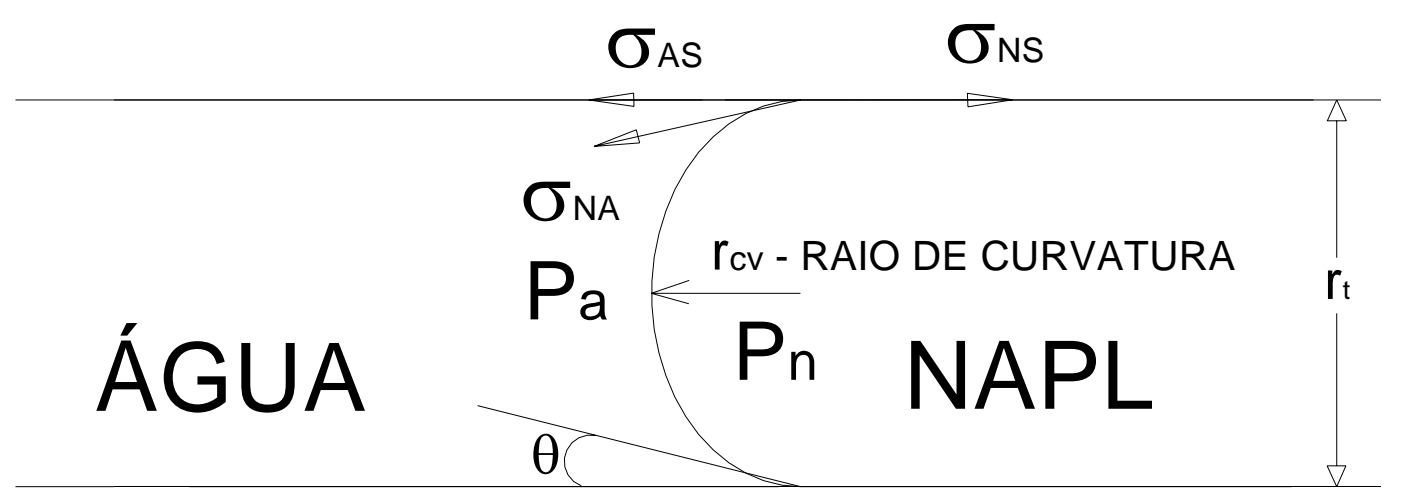

\section{DRENAGEM EMBEBICÃ̃O}

Figura 3.10 - Pressões atuantes em um tubo capilar.

A pressão capilar é maior em meios com granulometria fina (por exemplo, silte, argila) do que em meios com granulometria grosseira (por exemplo, pedregulho, brita, cascalho). A franja capilar sobre o lençol freático é um exemplo da atuação da pressão capilar. A altura da franja capilar é maior em meios de granulometria fina, pois a pressão capilar é inversamente proporcional ao raio do poro (COHEN e MERCER, 1993; USEPA, 1994b; USEPA, 1996a).

A pressão capilar influencia a distribuição e acumulação de fase livre em sub-superfície. A infiltração da fase livre na zona não saturada é afetada pelo conteúdo de água do solo e pelo tamanho e orientação do espaçamento poroso. A infiltração de fase livre em sub-superfície é acentuada pelas condições de solo seco e "liberdades acidentais" do escoamento como as providas por características de permeabilidade secundárias (por exemplo, fraturas, buracos de raiz, e acamamentos laminares planos) (COHEN e MERCER, 1993; USEPA, 1996a). Ao alcançar a franja capilar, a resistência ao movimento descendente é aumentada e o NAPL passa a se espalhar lateralmente e a se acumular sobre o meio saturado. Enquanto houver fonte de NAPL nas camadas superiores, a espessura da lente e a pressão descendente aumentam. Eventualmente, o soluto (fluido não-molhante) começa a deslocar água (fluido molhante) e invade os maiores poros (menor pressão capilar, pois a pressão capilar é inversamente proporcional ao raio). A pressão necessária para este rompimento é conhecida com pressão de entrada de deslocamento ou simplesmente pressão de entrada (SCHWILLE, 1988). A pressão de deslocamento é dada por: 


$$
h_{c}=\frac{2 \cdot \sigma_{N A} \cdot \cos \theta}{\rho_{\text {agua }} \cdot g \cdot r_{t}}
$$

Onde:

$h_{c}$ - altura capilar;

$\rho_{\text {agua }}$ - densidade ou massa específica da água.

$\mathrm{Na}$ zona saturada, os hidrocarbonetos tendem a se espalhar lateralmente sobre formações pouco permeáveis (por exemplo, argila e silte) e se movem por fraturas e meios mais permeáveis. A espessura ou altura de uma coluna de hidrocarbonetos requerida para vencer a resistência da força capilar é conhecida como espessura crítica de hidrocarboneto (ou altura crítica). Como as forças capilares podem restringir a migração da fase livre para a zona saturada, camadas pouco permeáveis podem agir como barreiras capilares também. Isto significa que antes que a fase livre possa invadir o meio poroso saturado, a pressão dos hidrocarbonetos deve exceder a resistência das forças capilares (SCHWILLE, 1988). Em meio heterogêneo, a fase livre escoa por onde ocorram as menores forças capilares, como lentes de areia e pedregulho ou fraturas grandes. Cohen e Mercer (1993) propuseram que a espessura crítica, $z_{n}$, requerida para haver a penetração de DNAPL em poros saturados por água é dada por:

$$
Z_{n}=\frac{2 \cdot \sigma_{N A} \cdot \cos \theta}{r \cdot g \cdot\left(\rho_{n}-\rho_{\text {agua }}\right)}
$$

Onde:

$z_{n}$ - espessura crítica de DNAPL;

$r$ - raio dos poros;

$g$ - aceleração da gravidade;

$\rho_{n}$ - densidade ou massa específica do DNAPL.

Embora a pressão capilar não seja medida em campo (pode ser medida em laboratório ou pode ser estimada pelo tamanho de grão), os efeitos de pressão capilar deveriam ser considerados na análise de dados de campo (USEPA, 1996a). Um parâmetro de campo comumente medido é a espessura de fase livre acumulada no poço. Porém esta espessura é normalmente muito maior que a verdadeira espessura da fase livre no aqǘf́ro. Este erro é mais 
acentuado em meios com forte efeito capilar (por exemplo, em camadas pouco permeáveis como silte e argila) e menos pronunciado em meios com fraco efeito capilar (por exemplo, areias e pedregulhos) (USEPA, 1996a). O efeito é obviamente de grande significação prática no projeto de um sistema de recuperação de fase livre. Por exemplo, acumulação de DNAPL em poços de monitoramento pode ser causada por ambos: quantidade significativa de fase livre ou pequena quantidade de fase livre em meio poroso muito permeável. Um sistema de recuperação convencional (por exemplo, coador de superfície do inglês "skimmer") pode ser apropriado em meio bastante permeável com espessa acumulação de fase livre. No caso de reduzida acumulação em meio bastante permeável, é mais adequado um sistema de recuperação a vácuo, em lugar de um sistema de recuperação convencional (USEPA, 1996a).

A relação entre a pressão capilar e a saturação é obtida pelo uso de experimentos de deslocamento de fluidos imiscíveis em amostras não deformadas. Os experimentos são realizados controlando-se as condições de pressão capilar e monitorando-se as mudanças na saturação da amostra a cada mudança nas condições de equilíbrio capilar. Quando lançadas em gráfico a pressão capilar versus a saturação da amostra, obtém-se as curvas de pressão capilar. Na Figura 3.11 pode ser observada a variação da pressão capilar com a saturação quando uma amostra inicialmente é saturada por água em um ciclo de drenagem, embebição e drenagem. Na Figura 3.11, $P_{d}$ é a pressão de deslocamento; $S_{r m}$ é a saturação residual da fase molhante; $S_{r n m}$ é a saturação residual da fase não molhante. Considerando-se inicialmente uma amostra saturada pelo fluido molhante: 1) inicialmente o fluido não molhante acumulado acima da franja capilar excede a pressão de deslocamento e penetra nos poros mais largos, inicia-se a drenagem; 2) em seqüência, com o aumento do acúmulo de NAPL e conseqüente aumento da pressão exercida pela massa de NAPL os menores poros são paulatinamente tomados pelo fluido não molhante; 3) neste momento, a maioria dos poros está preenchida pelo NAPL e o fluido molhante encontra-se virtualmente imóvel; 4) saturação residual do fluido molhante. No caso do fluido molhante ser a água, seria a situação de água irredutível. São necessárias as mais elevadas pressões para atingir este estágio, término da drenagem; 5) agora, o fluido molhante começa a retomar os menores poros preenchidos pelo NAPL, inicia-se a embibição e 
percebe-se um comportamento histerético. O bloqueio de regiões com o fluido não molhante provoca a histerese; 6) o líquido não molhante presente na amostra apresenta-se sob a forma de blobs (do inglês, gotas ou bolhas) e ganglia (do grego, gânglios ou nódulos) (ver Figura 3.12). O residual de NAPL está desconectado e imóvel, mesmo com bombeamento não se consegue extraí-lo. No caso deste NAPL ser um contaminante, ele passaria a ser uma fonte de contaminação dissolvida por um longo período. Final da embebição.

A histerese presente na curva de pressão capilar resulta do residual de fluido não molhante retido nos poros e de diferenças no ângulo de contato (ver Figura 3.13) durante o processo de embebição e drenagem. Durante a drenagem, os poros maiores drenam o fluido molhante rapidamente, enquanto que os menores poros o drenam lentamente. Como resultado desta retenção capilar, na curva de drenagem as pressões capilares correspondem às saturações mais elevadas (COHEN e MERCER, 1993). Por outro lado, durante a embebição, os menores poros são preenchidos no princípio e os maiores poros são preteridos para serem preenchidos pelo fluido molhante, desta forma correspondem a curvas de brandas pressões capilar versus saturação.

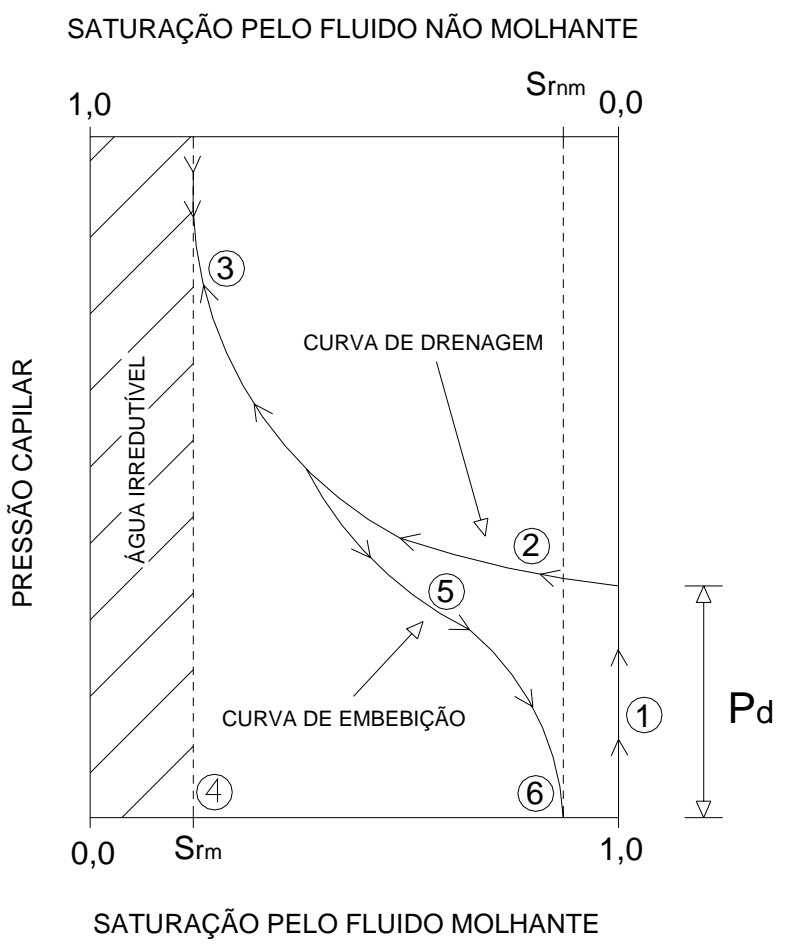

Figura 3.11 - Curva de pressão capilar - curva de saturação do fluido molhante para escoamento bifásico. 


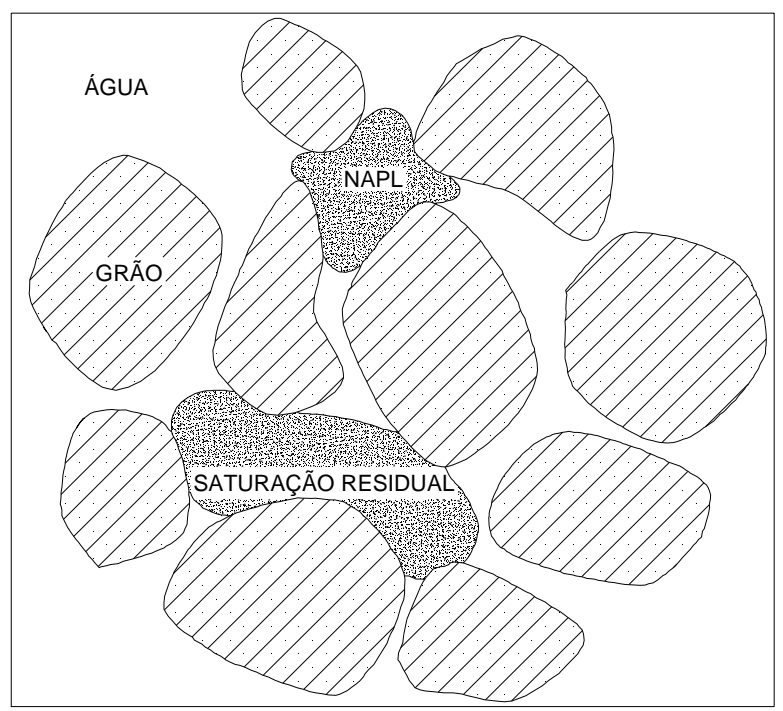

Figura 3.12 - Retenção de blob e ganglion pelo solo.

Na Figura 3.14 são representadas esquematicamente quatro variações na condutividade hidráulica na curva de pressão capilar, onde $K_{1}<K_{2}<K_{3}<K_{4}$. Percebe-se que as menores pressões de deslocamento correspondem às estruturas mais permeáveis (maior condutividade hidráulica) e as maiores pressões de entrada correspondem às estruturas menos permeáveis (BEAR, 1972; KUEPER e FRIND,1991).

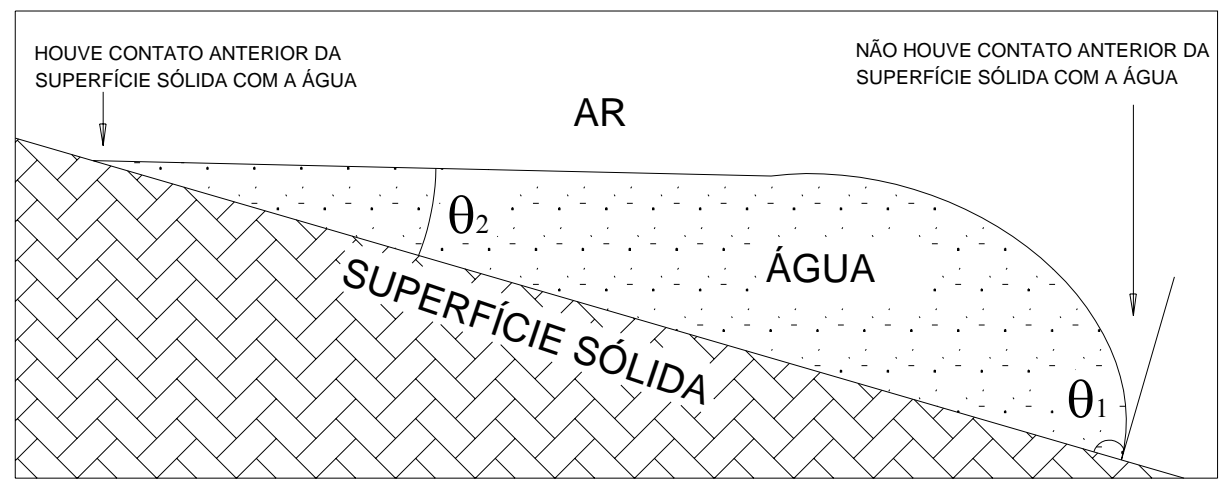

Figura 3.13 - Escoamento de uma gota de água por uma superfície inclinada. Percebe-se que os ângulos de contato nas extremidades da gota são diferentes (histerese).

Para a Figura 3.15 percebem-se comportamentos diferentes para diferentes formações. A situação (1) é composta por material extremamente fino, por exemplo, silte ou argila. Já a situação (2) é constituída por material bem graduado (pouco sortido), por exemplo, uma mistura de areia, argila e silte. Em seguida, para a situação (3) é formada por material muito mal 
graduado (mesma dimensão), como exemplo se pode citar uma areia bem homogeneizada.Finalmente, a situação (4) é composta por material grosseiro, como referência pode-se citar pedregulho ou cascalho.

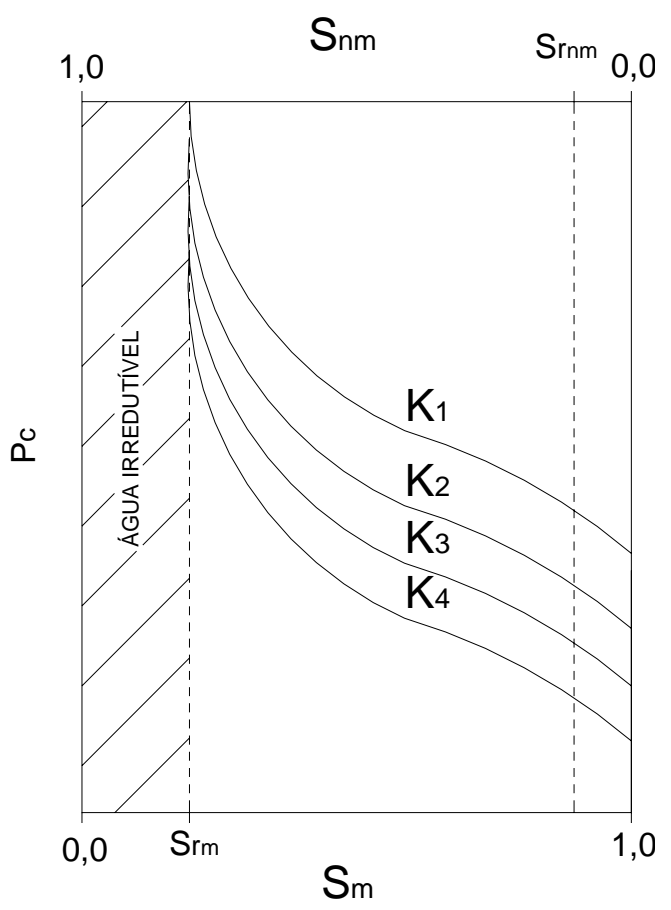

Figura 3.14 - Efeito da variação da condutividade hidráulica na curva de pressão capilar versus saturação.

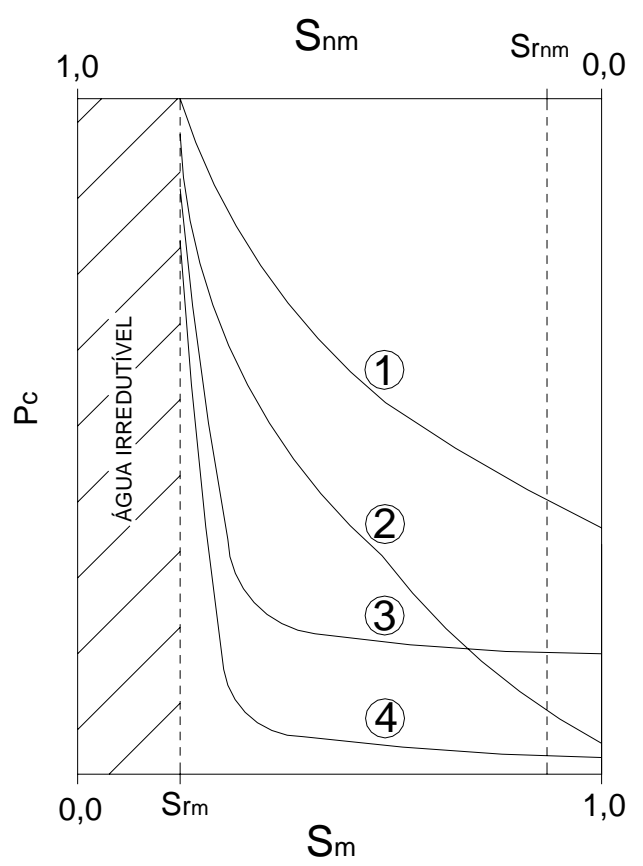

Figura 3.15 - Efeitos da variação da formação na curva de pressão capilar versus saturação. 
Para facilitar a análise das curvas capilares, ensaios de laboratório são ajustados a modelos paramétricos empíricos por regressão não linear. Exemplos característicos são os modelos propostos por Brooks-Corey $\left(S_{c}=\left(P_{c} / P_{d}\right)^{-\lambda}\right)$ e van Genuchten $\left(S_{c}=\left(1+|\alpha \cdot \psi|^{n}\right)^{-m}\right)$. Maiores detalhes sobre a aplicação destes modelos podem ser obtidos em Bear (1972) e Cohen e Mercer, (1993).

\subsubsection{Permeabilidade Relativa}

Quando há mais de um fluido presente num meio poroso, esses fluidos competirão pelos espaços porosos. Como resultado ocorrerá uma diminuição dos espaços disponíveis para a movimentação de cada fluido. Esta diminuição pode ser quantificada multiplicando a permeabilidade intrínseca por uma razão adimensional, denominada de permeabilidade relativa. Ela é a razão da permeabilidade efetiva de um fluido em uma saturação fixa da permeabilidade intrínseca (BEAR, 1972; COHEN e MERCER, 1993; USEPA, 1996a; FETTER, 1998). Como tal, a permeabilidade relativa varia com a saturação de zero a um. Assim, para os fluidos molhante e não molhante, respectivamente, tem-se:

$$
\begin{aligned}
& k_{r_{m}}=\frac{k_{m}}{k} \\
& k_{r_{n m}}=\frac{k_{n m}}{k}
\end{aligned}
$$

Onde:

$k$ - permeabilidade do meio;

$k_{m}$ - permeabilidade efetiva para o fluido molhante;

$k_{n m}$ - permeabilidade efetiva para o fluido não molhante;

$k_{r_{m}}$ - permeabilidade relativa para o fluido molhante;

$k_{r_{n m}}$ - permeabilidade relativa para o fluido não molhante.

Na Figura 3.16 podem ser observadas curvas de permeabilidade relativa para ambos fluidos, molhante (água) e não molhante (NAPL). Como mencionado anteriormente, água irredutível (localizado no lado esquerdo da 
Figura 3.16) é o conteúdo de água no qual cessa o escoamento do fluido molhante. Desse modo não haverá escoamento de água enquanto a saturação de água irredutível $\left(S_{r_{m}}\right)$ não for ultrapassada. A mesma constatação é válida para o fluido não molhante: não haverá escoamento de NAPL até que se exceda a saturação residual do fluido não molhante $\left(S_{r n m}\right)$ (localizado no lado direito da Figura 3.16). Dessa forma, para um sistema bifásico NAPL-água, se o conteúdo de água for menor do que a saturação conhecida como água irredutível, o NAPL poderá escoar, mas a água ficará retida por forças capilares. O mesmo acontece em parte para o NAPL, pois se o conteúdo de for menor que a saturação residual, a água fluirá, mas o NAPL em fase separada ou livre não, porém gotículas de NAPL podem se dispersar e continuar fluindo.

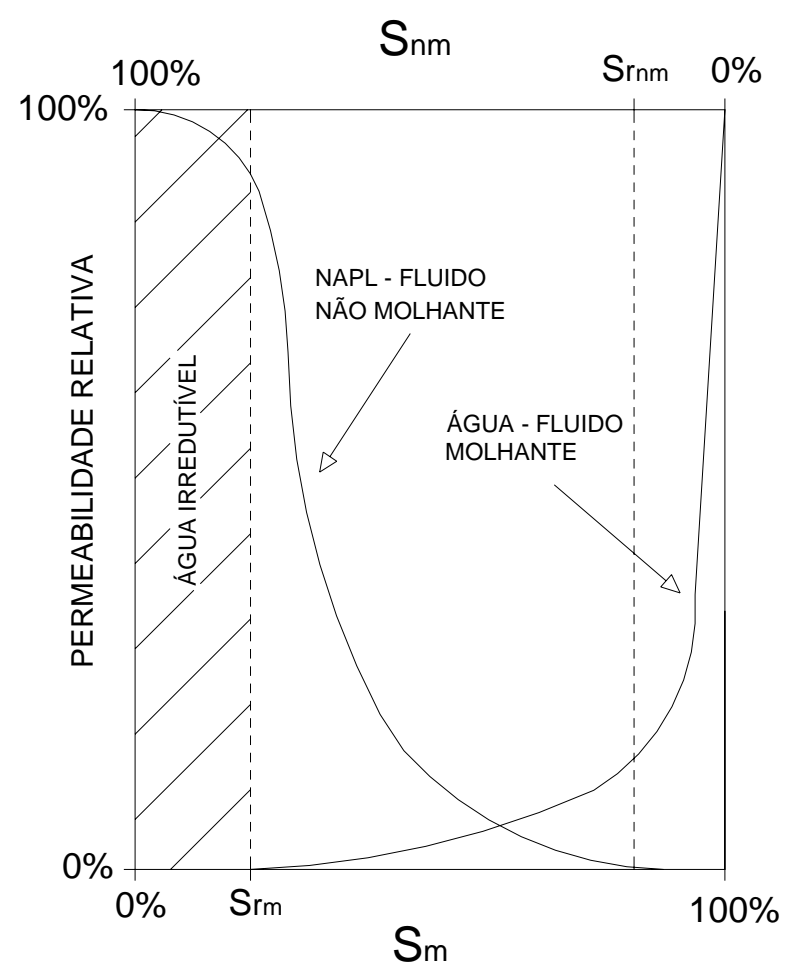

Figura 3.16 - Curva de permeabilidade relativa para um sistema NAPL-água em uma matriz porosa.

Quando se simula numericamente problemas de escoamento de fluidos imiscíveis são necessárias relações de permeabilidade relativa (COHEN e MERCER, 1993). Como a pressão capilar, a permeabilidade relativa pode ser representada como uma função da saturação e também apresenta comportamento histerético. Devido a dificuldades associadas à determinação 
da permeabilidade relativa em laboratório e campo, são utilizadas aproximações teóricas alternativas para estimar esta função. São utilizados dados de pressão capilar versus saturação, dados esses que são de obtenção mais simples (FAUST et al., 1989; COHEN e MERCER, 1993). Dados de laboratório para a permeabilidade relativa em escoamento bifásico são, tipicamente, expressos em termos de saturação elevada a uma potência entre 2 e 4 (FAUST et al., 1989).

No caso de um sistema trifásico NAPL-água-ar são necessárias as permeabilidades relativas para descrever os movimentos simultaneamente. Entretanto, geralmente a obtenção de dados de permeabilidade relativa para sistemas trifásicos envolve determinações caras e de execução difícil. Por esses motivos, vários modelos teóricos foram desenvolvidos para estimar a permeabilidade relativa em sistemas trifásicos (FAUST et al., 1989; COHEN e MERCER, 1993). Por exemplo, o método proposto por Stone (1973) considera a princípio a permeabilidade relativa da água, $k_{r m}$, como função da saturação da água, $S_{m}$, que é obtida para um sistema água-NAPL. Em seguida é considerada a permeabilidade relativa do $a r, k_{r a}$, como função da saturação de ar, $S_{a}$, que é determinada para um sistema ar-NAPL. Finalmente, a permeabilidade do NAPL, $k_{r n m}$, no sistema trifásico é determinada por:

$$
k_{r n m}=k_{r n m m}^{*}\left[\left(\frac{k_{r n m m}}{k_{r n m m}^{*}}+k_{r m}\right)\left(\frac{k_{r n m a}}{k_{r n m m}^{*}}+k_{r a}\right)-\left(k_{r m}+k_{r a}\right)\right]
$$

Onde:

$k_{r n m m}^{*}$ - permeabilidade relativa do NAPL na saturação residual de água num sistema água-NAPL;

$k_{r n m m}$ - permeabilidade relativa do NAPL em função da $S_{m}$;

$k_{r_{n m a}}-$ permeabilidade relativa do NAPL em função da $S_{a}$.

Este tipo de equacionamento, muitas vezes, é usado para a construção de diagramas ternários. Faust et al. (1989) afirmaram que, observando o controle exercido pela heterogeneidade da formação no escoamento do NAPL e da água numa área contaminada, a permeabilidade relativa deveria ser 
relacionada a dados de campo, os quais, em muitos casos, tendem a se mostrar menos lineares do que os dados de laboratório.

\subsubsection{Saturação Residual}

Segundo USEPA (1996a), saturação residual refere-se ao nível de saturação no qual uma massa de NAPL se torna descontínua e imobilizada por forças capilares. Adicionalmente, a saturação residual é um referencial importante para aplicações de recuperação de fase livre, pois representa a quantidade de NAPL que não pode ser recuperada por bombeamento ou drenagem.

Segundo Cohen e Mercer (1993), a saturação residual resulta da ação das forças capilares e de vários fatores, dentre eles: a) distribuição do tamanho dos poros (estrutura, heterogeneidade e tamanho dos grãos), b) molhabilidade, c) viscosidade e densidade do fluido, d) tensão interfacial e e) gradiente hidráulico.

Em geral, quanto menor a granulometria do solo, maior será a saturação residual. Há uma diferença conceitual entre a saturação residual de um fluido molhante e um fluido não molhante. Quando o fluido molhante (por exemplo, água) é drenado de um meio poroso, mesmo até o nível de água irredutível, ainda assim uma fina camada contínua de água permanece nos menores poros e envolve os grãos do meio poroso. Já quando um fluido não molhante (por exemplo, NAPL) é drenado de uma matriz porosa, a drenagem é incompleta pela presença de residual de água nos menores poros (USEPA, 1996a). Como resultado dessa diferença de comportamento entre os fluidos molhante e não molhante, observa-se a formação de pequenos pontos de acumulação de NAPL, pontos estes descontínuos e imóveis que permanecem no solo como saturação residual. Embora já tenham sido descritos no presente trabalho, é importante lembrar que esta fase residual é denominada "blob" ou "ganglion" na literatura (ver Figura 3.12). Embora seja difícil de se determinar ou estimar valores para a saturação residual em campo, em geral os níveis de saturação 
residual tendem ser mais elevados na zona saturada $(0,15$ a 0,50$)$ do que na zona não saturada $(0,10$ a 0,20) (COHEN e MERCER, 1993; USEPA, 1996a).

Schwille (1988) propôs um equacionamento para estimar a capacidade de NAPL retida na zona não saturada na forma de capacidade de retenção volumétrica:

$$
R_{v}=1000 \cdot S_{r n m} \cdot \eta
$$

Onde:

$R_{v}$ - é o residual de NAPL em litros por metro cúbico de solo.

Em geral, a saturação residual e a capacidade de retenção na zona não saturada aumentam com a redução da permeabilidade intrínseca, porosidade efetiva e umidade (SCHWILLE,1988).

\subsubsection{Equação de Darcy para Escoamentos Bifásicos}

Segundo Bear (1972), "quando dois fluidos imiscíveis escoam simultaneamente por um meio poroso cada um dos fluidos estabelecerá seu caminho tortuoso característico, os quais formam estáveis "canais". Se considerarmos um fluido molhante à uma saturação específica, $S_{m}$, e um fluido não molhante, também, à uma saturação específica, $S_{n m}$, caso a saturação do fluido não molhante seja reduzida, os canais do fluido não molhante tendem a ser interrompidos e permanecerão apenas regiões com saturações residuais do fluido não molhante. Podemos concluir que o mesmo acontece para o fluido molhante até o ponto de irredutibilidade. Quando qualquer destes fluidos se tornam descontínuos cessará seu escoamento".

Partindo-se dos conceitos apresentados no parágrafo anterior, parece natural ampliarmos o conceito de permeabilidade de um escoamento de apenas um fluido, para aplicarmos o conceito de permeabilidade relativa e considerarmos o escoamento de dois fluidos. Assim podemos supor que a Lei de Darcy (eq. 45), originalmente descrita para o escoamento de um fluido em um meio completamente saturado, pode ser estendida para descrever o 
escoamento de cada um dos fluidos imiscíveis escoando simultaneamente (BEAR, 1972).

$$
q=-\frac{k \cdot \rho \cdot g}{\mu} \frac{d h}{d x}
$$

Para o fluido molhante:

$$
q_{i m}=-\frac{k_{i j} \cdot k_{r m}}{\mu_{m}}\left(\frac{\partial P_{m}}{\partial x_{j}}+\rho_{m} \cdot g \cdot \frac{\partial z}{\partial x_{j}}\right)
$$

Para o fluido não molhante:

$$
q_{i n m}=-\frac{k_{i j} \cdot k_{r n m}}{\mu_{n m}}\left(\frac{\partial P_{n m}}{\partial x_{j}}+\rho_{n m} \cdot g \cdot \frac{\partial z}{\partial x_{j}}\right)
$$

Onde:

q- fluxo de Darcy (volume por unidade de área por unidade de tempo);

$\mu$ - viscosidade absoluta;

$\frac{d h}{d x}$ - gradiente hidráulico;

$P$ - pressão.

\subsubsection{Migração de Líquidos em Fase Não Aquosa}

\subsubsection{Constituintes}

Os hidrocarbonetos do petróleo são formados a partir de combustíveis fosseis líquidos denominados, muitas vezes, de óleo cru ou, mais corretamente, de petróleo. O petróleo é um líquido encontrado naturalmente em diferentes composições e complexidades. Com exceção de acidentes superficiais, o petróleo é encontrado em grandes profundidades, sendo extraído somente através de poços profundos. O petróleo é uma mistura complexa de hidrocarbonetos, sendo elementarmente constituído por carbono e hidrogênio, com quantidades variadas de oxigênio e enxofre, com traços de nitrogênio, com metais e com outros elementos. 
As refinarias modernas usam um procedimento conhecido como "craqueamento" para fracionar novos cortes. Neste processo, o material é aquecido a uma temperatura de $230{ }^{\circ} \mathrm{C}$ em diferentes pressões, com ou sem catalisador. O craqueamento provoca a perda de hidrogênio, convertendo hidrocarbonetos pesados e complexos em moléculas simples com baixo ponto de ebulição. Durante este processo são produzidas diversas frações de produtos, variando desde o metano até o asfaltano (NADIM et al. 2000).

Segundo Balba et al. (1998), os hidrocarbonetos do petróleo podem ser inseridos em quatro frações: saturados, aromáticos, resinas $(N, S, O)$ e asfaltano. A fração saturada é formada por cadeias de alcanos (alcanos normais), alcanos ramificados (isoalcanos) e cicloalcanos (nafitanos). A fração aromática apresenta hidrocarbonetos monoaromáticos voláteis, tais como: benzeno, tolueno, xilenos etc., hidrocarbonetos poliaromáticos e compostos aromáticos de enxofre. Também na fração dos aromáticos estão incluídos os hidrocarbonetos poliaromáticos (PAHs, polyaromatic hydrocarbon), nafitenoaromático e aromáticos do enxofre. Muitos dos PAHs são carcinogênicos comprovados ou suspeitos, estando vinculados a contaminações por óleos, e, neste contexto, o mais tóxico é o benzo(a)pireno (BALBA et al., 1998). As frações de resinas (N, S, O) e asfaltanos consistem de moléculas polares contendo nitrogênio, enxofre e oxigênio.

Guiguer (1996) afirmou que além de uma combinação de tipos de refino, também são usados aditivos e agentes de mistura para melhorar o desempenho e a estabilidade do combustível. Os hidrocarbonetos que enfatizamos neste item são os destilados médios, tais como óleo diesel, óleo para aquecimento e óleos lubrificantes.

Os derivados do petróleo que se apresentam em fase líquida, também são denominados de líquidos em fase não aquosa (NAPL, non-aqueous phase liquids). Como já descrito em item próprio deste trabalho, em geral os NAPLs são subdivididos em duas classes: mais leves que a água (LNAPLs) e mais densos que a água (DNAPLs). Hidrocarbonetos combustíveis como a gasolina, querosene, óleo para aquecimento, combustíveis para aviação são LNAPLs. Benzeno, tolueno, etilbenzeno e xileno (BTEX) são hidrocarbonetos aromáticos leves que apresentam solubilidade moderada em água (150 - 1.800 mg/L). 
Guiguer (1996) afirmou ainda que a maioria das misturas de destilados médios, tais como diesel e querosene, pode conter até 500 constituintes individuais, grande parte dos quais tendem a ser menos voláteis e menos solúveis que os de mistura de gasolina. Os destilados médios, também, possuem frações menores de aromáticos como BTEX (menos de 1,5 por cento por peso). Daí pode se concluir que vazamentos antigos desses destilados médios podem não mais apresentar níveis apreciáveis e detectáveis de compostos aromáticos porque estes compostos podem volatilizar após um determinado período de tempo. É importante frisar que esse fato deve ser levado em consideração quando os compostos aromáticos são usados como indicadores da presença de hidrocarbonetos em combustíveis expostos às intempéries.

\subsubsection{Propriedades Físico-Químicas dos NAPLs}

Nesta seção são apresentadas algumas propriedades que controlam a persistência e a mobilidade de NAPL em sub-superfície.

\subsection{Densidade}

A densidade de um fluído é definida em alguns setores técnicos mais afins às ciências químicas como sua massa por unidade de volume. Muitas vezes a densidade é expressa sob a forma de densidade relativa que é a razão entre a densidade de um substância qualquer em relação a densidade de uma substância padrão, freqüentemente a água. A densidade é função de vários parâmetros, sendo a temperatura o mais relevante. Segundo Grubb e Palomino (1998) e USEPA (1994b), um DNAPL pode ser convertido eficientemente em LNAPL pela elevação da temperatura no sistema, sendo esta constatação de extrema relevância do planejamento de sistemas de remediação. Hidrocarbonetos halogenados são geralmente mais densos que a água, portanto DNAPLs, e a densidade aumenta com o grau de halogenação. 
Segundo Mackay et al. (1985), diferenças de densidade de 1\% influenciam no escoamento de fluidos em sub-superfície. Contudo, foi comprovado que diferenças de densidade tão pequenas quanto 0,1\% causam o afundamento de água contaminada em modelos físicos de aqüífero (COHEN e MERCER, 1993). A densidade relativa (em relação a água) da maioria dos LNAPLs gira entre 0,75 e 0,99 e para os DNAPLs oscila entre 1,01 e 1,65.

\subsection{Viscosidade Dinâmica}

A viscosidade dinâmica é a medida da resistência de um fluído para escoar, sendo esta resistência causada pelo choque interno das moléculas do fluido. Segundo USEPA (1996a), para aplicações mais práticas, a viscosidade pode ser descrita qualitativamente como: quanto maior for a viscosidade de um fluido maior será a sua resistência a escoar. Fluidos menos viscosos movem-se mais rapidamente em sub-superfície do que fluidos mais viscosos e isto pode ser explicado pela condutividade hidráulica ser inversamente proporcional à viscosidade dinâmica (COHEN e MERCER, 1993; USEPA, 1996a).

Segundo Cohen e Mercer (1993), durante o deslocamento de dois fluidos imiscíveis em uma matriz porosa, a interface entre os fluidos é instável, sendo esta instabilidade observada freqüentemente quando um fluido menos viscoso invade os poros de um fluido mais viscoso. Este fenômeno é conhecido como dedos (do inglês, fingers). Percebe-se também que a ocorrência deste fenômeno é influenciada pela heterogeneidade do meio. Como exemplo, a viscosidade dinâmica do tetracloroetileno (PCE), um DNAPL, é de 0,89cP.

\subsection{Solubilidade Aquosa}

Solubilidade aquosa é a concentração máxima de uma espécie química que se dissolve em água pura à uma temperatura específica. Schwille (1988), usando experimentos de dissolução em laboratório, obteve concentrações de espécies químicas em água próximas à solubilidade aquosa, com velocidades 
de escoamento entre 10 e $100 \mathrm{~cm} / \mathrm{d}$. Contudo, Mackay et al. (1985), afirmam que os compostos orgânicos são comumente encontrados em águas subterrâneas a concentrações menores do que $10 \%$ do limite de solubilidade do NAPL, mesmo que haja suspeita da presença de fase livre ou separada. A discrepância entre resultados obtidos em laboratório e campo é provavelmente causada pelas condições de heterogeneidade em campo, tais como escoamento não uniforme, distribuição complexa do NAPL e mistura de água estratificada no poço. Adicionalmente, mas com menos importância, a discrepância pode residir em limitações na transferência de massa água-NAPL (MACKAY, 1985; POWERS et al., 1991; COHEN e MERCER, 1993). Outro fator a ser considerado na concentração de espécies químicas dissolvidas é o efeito de mistura apresentado no item 3.3.2.4.4.

Segundo Cohen e Mercer (1993), os fatores que afetam a solubilidade são: temperatura, cosolvência, salinidade e teor de matéria orgânica dissolvida. Embora a solubilidade aquosa de muitas espécies químicas aumente com a temperatura, esta relação é variável em direção e magnitude (LYMAN et al., 1982). Segundo Lyman et al. (1982), as solubilidades aquosas das espécies Benzeno, Tolueno, PCE e benzo(a)pireno são 1780, 515, 149 e 0,0034 mg/L, respectivamente.

\subsection{Volatilização}

Volatilização é a transferência de massa da fase sólida ou líquida para a fase gasosa. Assim, espécies químicas presentes nos gases do solo derivam da presença do NAPL, de espécies dissolvidas e espécies adsorvidas (COHEN e MERCER, 1993). As propriedades químicas que afetam a volatilização são a pressão de vapor e a solubilidade aquosa. Já os fatores que afetam a taxa de volatilização são: concentração no solo, umidade do solo, movimento de ar no solo, características sorcivas e difusivas do solo, temperatura do solo, teor de carbono orgânico, porosidade, densidade e conteúdo de argila (LYMAN et al., 1982). 
Cohen e Mercer (1993) afirmaram que compostos orgânicos voláteis VOCs (sigla derivada do inglês, volatile organic compounds) podem: migrar e condensar, adsorver-se nas partículas sólidas, dissolver-se em água subterrânea, degradar-se e difundir-se para a atmosfera. Se houver ignição e acúmulo de vapores acima da concentração de combustão, a volatilização de compostos orgânicos inflamáveis pode provocar incêndios e explosões, como os noticiados por Reggiani (1999).

A Lei de Henry relaciona a concentração de espécies químicas em água com a pressão parcial da espécie na fase gasosa, sendo descrita da seguinte forma:

$$
p_{i}=H_{p c} \cdot C_{a i}
$$

Onde:

$p_{i}$ - pressão parcial do composto "i" na fase de vapor ( $\mathrm{atm}$ );

$H_{p c}-$ constante de Henry $\left(\mathrm{atm} \cdot \mathrm{m}^{3} / \mathrm{mol}\right)$;

$C_{a i}$ - concentração do composto "i" em água $\left(\mathrm{mol} / \mathrm{m}^{3}\right)$.

Como citado por Oliveira (2002), existem várias formas de apresentar a Lei de Henry, cada qual com um valor de constante diferente e, na maioria das vezes, as unidades também não são citadas. A Lei de Henry é válida para não eletrólitos pouco solúveis onde a fase gasosa é considerada ideal (COHEN e MERCER, 1993).

Já a Lei de Raoult é usada para quantificar o equilíbrio entre NAPL e o ar. São relacionados a pressão de vapor em condições ideais e a fração molar na forma seguinte:

$$
p_{i}=X_{i} \cdot p_{i}^{o}
$$

Onde:

$X_{i}$ - fração molar do composto "i" em mistura;

$p_{i}^{o}$ - pressão de vapor do composto "i" puro.

Valores típicos de pressão de vapor, citados por Lyman et al. 1982, para as espécies Benzeno, Tolueno, PCE e benzo(a)pireno são 0,125; 0,0375; 0,02 e $6,6 \cdot 10^{-12} \mathrm{~atm}$, respectivamente. 


\subsubsection{Migração dos NAPLs}

Os NAPLs, por apresentarem uma extensa composição, afiguram-se em uma grande quantidade de substâncias com características diferentes de adsorção no solo, pressão de vapor e solubilidade que, ao entrarem em contato com o solo podem situar-se em três, quatro e até cinco fases distintas. Oliveira (2000) afirmou que ao migrar pela zona não saturada, o produto é parcialmente retido (adsorvido) pelas partículas do solo, formando assim a fase adsorvida (que também pode ser encontrada na literatura como fase líquida). Esta fase adsorvida pode ser subdividida em uma fase em que as moléculas do produto estão aderidas às partículas sólidas do aqüífero, denominada de adsorvida corretamente e outra em que pequenas quantidades do produto estão isoladas e sem mobilidade nos vazios do solo, denominada de residual. No caso de um LNAPL, ao entrar em contato com o lençol freático ou com uma camada de condutividade hidráulica muito baixa, o LNAPL derramado passa a fluir na superfície do mesmo, gerando assim uma fase livre (ver Figura 3.17). Já no caso de um DNAPL, ao entrar em contato com a zona saturada o mesmo continua descendo até atingir uma camada com condutividade hidráulica muito baixa ou impermeável. A partir deste momento passa a fluir lateralmente (ver Figura 3.18). Uma parcela do produto que atingiu o lençol se dissolve em contato com a água subterrânea formando uma pluma de contaminação designada como fase dissolvida.

Existem alguns autores, como Guiguer (1996) e API (1993), que consideram a fase dissolvida como sendo os hidrocarbonetos presentes na água do solo e nas superfícies dos sólidos de solo como películas. Uma pequena parcela do produto pode ser encontrada como componente do vapor do solo, e com isso gerando a chamada fase de vapor. Devido à dinâmica do processo, poderão ocorrer trocas (partições) entre as fases, sendo que hidrocarbonetos que se encontram na fase de vapor podem se condensar e serem adsorvidos pelos sólidos do solo ou se dissolver na água do solo, por exemplo.

Na Tabela 3.7 pode ser observada a distribuição estimada por fases para a contaminação de um solo caracterizado como areia média, com o lençol freático situado à uma profundidade de aproximadamente de 5 metros. 


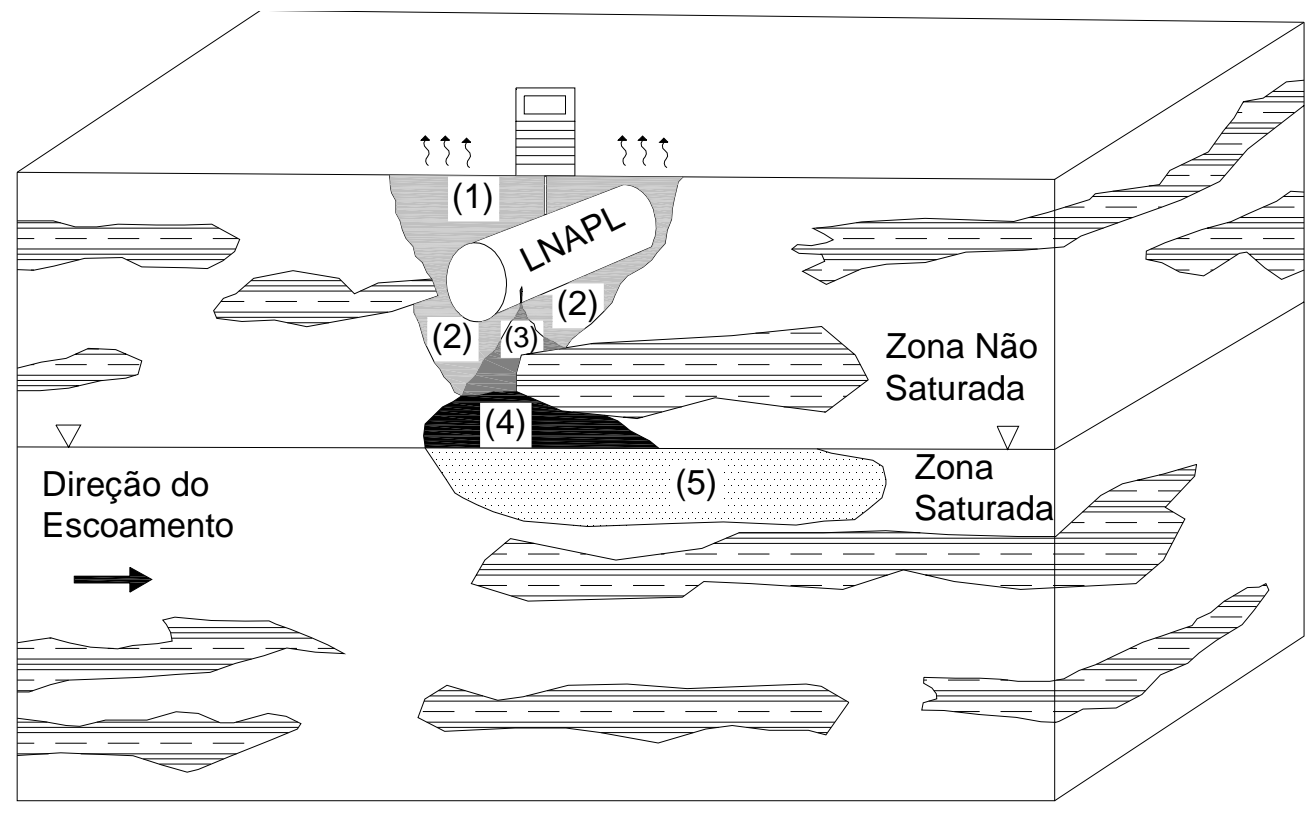

Figura 3.17 - Representação esquemática do comportamento de LNAPLs em sub-superfície. As fases são: (1) vapor, (2) adsorvida, (3) residual, (4), livre ou separada e (5) dissolvida.

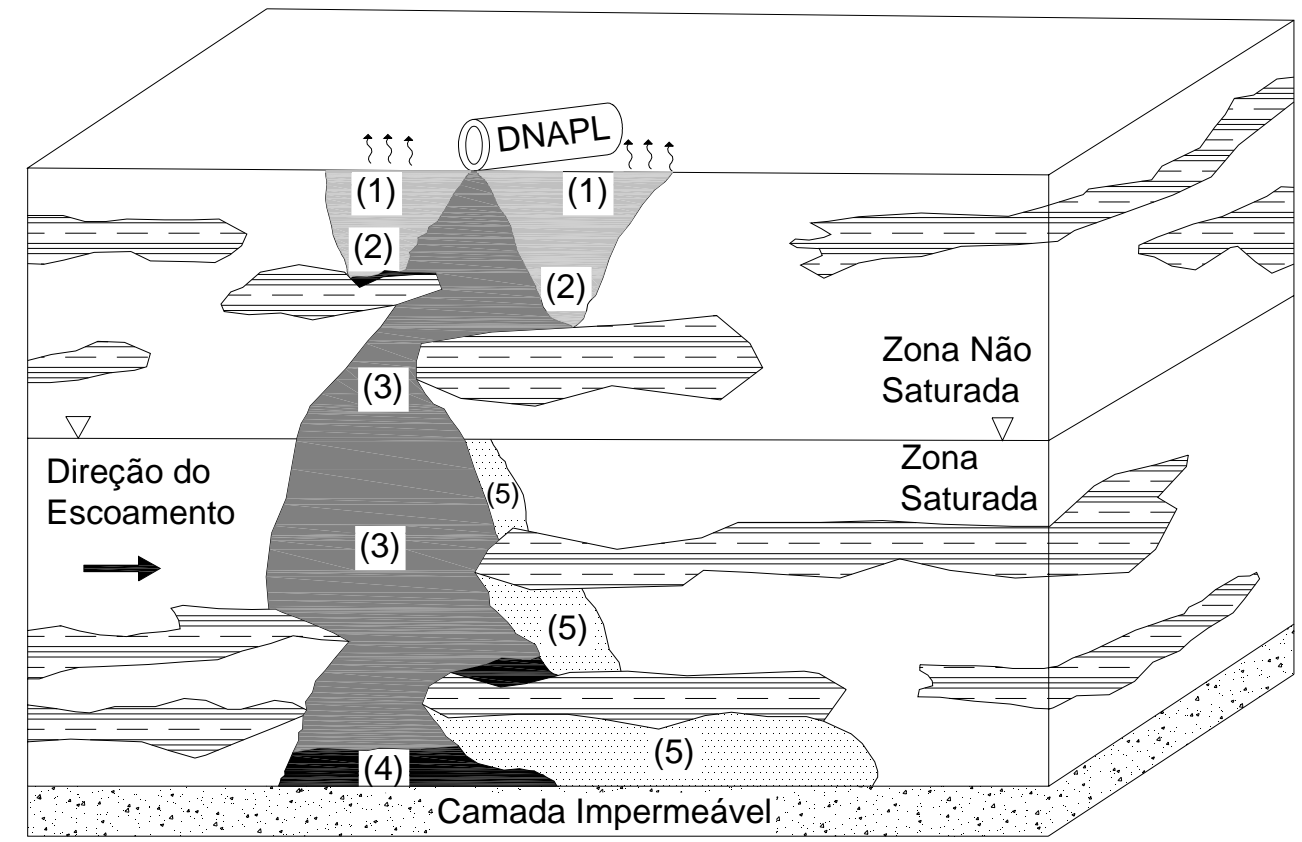

Figura 3.18 - Representação esquemática do comportamento de DNAPLs em sub-superfície. As fases são: (1) vapor, (2) adsorvida, (3) residual, (4), livre ou separada e (5) dissolvida.

Pela observação da Tabela 3.7 verifica-se a contribuição de cada uma das fases. Segundo EPA (1996a), a quantidade do produto dissolvido em água subterrânea é relativamente pequena (1-5\%) em comparação ao total derramado, mas é a responsável pela maior quantidade de material 
contaminado (79\%), uma vez que o escoamento da água subterrânea é o mecanismo de maior capacidade de espalhamento da contaminação, devido a sua alta mobilidade. A quantidade do produto retida na fase sorvida (33\% do total derramado), embora de mobilidade baixíssima, funciona como uma fonte permanente de contaminação das águas subterrâneas pela liberação lenta e contínua de produto para a fase dissolvida.

Tabela 3.7 - Distribuição das Fases do Contaminante (Adaptado de EPA, 1996a).

\begin{tabular}{lrrrr}
\hline \hline \multicolumn{1}{c}{ Fase } & \multicolumn{1}{c}{$\begin{array}{c}\text { Volume } \\
\text { Contaminado } \\
\left(\mathrm{m}^{3}\right)\end{array}$} & $\begin{array}{c}\text { \% do } \\
\text { Total }\end{array}$ & $\begin{array}{c}\text { Volume de } \\
\text { Contaminante } \\
\left(\mathrm{m}^{3}\right)\end{array}$ & $\begin{array}{r}\text { \% do } \\
\text { Total }\end{array}$ \\
\hline Livre & 7.100 & 1,0 & 18.500 & 62 \\
Adsorvida & 250.000 & 20,0 & 10.000 & 33 \\
Dissolvida & 960.000 & 79,0 & 333 & $1-5$ \\
\hline \hline
\end{tabular}

\subsubsection{Comportamento das Fases dos NAPLs}

Para se caracterizar aproximadamente um vazamento de hidrocarboneto torna-se necessário uma compreensão qualitativa sobre o comportamento das fases dos hidrocarbonetos no solo. O mesmo ocorre para selecionar e implementar uma ação corretiva mais efetiva. Assim, a seguir é descrito o comportamento geral das fases dos hidrocarbonetos no solo.

\subsection{NAPLs em Fase Adsorvida}

Segundo Guiguer (1996), quando os derivados do petróleo líquidos são liberados no solo, hidrocarbonetos em fase líquida migram descendentemente sob efeito da gravidade e de forças capilares. Algum espalhamento horizontal ocorre enquanto hidrocarbonetos em fase líquida migram descendentemente devido também às forças capilares e às diferenças nas condutividades hidráulicas de cada camada do solo. 
Guiguer (1996) menciona ainda que a presença de camadas de solo com condutividade hidráulica baixa também promove espalhamento horizontal dos NAPLs em fase líquida nas camadas do solo sobrejacentes com condutividade hidráulica maior. Fluídos em movimento descendente (água ou NAPL em fase líquida) podem se acumular acima dessas camadas com baixa condutividade. Ao cessar o movimento vertical, seja pela presença de uma camada de condutividade muito baixa ou por se atingir o lençol freático, o produto que ficou retido nos poros do material geológico passa a ser denominado de fase adsorvida. Como já mencionado, esta fase adsorvida na verdade pode ser subdividido em três fases: uma fase adsorvida nas partículas do solo, uma fase residual (líquido sem mobilidade e livre nos vazios existentes nos poros do material geológico) e uma fase de vapor, (tratada em particular no item 3.4.9.4.4). Caso a fase residual não seja removida, agirá como fonte permanente de contaminação para a água subterrânea. De acordo com Jury et al. (1990), a concentração da fase adsorvida $C_{s}$ é expressa em microgramas por grama de solo; a concentração da fase dissolvida $C_{l}$ é expressa em microgramas por centímetro cúbico de solução de solo; e a concentração da fase gasosa $C_{g}$ é expressa em microgramas por centímetro cúbico de ar do solo. A concentração total $C_{t}$ em microgramas por centímetro cúbico de solo é expressa na forma da eq. (50):

$$
C_{t}=\rho_{b} \cdot C_{s}+\Theta \cdot C_{l}+a \cdot C_{g}
$$

Onde:

$\rho_{b}$ - é a densidade volumétrica do solo $\left(\mathrm{g} / \mathrm{cm}^{3}\right)$;

$\Theta$ - é conteúdo volumétrico de água;

$a$ - é o teor volumétrico de ar.

$\mathrm{Na}$ Tabela 3.8 são apresentadas as extensões aproximadas da concentração de destilados médios residual na zona não saturada.

Segundo Oliveira (1992), a quantidade de produto que atinge o lençol freático depende da sua quantidade inicial, da distância vertical que separa o ponto de vazamento ou derramamento do lençol freático e da quantidade residual do produto que fica retida pelo solo. Esta última, sendo uma característica própria de cada tipo de material geológico, pode ser descrita de 
modo análogo à porosidade de retenção ou retenção específica do solo $\left(S_{R}\right)$. Para um volume $V_{R}\left[\mathrm{~L}^{3}\right]$ de produto derramado, que se infiltra na área $A\left[\mathrm{~L}^{2}\right]$ de solo, por uma distância vertical $d[L]$, para um material que apresente uma retenção específica para a gasolina $S_{R}\left[\mathrm{~L}^{0}\right]$, tem-se que:

$$
V_{R}=A \cdot d \cdot S_{R}
$$

Onde:

$V_{R}-$ volume de produto retido pelos poros;

$A$ - área atingida pelo vazamento;

$d$ - distância vertical percorrida pelo produto até atingir o nível da água (N.A.);

$S_{R}$ - retenção específica do material geológico para o produto.

Oliveira (1992), menciona ainda que a conjunção dos fatores acima descritos é determinante para que o produto derramado atinja ou não a zona saturada.

Tabela 3.8 - Valores Típicos da Concentração de Destilados Médios Residuais na Zona Não Saturada (Adaptado de API, 1993).

\begin{tabular}{lcc}
\hline \hline \multicolumn{1}{c}{ Meio } & \multicolumn{2}{c}{ Destilados Médios } \\
& $\left(\mathrm{L} / \mathrm{m}^{3}\right)$ & $(\mathrm{mg} / \mathrm{kg})^{\mathrm{a}}$ \\
\hline Cascalho grosseiro & 5,0 & 2.200 \\
Areia e cascalho grosseiros & 8,0 & 3.500 \\
Areia média a grosseira & 15,0 & 6.500 \\
Areia fina a média & 25,0 & 11.000 \\
Sedimento a areia fina & 40,0 & 17.000 \\
\hline \hline
\end{tabular}

Notas:

${ }^{a}$ = cálculo feito considerando a densidade do solo $1,85 \mathrm{~g} / \mathrm{cm}^{3}$ e as densidades dos combustíveis líquidos $0,7 \mathrm{~g} / \mathrm{cm}^{3}$ para a gasolina; $0,8 \mathrm{~g} / \mathrm{cm}^{3}$ para os destilados médios e $0,9 \mathrm{~g} / \mathrm{cm}^{3}$ os óleos combustíveis.

As variações de nível do lençol freático promovem um espalhamento vertical de LNAPLS (API, 1993). Hidrocarbonetos líquidos livres retidos na franja capilar se moverão descendentemente se o nível do lençol freático abaixar, deixando líquido residual na zona não saturada expandida acima da 
nova posição do lençol freático (USEPA, 1996a). Segundo Oliveira (1992), uma nova elevação subseqüente do lençol freático fará com que a franja capilar e os hidrocarbonetos líquidos livres associados se movam ascendentemente. Hidrocarbonetos residuais na zona não saturada podem ser remobilizados devido ao aumento de hidrocarbonetos líquidos livres, causando um espalhamento lateral numa elevação diferente (OLIVEIRA, 1992). Além do que, uma fase líquida residual pode permanecer na zona saturada abaixo do lençol freático reposicionado. Apenas a quantidade móvel de hidrocarbonetos líquidos, e não a quantidade total, é que muda sob essas condições. Também, as variações de nível do lençol freático, como aquelas que foram descritas, podem afetar a quantidade de combustível passível de ser recuperada e as espessuras dos combustíveis medidas em poços de monitoramento (OLIVEIRA, 1992; USEPA, 1996a; FETTER, 1998).

\subsection{NAPLs em Fase Dissolvida}

Nadim et al. (2000) afirmaram que a fase dissolvida dos hidrocarbonetos resulta do contato entre e a água subterrânea e os NAPLs, onde a água subterrânea dissolve lentamente o NAPL formando uma pluma de hidrocarbonetos no escoamento subterrâneo. A pluma contém os hidrocarbonetos mais leves e solúveis.

Guiguer (1996) apresentou as prováveis vias de contato entre NAPL e a água subterrânea:

- Processos de infiltração através da zona não saturada, contendo hidrocarbonetos residuais;

- Movimento da água subterrânea que se infiltra, e entra em contato com a pluma de contaminação de hidrocarbonetos livres;

- Contato direto entre a pluma de contaminação e lençol subterrâneo.

Guiguer (1996) acrescentou ainda que a concentração de hidrocarbonetos dissolvidos e a transferência para a água subterrânea dependem de alguns fatores, tais como: 
- Profundidade do lençol freático;

- Condutividade hidráulica do solo;

- Valores de recarga pluviométrica;

- Flutuações no lençol freático;

- Velocidade da água subterrânea;

- Solubilidade do produto;

- Temperatura da água;

- Concentração destes compostos dentro da fase de hidrocarboneto residual.

Contudo, Cohen e Mercer, (1993) e Nadim et al. (2000), acrescentam que os fatores que mais interferem no processo de dissolução são solubilidade e grau de mistura entre as fases. As solubilidades dos hidrocarbonetos em misturas (como a gasolina) são muito reduzidas em comparação com a solubilidade dos componentes individuais. Por exemplo, o benzeno, presente na gasolina comercializada no Brasil apresenta em água uma concentração da ordem de $50 \mathrm{mg} / \mathrm{L}$, enquanto que a substância pura apresenta uma concentração em água que ultrapassa $1.700 \mathrm{mg} / \mathrm{L}$, sendo que este o fenômeno da cosolubilidade. Entretanto, com a adição de solventes hidrofílicos para aumentar o rendimento dos motores e/ou reduzir o volume de compostos voláteis lançados ao meio ambiente, como acontece no Brasil com a adição de $24 \%$ de etanol a gasolina (BRASIL, LEIS, etc. 1998), origina-se o fenômeno chamado de cossolvência. Estudado por alguns autores como Banerjee e Yalkowsky (1988); Pinal et al. (1990), o efeito da cossolvência provoca o aumento da solubilidade dos hidrocarbonetos em contato com a água. Segundo Fernandes et al. (1997), com a adição de 10 \% de etanol a gasolina, as solubilidades dos solutos excederam a solubilidade em água pura (no sistema sem etanol) por um fator de 1,2; 1,4 e 1,5 para o benzeno, tolueno e oxileno, respectivamente.

Guiguer (1996), afirma que os processos de advecção e dispersão hidrodinâmica controlam o movimento dos NAPLs em fase dissolvida na água subterrânea. A dispersão hidrodinâmica causa a diluição das concentrações de NAPL dentro da pluma de contaminação em fase dissolvida. $O$ espalhamento 
causado por difusão molecular (movimento das espécies na ausência do escoamento) é mínimo e domina o transporte sob condições relativamente estáticas, como meios com baixa condutividade hidráulica e reduzida velocidade de escoamento. A dispersão derivada de processos de mistura mecânica causada pelo movimento da água no solo é o principal mecanismo de transporte. Em casos de topografia acentuando a elevação da condutividade hidráulica, a velocidade da água poderá atingir dezenas de metros por ano, a advecção passa a ser relevante.

Segundo Fels (1999), embora o produto livre raramente percorra grandes distâncias da fonte, contaminações em fase dissolvida podem migrar por grandes distâncias através do subsolo. A fase dissolvida paticiona-se e degaseifica-se da água subterrânea nestas condições. Conseqüentemente, água subterrânea contaminada não é comumente encontrada a distâncias superiores a um quilometro ou dois da fonte. Já Oliveira (2002) afirmou que a provável distância máxima para uma pluma de hidrocarbonetos dissolvidos não ultrapassa 200 metros.

\subsection{NAPLs em Fase Livre ou Separada}

Em um derramamento de LNAPL no solo, quando o produto atinge a zona saturada, passa a flutuar sobre o lençol freático ou franja capilar, por possuir densidade menor que a da água e por ser, de forma global, imiscível. Como conseqüência, esta fase é designada de fase livre. Dependendo da quantidade de produto que atinge a zona saturada e das características do lençol freático, o peso exercido pelo LNAPL sobre o lençol subterrâneo pode deprimir o mesmo, reduzindo a sua espessura. Por outro lado, em um derramamento de DNAPL em solo, este passará a migrar verticalmente até encontrar uma camada de baixa condutividade hidráulica ou a base do aqǘf́rero. Nesse momento o DNAPL passa a fluir lateralmente.

O deslocamento da fase livre de hidrocarbonetos apresenta características próprias diferentes das apresentas pela água subterrânea. Assim técnicas de campo geralmente utilizadas para estimar características do 
lençol subterrâneo tornam-se difíceis de serem aplicadas a fase livre, pois a espessura da camada contaminante geralmente apresenta valores insuficientes para tais técnicas (OLIVEIRA, 1992).

Segundo EPA (1996a), um fator relevante a ser levado em consideração no momento em que se vai estimar a espessura da camada contaminante é que a espessura acumulada em poço de monitoramento é considerada aparente e não corresponde à real espessura da fase livre. Fetter (1998), afirma ainda que a diferença relativa entre a espessura da camada de hidrocarbonetos aparente e a real aumenta com a diminuição do tamanho dos grãos do material poroso e com o aumento do peso específico dos hidrocarbonetos.

Testa e Paczkowski (1989), apresentam um método de estimativa dos volumes de hidrocarbonetos em fase livre pela determinação da espessura real baseada nas características hidrogeológicas do solo e da espessura aparente de hidrocarbonetos no poço de monitoramento.

Segundo Oliveira (1992), o movimento vertical do lençol freático afeta a presença de produto livre e a distribuição do produto residual nas zonas saturada e não saturada. $O$ movimento descendente resulta em hidrocarbonetos residuais presos ao solo na zona não saturada, enquanto que o movimento ascendente resulta em um aparente desaparecimento do produto livre, no momento em que uma nova fase residual é desenvolvida. Quando o nível da água volta ao normal, esta fase residual pode ser remobilizada e produz novamente a fase livre. A remobilização pode ser confundida com um novo vazamento quando, na verdade, trata-se do mesmo vazamento (OLIVEIRA, 1992).

\subsection{NAPLs em Fase de Vapor}

Os hidrocarbonetos em fase de vapor resultam principalmente da volatilização das espécies em fase sorvida presentes nas zonas saturada e não saturada. Em menor escala, também pode ocorre volatilização a partir de hidrocarbonetos em fase livre e/ou fase dissolvida presente na água 
subterrânea. A transferência de hidrocarbonetos da fase líquida para a fase de vapor é controlada pela lei de Henry. Num vazamento recente de gasolina, os constituintes com elevada pressão de vapor e menor peso molecular (por exemplo, butano e pentano) geralmente correspondem a cerca de 75 a $85 \%$ dos hidrocarbonetos em fase de vapor, no equilíbrio, com a gasolina (GUIGUER, 1996). Já em vazamentos mais antigos são encontrados percentuais menores de constituintes voláteis e, conseqüentemente, a mistura resultante apresentará uma pressão de vapor mais reduzida (GUIGUER, 1996).

Segundo USEPA (1996a), uma parcela de hidrocarbonetos em fase de vapor pode aderir ao solo ou ser adsorvida. Contudo, o vapor da água e o vapor dos hidrocarbonetos disputam os mesmos espaços de adsorção nos sólidos do solo, e, na maioria dos casos, a água acarreta uma redução drástica da capacidade de adsorção do solo. Em solo seco ou solo com uma concentração baixa de umidade, a quantidade adsorvida está diretamente relacionada à área da superfície das partículas do solo e à quantidade de matéria orgânica. A área da superfície disponível para adsorção passa a ser reduzida com o aumento da quantidade de água no solo. Entretanto, os hidrocarbonetos adsorvidos podem ser remobilizados como hidrocarbonetos em fase dissolvida devido ao movimento da água que percola a zona não saturada (FETTER, 1998).

Segundo Guiguer (1996), a migração de vapor na sub-superfície é controlada por vários parâmetros, dentre eles:

a) Propriedades físicas e químicas do produto liberado:

- Pressão de vapor;

- Solubilidade;

- Concentração;

- Densidade;

- Viscosidade.

b) Propriedades hidrogeológicas:

- Condutividade hidráulica;

- Profundidade da água subterrânea;

- Direção do fluxo da água subterrânea; 
- Temperatura da água;

- Porosidade;

- Conteúdo de água.

c) Outros:

- Pressão barométrica;

- Duração e intensidade de precipitação pluviométrica;

- Estruturas feitas pelo homem.

Em geral, os hidrocarbonetos em fase de vapor tendem a seguir caminhos preferenciais e a migrar de sítios de maior pressão para sítios de menor pressão (API, 1993). Como os vapores dos hidrocarbonetos são mais densos que o ar pode haver acumulo no subsolo de prédios, galerias de drenagem, caixas telefônicas subterrâneas e outras estruturas (HIRATA, 1990). O monitorados da concentração de vapores e explosividade são métodos usados para detectar a ocorrência de um vazamento de maneira expedita.

Em resumo, num vazamento de combustíveis líquidos no solo consiste, inicialmente, observa-se à formação de uma pluma em fase líquida livre. Com o passar do tempo, os constituintes em fase sorvida particionam-se para a fase de vapor e dissolvida. Por conseguinte, hidrocarbonetos móveis em fase adsorvida, dissolvida, livre ou de vapor, tendem a se tornar mais distintos e a se separar com o tempo. Em muitos casos, essas fases estão posicionadas como corpos distintos ou plumas de contaminação que podem migrar para direções diferentes. $\mathrm{Na}$ avaliação de um vazamento, fases distintas devem ser avaliadas com relação aos riscos inerentes. Os hidrocarbonetos em fase adsorvida, livre e dissolvida representam a maior ameaça para qualidade da água subterrânea, enquanto a fase de vapor, por estar próxima à superfície, apresentam riscos à segurança de pessoas e instalações, devido à possibilidade de explosão. Como exemplo desta periculosidade, REGGIANI, (1999), apresenta um histórico de casos onde houveram explosões decorrentes de vazamentos. 


\subsection{Geofísica Aplicada à Avaliação de Áreas Contaminadas}

A ciência da geofísica aplicada estuda o comportamento dos materiais do solo por medidas indiretas de propriedades físicas para compreender as condições de sub-superfície (TELFORD et al., 1990). Segundo Dehaini (2001), conforme as características de cada caso se utiliza a integração de pelo menos dois métodos diferentes para medir as grandezas que melhor expressam as condições dos materiais a serem estudados.

Segundo Zhdanov e Keller (1994), os métodos geofísicos classificados como geoelétricos estudam basicamente os contrastes das propriedades eletromagnéticas dos meios. Tais métodos são bastante flexíveis e podem variar bastante na forma de aplicação: campo elétrico natural ou artificial, contato com o solo galvânico ou indutivo, corrente contínua ou alternada e diversos procedimentos de medida (DEHAINI, 2001).

Telford et al. (1990) afirmam que os métodos geoelétricos podem ser divididos em duas categorias: aquele que enfatiza o conceito de eletrorresistividade e aquele que enfatiza o conceito eletromagnético. No primeiro método não há variação no campo elétrico em relação ao tempo (corrente contínua) e no segundo há variação no campo elétrico em relação ao tempo (corrente alternada). Evidentemente, as duas vertentes são regidas pelo mesmo fundamento (equação de Maxwell) que é o princípio básico do eletromagnetismo. Uma vez que o mesmo princípio básico é utilizado, autores como Zhdanov e Keller (1994) consideram todos os métodos (sejam eletrorresistivos ou eletromagnéticos) como eletromagnéticos, porém com uma sub-classificação diferente, qual seja: estáticos, quase-estáticos e irradiativos.

As ondas eletromagnéticas sofrem forte atenuação ao penetrar no solo. Em decorrência, são priorizados métodos de baixa freqüência, possibilitando que o sinal atinja maiores profundidades. O comportamento das rochas (a sua resposta ao método) depende das propriedades e da agregação dos minerais, da forma, preenchimento e volume dos poros e/ou fraturas e grau de alteração. $\mathrm{Na}$ área de águas subterrâneas, os métodos geoelétricos são mais eficientes e viáveis. Neste caso, as grandezas eletromagnéticas que fornecem os 
contrastes são: resistividade elétrica ou de forma inversa a condutividade elétrica, constante dielétrica e permeabilidade magnética (TELFORD et al., 1990). O conteúdo de água controla as propriedades elétricas dos materiais geológicos, sendo que a água presente em sub-superfície apresenta condutividade elétrica mensurável por possuir sais dissolvidos. As rochas, por apresentarem poros e/ou fissuras em maior ou menor intensidade, podem ser ocupadas total ou parcialmente, por água acarretando um comportamento condutor com resistividade variável (ORELLANA, 1982).

Segundo Elis (2001), o fator determinante na escolha do método geofísico mais adequado ao estudo de um local com problema de contaminação ambiental é o conhecimento prévio do tipo de informação necessária para avaliar o problema. Dessa forma, é importante saber que método é capaz ou mais apropriado para atingir cada objetivo específico de uma investigação.

\subsubsection{Geofísica Aplicada a Contaminação por Hidrocarbonetos}

Sauck et al. (1998) comentam que o volume contaminado por vazamentos de hidrocarbonetos (neste caso LNAPLs) no ambiente natural, quando observado segundo suas características elétricas, muda de um comportamento eletricamente resistivo para um comportamento mais condutivo com o passar do tempo, devido a uma variedade de processos biogeoquímicos. Em Wurtsmith AFB, ao noroeste de Michigan, nos Estados Unidos da América, vários métodos elétricos, especialmente o GPR, apresentaram baixas resistividades anômalas coincidindo com plumas de produtos combustíveis (SAUCK et al., 1998). Esta mudança temporal no comportamento resistivo de zonas contaminadas por hidrocarbonetos não vem sendo adequadamente explorada nas interpretações geofísicas e nos modelos de sítios contaminados, embora tenha sido sugerido que muitas plumas de hidrocarbonetos e contaminantes orgânicos mudam com o tempo devido a uma grande variedade de processos ativos (BENSON et al., 1997). Bases para esta 
constatação vêm dos estudos geoquímicos de sítios contaminados por hidrocarbonetos, os quais indicaram a presença de condutividade elevada na água subterrânea abaixo de algumas plumas de LNAPLs (BAEDECKER et al., 1993; BENNET et al., 1993). Segundo Mcmahon et al., (1995), a degradação de hidrocarbonetos por atividade bacteriana na zona não saturada e saturada produz ácido carbônico e compostos orgânicos, os quais aceleram a dissolução mineral do aqüífero. Isto conduz à produção de uma elevada concentração de sólidos totais dissolvidos (STD), que se reflete no crescimento da condutividade observada na água subterrânea e em zonas de biodegradação ativa (BENSON et al., 1997). Conseqüentemente, a composição e as propriedades físicas da pluma em fase livre/residual, bem como o meio ao redor, irão mudar ou evoluir com o tempo (SAUCK et al., 2000).

Sauck (2000), em uma publicação esclarecedora, apresenta os três fatores-chave que devem ser considerados na interpretação e modelagem de sítios contaminados por LNAPL. São eles: 1) Produção de ácidos orgânicos e carbônicos durante a biodegradação, 2) Dissolução de sais do solo natural e, finalmente, 3) A natureza do contaminante livre. O autor citado descreve detalhadamente cada um dos itens acima mencionados e propõe um modelo para a resposta geoelétrica nas imediações de sítios contaminados por LNAPLs. Werkema et al. (2000) realizaram um levantamento geoelétrico em amostras de solo utilizadas para contagem de bactérias em local contaminado por LNAPL. Nos pontos de alta contagem de bactérias a resistividade aparente foi mínima. Os autores acreditam que medidas de resisitividade aparente proporcionam uma visualização de processos biogeoquímicos em sítios contaminados por LNAPLs.

Percebe-se que o tema é recente e que são necessários mais estudos na área em questão. A bibliografia acima citada mostra também que o tema está sendo discutido no contexto dos LNAPLs, o que constitui uma base de início de abordagem para o presente trabalho. Acreditamos (esperamos) estar contribuindo também de forma prática e esclarecedora neste trabalho, quando mostramos a aplicabilidade do caminhamento elétrico em um sítio contaminado por NAPLs. 


\subsection{Determinação da Condutividade Hidráulica por Slug Test}

Condutividade hidráulica e armazenabilidade são dois dos mais importantes parâmetros hidrogeológicos requeridos para análise quantitativa de problemas de águas subterrâneas (YANG e YEH, 2004). No presente trabalho utilizam-se os "Slug Tests", que são largamente utilizados em investigações hidrogeológicas, geotécnicas e ambientais. O slug test consiste num rápido deslocamento (injeção ou retirada) da superfície da água num poço ou piezômetro, depois do qual a recuperação (subida ou descida) do nível de água é medida em função do tempo. Contudo, existem relativamente poucos métodos de análise de dados de slug test disponíveis para situações vinculadas a aqüíferos superficiais não confinados (BROWN et al., 1995). Dois dos métodos mais largamente utilizados são descritos em Hvoslev (1951) e Bouwer e Rice (1976).

O método de Bouwer e Rice (1976) foi originalmente proposto para poços parcialmente ou totalmente penetrantes em aqüíferos não confinados. Bouwer e Rice (1976) usaram a eq. de Thiem modificada para condições de estado permanente e aqüífero não confinado, e apresentaram um procedimento para a determinação da condutividade hidráulica e da armazenabilidade. Acrescenta-se ainda que, na pesquisa desenvolvida por Bouwer e Rice, foram usados modelos elétricos análogos para a obtenção de duas equações empíricas que são relacionadas ao raio efetivo de poços parcialmente ou totalmente penetrantes. Bouwer (1989) descreveu a aplicação do método Bouwer e Rice na validação de testes de descida de nível, na aplicação a aqǘferos confinados, no efeito do diâmetro do poço e no processamento de dados de campo.

Kemblowski e Klein (1988) estimaram a condutividade hidráulica por aproximação usando o método dos mínimos quadrados e análise de sensibilidade. A dificuldade no uso desta solução decorre da necessidade de leitura de um coeficiente em uma figura do artigo publicado por Bouwer e Rice (1976), onde erros podem ser introduzidos na estimativa deste coeficiente. Chirlin (1989) apresenta uma revisão de vários modelos matemáticos que 
representam experimentos de slug test para estimar parâmetros como: condutividade hidráulica, coeficiente de armazenamento e efeito do pré-filtro. Chirlin (1989) abordou, também, a relação entre o raio efetivo e o coeficiente de armazenamento. Hyder et al. (1994), por sua vez, forneceram uma solução semi-analítica para um modelo matemático que descreve o escoamento da água subterrânea em resposta a um slug test em aqüíferos confinados e não confinados. Este modelo incorporou os efeitos de penetração parcial, anisotropia, condições de nível constante e efeito do pré-filtro em formações mais ou menos permeáveis. A solução foi aplicada para quantificar o erro na estimativa de parâmetros usando dados de resposta de slug test. Hyder e Butler Jr. (1995) sugeriram uma estimativa de parâmetros usando soluções semi-analíticas derivadas do modelo proposto por Hyder et al. (1994). Já Brown et al. (1995) usaram um modelo numérico de escoamento transiente para avaliar o método Bouwer e Rice em duas situações. Primeiro, aplicando o modelo a dados sintéticos de slug test e observando o erro na estimativa da condutividade hidráulica. Segundo, analisando a base lógica do método. Rupp et al. (2001) aplicaram um modelo de transporte de água subterrânea bidimensional, com simetria radial e com saturação variável, para simular a recuperação no poço variando a geometria desse poço e do aqüífero e as propriedades do solo não saturado. O método Bouwer e Rice foi modificado para descrever as taxas de recuperação baseado na geometria do poço e tipos de solo. Esta modificação introduziu um parâmetro relacionado à capilaridade do solo para aumentar a acurácia dos resultados de condutividade hidráulica para dados de slug test. Butler Jr. (2002) propôs um procedimento simples para a correção da condutividade hidráulica estimada por slug tests em poços de pequeno diâmetro $(0,016 \mathrm{~m}$ de diâmetro interno) instalados em aqüíferos com elevada permeabilidade (areia grossa e cascalho). Já Halford e Kuniansky (2002) desenvolveram várias planilhas eletrônicas em Microsoft Excel versão 9.0 para a análise de dados de teste de aqüífero e slug test, vinculadas a um relatório em PDF. As planilhas podem ser acessadas para cópia gratuita na página eletrônica da Pesquisa Geológica dos Estados Unidos (http://water.usgs.gov/pubs/of/ofr02197/). Yang e Yeh (2004) propuseram três polinômios de quarta ordem para descrever a relação entre os coeficientes do 
método Bouwer e Rice e a razão entre o comprimento do filtro e o raio do préfiltro utilizados nos experimentos.

\subsection{Programa Groundwater Vistas}

Este texto foi traduzido e adaptado da referência Rumbaugu e Rumbaugu (2004). Groundwater Vistas (GV) é um ambiente de modelagem de águas subterrâneas para plataforma Microsoft Windows que une um poderoso sistema de criação de modelo com ferramentas de análises gráficas abrangentes. GV é um sistema de projeto gráfico para MODFLOW e outros modelos similares, quais sejam: MODPATH e MT3D. No GV o projeto do modelo a ser desenvolvido é realizado em planta e seção cruzada usando uma divisão de janelas (ambas visíveis ao mesmo tempo). Os resultados podem ser apresentados usando contornos, sombreados coloridos, vetores de velocidade e análise detalhada de balanço de massa. No MODPATH o caminhamento das partículas é também apresentado em planta e perfil. Um aspecto único do GV é o uso de uma grade (do inglês grid) de condições de contorno independente. Neste caso, os contornos de grade independente não são modificados de posição quando a grade é modificada. Esta função permite que sejam feitas modificações na malha sem que se perca tempo corrigindo a localização dos contornos.

O GV foi projetado para ser um sistema de modelagem independente. Assim, é somente necessário conhecer um único programa para utilizar uma variedade de modelos de água subterrânea. $\mathrm{Na}$ versão 4 do GV estão vinculados os seguintes modelos:

- MODFLOW - modelo de escoamento de água subterrânea tridimensional originalmente publicado pela Agência de Pesquisa Geológica dos Estados Unidos (USGS);

- MODFLOW2000 - última versão do MODFLOW publicada pela USGS que incorpora um modelo de inversão na estimativa de parâmetros; 
- MODFLOW-SURFACT - nova versão do MODFLOW desenvolvida pela HydroGeoLogic, Inc., inclui várias ferramentas de escoamento e transporte;

- MT3DMS - modelo tridimensional de transporte de contaminantes desenvolvido e distribuído por Chunmiao Zheng na Universidade do Alabama;

- MODFLOWT - nova versão do MODFLOW que incorpora transporte de contaminantes;

- MODPARH - modelo tridimensional de caminhamento de partículas que trabalha em conjunto com o MODFLOW;

- RT3D versão 2.5 - versão pública do MT3D que simula reações de atenuação natural;

- Stochastic MODFLOW/MODPATH/MT3D - versão Monte Carlo para MODFLOW, MODPATH e MT3D; é usado para avaliar incertezas no modelo.

Com o GV, vários formatos de arquivos podem ser importados para facilitar a criação do modelo. Entre eles podemos citar:

- MODFLOW data sets - ferramenta para importar arquivos criados no MODFLOW;

- ArcView shapefiles - podem ser importados e exportados para ArcView todos os aspectos do modelo. Esta ferramenta também permite que a apresentação final seja feita no ArcView;

- Digitized map files - podem ser importados os seguintes arquivos: AutoCAD DXF, ArcView shapefiles e SURFER BLN. Sendo que os arquivos são automaticamente convertidos para GV map;

- Calibration target data - dados de níveis de água, concentração, rebaixamento ou escoamento são comparados com os resultados gerados pelo modelo. Estes dados pode ser importados no formato ASCII para regime permanente ou transiente;

- Boundary condition data - dados de qualquer tipo de condição de contorno podem ser importados na forma ASCII; 
- Aquifer property data - podem ser importados arquivos grade do SURFER ou ASCII (formato $X, Y, Z$ ) vinculados a qualquer propriedade do aqǘfero (como condutividade hidráulica, elevação, etc.).

Os resultados pode ser apresentados em diversas formas, para facilitar a análise:

- Contornos de nível de água, rebaixamento, concentração ou escoamento;

- Escala de cores de nível de água, rebaixamento, concentração ou escoamento;

- Vetores de velocidade;

- Caminhamento e tempo de percurso para MODPATH;

- Quadro de balanço de massa;

- Lançados em gráfico o nível de água, o rebaixamento ou a concentração versus o tempo para cada poço de monitoramento;

- Gráficos de sensibilidade de parâmetros;

- Perfis de nível de água, rebaixamento, concentração ou escoamento ao longo de uma seção;

- Gráficos com os objetos da calibração;

- Estatística de calibração para nível de água, concentração e escoamento.

GV possibilita a estimativa de parâmetros pelo método não linear dos mínimos quadrados e também permite o uso de um dos três modelos de inversão: PEST-ASP, UCODE e MODFLOW2000. Além disso, uma outra forma de calibração permitida pelo programa é a análise de sensibilidade detalhada por parâmetro. Neste caso deve ser selecionado o parâmetro, o número de simulações e incremento percentual no valor do parâmetro para cada simulação. 


\section{Material e Métodos}

\subsection{Histórico}

Na década de 60 entrou oficialmente em operação a "Indústria objeto" deste estudo, a qual possuía como principal atividade, o re-refino de óleo lubrificante automotivo. Como nessa época quase não existiam no Brasil leis voltadas para a área ambiental, bem como órgãos ambientais de controle e repreensão voltados à atividade citada, os resíduos gerados nesta indústria eram diretamente lançados em rios. Ao se iniciar a década de 70 , com a criação da CETESB, "foi recomendado aos proprietários deste tipo de atividade que depositassem seus resíduos em solos de áreas afastadas da zona urbana" (BARBIERE, 2000). Já em 1970, a Indústria objeto passou a depositar seus resíduos em uma área adquirida para este fim, sendo que nesta área de descarte foram escavadas quatro valas ou cavas, no sentido da declividade do terreno, com profundidade média de $6 \mathrm{~m}$, comprimento variando entre 49,0 e $41,0 \mathrm{~m}$ e largura de 36,0 e 24,0 $\mathrm{m}$, com taludes laterais de 1:2 aproximadamente, perfazendo um volume total aproximado de $25.000 \mathrm{~m}^{3}$. Ao longo de cerca de 25 anos essas cavas foram quase totalmente preenchidas com resíduos. As valas não receberam qualquer tipo de impermeabilização de fundo e laterais e após terem sido preenchidas, foram apenas cobertas com solo. Os proprietários paralisaram as descargas de resíduos nas valas em 24/10/1995. Desde então, a área não sofreu qualquer alteração devido à parca disponibilidade de recursos por parte dos proprietários. Na Figura 4.1 pode ser observada uma fotografia panorâmica da área de estudo. 


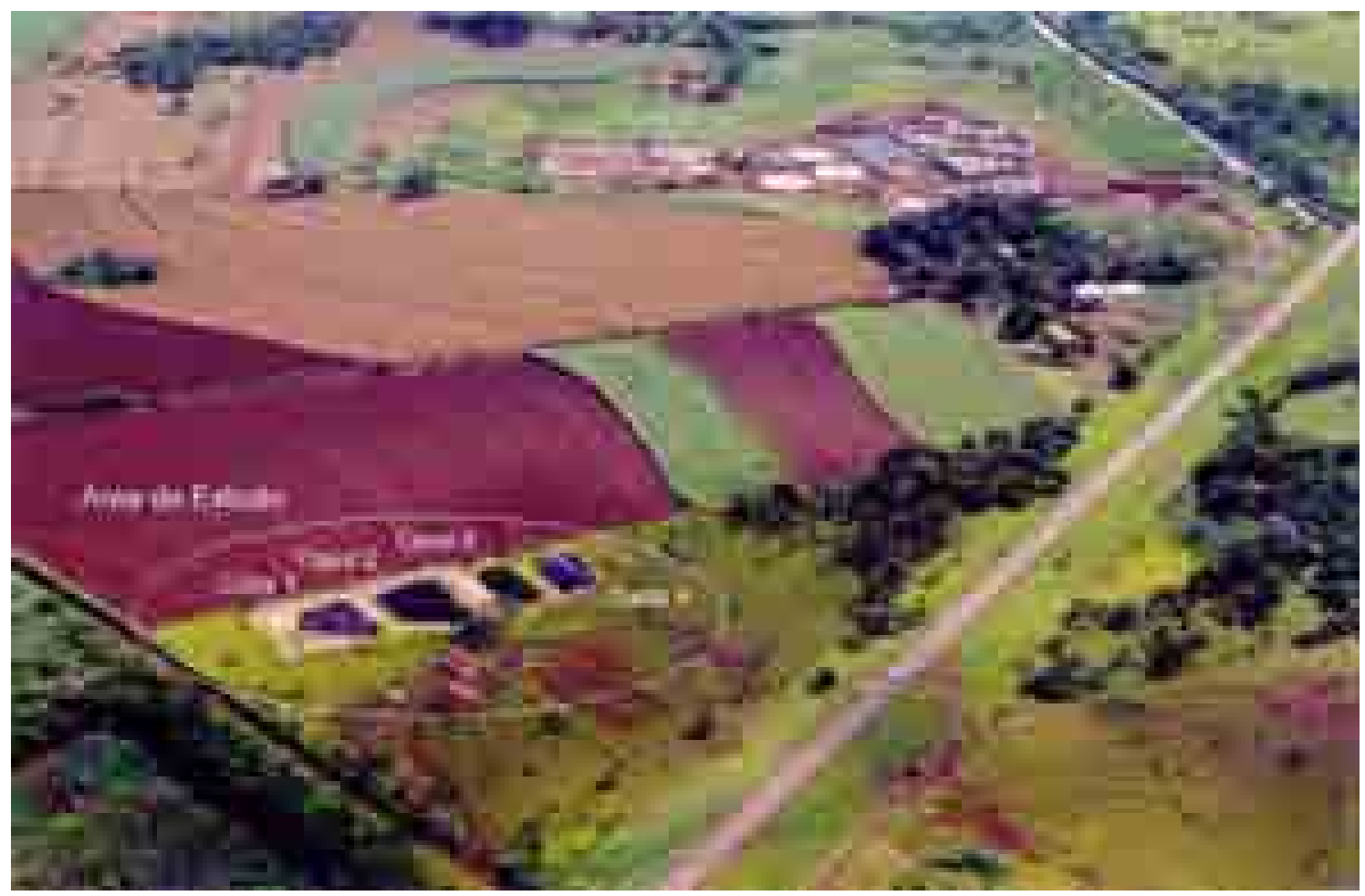

Figura 4.1 - Fotografia panorâmica do sítio estudado.

\subsection{Localização}

A área da Indústria objeto está restrita a 20.122,18 $\mathrm{m}^{2}$, conforme pode ser visto no mapa plani-altimétrico no Apêndice A. As divisas são: ao sul e a leste com o terreno do senhor Welton Tadeu de Bortoli, ao norte com terreno do senhor Dalton Melo Reis e a oeste com a destilaria Galo Bravo.

Segundo Roseli (1995), a localidade é denominada Córrego do Campo e fica a $200 m$ do quilômetro 334,05 da Rodovia Alexandre Balbo (SP - 328), sendo o bairro mais próximo denominado Jardim Heitor Rigon, localizado no contorno norte do anel viário do Município de Ribeirão Preto. Na Figura 4.2 pode-se observar fotografia aérea do sítio, bem como a localização do sítio em relação ao Município de Ribeirão Preto, a localização do Município de Ribeirão Preto em relação ao Estado de São Paulo, e finalmente o Estado de São Paulo em relação ao Brasil. 
Figura 4.2 - Localização da área de estudo. 


\subsection{Revisão das Informações Existentes}

Antes do deslocamento de qualquer equipe de avaliação para o campo, fez-se uma revisão das informações existente sobre o sítio em questão. Também se mostra importante a realização de uma visita de campo com os responsáveis pela área em questão, procedimento que foi seguido neste estudo. Essas informações são necessárias pala selecionar a metodologia a ser empregada na avaliação, o(s) equipamento(s) de amostragem(ns), definir os métodos analíticos a serem empregados e a estratégia para uma rede de amostragem inicial, entre todas as decisões relevantes para os trabalhos de campo, coleta de dados e análises posteriores. A revisão das informações existentes incluiu: mapas topográficos, fotografias de diferentes tipos: panorâmica, aérea e por satélite, investigações geológicas-geotécnicas no sítio e/ou áreas vizinhas, usos passado e presente do solo, levantamento, localização e características de poços rasos e profundos, potenciais fontes de contaminação, potenciais caminhos de migração e seus receptores e as prováveis condições geológica e hidrogeológica. Para facilitar a organização das informações foi elaborada uma lista (ver Tabela 4.1) dos principais documentos obtidos.

\subsection{Desenvolvimento do Modelo Conceitual Inicial}

Com base nas informações adquiridas na etapa de revisão das informações existentes, foi desenvolvido um modelo conceitual inicial antes do início de qualquer trabalho de campo. Este modelo foi uma compilação básica da compreensão das condições existentes. Um mapa do sítio foi usado no desenvolvimento do programa inicial de investigação em campo. Os mapas, a princípio, foram elaborados à mão para ser revisados e corrigidos com 0 progresso da avaliação e, posteriormente, foram passados para arquivos em computador. Nesses mapas foram incluídas as condições geológicas e hidrogeológicas inicialmente supostas (hipótese inicial de trabalho), áreas de descarte dos resíduos, potenciais caminhos de migração e receptores e 
possíveis restrições da futura campanha de coleta de amostras (por exemplo, profundidade do embasamento rochoso, limites do terreno, etc.).

\section{Tabela 4.1 - Procedência e tipo de informações a respeito da área investigada.}

\begin{tabular}{|c|c|c|}
\hline Procedência & Documentos e registros & Tipo de informação disponível \\
\hline $\begin{array}{l}\text { Proprietário } \\
\text { e/ou } \\
\text { responsável } \\
\text { pelo sítio }\end{array}$ & $\begin{array}{l}\text { Inventários, documentos, mapas em } \\
\text { detalhe, fotografias antigas e } \\
\text { registro de consultoria ambiental. }\end{array}$ & $\begin{array}{l}\text { Detalhes sobre os descartes dos resíduos, } \\
\text { potenciais contaminantes e características } \\
\text { locais. }\end{array}$ \\
\hline $\begin{array}{l}\text { Secretaria } \\
\text { Municipal }\end{array}$ & $\begin{array}{l}\text { Registro de avaliações ambientais, } \\
\text { mapas diversos. }\end{array}$ & $\begin{array}{l}\text { Informações dos usos passado e presente, } \\
\text { histórico do local, mapa geológico e relatório } \\
\text { de incidentes e investigação. }\end{array}$ \\
\hline $\begin{array}{l}\text { Secretaria ou } \\
\text { Companhia } \\
\text { Estadual }\end{array}$ & $\begin{array}{l}\text { Listagem de áreas contaminadas, } \\
\text { licença de operação, mapas } \\
\text { diversos e dados climatológicos. }\end{array}$ & $\begin{array}{l}\text { Tipos de contaminantes e fases da } \\
\text { investigação, permissão para descarte de } \\
\text { resíduos industriais, cartas topográficas e } \\
\text { mapa geológico, condições climáticas. }\end{array}$ \\
\hline $\begin{array}{l}\text { Secretaria } \\
\text { Federal }\end{array}$ & Cartas topográficas. & Localização e uso do solo. \\
\hline $\begin{array}{l}\text { Universidades } \\
\text { e bibliotecas }\end{array}$ & $\begin{array}{l}\text { Teses, dissertações, monografias, } \\
\text { relatórios, arquivos e informações } \\
\text { históricas. }\end{array}$ & $\begin{array}{l}\text { Informações de pesquisas desenvolvidas no } \\
\text { local e arredores, usos do solo, atividades } \\
\text { desenvolvidas no sítio, geologia e } \\
\text { hidrogeologia. }\end{array}$ \\
\hline $\begin{array}{l}\text { Pessoas } \\
\text { envolvidas } \\
\text { (proprietários, } \\
\text { e vizinhos). }\end{array}$ & Entrevistas. & $\begin{array}{l}\text { Informações relacionadas ao histórico do local, } \\
\text { especialmente vinculadas aos descartes de } \\
\text { resíduos. }\end{array}$ \\
\hline
\end{tabular}

Fotografias panorâmicas, aéreas e por satélite: listagem de fotografias

Variadas aéreas públicas e privadas para fornecer localização e períodos. Informação sobre acontecimentos locais, usos do solo, atividades desenvolvidas.

Histórico de combate a incêndio com a localização das fontes.

A Figura 4.3 é um exemplo do croqui inicial elaborado para o sítio. Podem ser observados limites dos terrenos, área superficial das cavas de depósito de resíduos, casas habitadas por moradores vizinhos, poços usados no abastecimento das casas vizinhas, etc. 


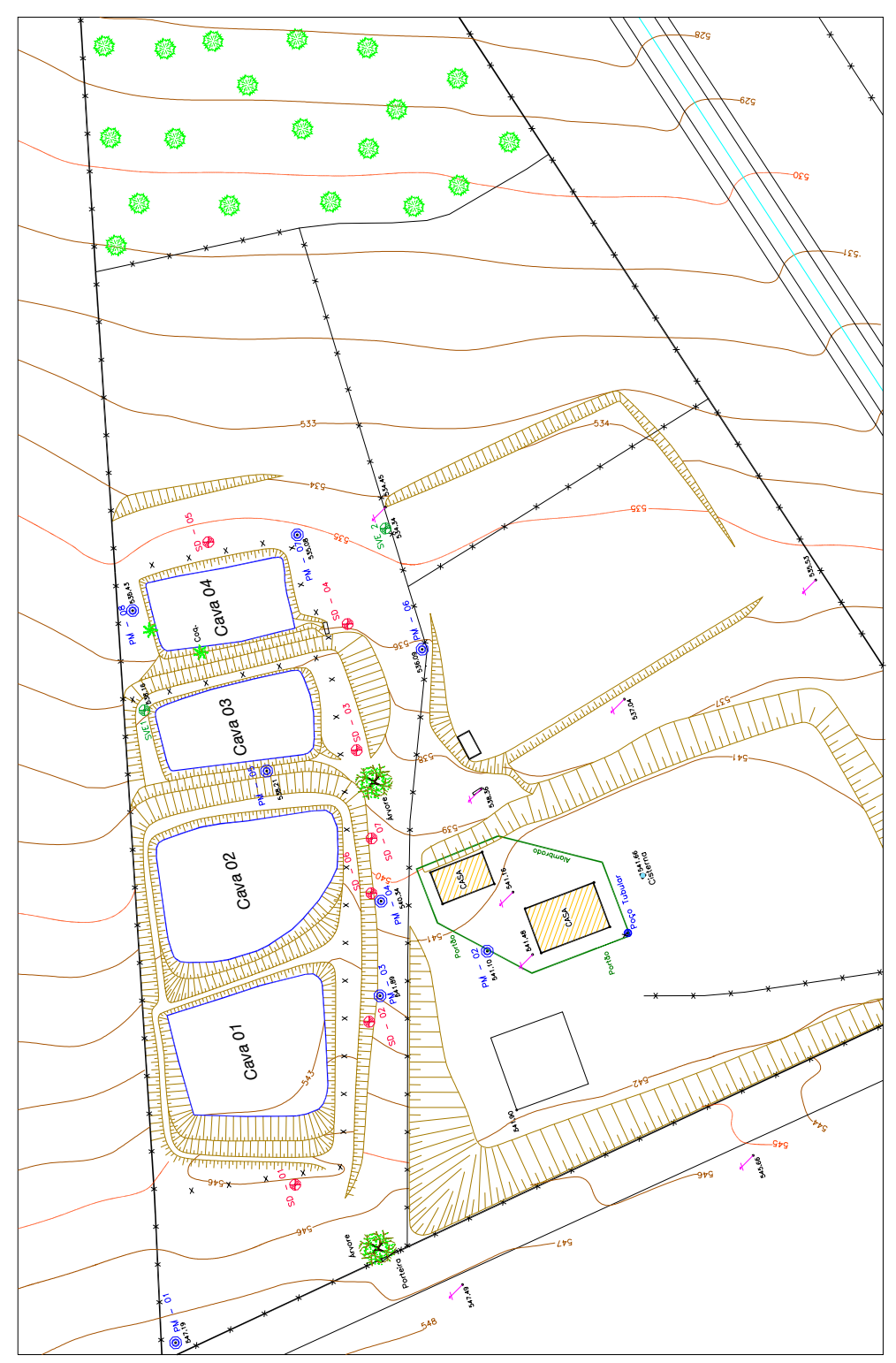

Figura 4.3 - Representação do croqui inicial do sítio.

Na Figura 4.4 pode ser observado um modelo digital da topografia do sítio. Mais uma vez, verifica-se a posição das cavas e os limites do terreno.

\subsection{Condições Climáticas}

As informações sobre as condições climáticas são baseadas em dados fornecidos pela Estação Experimental do Instituto Agronômico de Campinas, no Posto Climatológico de $1^{\underline{a}}$ Classe, que fica no quilômetro 321 da Rodovia 
Alexandre Balbo, localizado no contorno sul do anel viário do Município de Ribeirão Preto.

\subsubsection{Clima}

O clima de Ribeirão Preto enquadra-se na categoria $A w$, segundo classificação de Koppen. Esta categoria refere-se a clima úmido com estação chuvosa no verão e seca no inverno (T. ALVES ENGENHARIA AMBIENTAL S/C LTDA, 2001).

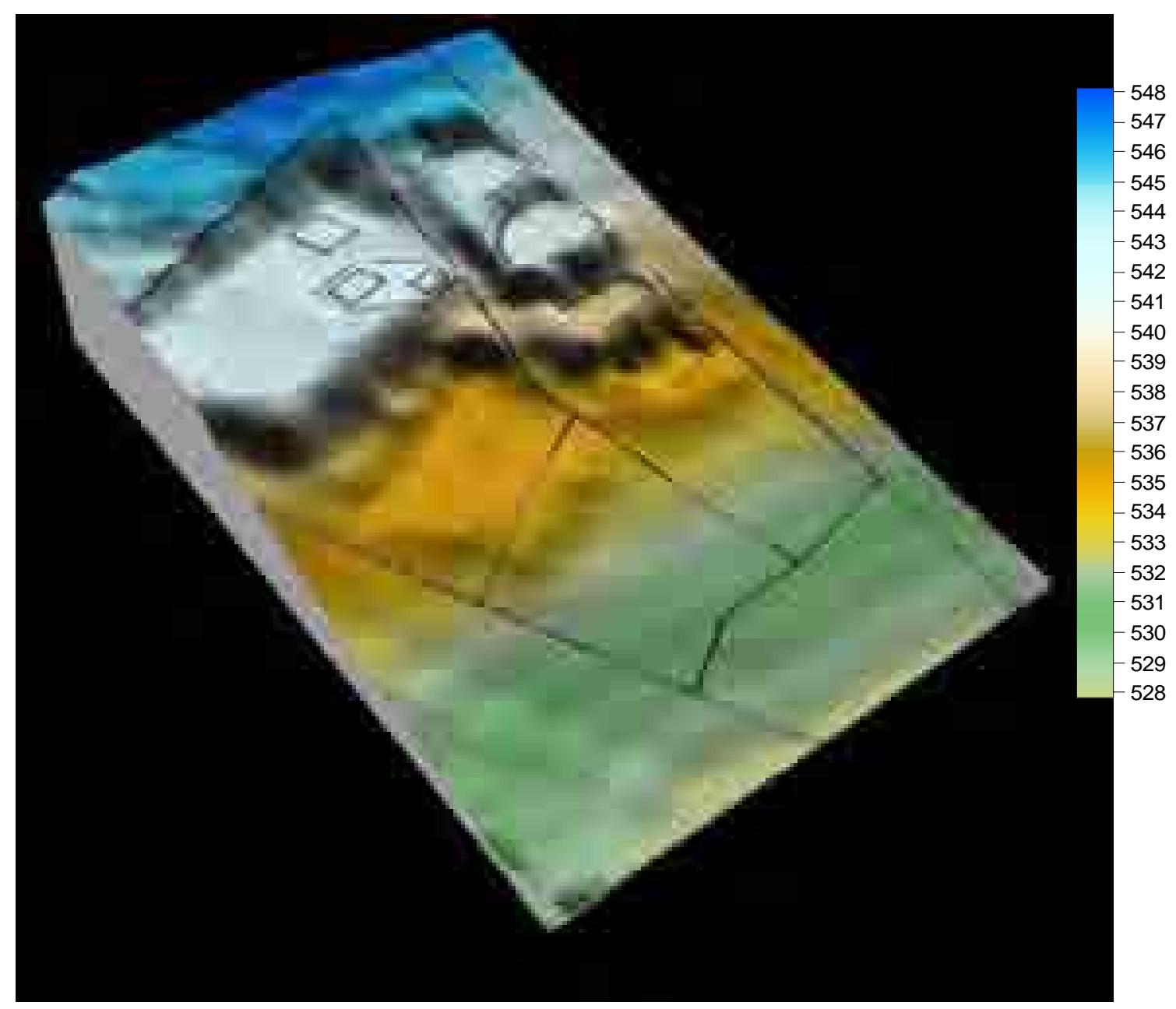

Figura 4.4 - Modelo digital da topografia do sítio. 


\subsubsection{Ventos}

Baseando-se em dados obtidos no período de 1943 a 1981, os ventos variam de um valor mínimo de 1,3 $\mathrm{m} / \mathrm{s}$ nos meses de fevereiro e março, até um valor máximo de $2,2 \mathrm{~m} / \mathrm{s}$ nos meses de setembro e outubro, sendo a velocidade média anual dos ventos de $1,7 \mathrm{~m} / \mathrm{s}$ (T. ALVES ENGENHARIA AMBIENTAL S/C LTDA, 2001). Nestas condições os ventos podem ser classificados como brisa. Já as direções preponderantes, baseadas em dados de 1988, variam entre as direções leste e sudeste em 10 dos 12 meses do ano de referência.

\subsubsection{Temperatura}

Tomado como referência períodos dos anos de 1943 a 1981 e 1992 a 2004, a temperatura média do mês mais quente é superior a $24{ }^{\circ} \mathrm{C}$ e do mês mais frio é superior a $18^{\circ} \mathrm{C}$.

\subsubsection{Precipitação}

Tomando-se como referência dados de precipitação mensal para o período entre os anos de 1937 a 2004, o regime de chuvas caracteriza-se pela existência de um período chuvoso que abrange os meses de outubro a março e um período seco que abrange os meses de abril a setembro.

A precipitação média anual é de 1.482,4 $\mathrm{mm}$, com desvio padrão de 253,9 mm. A máxima precipitação média, ocorrida em 1983, de 2.211,2 $\mathrm{mm}$ e mínima, ocorrida em 1944, de 735,4 mm. 


\subsection{Geologia Local}

Por proximidade geográfica, tomou-se inicialmente com referência o relatório elaborado por T. Alves Engenharia Ambiental S/C LTDA (2001) para a implantação do Distrito Industrial de Ribeirão Preto como primeira aproximação da geologia local.

A conformação estrutural da rocha basáltica apresenta espessura superior a $100 \mathrm{~m}$ na região mais ao leste (próxima a Rodovia Anhanguera), decrescendo a quase total ausência de rocha básica nas proximidades do Ribeirão Preto, onde o contato com a Formação Botucatu se apresenta em forma de cunha, em provável falha geológica (T. Alves Engenharia Ambiental S/C LTDA, 2001).

$\mathrm{Na}$ referência supracitada foram identificados três tipos de solos dentro da área de estudo. O primeiro composto por silte muito argiloso, vermelho escuro, com origem coluvionar. O segundo constituído por silte pouco arenoso e argiloso, às vezes contendo concreções de limonita e apresentando coloração variegada. O terceiro de origem da alteração do basalto, é composto por argila e silte, vermelho com manchas variegadas. Subjacente aos derrames de basalto, ocorre o pacote de arenitos da Formação Botucatu.

Adicionalmente na região marginal ao Ribeirão Preto ocorrem duas camadas de areias. A primeira entre 4 e $8 \mathrm{~m}$ de profundidade, tem provável origem aluvionar e a segunda entre 8 e $10 \mathrm{~m}$ de profundidade, com origem na alteração de arenito, levando crer tratar-se do topo do arenito Botucatu.

No Anexo A, pode ser observada uma interpretação de T. Alves Engenharia Ambiental S/C LTDA (2001), para a seção geológica partindo da Destilaria Galo Bravo até o CEASA situado às margens via Anhanguera.

\subsection{Levantamento Geofísico}

\subsubsection{Caminhamento Elétrico}

Segundo Elis (2001), o momento atual da pesquisa em campo utiliza com mais propriedade em estudos ambientais o arranjo de campo denominado 
brevemente de "caminhamento elétrico, dispositivo dipolo-dipolo (DD)", conforme o esquema apresentado na Figura 4.5. Neste dispositivo, os eletrodos $A B$ de introdução de corrente e $M N$ de potencial são dispostos segundo um mesmo perfil (alinhados) e o arranjo é definido pelos espaçamentos $X=A B=M N$. A profundidade de investigação cresce com 0 espaçamento $(R)$, e teoricamente corresponde a $R / 2$. Normalmente, as medidas são efetuadas em várias profundidades de investigação, isto é, $n=1$, 2, 3, 4 e 5, atribuídas à intersecção das linhas que partem do centro de $A B$ e MN com ângulos de $45^{\circ}$. Cada novo ponto de medida é determinado pelo deslocamento dos dipolos em uma distância igual a $X$, sendo os dados obtidos lançados em gráfico para as posições $n=1,2,3,4$ e 5, e interpolados, gerando uma seção de resistividade aparente.

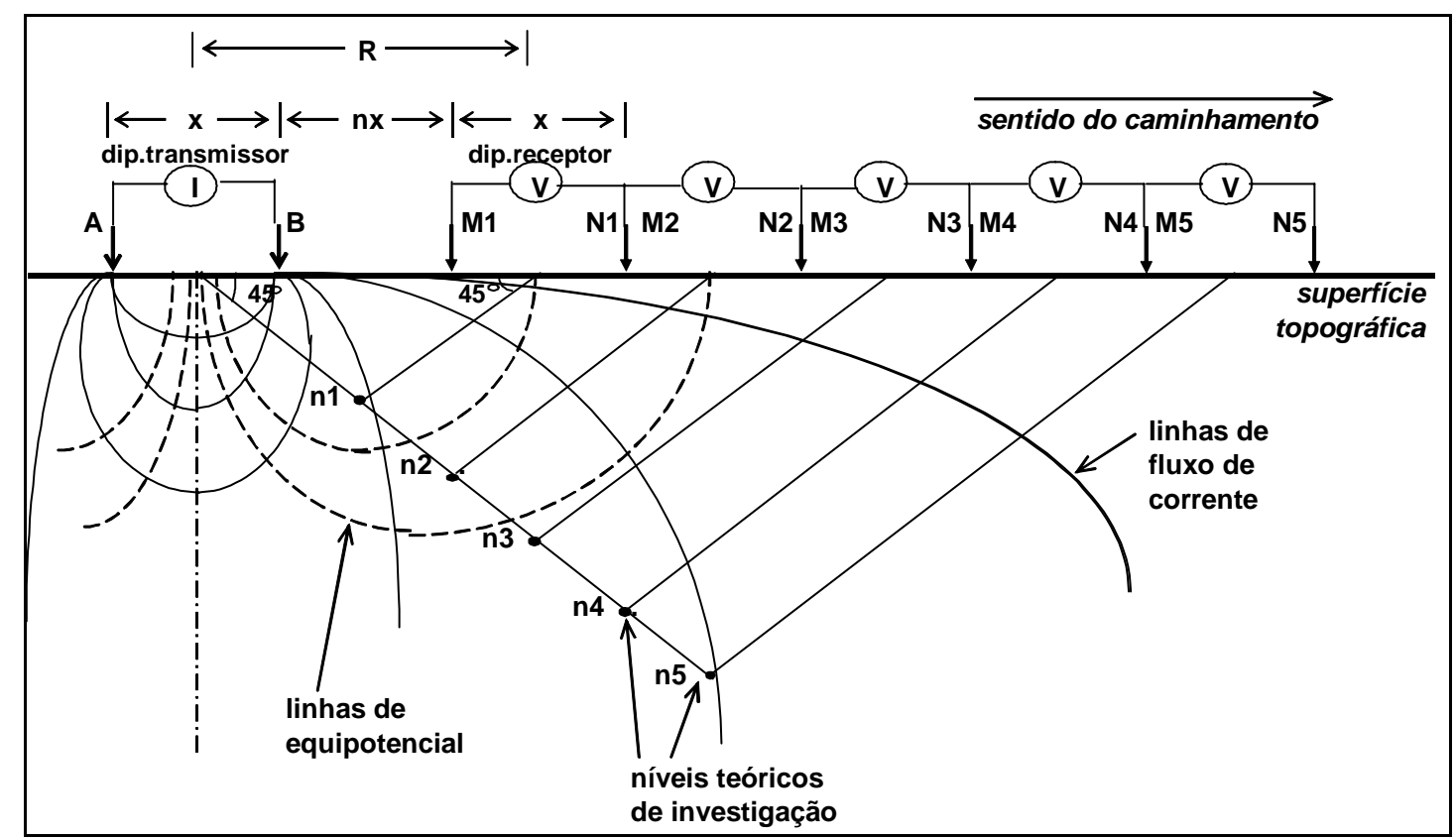

Figura 4.5 - Técnica de caminhamento elétrico, arranjo dipolo-dipolo (DD). (Fonte: Elis, 2001).

Os espaçamentos do dispositivo dipolo-dipolo usado nesta pesquisa foram: deslocamento dos dipolos " $X$ " de $10 \mathrm{~m}, 5$ profundidades de investigação "n" (10, 15, 20, 25 e 30 m), 10 linhas ou seções de investigação variando entre 100 e $250 \mathrm{~m}$.

Os dados foram interpretados usando-se os programas comerciais SURFER $6.0^{\circledR}$, no qual usou-se a técnica de "krigagem" universal para observar-se as resistividades aparente; e a versão semi-demo do RES2DINV, 
onde os dados foram invertidos usando-se a técnica não linear de suavização dos mínimos quadrados para observar-se as resistividades reais (LOKE, 1998). Esta fase contou com o auxílio, orientação e supervisão do professor Vagner Roberto Elis do Instituto de Astronomia e Geofísica da Universidade de São Paulo.

Com base nas características metodológicas descritas e das características do sítio a ser investigado, elaborou-se um "mapa de investigação" englobando a área de disposição dos resíduos e seu entorno. No mapa topográfico contido no Apêndice A pode ser observada a disposição das linhas de investigação geofísica.

\subsubsection{Sondagem Elétrica Vertical}

A técnica de sondagem elétrica vertical (SEV) é freqüentemente empregada na observação das alterações de resistividade em função da profundidade, sendo bastante útil na localização da zona saturada, contatos entre acamamentos plano-paralelos e embasamento rochoso (ZHDANOV e KELLER, 1994; ELIS, 2001; MIRANDA NETO, 2002).

O arranjo de campo mais utilizado para ensaios de sondagem elétrica vertical é conhecido como Schlumberger, onde são utilizados quatro eletrodos, sendo dois para aplicação de corrente (A e B) e dois para a leitura da diferença de potencial $(\mathrm{M}$ e $\mathrm{N}$ ), todos dispostos em um mesmo alinhamento no terreno (ver Figura 4.6). O ponto de referência do ensaio é o centro geométrico do arranjo e a principal característica deste arranjo é que a distância entre os eletrodos "M" e "N" deve ser muito menor que a distância entre os eletrodos " $A$ " e "B", procurando satisfazer-se a relação $M N \leq A B / 5$. Contudo, na prática, quando a diferença de potencial " $\Delta \mathrm{V}$ " medida torna-se muito pequena, aumenta-se a distância entre os eletrodos "M" e "N". Por exemplo, adota-se um espaçamento inicial "MN" e realiza-se várias medidas variando-se o espaçamento "AB". Em seguida aumenta-se "MN" e repete-se o procedimento anterior. Vale frisar que se evita deslocar em um mesmo momento os eletrodos de corrente "A" e "B" e os de potencial "M" e "N". Acrescenta-se ainda que a 
mudança no espaçamento "AB" mantendo-se o espaçamento "MN" constante permite confirmar a última leitura realizada (ELIS, 2001).

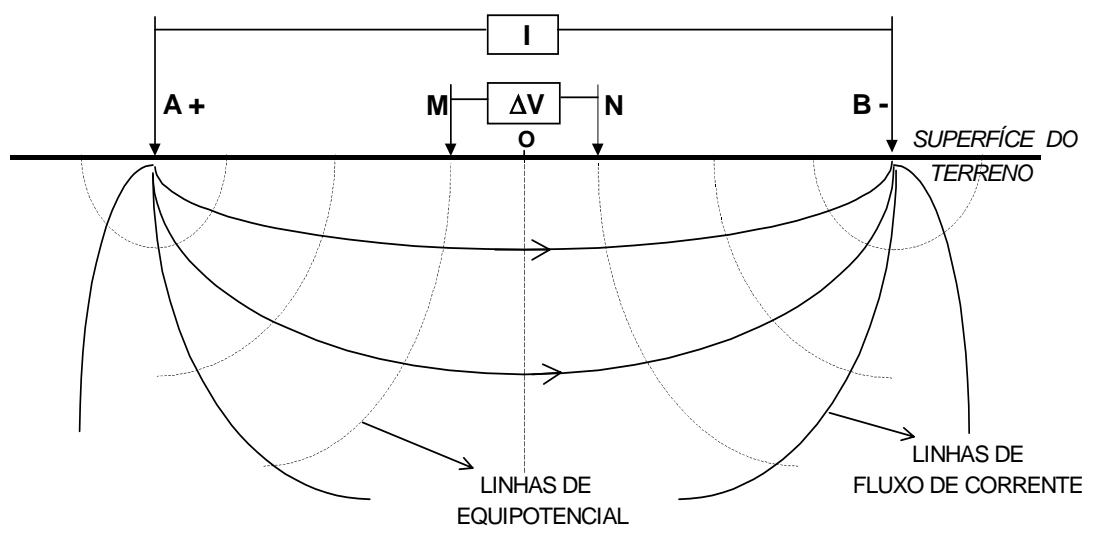

Figura 4.6 - Disposição em campo do arranjo Schlumberger. (Fonte: Elis, 2001).

Os valores de resistividade aparente obtidos são lançados em gráfico em função dos valores médios do espaçamento "AB", obtendo-se assim uma curva de resistividade aparente, a qual é interpretada quantitativamente.

No sítio em estudo, foram realizados 2 ensaios de sondagem elétrica vertical de resistividade e polarização induzida, arranjo Schlumberger, com espaçamento $A B$ máximo de $100 \mathrm{~m}$ (ver localização no mapa topográfico no Apêndice A). As curvas obtidas foram interpretadas qualitativamente, em um primeiro momento, ou seja, foi feita a análise morfológica da curva suavizada para identificar o número de camadas investigadas. Com base nestes procedimentos foram obtidos os modelos inicias.

Os modelos iniciais foram introduzidos no software RESIX-IP (1993) da Interpex Limited, e inicialmente interpretados pelo método direto. Esse método consiste em calcular a resposta de um modelo 1D de camadas horizontais com diferentes resistividades/cargabilidades. A partir do modelo inicial, o programa calcula uma curva teórica de resistividade aparente com base na teoria de filtragem linear descrita por Davis et al. (1980) apud Interpex (1993) e as curvas de cargabilidade aparente a partir do método de Seara \& Granda (1987) apud Interpex (op cit). O modelo inicial é então modificado sucessivamente pelo intérprete até que o ajuste seja satisfatório. Na prática, a curva de resistividade 
é calculada primeiramente e, com base nesta, ajustada a curva de cargabilidade.

Com o objetivo de refinar o modelo obtido pela interpretação através do método direto, utilizou-se o método inverso. Esse método busca ajustar os dados de campo à curva teórica, modificando automaticamente os parâmetros iniciais até que o ajuste mínimo seja alcançado. O algoritmo utilizado pelo programa é baseado no método de mínimos quadrados simples e no método Ridge Regression desenvolvido por Inman (1975).

O método inverso foi utilizado para alcançar o melhor ajuste, mas nem sempre o modelo matemático correspondeu ao melhor modelo geológico, optando-se sempre pelo segundo. Acrescenta-se que estas sondagens foram realizadas em uma aula experimental sob a coordenação do professor Vagner Roberto Elis do Instituto de Astronomia e Geofísica da Universidade de São Paulo e os resultados foram interpretados com o auxílio do mesmo professor.

\subsection{Caracterização do Resíduo de Re-refino de Óleo}

Óleo usado ou resíduo de óleo refere-se a óleos lubrificantes que completaram o seu ciclo de aplicação e devem ser dispostos ou tratados e reusados. Geralmente, o termo engloba óleos lubrificantes automotivos e óleos industriais, incluindo os usados para lubrificação, refrigeração e processos aplicados. Óleos automotivos e industriais são formados por uma mistura de espécies orgânicas básica e aditivos que foram desenvolvidos para aplicações específicas de lubrificação. A composição orgânica pode ser formada por centenas de constituintes orgânicos, dentre os quais a maioria é composta por hidrocarbonetos policíclicos aromáticos ou HPAs (do inglês, PAHs, polycyclic aromatic hydrocarbons). Os aditivos, que podem representar mais de $15 \%$ do óleo em volume, tipicamente apresentam constituintes inorgânicos como: enxofre, nitrogênio e metais traços (FREEMAN, 1998).

Segundo Andrade (2004), os hidrocarbonetos policíclicos aromáticos constituem uma família de compostos caracterizada por possuírem dois ou mais anéis aromáticos condensados. Estas substâncias e seus derivados 
nitrados e oxigenados têm vasta distribuição e são encontrados como constituintes de misturas complexas presentes no meio-ambiente de uma maneira geral. Dentre os HPAs, 16 estão incluídos na lista dos mais freqüentemente encontrados emitida pela Agência de Proteção Ambiental dos Estados Unidos e 17 (um constituinte a mais na lista dos prioritários) são priorizados para investigação pelo Instituto de Nacional de Saúde e Segurança Ocupacional dos Estados Unidos (NIOSH). Assim, os constituintes orgânicos investigados nesta pesquisa foram os 17 sugeridos por NIOSH (1998), quais sejam: acenafteno, acenaftileno, antraceno, benzo[a]antraceno, benzo[e]acefenantrileno, benzo[k]fluoranteno, benzo[g,h,i]perileno, benzo[a]pireno, benzo[e]pireno, criseno, dibenzo[a,h]antraceno, fluoranteno, fluoreno, indeno[1,2,3-cd]pireno, naftaleno, fenantreno e pireno.

Todas as etapas de caracterização das amostras de resíduo (PAHs) foram realizadas no Instituto de Química da UNESP de Araraquara, sob a coordenação do professor José Eduardo de Oliveira.

\subsubsection{Medidas com Detector de Fotoionização}

Realizou-se medidas de concentração de compostos orgânicos voláteis com o detector de fotoionização em duas visitas ao sítio experimental, nos dias 19/03/2002 e 15/07/2002. Nos dois eventos de amostragem o equipamento foi calibrado minutos antes do início das medidas em campo.

\subsubsection{Coleta de Amostras}

Para a caracterização do resíduo foram utilizadas as amostras coletadas no dia 06/02/03 (antes dessa campanha de campo foi realizada uma primeira em 19/03/2002, para a determinação da densidade do resíduo da cavas). Assim, na segunda coleta utilizou-se frasco de vidro de "boca larga" com capacidade para armazenar aproximadamente 1,0 kg de amostra. A limpeza prévia seguiu o roteiro: imersão em solução com detergente Extran por 48 
horas, enxágüe com água de torneira, enxágüe com água deionizada e secagem em estufa. Os frascos de coleta não foram lavados com acetona e hexano, pela suposição de que as amostras estariam muito concentradas.

Os pontos de amostragem foram escolhidos conforme a facilidade de acesso às cavas de resíduos devido às condições climáticas (período chuvoso). Foram tomadas amostras da superfície de cada cava mediante raspagem prévia e do "fundo" (aproximadamente 1,0 metro de profundidade, que é o limite da capacidade de cravação do trado utilizado). Para a cava 04 não foi possível realizar a coleta da amostra do fundo devido à elevada plasticidade do resíduo (deformação da parede do furo). As amostras obtidas foram acondicionadas em caixa térmica resfriada por gelo a uma temperatura inferior a $10^{\circ} \mathrm{C}$. Em laboratório, as amostras foram conservadas em congelador a temperaturas abaixo de $0^{\circ} \mathrm{C}$.

\subsubsection{Densidade do Resíduo}

\subsubsection{Densidade Absoluta}

Tomou-se recipiente com volume conhecido (proveta de $250 \mathrm{~mL}$ ) e introduziu-se um volume conhecido de água $(150 \mathrm{~mL})$, pesou-se o recipiente com água, introduziu-se uma amostra, mediu-se o volume de liquido deslocado e a massa do conjunto. Assim, pela divisão entre a massa da amostra e o volume de líquido deslocado, determinou-se a densidade absoluta para cada uma das amostras.

\subsubsection{Densidade Aparente}

Tomou-se recipiente de volume conhecido (Béquer de $300 \mathrm{~mL}$ ) e massa conhecida, compactou-se uma quantidade de amostra até um volume conhecido (150 mL) e mediu-se novamente a massa do conjunto. Assim, pela 
divisão entre a massa da amostra e volume da amostra, determinou-se a densidade aparente para cada uma das amostras.

\subsubsection{Caracterização da Fração Orgânica}

O método analítico utilizado inicialmente foi o USEPA 8270C, que se refere à determinação de compostos orgânicos semi-voláteis por cromatografia gasosa, seguida de espectrômetro de massa (GC/MS). O método de extração usado foi o USEPA 3540C, extração Soxhlet, e o método de eliminação de interferentes usado foi o USEPA 3610B, usando coluna de alumina. Devido ao fato dos extratos obtidos apresentarem um elevado percentual de partículas dissolvidas, tentou-se aplicar vários métodos de "cleanup" dos extratos, sem sucesso.

\subsubsection{Limpeza da Vidraria}

Toda a vidraria utilizada em laboratório foi imersa em solução com o detergente Extran alcalino (Merck) por 24 horas, em seguida enxaguada com água de torneira, água deionizada, acetona e hexano. A secagem foi realizada em estufa, com exceção do material volumétrico. Finamente, a vidraria foi envolvida em papel alumínio e acondicionada em armários individuais.

\subsubsection{Tratamento das Fases Sólidas}

O sulfato de sódio foi calcinado a $600{ }^{\circ} \mathrm{C}$ por aproximadamente 2 horas, sendo em seguida armazenado em dessecador.

A sílica, também, foi calcinada a $650{ }^{\circ} \mathrm{C}$ por um período de aproximadamente 12 horas e posteriormente armazenada em dessecador. Antes de qualquer utilização, procedeu-se a ativação em estufa a $110{ }^{\circ} \mathrm{C}$, por um período aproximado de 5 horas. 


\subsubsection{Solução Padrão}

Os padrões utilizados foram todos Aldrich (Milwaukee, USA), exceto o indeno[1,2,3-cd]pireno (Dr. Ehrenstorfer $\mathrm{GmbH}$, Augsburg, Alemanha). Estes padrões são de pureza em torno de $99 \%$. As soluções padrão matriz foram obtidas pela dissolução de cada padrão sólido em acetonitrila, para se obter concentração nominal de $100 \mu \mathrm{g} / \mathrm{mL}$ para cada analito (ANDRADE, 2000; ANDRADE 2004).

\subsubsection{Equipamentos}

Os equipamentos utilizados foram:

- Um HPLC Pro Star com injetor automático (Modelo 400) acoplado a detector de fluorescência (Modelo 360), fabricados pela Varian (Walnut Creek, USA). A coluna cromatográfica usada foi LC-PAH (C18) $(25 \mathrm{~cm} \times 4,6 \mathrm{~mm}, 5 \mu \mathrm{m})$ da Supelco (Milwaukee, USA) (ANDRADE, 2004).

- Um Cromatógrafo Gasoso (GC) com injetor automático (8200 cx) acoplado a um espectrômetro de massa (QP5050A) da Shimadzu. A coluna usada foi CP Sil 8 CB (30 $m \times 0,25 m m, 0,25 \mu m)(5$ \% difenil e 95 \% dimetil polisiloxano), Chrompack-Varian (Palo Alto, USA).

\subsubsection{Curvas de Calibração}

As curvas de calibração foram construídas na faixa de concentração onde os analitos de interesse apresentam constância na relação concentração/área de pico, com intervalos de concentração determinados e usando a solução padrão descrita no subitem 4.8.4.3. 


\subsubsection{Avaliação da Sensibilidade: Limites de Detecção e Quantificação}

A definição de limite de detecção (LD) usada nesta pesquisa é expressa da seguinte forma: "LD expressa a concentração derivada da menor medida que pode ser detectada com razoável certeza para cada método analítico". Já o limite de quantificação "(LQ) é a concentração a partir da qual se pode afirmar com razoável certeza que um determinado analito está presente e em uma concentração específica". Os limites de detecção e quantificação foram determinados com base nas curvas analíticas de cada espécie (LONG e WINWFORDER, 1983). Os valores de LD e LQ são dados por:

$$
L D=3 \cdot\left(\frac{D P}{a}\right)
$$

$$
L Q=10 \cdot\left(\frac{D P}{a}\right)
$$

Onde:

DP - desvio padrão dos valores usados na construção da reta;

$a$ - coeficiente angular da curva de calibração.

\subsubsection{Extração}

O principal objetivo da fase de extração é a retirada dos analitos presentes na amostra, utilizando-se o solvente mais adequado, o qual deve ser capaz de remover os constituintes de interesse, extraindo o mínimo de interferentes. Conforme o método USEPA 8270C, os solventes utilizados foram acetona e hexano. Ainda segundo o mesmo método USEPA, a técnica usada para a extração foi o Soxhlet USEPA 3540C. Esta técnica é conhecida, também, como extração exaustiva, pois o solvente é continuamente "refluxado" no sistema passando várias vezes pela amostra. O sistema de sifonamento remove o extrato para o solvente que volta a ser "refluxado" no sistema. O tempo de extração foi de 24 horas conforme USEPA 3540C. 


\subsubsection{Preparação das Amostras}

As alíquotas foram tomadas, em duplicata, com aproximadamente $10 \mathrm{~g}$ das amostras sólidas, e em seguida foram homogeneizadas com sulfato de sódio anidro. Em seqüência, a mistura da amostra mais sulfato de sódio foi introduzida em um cartucho de extração. Finalmente os extratos foram concentrados em evaporador rotativo e injetados no cromatógrafo.

\subsubsection{Caracterização da Fração Inorgânica}

A caracterização, semiquantitativa, da fração inorgânica do resíduo por Espectrômetro de Fluorescência de Raios-X por Energia Dispersiva, modelo EDX-800, marca Shimadzu, seguiu dois procedimentos: o primeiro utilizou o resíduo bruto sem qualquer tratamento, que foi inserido nos recipientes amostradores e lacrado com filme plástico fornecido pelo fabricante do equipamento (esse procedimento foi apenas indicativo, inicial). O segundo utilizou o residual sólido, que permaneceu retido no cartucho de extração cromatográfica. Este material foi seco em estufa a, aproximadamente, $105^{\circ} \mathrm{C}$. Em seguida, a amostra seca foi macerada para homogeneização, sendo depois inserida no recipiente amostrador e lacrada com filme plástico. Este procedimento foi seguido para cada amostra isoladamente. Finalmente, as amostras foram analisadas em ambiente a vácuo, buscando-se os íons elementares. A análise consiste em uma varredura qualitativa inicial de todas as amostras para a determinação das espécies químicas presentes e em seqüência, a leitura, propriamente dita, das substâncias químicas semiquantitativamente.

\subsection{Caracterização do Solo}

Para a compreensão do meio físico em estudo, com representatividade das características do solo local, foram necessárias, por se tratar de um estudo 
de contaminação, uma caracterização física, físico-química e mineralógica. Nesta fase da pesquisa contou-se com a relevante contribuição do professor Lázaro Valentin Zuquette do Departamento de Geotecnia da Escola de Engenharia de São Carlos da Universidade de São Paulo. Foram aplicadas as metodologias seguidas por Nogueira (1995), normas da Associação Brasileira de Normas Técnicas (ABNT), bem como as usadas na pesquisa de Leite (2001).

\subsubsection{Coleta e Preparação das Amostras}

Foram realizados 07 (sete) furos de sondagem, com coleta de amostras deformadas de solo a cada mudança de litologia. As profundidades variaram de 3 a 16 metros. No mapa topográfico no Apêndice A está indicada a locação dos furos. No Apêndice B são mostrados os perfis tátil-visuais para cada um dos furos de sondagem. É importante frisar que os furos de sondagem 6 e 7 foram cortesia da Empresa SondoBase Engenharia de Solos LTDA., responsável pela execução das sondagens, e nestes dois furos não foram coletadas amostras.

Seguidos os procedimentos recomendados por Nogueira (1995), em laboratório as amostras foram destorroadas (peneira com abertura de $4 \mathrm{~mm}$ ), secadas à sombra por mais de 4 (quatro) dias, homogeneizadas e quarteadas.

\subsubsection{Caracterização Física}

\subsubsection{Análise Granulométrica Conjunta}

Neste ensaio seguiru-se as recomendações de Nogueira (1995) e a norma ABNT - NBR 7181. Também, seguindo recomendações do professor Lázaro Valentin Zuquette, foi realizado ensaio modificado das referências citadas. Este ensaio modificado consiste no uso somente de água destilada ao invés de água e defloculante (hexametafosfato de sódio). 


\subsubsection{Massa Específica dos Sólidos}

O ensaio para determinação da massa específica dos sólidos $\left(\rho_{s}\right)$ seguiu a norma ABNT -NBR 6508 e as recomendações de Nogueira (1995).

\subsubsection{Caracterização Físico-Química}

\subsubsection{Potencial Hidrogeniônico (pH) e $\Delta \mathrm{pH}$}

Segundo Leite (2001), o $\Delta \mathrm{pH}\left(\mathrm{pH} \mathrm{KCl}-\mathrm{pH} \mathrm{H}_{2} \mathrm{O}\right)$ do solo é um parâmetro útil no estudo da magnitude e sinal das cargas existentes na superfície das partículas. Valores positivos de $\Delta \mathrm{pH}$ apontam para uma predominância de cargas positivas e valores negativos apontam para uma predominância de cargas negativas. Este fator torna-se relevante, pois a existência de cargas positivas confere ao solo não só uma CTC (capacidade de troca catiônica), como também uma CTA (capacidade de troca aniônica). Estas duas propriedades indicam tendência na retenção de contaminantes iônicos.

$\mathrm{O}$ pH em água $\left(\mathrm{H}_{2} \mathrm{O}\right)$ e o pH em solução de $\mathrm{KCl}(1 \mathrm{~N})$ foram determinados segundo as recomendações de Camargo et al. (1986), numa proporção de 1:2,5 solo/solução (50 $g$ de solo para $125 \mathrm{~mL}$ de água ou solução de $\mathrm{KCl}$ ). Depois de adicionar a água ou a solução de $\mathrm{KCl}$, os frascos foram rotacionados em um dispersor rotativo por 15 minutos, sendo posteriormente deixados em repouso, e, após 30 minutos ou mais (tempo necessário para a sedimentação das partículas) determinou-se o pH da solução final.

\subsubsection{Potencial Redox (Eh)}

O potencial de oxidação de uma solução aquosa, para reações químicas nas quais elétrons são transferidos de um íon para outro (reações de oxidaçãoredução ou reações redox), é conhecido como potencial redox ou 
simplesmente Eh. O sinal do potencial será positivo se o potencial for de oxidação (perda de elétrons) e negativo se for de redução (ganho de elétrons). Fetter (2001) menciona que altos valores de Eh indicam pouca atividade eletrônica, favorecendo a existência de substâncias oxidadas. Da mesma forma, baixos valores de Eh indicam alta atividade eletrônica e substâncias reduzidas.

Para este parâmetro utilizou-se a mesma solução final do procedimento sugerido por Camargo et al. (1986) para mensurar o pH em água, para a determinação do Eh.

\subsubsection{Condutividade Elétrica do Extrato Aquoso}

Neste ensaio determina-se de maneira indireta, a concentração de íons solúveis presentes no extrato aquoso do solo. Para esta determinação também seguimos a metodologia de Camargo et al. (1986), que utiliza uma proporção 1:1 solo/água (100 gramas de solo para $100 \mathrm{~mL}$ de água destilada).

\subsubsection{Estimativa da Capacidade de Troca Catiônica e Superfície Específica}

A capacidade de troca catiônica (CTC) refere-se à aptidão do solo em reter e trocar íons positivos. A superfície específica (SE) possui relação direta com a retenção de íons, pois quanto maior o contato maior será a retenção.

Pejon (1992) apresentou um método simples (Adsorção por Azul de Metileno) para estimar os valores de CTC e SE. O azul de metileno (cloridato de metilamina $-\mathrm{C}_{16} \mathrm{H}_{18} \mathrm{~N}_{3} \mathrm{SCl}-3 \mathrm{H}_{2} \mathrm{O}$ ) quando em contato com amostras de solo substitui os cátions adsorvidos. A quantidade de azul de metileno adicionada, quando todo o solo é contatado, indica a CTC e a SE. Utiliza-se no ensaio a fração que passa pela peneira 10,2 $\mathrm{mm}$, com massa seca variando entre 2 e 4 gramas. 


\subsubsection{Caracterização Mineralógica}

A composição mineralógica foi determinada segundo a norma ABNT NBR 6508. Para esta determinação considera-se somente a fração que passa pela peneira 0,037 $\mathrm{mm}$ (peneira \#400), pois se considera que partículas menores que esse diâmetro estão dentro da fração argila (menor que 0,002 $\mathrm{mm}$ ) e parte da fração silte $(0,002$ a $0,075 \mathrm{~mm})$. O método de análise foi a difração de raios-X.

\subsubsection{Preparação das Lâminas}

Do total de 29 amostras foram selecionadas 7, com o auxílio do professor Lázaro Valentin Zuquette, para confecção das lâminas. O método de preparação das lâminas foi a sedimentação. O procedimento de confecção foi o mesmo usado por Leite (2001), resumidamente descrito a seguir:

Pesou-se aproximadamente 3,0 gramas de amostra peneirada, colocando-a em suspensão com $80 \mathrm{~mL}$ de hexametafosfato de sódio $(45,7 \mathrm{~g} / \mathrm{L})$ e $320 \mathrm{~mL}$ de água destilada;

Efetuou-se uma dispersão inicial com auxílio de um dispersor mecânico por 10 minutos, deixou-se a suspensão em repouso por um tempo superior a 12 horas para a ação do agente dispersor;

Transferiu-se a suspensão para um recipiente de aproximadamente 200 $m L$ e boca larga, com um suporte para lâmina no fundo;

Colocou-se a lâmina no interior da suspensão após cinco minutos de repouso, tempo considerado suficiente para a sedimentação da fração grosseira;

Considerou-se um tempo de sedimentação superior a 12 horas, procedeu-se, cuidadosamente, a drenagem da fase aquosa do recipiente que contem a lâmina e, finalmente, esperou-se a secagem da lâmina. 


\subsubsection{Condições do Ensaio}

As lâminas de decantação foram analisadas no difratômetro do Departamento de Cristalografia do Instituto de Física de São Carlos - USP. A velocidade de varredura foi de $1^{\circ} / \mathrm{min}$, num intervalo de $0^{\circ}$ a $40^{\circ}$. Os resultados foram introduzidos no programa Excel para identificação dos picos. Os minerais foram identificados por comparação com a tabela fornecida por Brown e Brindley (1984). É importante acrescentar que os valores do ângulo de Bragg

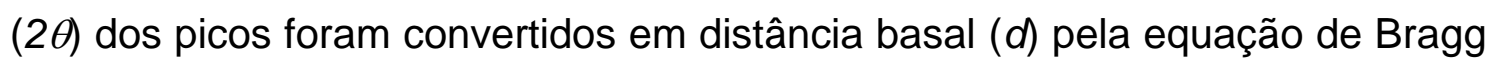
para a comparação com a tabela fornecida pelos autores citados.

\subsubsection{Caracterização Química}

\subsubsection{Teor de Carbono Orgânico Total}

A determinação do teor de carbono orgânico do solo é uma informação de extrema relevância no estudo da contaminação do solo por contaminantes hidrofóbicos, por estar vinculado ao retardamento dos mesmos. Muitos autores (MACKAY et al., 1985; MACKAY et al., 1986; ROBERTS et al., 1986; OLSEN e DAVIS, 1990; CLEARY, 1991; FETTER, 1998 e 2001; OLIVEIRA, 2002) consideram que a matéria orgânica domina ou controla a adsorção de contaminantes hidrofóbicos quando o conteúdo de matéria orgânica é superior a $0,1 \%$.

Segundo Cotta (2003), o carbono total é determinado pela oxidação do carbono orgânico e inorgânico da amostra a $\mathrm{CO}_{2}$, devido ao aumento da temperatura a $900{ }^{\circ} \mathrm{C}$. A determinação do carbono inorgânico é realizada quando se acidifica, com ácido fosfórico, e se aquece a amostra a $200{ }^{\circ} \mathrm{C}$, 0 que leva à liberação de $\mathrm{CO}_{2}$ proveniente do carbono inorgânico. Pela diferença entre o carbono total e inorgânico, calcula-se o valor do carbono orgânico total das amostras.

$\mathrm{O}$ equipamento utilizado foi o Carbono Total, modelo TOC- $\mathrm{V}_{\mathrm{CPH}}$, acoplado ao módulo de amostras sólidas, modelo SSM-5000A, marca 
SHIMADZU com detector de combustão. As curvas analíticas foram construídas com padrão de bifitalato de potássio para análise de carbono total e carbonato de sódio anidro para análise de carbono inorgânico das amostras (COTTA, 2003).

As amostras foram preparadas tomando-se $100 \mathrm{mg}$, aproximadamente, de cada profundidade. Em seguida as amostras foram secas em estufa a $50{ }^{\circ} \mathrm{C}$ por 24 horas, daí foram esfriadas em dessecador até a condição de massa constante. Finalmente as amostras foram maceradas em almofariz e inseridas no equipamento para a determinação da massa de carbono total e inorgânico, sendo a diferença entre elas a massa de carbono orgânico total. Para cada profundidade foram tomadas três alíquotas, onde os resultados são as médias das três determinações.

\subsubsection{Determinação de HPAs}

Para a caracterização do solo foram utilizadas amostras coletadas durante a perfuração (amostras deformadas) dos poços de monitoramento 03, 04 e 08 (ver item 4.10), as amostras coletadas durante as sondagens e amostras não deformadas (GEOPROBE ${ }^{\circledR}$ ) coletadas durante a perfuração dos poços de monitoramento (ver Figura 4.7). A metodologia utilizada para a caracterização da fração orgânica presente nas amostras de solo é a mesma empregada para a caracterização do resíduo. Entretanto foram utilizadas somente as amostras coletadas na zona saturada e na franja capilar, porque supõe-se que os HPAs movimentam-se principalmente na superfície da zona saturada (por se tratar de LNAPLs).

Em laboratório, para a caracterização dos HPAs em solo seguiu-se os mesmos procedimentos adotados para a caracterização orgânica do resíduo, subitem 4.8.4. 


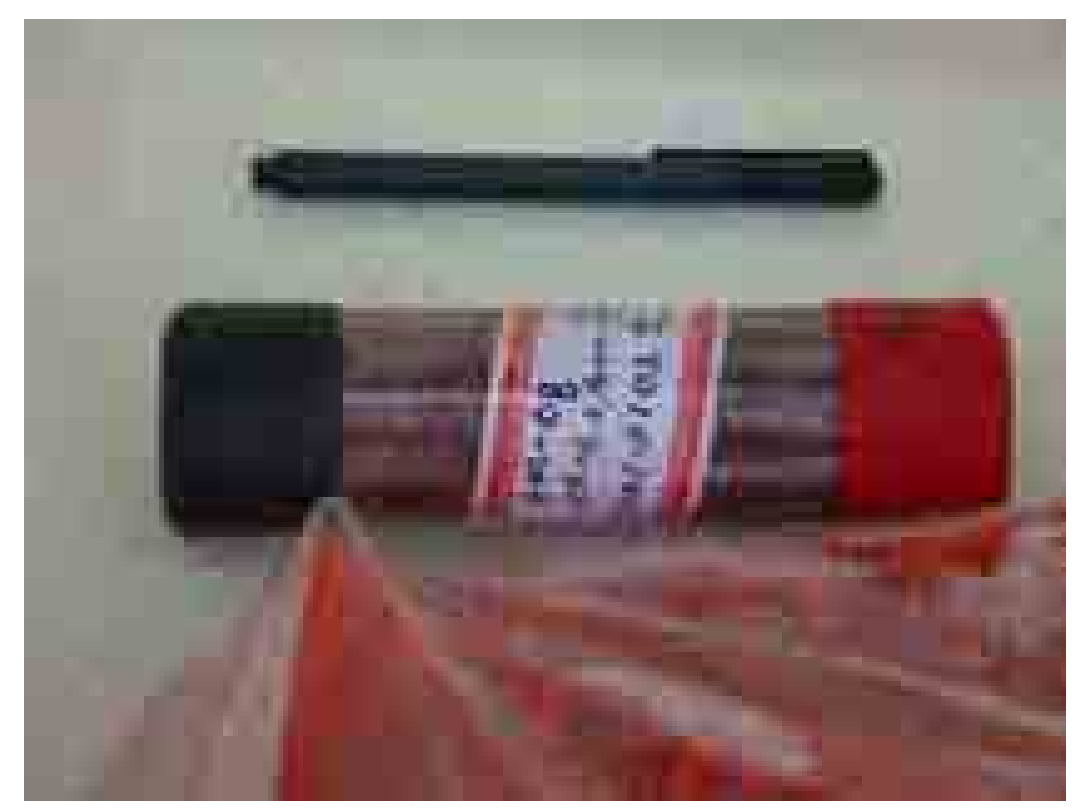

Figura 4.7 - Amostra não deformada obtida na perfuração do PM - 08.

\subsubsection{Determinação da Fração Inorgânica}

Para caracterização da fração inorgânica do solo, como no item anterior, foram utilizadas as amostras deformadas coletadas durante a perfuração dos poços de monitoramento 03, 04 e 08 e as amostras coletadas durante as sondagens. Inicialmente as amostras foram secas em estufa a, aproximadamente, $105{ }^{\circ} \mathrm{C}$. Em seguida o solo seco foi macerado para homogeneização. Finalmente, as amostras foram analisadas em um Espectrômetro de Fluorescência de Raios-X por Energia Dispersiva (EDX-800), marca SHIMADZU, em ambiente a hélio. Para as amostras de solo buscou-se os óxidos presentes. A análise consistiu em uma varredura qualitativa inicial de todas as amostras para a determinação dos óxidos presente e em seqüência, a leitura, propriamente dita, dos óxidos semi-quantitativamente.

\subsection{Poços de Monitoramento}

\subsubsection{Construção}

Foram executados 8 poços de monitoramento, sendo um deles um poço multinível (ver localização dos poços de monitoramento no Apêndice A). Os 
serviços de instalação dos poços foram realizados com uma perfuratriz hidráulica, marca Maquesonda, modelo Mach14, montada sobre caminhão Mercedes Benz, modelo 1215-C, de propriedade da empresa American Drilling do Brasil. A equipe de operação foi composta por um sondador e dois auxiliares.

O sistema de perfuração empregado foi o sistema rotativo, sem uso de fluído de perfuração, com brocas tipo "rabo de peixe", com trados ocos (do inglês, hollow stem auger). Os trados ocos são construídos com tubos de aço carbono, circundados por uma hélice que, introduzidos rotativamente no solo por uma perfuratriz hidráulica, permitem a execução de manobras e colocação de tubulações no seu interior.

$\mathrm{Na}$ perfuração foram utilizados trados com 5" de diâmetro interno, ficando os furos com 10" de diâmetro. No interior dos trados foram coletadas amostras de solo utilizando amostrador tipo Macro Core Sampler $\left(\right.$ GEOPROBE $\left.^{\circledR}\right)$. No interior do amostrador foi inserido tubo de PVC transparente, com $44 \mathrm{~mm}$ de diâmetro e 1,2 $\mathrm{m}$ de comprimento. Finalmente, o tubo foi cortado no comprimento da amostra recuperada, tampado com tampa colorida para identificação de topo (preto) e base (vermelho) e refrigerado para análise química em laboratório. O material perfurado foi objeto de descrição litológica tátil-visual e parcialmente amostrado em sacos plásticos para análises em laboratório.

Para a construção dos sete poços de monitoramento convencionais e um multinível (todos com 2"), foram utilizados os seguintes materiais:

- Revestimento piezométrico em PVC geomecânico, DN 50, barras de $1,0 \mathrm{~m}$ e $2,0 \mathrm{~m}$;

- $\quad$ Filtro piezométrico em PVC geomecânico, DN 50, barras de $1 \mathrm{~m}$ e $2 \mathrm{~m}$, abertura das ranhuras de $0,5 \mathrm{~mm}$;

- $\quad$ Tampa (cap) inferior roscável em PVC geomecânico, DN 50;

- Luvas roscáveis em PVC geomecânico, DN 50;

- Tampas (boca do tubo geomecânico) de alumínio de 2", com borracha expansível;

- Pré-filtro tipo pérola, granulometria de 1,0 a 2,0 $\mathrm{mm}$;

- Bentonita Compactolit; 
- Bentonita em pó;

- Cimento;

- $\quad$ Areia comum lavada;

- $\quad$ Tampa de proteção de alumínio, com cadeado de segurança devido a se tratar de área abandonada, com 0,60 $\mathrm{m}$ de altura e pintadas em amarelo, para facilitar localização.

Os poços de monitoramento (PMs) foram desenvolvidos utilizando mangueira de irrigação de $3 / 4$ " conectados a válvula de retenção. O nível da água foi medido, antes e após a limpeza dos poços, com medidor elétrico de nível da água, com fio de 30,0 m.

Os PMs 01 a 04 são totalmente penetrantes, isto é, foram perfurados até atingir a base (início da camada mais argilosa) do aqǘf́ero suspenso situado entre o colúvio superficial e solo residual de basalto. Sendo o PM - 01 de montante (para controle), os PMs 02, 03 e 04 de jusante para o monitoramento de fato. O PM - 02 é multinível, apresentando filtro a duas profundidades, próximo à superfície do lençol freático e próximo à base do aqüífero suspenso. Os PMs 03 e 04 apresentam filtro apenas próximo a base do aqüífero. Já os PMs 05 a 08 são parcialmente penetrantes devido à não identificação da base do arenito. É importante acrescentar que o topo da zona saturada no entorno dos PMs 05 a 08 é de aproximadamente 28 metros, assim, os poços foram perfurados até a profundidade máxima de 32 metros, para termos uma margem de segurança durante a realização das coletas de amostras de água e determinação dos parâmetros do aqüífero. Na Figura 4.8 pode ser observada a perfuração do PM - 05. Os filtros foram posicionados segundos as formações geológicas de interesse.

\subsubsection{Características dos Poços de Monitoramento}

As características gerais construtivas dos poços de monitoramento instalados estão resumidas na Tabela "Dados Gerais dos Poços de Monitoramento" do Apêndice C. O furo identificado com S 03, localizado a $2 \mathrm{~m}$ de distância do PM-03, foi executado com o objetivo de instalar um poço de 
bombeamento com 4". No entanto, como não atingiu a camada de arenito até a profundidade de $32 \mathrm{~m}$, esse furo foi abandonado e a instalação do poço de bombeamento foi cancelada. Os perfis dos poços com as identificações tátilvisuais das formações perfuradas são apresentados no Apêndice B.

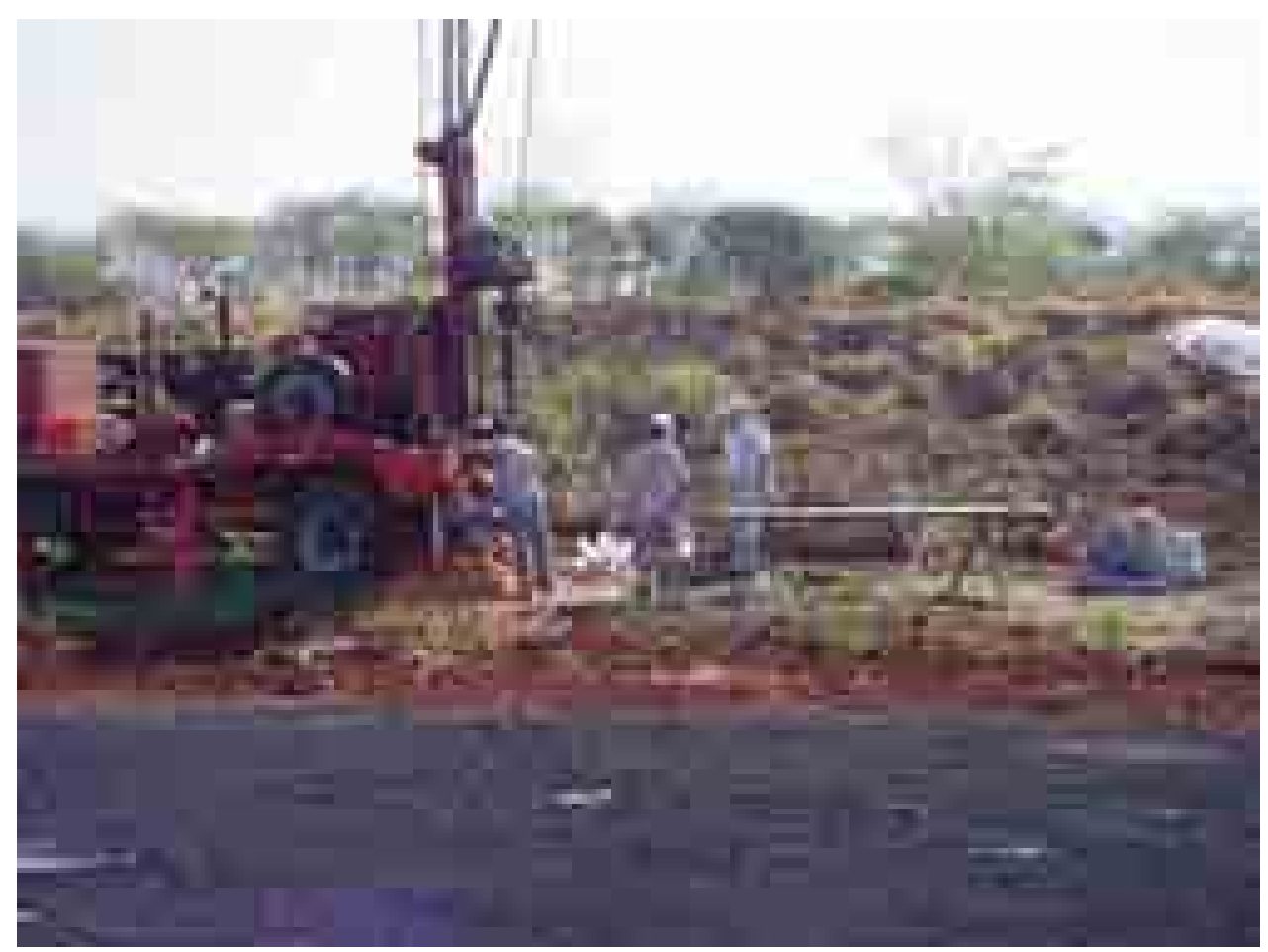

Figura 4.8 - Perfuração do poço de monitoramento PM - 05.

\subsubsection{Desenvolvimento dos Poços de Monitoramento}

Os dados de nível da água medidos antes e depois do desenvolvimento dos poços de monitoramento estão dispostos na Tabela 4.2 (primeira campanha de desenvolvimento). Observa-se na Tabela 4.2 as seguintes informações: a identificação dos PMs, a data do desenvolvimento, a altura do revestimento do poço acima da superfície do solo "h", o primeiro desenvolvimento do dia denominado "antes" com o horário do início do procedimento e as variações de nível, e finalmente, o segundo desenvolvimento do dia denominado "depois" com o horário do início do procedimento e as variações de nível. 
Tabela 4.2 - Dados de níveis de água durante a primeira campanha de desenvolvimento.

\begin{tabular}{|c|c|c|c|c|c|c|c|}
\hline \multirow[b]{2}{*}{ Identificação } & \multirow[b]{2}{*}{ Data } & \multirow[b]{2}{*}{$h(m)$} & \multicolumn{3}{|c|}{ Antes } & \multicolumn{2}{|c|}{ Após } \\
\hline & & & Hora & $\begin{array}{r}\text { Profu } \\
\mathrm{N} /\end{array}$ & $\begin{array}{l}\text { Ididade } \\
\text { (m) }\end{array}$ & Hora & $\begin{array}{c}\text { Profundidade } \\
\text { NA (m) }\end{array}$ \\
\hline PM 01 & 09/10/03 & $-0,30$ & $8: 15$ & 15,60 & 15,30 & $12: 06$ & $15,58 \quad 15,28$ \\
\hline PM 02 B & 09/10/03 & $-0,18$ & $7: 15$ & 11,60 & 11,42 & $11: 14$ & $12,10 \quad 11,92$ \\
\hline PM $02 \mathrm{~A}$ & 09/10/03 & $-0,32$ & $7: 17$ & 11,60 & 11,28 & $11: 16$ & $11,63 \quad 11,31$ \\
\hline PM 03 & 09/10/03 & $-0,34$ & $7: 25$ & 11,70 & 11,36 & $11: 24$ & $12,02 \quad 11,68$ \\
\hline PM 04 & 09/10/03 & $-0,28$ & $7: 21$ & 10,70 & 10,42 & $11: 18$ & $10,75 \quad 10,47$ \\
\hline PM 05 & 09/10/03 & $-0,30$ & $7: 31$ & 28,60 & 28,30 & $11: 30$ & $28,54 \quad 28,24$ \\
\hline PM 06 & 09/10/03 & $-0,30$ & $7: 38$ & 27,60 & 27,30 & $11: 37$ & $27,45 \quad 27,15$ \\
\hline PM 07 & 09/10/03 & $-0,20$ & $7: 50$ & 27,68 & 27,48 & $11: 51$ & $27,53 \quad 27,33$ \\
\hline PM 08 & 09/10/03 & $-0,34$ & $8: 05$ & 28,60 & 28,26 & $12: 01$ & $27,55 \quad 27,21$ \\
\hline
\end{tabular}

Ressalta-se que o cronograma inicial previa uma campanha de coleta de amostras de água subterrânea para o mês de novembro de 2003. Entretanto devido ao estado sofrível dos poços (grande quantidade de partículas em suspensão, por exemplo), decorrente de má qualidade no serviço de desenvolvimento dos poços, foi necessário contatar a empresa responsável e solicitar novo desenvolvimento, que apenas foi finalizado em janeiro de 2004. Isto atrasou o cronograma previsto. Na Tabela "Dados da Segunda Campanha de Desenvolvimento", inserida no Apêndice C, são apresentados os resultados do segundo evento de desenvolvimento.

\subsubsection{Direção do Escoamento, Gradiente Hidráulico e Superfície Potenciométrica}

Em situações nas quais existem poucos poços em um sítio para a elaboração de um mapa completo da superfície potenciométrica do aqüífero (que é o caso de investigações em sítios contaminados de pequeno porte), pode-se usar métodos gráficos para determinação da direção do escoamento em sub-superfície e o gradiente hidráulico aproximado dentro da área delimitada pelos poços. Weaver (2004) sugere o ajuste simples de um plano $(h=a \cdot x+b \cdot y+c)$ para a determinação da direção e gradiente do escoamento subterrâneo, no qual as constantes podem ser ajustadas com um mínimo de 
três poços. Quando mais do que três pontos forem usados, os coeficientes podem ser calculados por ajuste de mínimos quadrados. Adicionalmente, a magnitude do gradiente pode ser calculada pela raiz quadrada da soma dos quadrados dos coeficientes "a" e "b" $\left(\sqrt{a^{2}+b^{2}}\right)$ e a direção em relação ao Norte pode ser determinada pelo arco tangente de "a/b" ou "b/a", dependendo do quadrante (WEAVER, 2004). Este método pode ser acessado diretamente da página da Internet da USEPA pelo endereço: http://www.epa.gov/athens/learn2model/part-two/onsite/gradient4plus.htm.

Um mapa da superfície potenciométrica local apresenta substancial relevância para se definir que aqǘf́ro pretende-se monitorar e qual a direção do escoamento. Usando-se o método de interpolação da krigagem universal foi elaborado um mapa da superfície potenciométrica tomando-se como referência as médias dos níveis de água medidos nos poços de monitoramento e poços localizados no terreno vizinho.

\subsubsection{Determinação da Condutividade Hidráulica por Slug Tests}

A determinação das propriedades hidráulicas dos aqüíferos e as unidades de confinamento são informações fundamentais para a compreensão do escoamento em sub-superfície e para o desenvolvimento de um modelo de escoamento.

O slug test pode ser usado para estimar a condutividade hidráulica $(K)$, a transmissividade $(T)$ e o coeficiente de armazenamento $(S)$ nas proximidades do poço onde se realizou o teste. Estes parâmetros ( $K, T$ e $S$ ) são usados para determinar a razão de escoamento subterrâneo e o transporte de contaminantes (WESTON, 2001).

O slug test envolve o deslocamento de um volume de água conhecido instantaneamente no poço e acompanhar as mudanças no nível de água ao longo do tempo, com o nível de água retornando à posição de equilíbrio inicial. O deslocamento de água no poço é feito com elevação ou rebaixamento provocado por um corpo (slug). Este corpo é um cilindro sólido (oco, pesado e 
com um lado tapado) de PVC (ou Teflon ou aço inoxidável) com um ponto para amarração. Outras variações do método incluem a adição instantânea ou remoção de um volume de água para ou do poço e a utilização de um sistema de pressurização do poço. O teste executado baixando-se um corpo no poço e elevando-se o nível de água é conhecido como slug test de rebaixamento. Já o teste realizado retirando água do poço rebaixando o nível de água é denominado slug test de recuperação. Os dados de ambos podem ser comparados, desde que o filtro e o pré-filtro do poço estejam totalmente saturados (slug test de rebaixamento produzirá resultados errôneos se o filtro ou pré-filtro estiverem parcialmente saturado). Freqüentemente, slug tests de rebaixamento e recuperação são realizados em conjunto (quando conveniente) para conferir a consistência dos resultados encontrados (controle de qualidade).

O slug test apresenta várias vantagens quando comparado com outros testes de aqüíferos, como por exemplo:

- Avaliar a condutividade hidráulica de zonas específicas para determinar a heterogeneidade do aqüífero;

- Simples de se conduzir em campo;

- Baixo custo de realização, mesmo em vários pontos;

- Em geral são executados em curto intervalo de tempo (ordem de minutos);

- Apresenta risco reduzido à saúde e à segurança da equipe de campo;

- Acarreta pouco ou nenhum problema de geração de água contaminada.

Apesar das vantagens pronunciadas, freqüentemente, slug tests são considerados ensaios com baixa confiabilidade. Esta é uma crítica bastante severa, pois como CHU et al. (1987) observaram, uma estimativa acurada das propriedades do aqüífero (por exemplo, $K, T$ e $S$ ) é essencial para uma avaliação adequada do escoamento da água subterrânea e para a modelagem do transporte de contaminantes.

Dados de slug test obtidos em campo normalmente são analisados usando os métodos propostos por Hvorslev (1951), Cooper et al. (1967), Bouwer e Rice (1976) e van Der Kamp (1976). O método proposto por Hvorslev pode ser aplicado a uma gama variada de geometrias de poço e aqüífero, mas 
vem sendo usado em sistemas confinados. Por outro lado, o método proposto por Bouwer e Rice foi também desenvolvido para sistemas não confinados e é mais usado que o método Hvorslev por apresentar maior facilidade nos cálculos. Já o método desenvolvido por van der Kamp aplica-se à análise de dados de aqüíferos de elevada transmissividade, que são evidenciados pela oscilação do nível de água próximo ao equilíbrio. Finalmente, o método proposto por Cooper, Bredehoeft e Papadopulos (CBP) é usado com mais freqüência para analisar sistemas confinados, sendo o único que usa ajuste de curva-chave ao invés de ajustar uma reta para analisar os dados de variação de nível de água (HALFORD e KUNIANSKY 2002). Como se optou por utilizar o método desenvolvido por Bouwer e Rice no subitem 4.10.5.1, o mesmo será descrito com mais detalhes.

Para a realização dos testes em campo foi elaborado um protocolo na forma de planilha para melhor controle dos ensaios. Neste protocolo constam as datas e os horários de saída da sede e chegada em campo e vice-versa, trabalho a ser realizado, participantes, responsável pelo trabalho, condições climáticas, descrição do ensaio, identificação do sítio, coordenadas e profundidade dos poços, profundidade do nível de água, altura de lâmina de água em cada poço e observações gerais.

Conforme recomendado por vários autores (BOUWER e RICE, 1976; BOUWER, 1989; FETTER, 2001; HALFORD e KUNIANSKY 2002), os dados foram obtidos em duas campanhas de campo dias 06/05/2004 e 29/06/2004, variando-se as condições do teste. Na primeira condição, os testes foram realizados com a introdução de cilindro em PVC (com barra de metal interna para aumentar a massa), sendo que para os poços com mais de 3,0 metros de lâmina de água utilizou-se cilindro de 2,0 metros e para os poços com menos de 3,0 metros de lâmina de água utilizou-se cilindros proporcionais, quais sejam, 1,0 e 0,5 metros. As dimensões destes cilindros em PVC foram determinadas em função das características dos poços de monitoramento e seguindo-se as recomendações de volume contidas em Halford e Kuniansky (2002). Na segunda condição, os ensaios foram efetuados retirando-se, aproximadamente, 1 litro de água (maior volume de amostrador, bailer, disponível) dos poços 01 a 04 e introduzindo-se de 1,5 a 3,0 $L$ de água nos poços 05 a 08. Como, supostamente, o sítio estudado estava contaminado, 
toda retirada e introdução de equipamento e instrumento nos poços foi seguida de uma descontaminação conveniente, para reduzir ao máximo as assim denominadas "contaminações cruzadas".

Uma ilustração do tipo de equipamento necessário para a aquisição de dados em campo é apresentada na Figura 4.9. Os equipamentos (carretel do transdutor, armazenador de dados "datalogger" e indicador) foram mantidos no porta-malas do automóvel. Percebe-se que o cabo do transdutor está inserido no poço de monitoramento (nesse caso, o PM - 02) e a corda azul amarrada na placa de identificação foi usada para manter estabilizado o cilindro de PVC que gerou o deslocamento do nível de água dentro do poço.

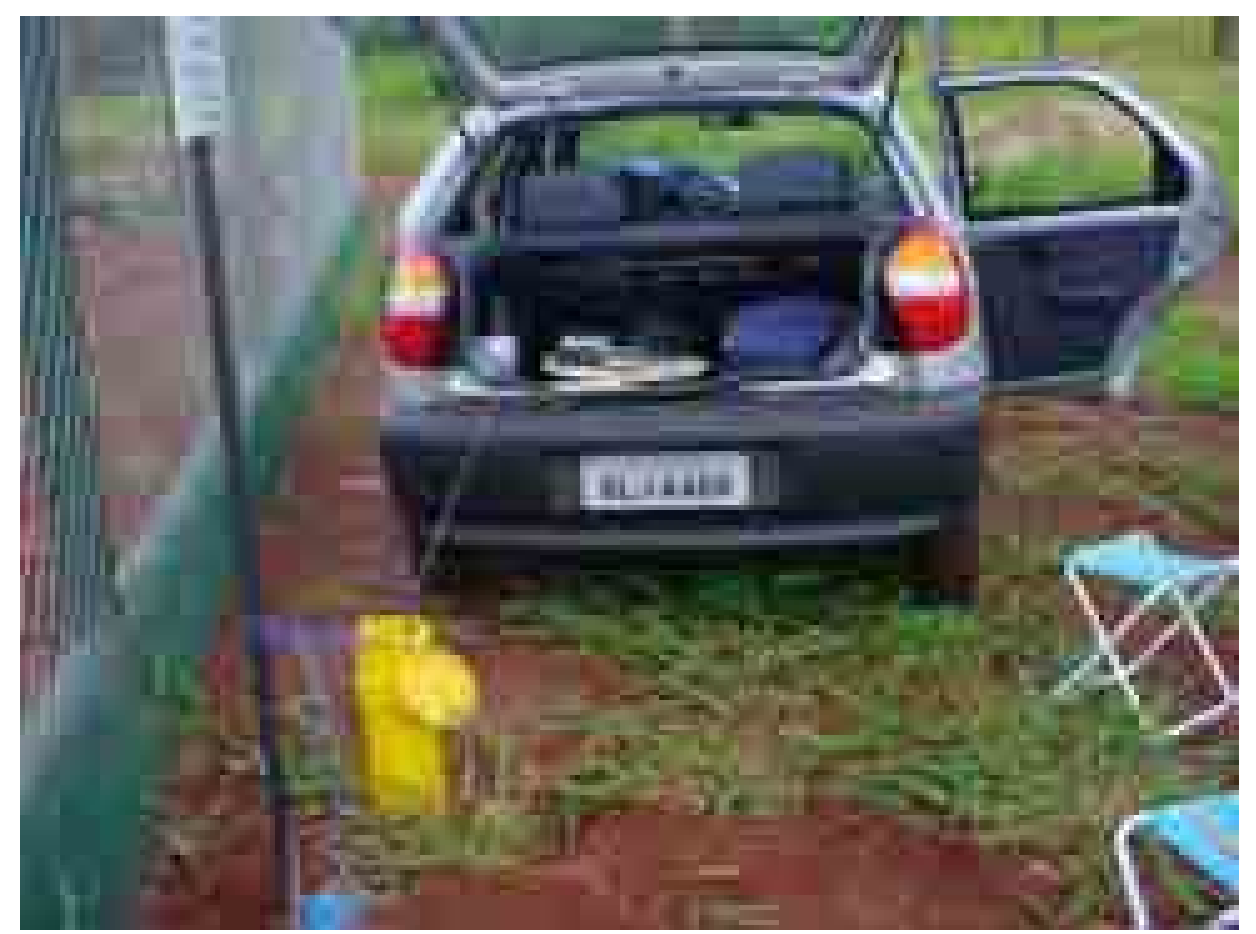

Figura 4.9 - Realização de slug test no PM - 02 A. Percebe-se que todos os equipamentos (carretel do transdutor, armazenador de dados "datalogger" $\mathrm{e}$ indicador) foram mantidos no porta-mala do automóvel.

\subsubsection{Método de Bouwer e Rice}

O método proposto por Bouwer e Rice (1976) e complementado por Rice (1989) é baseado na solução analítica de Thiem (1906) e foi originalmente idealizado para análise de dados obtidos em poços locados em aqüíferos não 
confinados. Contudo pode ser aplicado a aqüíferos confinados, se o topo do filtro estiver distante da base da camada confinante. Caso o nível de água esteja situado abaixo da extremidade superior do filtro, deve ser realizado somente o teste de recuperação. Vale mais uma vez ressaltar que o método proposto por Bouwer e Rice estima a condutividade hidráulica próxima ao filtro do poço onde o ensaio foi realizado. Na Figura 4.10 é apresentado um esquema das dimensões envolvidas no método. A equação proposta por Bouwer e Rice é:

$$
K=\frac{r_{c}^{2} \ln \left(R_{e} / R\right)}{2 \cdot L_{e} \cdot t} \cdot \ln \left(\frac{H_{0}}{H_{t}}\right)
$$

Onde:

$K$ - condutividade hidráulica (L/T);

$r_{c}$ - raio interno do revestimento do poço (L);

$R$ - raio da região preenchida com pré-filtro $(\mathrm{L})$;

$R_{e}$ - raio de interferência da variação na carga hidráulica (L);

$L_{e}$ - comprimento do filtro (L);

$H_{0}$ - variação inicial do nível de água $t=0(\mathrm{~L})$;

$H_{t}$ - variação do nível de água em um tempo qualquer " $t$ " (L);

$t-$ instante inicial $H=H_{0}(T)$.

Embora não exista uma maneira conhecida de determinar o valor de $R_{e}$ para um dado poço, Bouwer e Rice propuseram um método de estimar a relação adimensional $\ln \left(R_{e} / R\right)$ para a eq. (54).

Se $L_{w}$, a distância entre o nível de água e a base do filtro do poço, é menor do que $h$, a espessura saturada do aqüífero, então:

$$
\ln \frac{R_{e}}{R}=\left[\frac{1,1}{\ln \left(L_{\mathrm{w}} / R\right)}+\frac{A+B \cdot \ln \left\{\left(h-L_{w}\right) / R\right\}}{L_{e} / R}\right]^{-1}
$$

Se $L_{w}$ é igual a $h$, então: 


$$
\ln \frac{R_{e}}{R}=\left[\frac{1,1}{\ln \left(L_{W} / R\right)}+\frac{C}{L_{e} / R}\right]^{-1}
$$

Onde:

A, B e C - são números adimensionais lançados em gráfico em função do $\ln \left(L_{e} / R\right)$ (ver Figura 4.11).

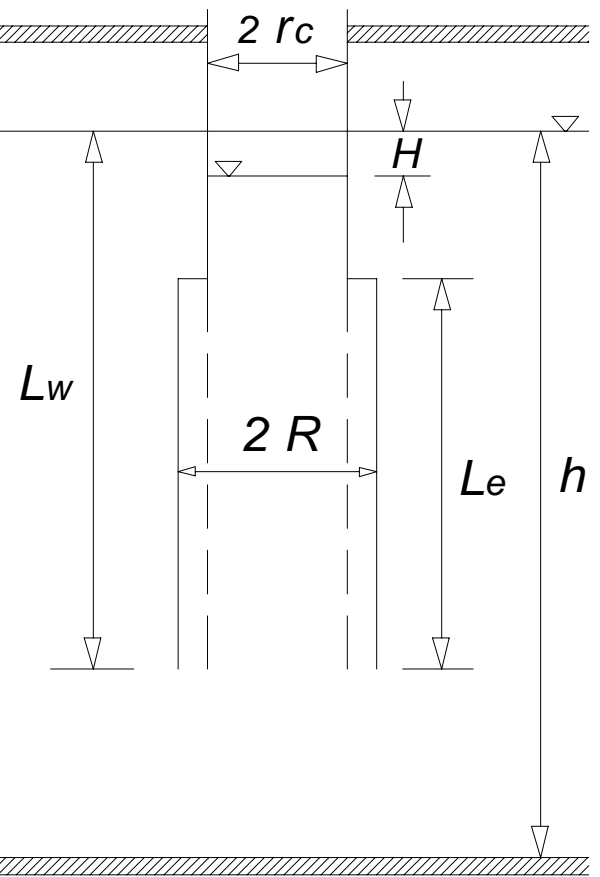

Figura 4.10 - Geometria e simbologia para slug tests em um poço parcialmente penetrante para aqüíferos não confinados (modificado de BOUWER, 1989).

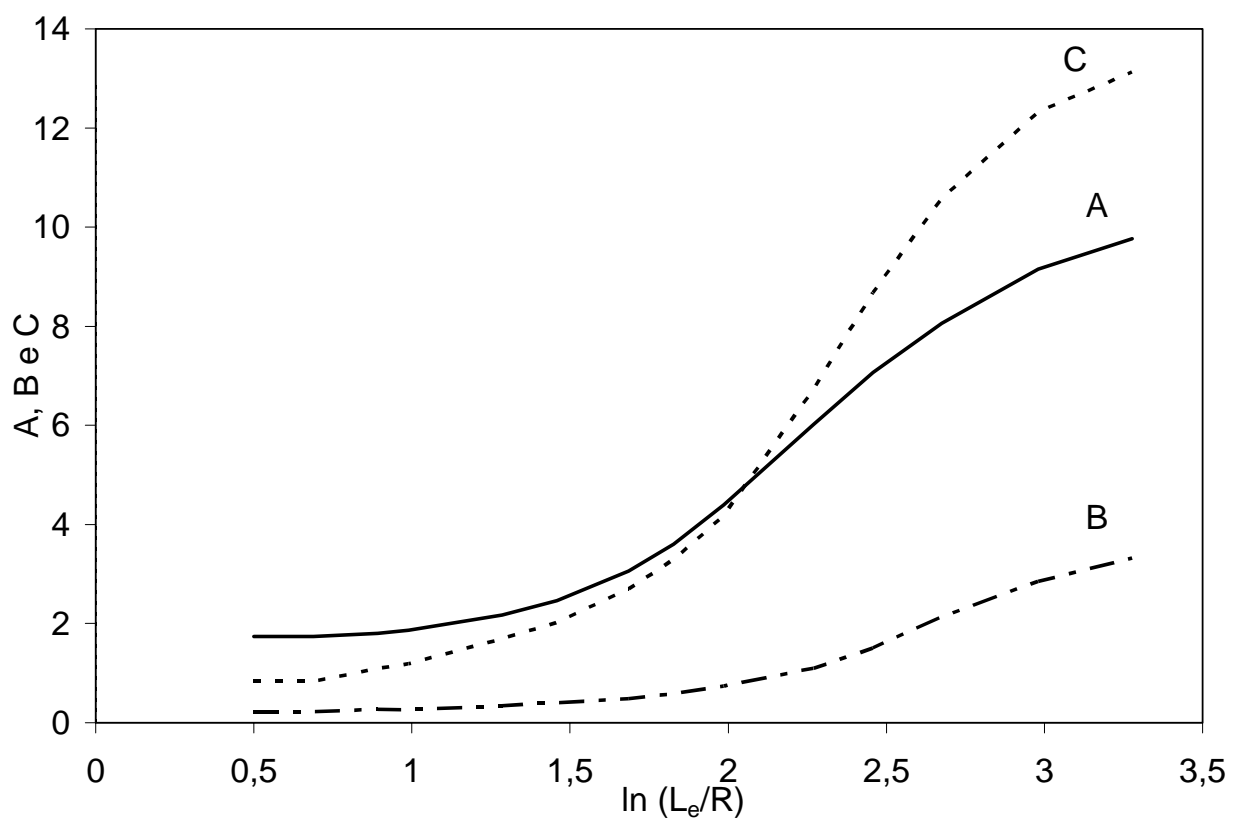

Figura 4.11 - Parâmetros adimensionais A, B e C em função do $\ln \left(L_{e} / R\right)$. 
Uma descrição mais detalhada do método Bouwer e Rice pode ser encontrada nos textos Bouwer e Rice, 1976; Bouwer, 1989; Fetter, 2001; Halford e Kuniansky 2002, dentre outros.

\subsection{Qualidade da Água Subterrânea}

\subsubsection{Determinação de Metais em Amostras de Água Subterrânea}

Segundo o fundamento da espectrometria de absorção atômica por chama EAAC (ou do inglês FAAS - Flame Atomic Absorption Spectrometry), quando uma solução com sal metálico (ou com outro composto metálico) é aspirada por uma chama, por exemplo, a chama do acetileno queimando no ar, forma-se um vapor que contém átomos do metal. Alguns desses átomos podem ser promovidos a um nível energético suficientemente elevado para que ocorra a emissão da radiação característica do metal. Um grande número de átomos gasosos metálicos, no entanto, permanecem normalmente num estado não excitado, ou seja, no estado fundamental. Os átomos no estado fundamental podem absorver a energia radiante que tenha o comprimento de onda específico da sua ressonância. Este comprimento de onda é, em geral, o comprimento de onda da radiação que os átomos emitiriam se fossem excitados acima do estado fundamental. Por isso, se a luz do comprimento de ressonância passar por uma chama que contém os átomos no estado gasoso, parte da luz será absorvida e o grau desta absorção será proporcional ao número de átomos no estado fundamental presentes na chama (VOGEL, 1979; COTTA, 2004).

Já a espectrometria de absorção atômica por forno de grafite EAAFG (ou do inglês, GFAAS - Graphite Furnace Atomic Absorption Spectrometry), ou também conhecida como absorção atômica eletrotérmica permite determinar a maioria dos elementos metálicos com limite de detecção e sensibilidade $20 \mathrm{a}$ 1.000 vezes menor do que a EAAC sem a necessidade de concentrar as amostras. A EAAFG baseia-se no mesmo princípio da EAAC, porém o 
queimador padrão é substituído por forno de grafite ou atomizador aquecido eletricamente. Um volume discreto de amostra é introduzido no tubo de grafite e, geralmente, as amostras são aquecidas em três ou mais estágios. Sendo que no primeiro uma corrente baixa aquece o tubo para secar a amostra. $O$ segundo destrói a matéria orgânica e volatiliza outros componentes em uma temperatura intermediária. Finamente, no terceiro uma corrente elevada aquece o tubo à incandescência e numa atmosfera inerte atomiza o elemento a ser medido. Estágios adicionais, freqüentemente, são inseridos para auxiliar na secagem e na queima da amostra e para resfriar e limpar o tubo de grafite. $O$ vapor atômico resultante em estágio fundamental absorve radiação monocromática vinda da fonte e a intensidade da radiação transmitida é mensurada por um detector fotoelétrico (AMERICAN PUBLIC HEALTH ASSOCIATION, 1998). A EAAFG é recomendada em situações onde os níveis de concentração estão abaixo do intervalo ótimo para EAAC, pois a EAAFG requer mais tempo durante a análise, os custos dos tubos de grafite são onerosos e pode haver mais interferências.

\subsubsection{Equipamentos}

Os equipamentos utilizados na coleta foram:

- 12 Amostradores bailer reutilizáveis (devidamente limpos)

e 2 descartáveis;

- $\quad$ Cordas de varal novas (um por ponto de amostragem);

- Luvas cirúrgicas de látex;

- Etiquetas de identificação e caneta;

- $\quad$ Frascos para coleta em PVC âmbar com tampa e lacre;

- $\quad$ Medidor de interface, marca Hidrosuprimentos, de 50 m;

- Multisensor $(\mathrm{pH}, \mathrm{Eh}, \mathrm{OD}$, temperatura e condutividade elétrica), marca Environmental Monitoring System, modelo 6500;

- $\quad$ Caixa térmica e gelo em recipientes de $200 \mathrm{~mL}$.

Os equipamentos utilizados em laboratório foram: 
- Um espectrômetro de absorção atômica por chama, modelo Varian SpectrAA 220;

- Um espectrômetro de absorção atômica por forno de grafite, modelo Varian SpectrAA 220/GTA 110;

- Chapa aquecedora.

\subsubsection{Preparação para Coleta}

Esgotamento dos Poços em Campo: foram retirados três volumes da lâmina de água de cada poço, aproximadamente 24 horas antes da coleta para obtenção de amostras representativas da formação geológica. Estes três volumes retirados referem-se, teoricamente, à água estagnada no poço e no pré-filtro.

Limpeza dos Equipamentos: ao final de cada esgotamento, os equipamentos de coleta foram lavados (cordas e amostradores) com água de torneira e em seguida com água deionizada, sendo armazenados em sacos plásticos individuais para descontaminação em laboratório.

\subsubsection{Pontos de Amostragem}

Foram coletadas duas amostras em cada ponto de coleta, uma para determinação de metais totais e outra para metais dissolvidos. Os pontos de coleta foram: PM - 01, PM - 02 (A e B), PM - 03, PM - 04, PM - 05, PM - 06, PM - 07, PM - 08, "poço caipira" do vizinho ou "cisterna" e poço tubular do vizinho (ver mapa de localização no Apêndice $A$ ).

\subsubsection{Coleta}

Antes de se proceder a primeira coleta de água dos poços de monitoramento foi realizada a coleta de um branco de amostrador, que consiste 
na passagem de água deionizada pelo amostrador (bailer) até preenchimento por completo de um frasco de coleta. Ao iniciar, de fato, a coleta de água nos poços descartou-se a primeira alíquota de água de cada poço para ambientar o amostrador com a água da formação. Com a segunda alíquota foram determinados os parâmetros de campo: $\mathrm{pH}$, Eh, condutividade elétrica, temperatura e oxigênio dissolvido (OD). Na terceira alíquota coletada, a amostra foi acidificada com 1,5 $\mathrm{mL}$ de $\mathrm{HNO}_{3}$ (quantidade suficiente para manter o pH abaixo de 2) e armazenada para a determinação de metais totais. Na quarta alíquota, coletou-se uma amostra para a determinação de metais dissolvidos, que em laboratório foi filtrada e acidificada. Todas as amostras foram etiquetadas (data, hora, ponto de amostragem, tipo de amostra) e acondicionadas em caixa térmica resfriada a mais ou menos $4{ }^{\circ} \mathrm{C}$. Adicionalmente, foi introduzido um branco de acondicionamento que consiste em manter frasco de amostragem com água deionizada destampado dentro da caixa térmica usada para 0 acondicionamento das amostras até 0 encerramento da coleta. Uma ilustração do procedimento de coleta pode ser observada na Figura 4.12.

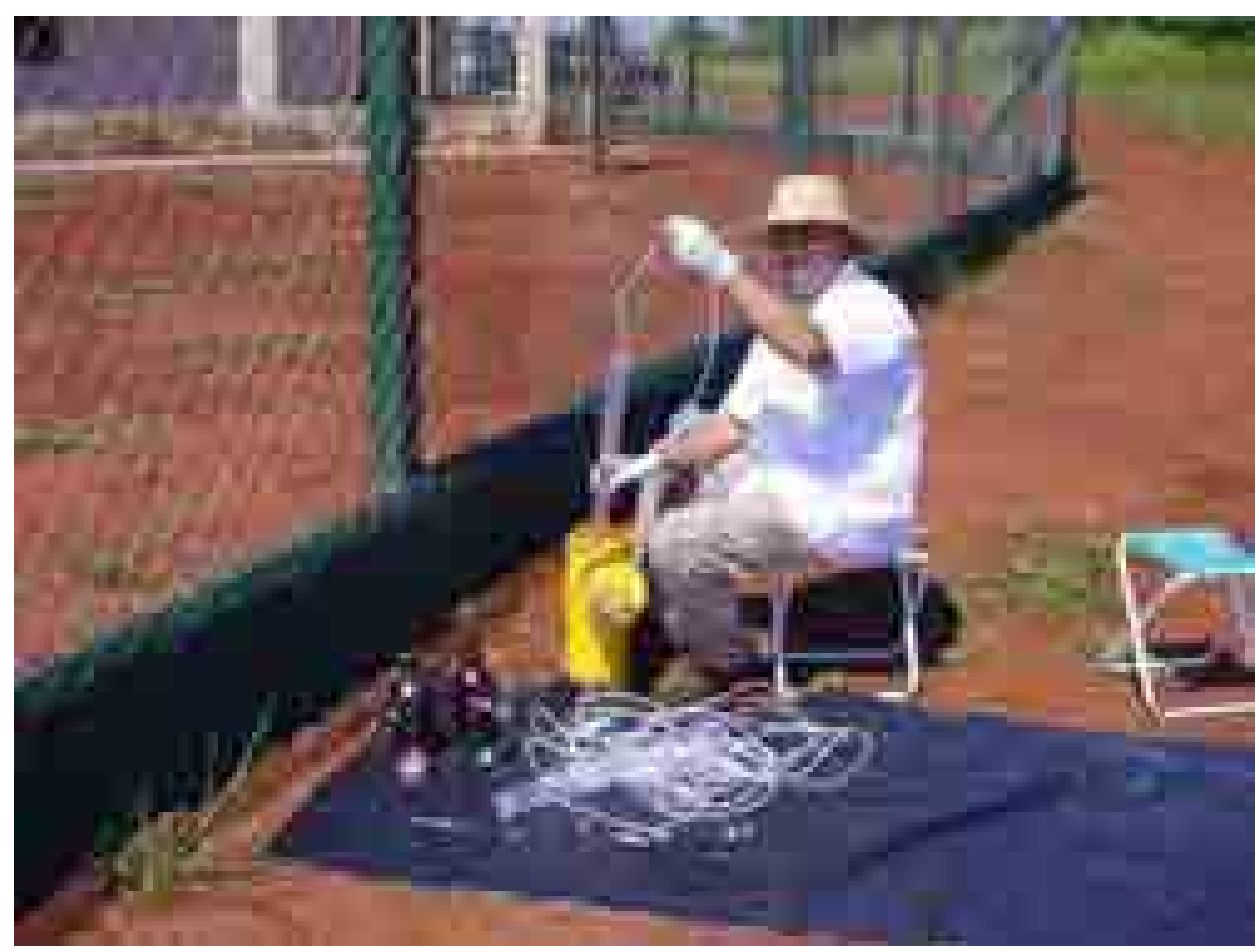

Figura 4.12 - Uma ilustração do procedimento de coleta. 


\subsubsection{Filtração para Metais Dissolvidos}

Para as amostras de metais dissolvidos seguiu-se, em laboratório, o procedimento: as amostras foram agitadas, filtradas a vácuo com membrana de $45 \mu \mathrm{m}$ e acidificadas com $1,5 \mathrm{~mL}$ de ácido nítrico $\left(\mathrm{HNO}_{3}\right)$ (manter o $\mathrm{pH}$ menor do que 2). Adicionalmente, foram realizados um branco de filtração inicial e um branco de filtração final.

\subsubsection{Abertura das Amostras}

Os procedimentos descritos neste subitem tempo por objetivo desprender os metais presentes em eventuais partículas presentes nas amostras, bem como a concentração das mesmas.

Toda a vidraria (10 balões volumétricos de $500 \mathrm{~mL}$ e 10 de $50 \mathrm{~mL}, 10$ béqueres de $500 \mathrm{~mL}, 2$ pipetas de $5 \mathrm{~mL}, 10$ vidros de relógio, 10 funis para filtração a vácuo e várias bolinhas de vidro) utilizada na abertura das amostras foi limpa por imersão em solução contendo o detergente Extran por 24 horas e depois em solução de ácido nítrico a 30\% por aproximadamente 48 horas.

Foram tomados $500 \mathrm{~mL}$ de amostra em um balão volumétrico e introduzidos em um béquer de $500 \mathrm{~mL}$. Em seguida, foram adicionados em cada amostra $2 \mathrm{~mL}$ de ácido nítrico e acrescentadas algumas bolinhas de vidro. Em seqüência, as amostras foram levadas à chapa aquecedora a uma temperatura que não provocou a fervura (em torno de $150{ }^{\circ} \mathrm{C}$ ) e mantidas em digestão até a redução a um volume aproximado de $50 \mathrm{~mL}$. Finalmente, as amostras foram filtradas em sistema de filtração a vácuo, filtro Watiman $45 \mu \mathrm{m}$. Também foram realizados brancos de digestão ao longo de cada bateria de amostras inseridas no sistema. 


\subsubsection{Curvas de Calibração}

Inicialmente as curvas de calibração foram construídas tentando abranger a faixa de concentração para as amostras mais contaminadas e menos contaminadas. Em um segundo passo (refinamento), quando amostras apresentavam concentrações fora dos limites superior ou inferior préestabelecidos, novas curvas de calibração foram traçadas.

\subsubsection{Avaliação da Sensibilidade: Limites de Detecção e Quantificação}

Seguiu-se os mesmos procedimentos descritos no subitem 4.8.4.6., que possui o mesmo título.

\subsubsection{Metais Investigados}

Conforme a Espectrômetria de Fluorescência de Raios-X por Energia Dispersiva das amostras de resíduos, foram selecionados os seguintes metais de int?eresse: chumbo $(\mathrm{Pb})$, zinco $(\mathrm{Zn})$, cobre $(\mathrm{Cu})$, titânio $(\mathrm{Ti})$, estrôncio $(\mathrm{Sr})$, ferro (Fe), alumínio (Al) e manganês ( $M n)$, sendo todos utilizados na investigação por Absorção Atômica.

A qualidade dos resultados foi controlada pelo uso de branco analítico e de análise em duplicata com distribuição aleatória.

Os metais zinco, ferro, cobre e manganês foram analisados por espectrometria de absorção atômica por chama nas condições da Tabela 4.3. Por outro lado, os metais chumbo, titânio, estrôncio e alumínio foram analisados por espectrometria de absorção atômica por forno de grafite. 
Tabela 4.3 - Condições utilizadas na espectrometria de absorção atômica por chama.

\begin{tabular}{lcrrrrr}
\hline \hline Metal & Chama & $\begin{array}{r}\text { Comprimento } \\
\text { de onda }(n m)\end{array}$ & $\begin{array}{r}\text { Corrente da } \\
\text { lâmpada }(m A)\end{array}$ & $\begin{array}{r}\text { Fenda } \\
(n m)\end{array}$ & $\begin{array}{c}\text { Taxa de ar } \\
(L / m i n)\end{array}$ & $\begin{array}{c}\text { Taxa de gás } \\
(L / m i n)\end{array}$ \\
\hline Zinco & Ar/Acetileno & 213,9 & 5,0 & 1,0 & 3,5 & 1,5 \\
Ferro & Ar/Acetileno & 248,3 & 5,0 & 0,2 & 3,5 & 1,5 \\
Cobre & Ar/Acetileno & 324,8 & 4,0 & 0,5 & 3,5 & 1,5 \\
Manganês & Ar/Acetileno & 279,5 & 5,0 & 0,2 & 3,5 & 1,5 \\
\hline \hline
\end{tabular}

\subsection{Simulação Numérica com o Programa Groundwater Vistas}

A fase de simulação numérica com o programa "Groundwater Vistas" foi desenvolvida na Agência de Proteção Ambiental dos Estados Unidos (USEPA), na Sede da Cidade Athens, no Estado da Georgia, sob a coordenação do pesquisador James W. Weaver. O doutor Weaver foi o anfitrião do doutorando Giovanni Chaves Penner no período de 11 de agosto a 8 de novembro de 2004, tendo sido seu nome sugerido pelo Dr. Jack Hwang, inicialmente contatado para este projeto. A licença para o uso do programa "Groundwater Vistas", na versão 4 (mais recente), foi adquirida pela USEPA por sugestão do pesquisador Weaver para a realização destas simulações. Ressalte-se ainda que a USEPA cedeu ao doutorando Giovanni Chaves Penner espaço físico (sala com telefone, armários, etc.) e computador compatível às necessidades do programa. Também foram disponibilizados outros programas como: editor de texto, planilha eletrônica, navegador de Internet, etc. e biblioteca.

\subsubsection{Definição dos Objetivos da Simulação}

O primeiro ponto a ser considerado na aplicação de um modelo de transporte de contaminantes é: qual o propósito da modelagem? Em geral, a resposta pode ser enquadrada em uma das seguintes categorias: 1) em uma abordagem científica, o objetivo é compreender o regime de transporte mais 
detalhadamente, testar hipóteses, assegurar a consistência das observações e princípios governantes e quantificar os processos de controle dominantes; 2) nos casos vinculados à atribuição de responsabilidades e avaliação da exposição, muitas vezes faz-se necessária a reconstrução histórica do deslocamento da contaminação, estabelecendo-se o intervalo de tempo em que o evento se iniciou, ou quais contaminantes apresentam níveis superiores aos aceitáveis em uma receptor de referência; ou 3) determinar a distribuição e propagação futura de um contaminante de interesse, nas condições atuais ou com a aplicação de um sistema de remediação (ZHENG e BENNETT, 1995).

Assim, os objetivos definidos nesta modelagem foram:

- Desenvolver uma primeira aproximação para o modelo de escoamento e transporte na área em estudo e entorno;

- Tentar uma aproximação do avanço da concentração de chumbo sem qualquer sistema de intervenção.

\subsubsection{Coleta de Dados e Desenvolvimento do Modelo Conceitual}

Como primeiro estágio em qualquer tentativa de simular o escoamento e o transporte de contaminantes em campo parte-se para a revisão e compilação de todas as informações em escalas local e regional. Estas informações são integradas em um modelo conceitual, em geral partindo-se de suposições, simplificações e interpretações qualitativas dos processos vinculados ao escoamento e transporte no sítio em questão (ZHENG e BENNETT, 1995).

As informações angariadas na etapa de coleta de dados foram organizadas em concordância com as formas de inserção requeridas pelo programa Groundwater Vistas. Desta forma foi elaborado um arquivo em AutoCAD com a extensão ".dxf" contendo informações sobre:

- Topografia de todo o domínio utilizado (ver Apêndice D);

- Localização dos elementos de referência, compreendendo as condições de contorno (contornos físicos: rios, ribeirões e córregos);

- Localização das cavas de descarte de resíduos; 
- Localização dos poços de monitoramento construídos no decorrer desta pesquisa e poços de bombeamento cadastrados.

A área total, inserida como domínio da modelagem é de 128.040.000 $\mathrm{m}^{2}$, formada por um retângulo de $9.700 \mathrm{~m}$, na direção oeste-leste e $13.200 \mathrm{~m}$, na direção sul-norte. As coordenadas UTM do ponto de interseção entre os limites sul e oeste são 199.448,3043 e 7.655.385,1063, respectivamente. Esta área foi definida segundo a hidrografia local. Os contornos físicos são: a norte, o Rio Pardo, a leste, o Ribeirão Preto, ao sul, o Córrego Laureano e a oeste, o Córrego do Jatobi. Foram inseridos ainda, como condições de contorno, o Córrego da Macaúba e Córrego dos Campos. A hidrografia usada como condição de contorno para o modelo de escoamento é considerada com condição de primeiro tipo ou de Dirichlet (nível constante).

\subsubsection{Escolha do Programa de Escoamento e Transporte}

Os modelos numérico-computacionais utilizados nesta pesquisa foram selecionados dentre os disponíveis com aplicação para simulação do transporte do contaminante chumbo em água subterrânea. O chumbo foi escolhido com referência por ser a única substância a apresentar, no momento da simulação numérica, concentração acima do limite de potabilidade.

Mediante discussão com o pesquisador James W. Weaver da USEPA, optou-se pela utilização do programa "Groundwater Vistas" e dentro deste, utilizou-se os módulos MODFLOW2000win32 (ou simplesmente MODFLOW2000) para o escoamento de água subterrânea e MT3DMSwin32 (ou versão 4.5 do MT3D) para o transporte de chumbo.

O programa MODFLOW2000win32 possibilita a resolução das equações de escoamento de água subterrânea em zona saturada pelo método das diferenças finitas e fornece como saída a distribuição das cargas hidráulicas e velocidades. O modelo MODFLOW foi desenvolvido pelo "United States Geological Survey", sendo bem conhecido pelos profissionais da área é muito bem aceito, consagrado e utilizado. 
O módulo MT3DMSwin32 possibilita a solução dos processos de transporte de contaminantes em zona saturada (advecção, dispersão, adsorção e decaimento), mediante a leitura prévia dos resultados de distribuição das cargas hidráulicas e velocidades fornecidas pelo MODFLOW. O modelo MT3D foi desenvolvido por Chunmiao Zheng na University of Alabama.

\subsubsection{Construção do Modelo de Escoamento}

A malha de discretização inicial, que representa o modelo conceitual do aqüífero, foi gerada com 264 linhas e 194 colunas, com espaçamentos iguais de $50 \mathrm{~m}$ nas duas direções. Adicionalmente, a malha foi refinada nas imediações do sítio em estudo e nas regiões próximas aos poços de bombeamento cadastrados (Destilaria Galo Bravo e estação de tratamento de esgoto). Tal refinamento foi realizado pela divisão sucessiva das células na região da área de estudo em quadrados de lado 6,25 $\mathrm{m}$ e nas imediações dos poços de bombeamento em quadrados de $12,5 \mathrm{~m}$. Ao final do refinamento, a malha possuía 367 linhas e 321 colunas. Vale acrescentar que se seguiu as recomendações sugeridas por Anderson e Woessner (1992), Zheng e Bennett (1995), Rumbaugu e Rumbaugu (2004) e Weaver (2004) quanto à não divisão de uma célula ser maior do que a metade da célula vizinha devido à ocorrência de problema numérico.

Com base em sondagens (Destilaria Galo Bravo, área de estudo e estação de tratamento de esgoto), perfis de poços de monitoramento (destilaria Galo Bravo, área de estudo) e perfis de poços profundos (destilaria Galo Bravo, DAERP - Jardim Piratininga, Santa Tereza, Jardim Pompolo e CDHU e estação de tratamento de esgoto), foi elaborada uma seção geológica oesteleste (ver Apêndice E) na área do modelo conceitual do aqüífero. Após várias tentativas de se representar as condições geológicas, obteve-se os melhores resultados para uma seção composta por 7 camadas (ver Figura 4.13). A camada 1 representa a cobertura superficial do solo sendo, delimitada pelos contornos físicos, variando entre as elevações $480 \mathrm{~m}$ e $640 \mathrm{~m}$. As camadas 2 , 3 e 4 representam os vários níveis de basalto da formação Serra Geral. 
Adicionalmente, essas camadas, nas extremidades leste das mesmas, representam o contato direto do aqüífero profundo com solo superficial, variando entre as elevações $460 \mathrm{~m}$ e $480 \mathrm{~m}, 440 \mathrm{~m}$ e $460 \mathrm{~m}$ e $400 \mathrm{~m}$ e $440 \mathrm{~m}$, respectivamente. As camadas 5 e 6 representam o aqüífero profundo, variando entre as elevações $320 \mathrm{~m}$ e $400 \mathrm{~m}$ e $240 \mathrm{~m}$ e $320 \mathrm{~m}$, respectivamente. Finalmente, a camada 7 , base do modelo, representa o diabásio, variando entre as elevações $160 \mathrm{~m}$ e $240 \mathrm{~m}$.

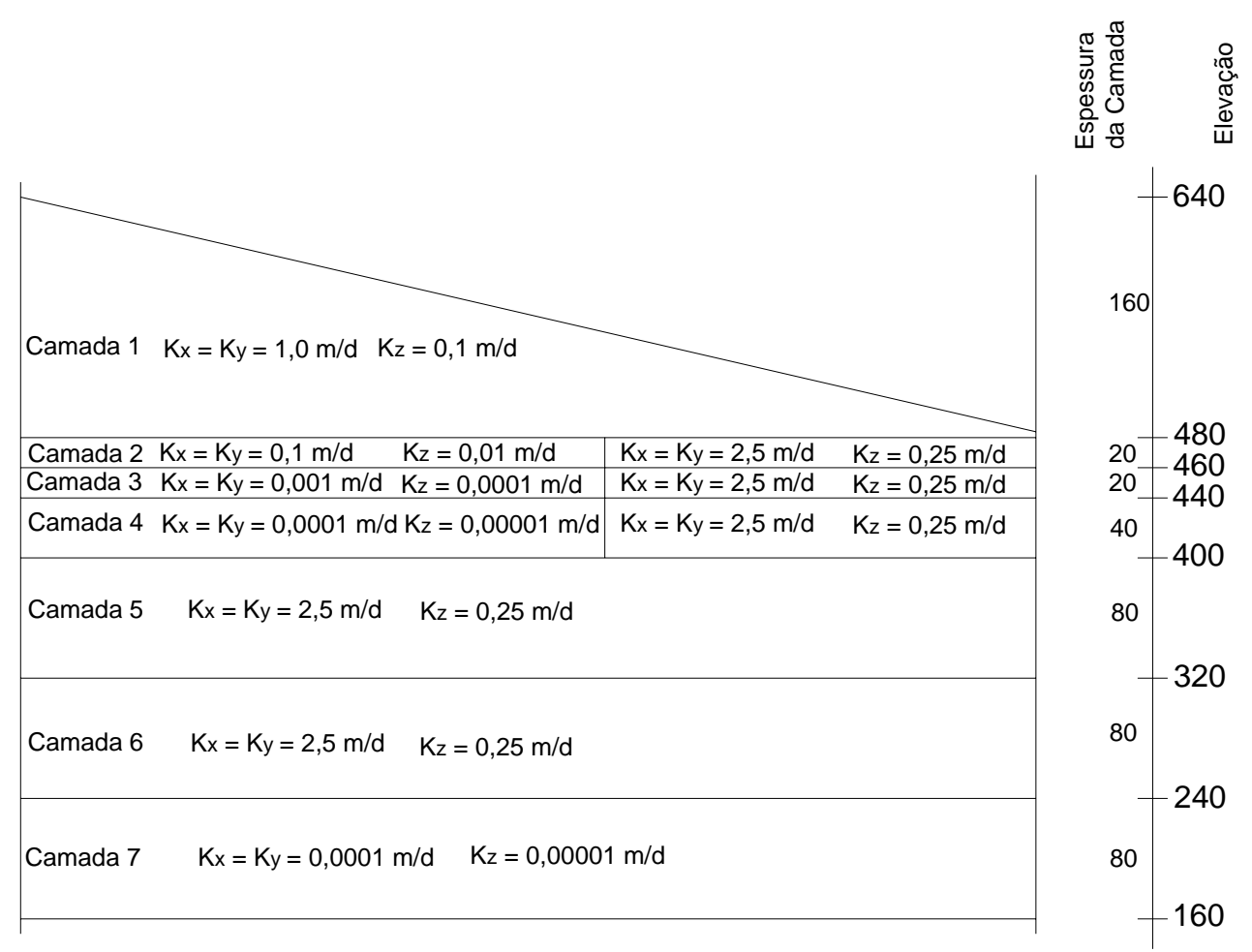

Figura 4.13 - Representação esquemática da distribuição das camadas no modelo numérico.

As cotas dos níveis de água dos córregos, rio e ribeirão foram obtidas do mapa topográfico considerando-se que os mesmos nunca secam.

A recarga foi estimada pela diferença entre precipitação média anual (1937 - 2004) 1.482,4 mm/ano e 40 \% do valor da evapotranspiração média anual (1992 - 2004) 1.165,2 mm/ano (WEAVER, 2004).

Foram inseridos 3 poços de bombeamento: o poço tubular do terreno do vizinho Welton Tadeu de Bortoli, na camada 2, com vazão de $10 \mathrm{~m}^{3} / \mathrm{d}$, o poço de bombeamento da Destilaria Galo Bravo, na camada 6, com vazão de 1.440 $m^{3} / d$ e o poço da estação de tratamento de esgoto, na camada 6 , com vazão de $4.272 \mathrm{~m}^{3} / \mathrm{d}$. A profundidade e vazão para o primeiro poço de bombeamento 
foram estipuladas de informações verbais dos moradores. Já a profundidade, nível dinâmico e vazão dos dois últimos poços de bombeamento foram adotadas do levantamento feito na Secretaria de Planejamento e Gestão Ambiental da Prefeitura Municipal de Ribeirão Preto com o Geólogo Maurício de Melo Figueiredo Junior.

Os valores adotados para (porosidade efetiva) $\eta_{\mathrm{e}}=0,20$ e drenança $=$ 0,01, foram assumidos em função das informações contidas no "Relatório Ambiental Preliminar para o Distrito Industrial de Ribeirão Preto" e da referência Chang e Silva (2004), sendo também avalizadas pelo pesquisador James Weaver.

Por não se dispor de uma grande quantidade de dados de poços e conseqüentemente medidas de nível de água ao longo do tempo, o modelo de escoamento foi executado somente em regime permanente.

\subsubsection{Construção do Modelo de Transporte}

Para o modelo de transporte foi utilizada a espécie química chumbo como referência. As condições de contorno do modelo de transporte foram geradas pela recarga do aqüífero na região das cavas de resíduo com a concentração constante de $25 \mu \mathrm{g} / \mathrm{L}$. Este valor foi adotado por ter sido obtida concentração de chumbo próxima a esta nos PMs 5 e 8. A discretização temporal da simulação foi de 10 anos a contar do preenchimento das cavas (está-se considerando uma condição inicial igual em todas as cavas, o que foge da condição que foi vivenciada nesse sítio, mas permite obter uma avaliação adequada das direções para as quais a pluma se movimenta). 0 tempo de dez anos representa a ordem de grandeza desde o término de deposição de material nas cavas (1995) até a presente época (2005). Os mecanismos de transporte considerados foram: advecção, sorção linear, dispersão e difusão.

Finalmente, os valores de (dispersividade longitudinal) $\alpha_{L}=20 \mathrm{~m}$, (dispersividade transversal) $\alpha_{T}=2 \mathrm{~m}$ e (dispersividade vertical) $\alpha_{V}=0,2 \mathrm{~m}$ 
foram adotados em função da referência Galhear et al. (1992), e o (coeficiente de distribuição para o chumbo) $K_{d}=900 \mathrm{~L} / \mathrm{kg}$ foi obtido das referências USEPA (1999a e b). Na Figura 4.14 resume-se as condições de trabalho consideradas para o transporte de contaminantes. Não se atribuiu nenhum valor de $f_{\text {oc }}$, pois não foram encontrados níveis consideráveis de carbono orgânico total dentre as amostras de solo analisadas para o arenito.

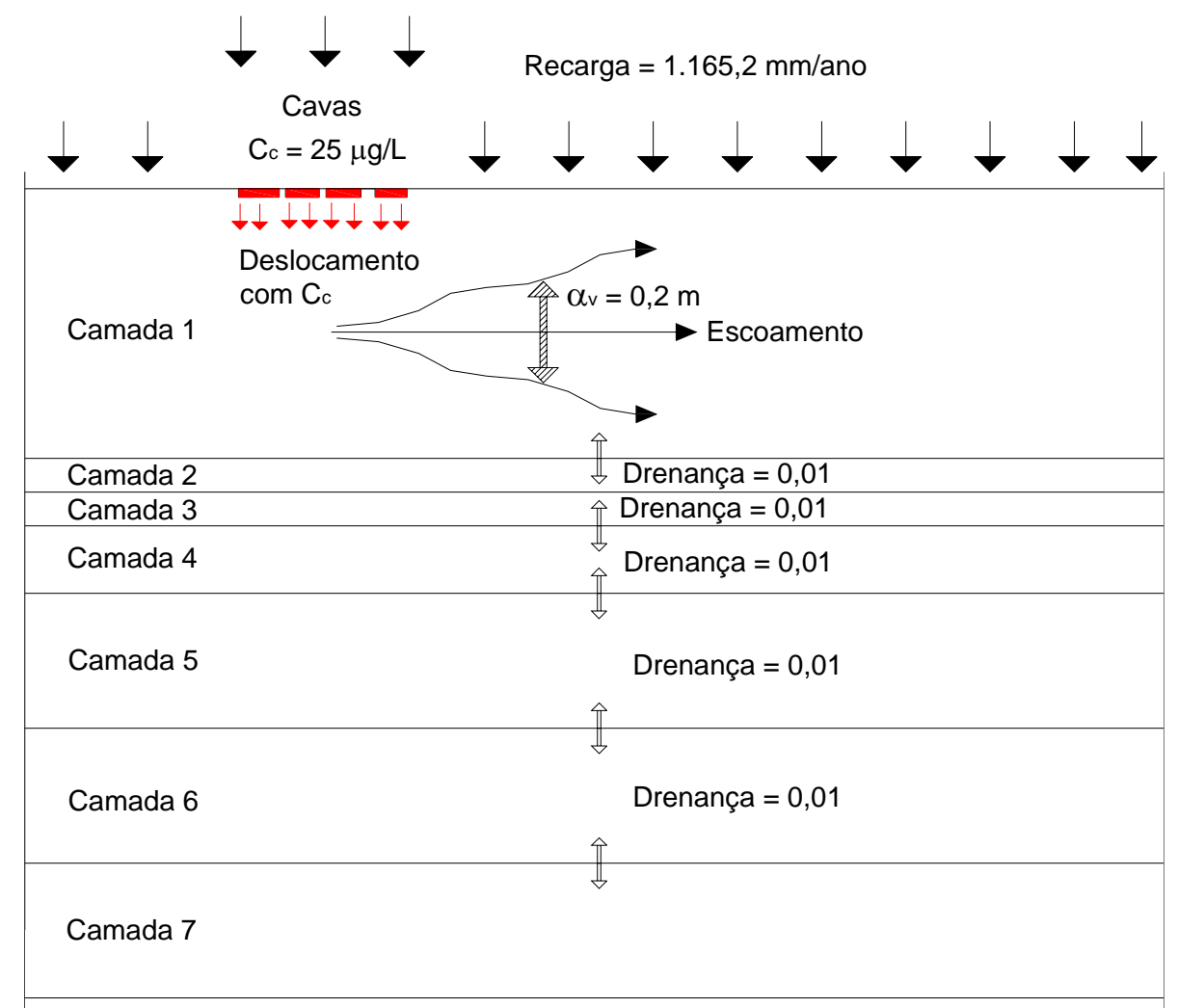

Figura 4.14 - Esquematização das condições impostas as modelo de transporte. Nota-se a ação da dispersividade vertical $\left(\alpha_{v}\right)$ na mistura vertical, da condição de recarga com $C_{c}=25 \mu g / L$ (área das cavas) e o efeito de transporte entre as diferentes camadas pela drenança.

\subsubsection{Calibração por Pontos de Referência (Targets)}

A calibração por um ponto de referência utiliza no modelo um ponto onde uma variável dependente foi medida no espaço e no tempo (neste caso nível de água). Esse método fornece uma maneira de avaliar a qualidade da calibração, pois é computado o erro residual para cada ponto de referência. Este residual é a diferença entre a medida de campo e o valor computado pelo 
modelo. O intervalo de variação do erro auxilia na decisão se a qualidade da calibração é adequada para um dado propósito. O programa GV possui várias maneiras de apresentação à estatística destes pontos de referência.

Os pontos de referência na calibração podem ser medidas de nível de água, concentração, rebaixamento ou escoamento de água subterrânea (muitas vezes denominado de fluxo). Os pontos de referência podem estar em regime permanente ou ser associado a variações de tempo (conhecidos pontos de referência transiente). Nesse caso, uma das limitações do GV é que pontos de referência de escoamento de água subterrânea devem estar em estado permanente. Os outros referenciais para calibração: nível de água, rebaixamento e concentração, podem estar em regime permanente ou transiente.

Foram inseridos 6 poços de observação (targets), sendo eles: PM - 01, PM - 05, PM - 08 e poço de grande diâmetro do terreno vizinho, todos estes na camada 1, o poço de bombeamento da Destilaria Galo Bravo na camada 3 e o poço da estação de tratamento de esgoto na camada 6.

\subsubsection{Análise de Sensibilidade}

A análise de sensibilidade é o processo de identificação dos parâmetros do modelo que mais atuam efetivamente na calibração do modelo ou nas previsões do modelo. A análise de sensibilidade avalia os efeitos de uma mudança nos parâmetros do modelo ou nas condições de contorno, nas estatísticas de calibração. O programa GV possui dois métodos de análise de sensibilidade, quais sejam, sensibilidade simples e análise de sensibilidade automática. Entretanto, apenas nas simulações de escoamento no MODFLOW podem ser usados os dois tipos de análise de sensibilidade. No presente trabalho foram usadas análises de sensibilidade automáticas no MODFLOW2000win32.

Neste contexto foram realizadas duas análises de sensibilidade automática. A primeira teve como objetivo avaliar o efeito de variações nos valores das condutividades hidráulicas inseridas no modelo inicial. Para tanto 
se testou a hipótese de variação dos valores inicialmente introduzidos multiplicando-os por coeficientes que variaram de 0,5 até 1,5, com incrementos de 0,1 em 0,1. A segunda teve como objetivo avaliar o efeito de variações nos valores de armazenabilidade, drenança e porosidade no modelo modificado pela primeira análise de sensibilidade. O procedimento de incremento nos valores seguiu o mesmo procedimento da primeira análise de sensibilidade. 


\section{Resultados e Discussão}

\subsection{Levantamento Geofísico}

O levantamento geofísico proposto inicialmente para este trabalho foi efetuado e largamente ampliado, uma vez que foi possível contar com o auxílio de pesquisadores de ampla experiência. A área levantada está indicada no mapa topográfico no Apêndice $A$, com as linhas de caminhamento nele apresentadas.

\subsubsection{Caminhamento Elétrico}

A seguir são apresentadas as seções (linhas de andamento) devidamente interpretadas. Considerando o atual estágio de conhecimento da área, refinamentos de interpretação podem ocorrer ao longo de trabalhos futuros. Na seqüência de figuras apresentadas neste subitem, em cada seção, a primeira figura representa a interpretação dos resultados de resistividade aparente com o programa SURFER $6.0^{\circledR}$, usando-se o método da krigagem universal. A segunda figura representa a interpretação dos resultados (neste caso resistividades reais) com o programa RES2DINV na versão 3.3 semidemo (específico para interpretar seções geofísicas), sendo os dados interpretados por inversão usando a técnica de otimização dos mínimosquadrados com suavização não-linear (LOKE, 1998). Esta etapa da pesquisa contou com o importante auxílio do Prof. Dr. Vagner Roberto Elis, do Instituto de Astronomia e Geofísica da Universidade de São Paulo.

Para cada imagem analisada com o programa RES2DINV, as interpretações geradas pelo programa apresentam uma escala de cores 
específica para aquela análise, não sendo possível efetuar uma comparação de cores para análises de diferentes linhas (seções). Para este tipo de análise torna-se, portanto, necessário usar diretamente os valores obtidos ou as suas ordens de grandeza. É importante ressaltar, também, que a escala horizontal e vertical das figuras de cada seção é diferente.

A análise das Figuras 5.1 e 5.2, seção 1, sugere que o topo da zona saturada esteja entre 12,5 e 20 metros. Entretanto como os valores apresentados na Figura 5.1 são de resistividade elétrica aparente e os da Figura 5.2 são de resistividade elétrica real (interpretados pelo modelo), acredita-se que os resultados apresentados na Figura 5.2 estão mais próximos da realidade local. Observa-se na Figura 5.2 uma variação brusca na resistividade elétrica para a profundidade $12,5 \mathrm{~m}$, formando uma superfície quase plana. Essa superfície apresenta-se delineada, nesta seção, pelos valores de resistividade elétrica inferiores a $200 \mathrm{ohm}$. Comparando com os níveis da água medidos nas imediações (poço vizinho, sondagens mecanizadas e poços de monitoramento), esta constatação mostrou estar suficientemente bem fundamentada.

Palas elevadas alterações de resistividade elétrica e pela proximidade entre esta seção de investigação e a primeira cava (aproximadamente 15 metros), acredita-se que a região que abrange esta seção foi alterada pela presença dos resíduos, principalmente quando se atinge a zona saturada, e, em menor dimensão, na zona não saturada.

\section{Linha 1}

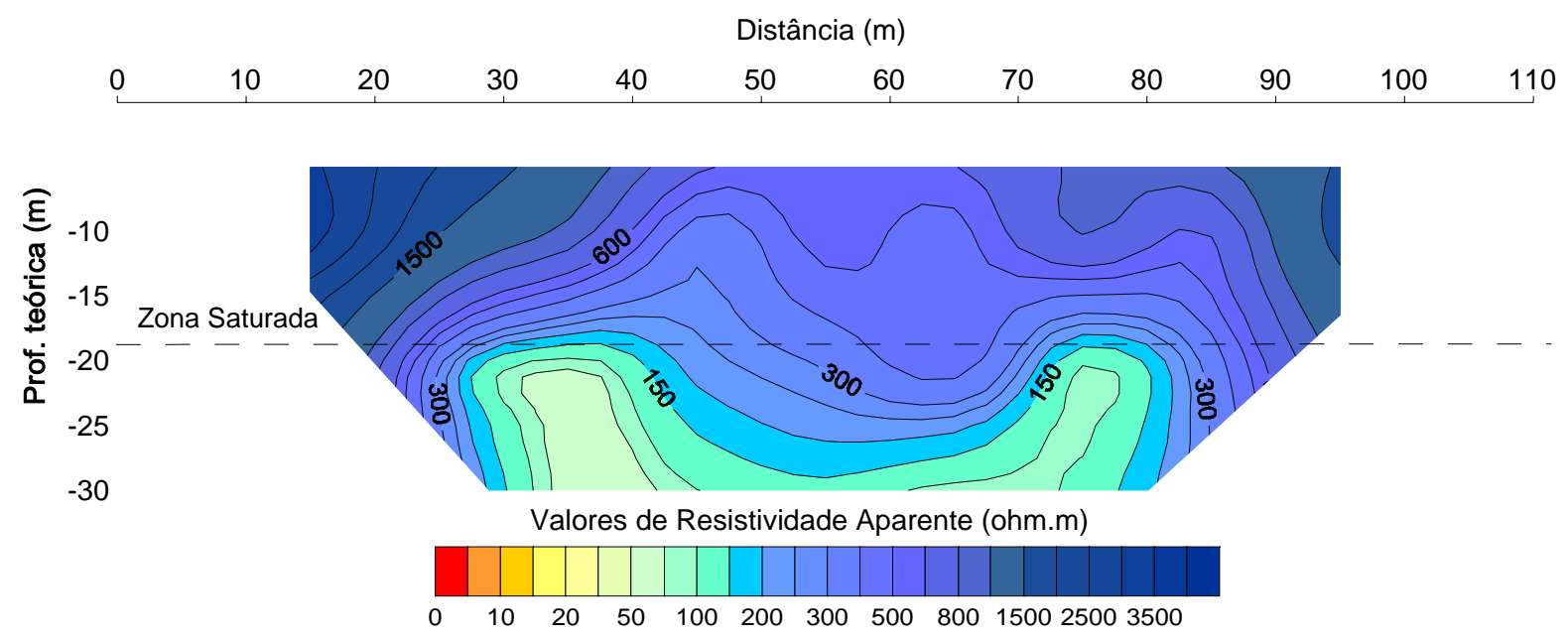

Figura 5.1 - Seção 1 interpretada com o programa SURFER 6.0. 


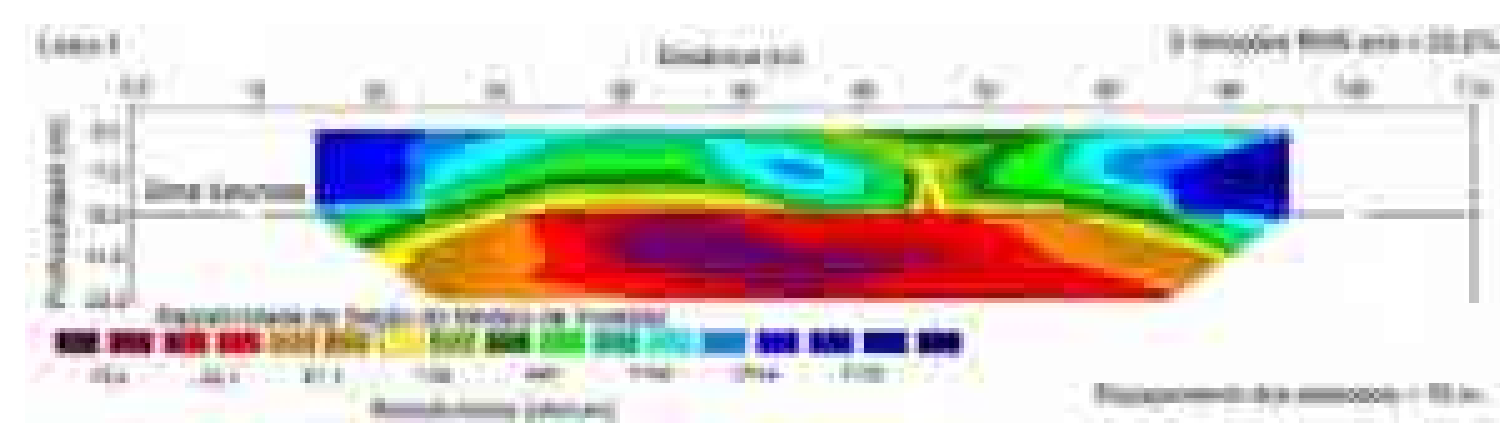

Figura 5.2 - Seção 1 interpretada com o programa RES2DINV.

$\mathrm{Na}$ análise das Figuras 5.3 e 5.4, seção 2, a interpretação evidencia a conclusão anterior acerca da zona saturada, com grande probabilidade de estar entre 12,5 e 20 metros (posteriormente esta conclusão foi corroborada pelos poços construídos no local).Percebe-se que a linha de investigação geofísica 2 seccionou a cava 1 , ainda que o resíduo bruto seja resistivo eletricamente, nas zonas de maior aeração (laterais da cava) e zona saturada, o meio passa a condutor. Entende-se que reações químicas e/ou atividade biológica presente nestas zonas provoquem esta redução na resistividade. Uma causa adicional pode ser a alteração das características naturais do solo provocada pelo movimento de terra quando da confecção das cavas.

Observa-se, principalmente, na Figura 5.4 que os limites inicialmente definidos para a cava 2, quais sejam, profundidade de $6,0 \mathrm{~m}$ e taludes laterais de 1:2 não são observados. Acredita-se que houve movimentação (acomodação), lixiviação e compactação do resíduo ao longo dos anos.

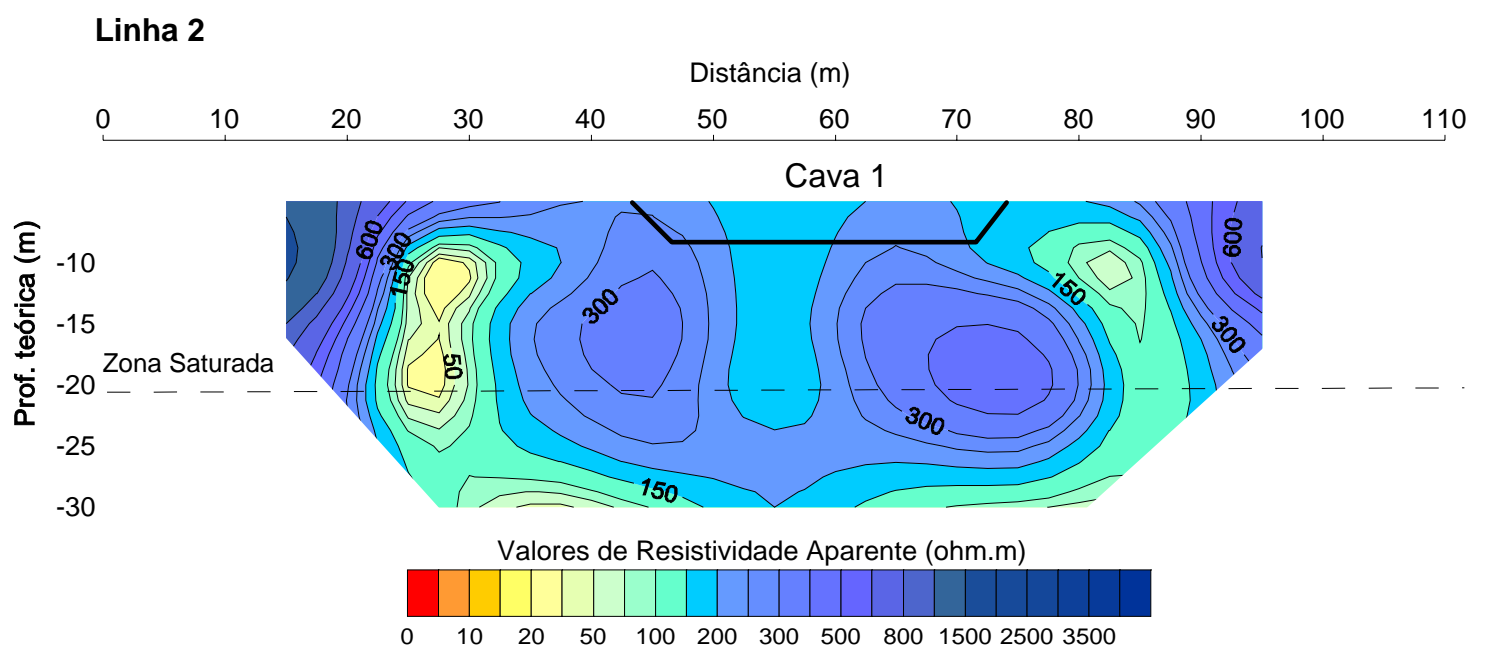

Figura 5.3 - Seção 2 interpretada com o programa SURFER 6.0. 


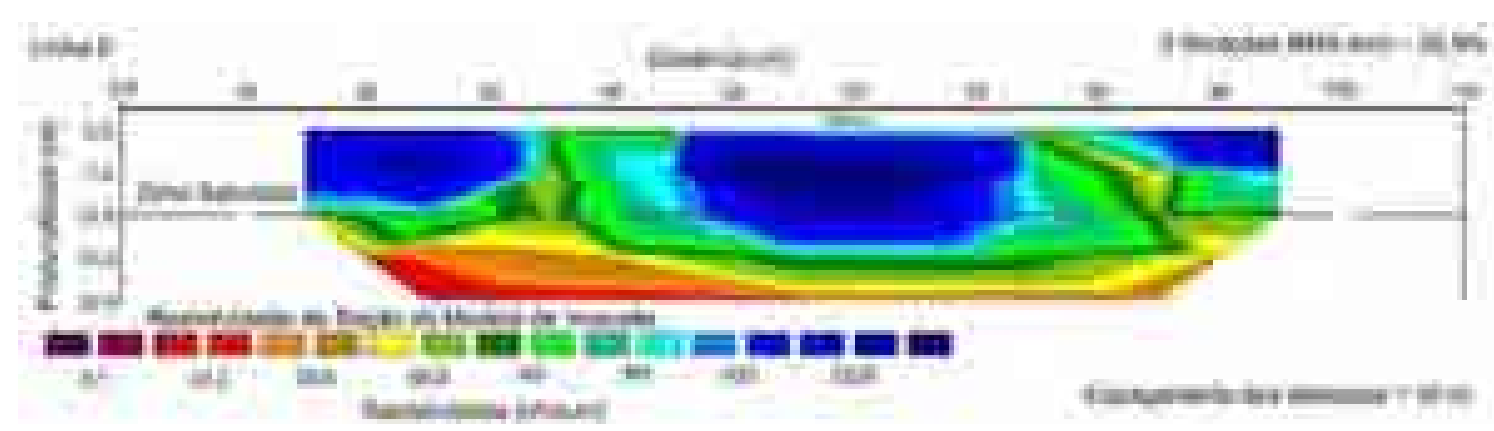

Figura 5.4 - Seção 2 interpretada com o programa RES2DINV.

Pela análise das Figuras 5.5 e 5.6, seção 3, reafirma-se a concordância com relação ao topo da zona saturada estar entre 12,5 e 20 metros. Sendo mais evidente a apreciação de uma superfície quase plana denominada de zona saturada na Figura 5.6. Como a seção 3 está situada entre as cavas 1 e 2, pelas variações na resistividade elétrica do solo nota-se que esta seção, provavelmente, sofreu influência do resíduo das cavas. Tal alteração pode ser observada entre as distâncias de 40 e 80 metros aproximadamente. Na Figura 5.6 observa-se um meio mais resistivo eletricamente nas extremidades (solo natural) e, pontualmente no centro, uma região supostamente atingida pelo resíduo bruto.

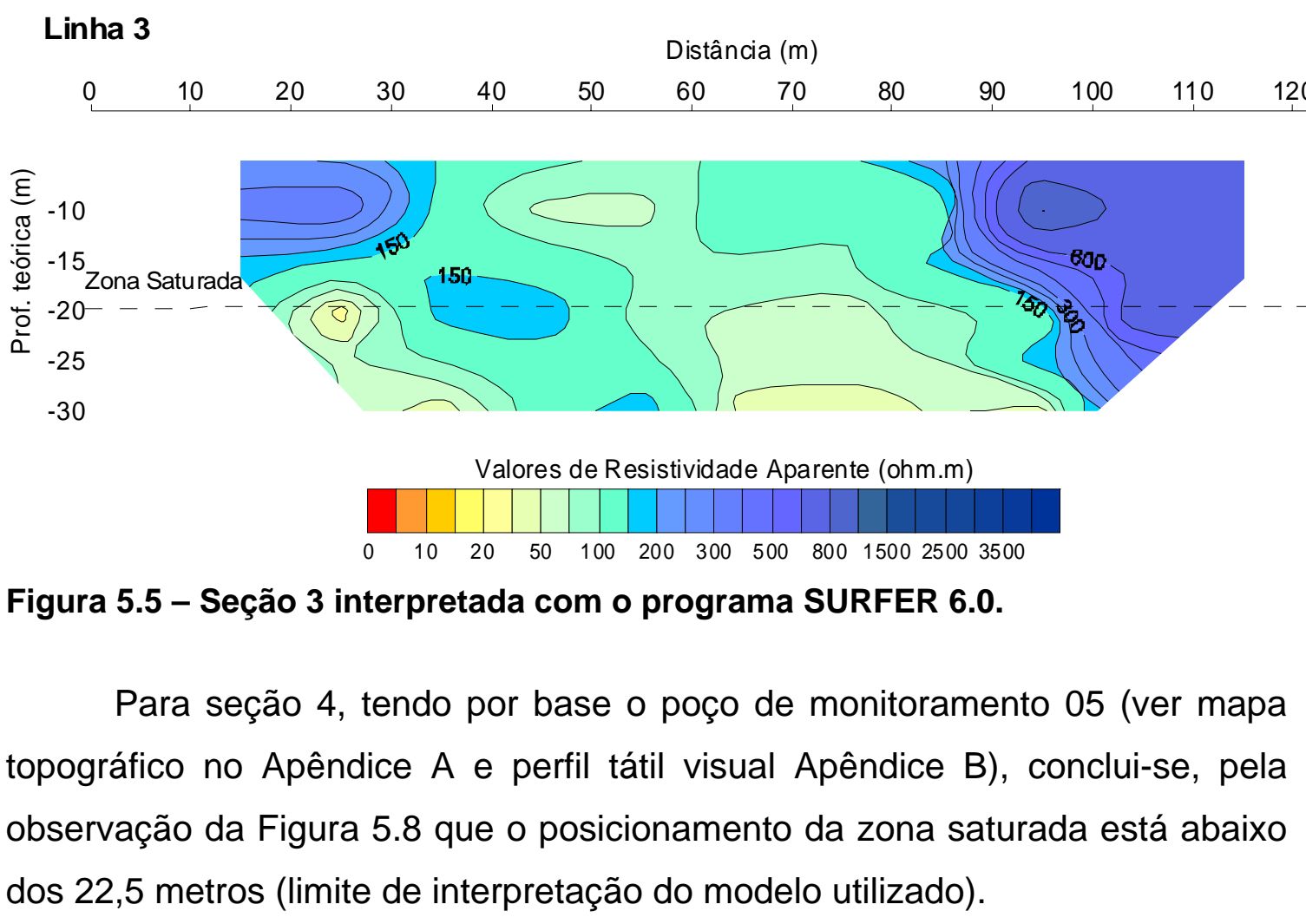




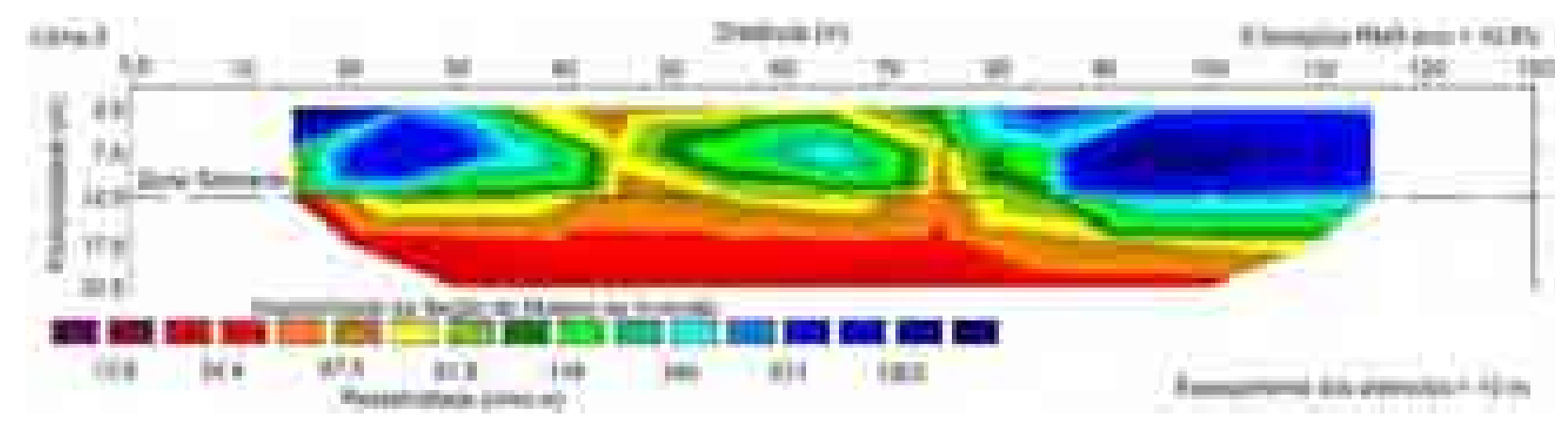

Figura 5.6 - Seção 3 interpretada com o programa RES2DINV.

Pelas Figuras 5.7 e 5.8 pode-se inferir que houve movimento de líquidos percolados das cavas descendente e lateral (do centro para esquerda) no sentido da região mais condutora eletricamente (há uma descentralização da "mancha" observada nas figuras). Mais uma vez a afirmação anterior encontra base nas sondagens realizadas e poços de monitoramento. Frisa-se que nas proximidades deste caminhamento observou-se em sondagens e poços na profundidade aproximada de $12 \mathrm{~m}$, solo residual de arenito. Pelo fato de o arenito seco apresentar resistividade elevada (ordem de grandeza de 1.000 ohmm ou superior), conclui-se que a elevação da condutividade elétrica do solo deve-se à presença ou passagem dos líquidos percolados em questão (água percolada ou líquido "exsudado" do material das cavas). Por esta primeira interpretação, entendeu-se que esta seção de investigação está sendo fortemente influenciada principalmente pelos líquidos percolados da cava 2, pois há um desnível da ordem de 2 a 3 metros entre as cavas 2 e 3.

\section{Linha 4}

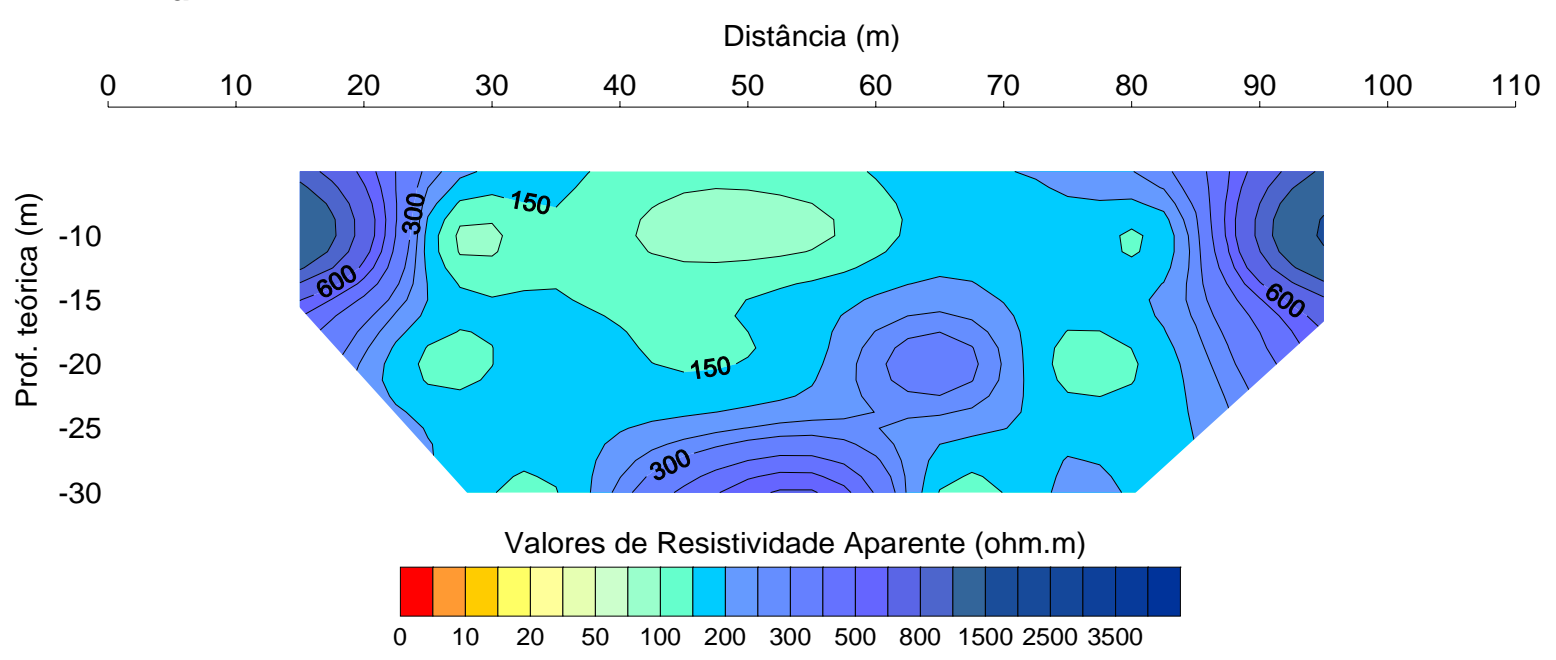

Figura 5.7 - Seção 4 interpretada com o programa SURFER 6.0. 


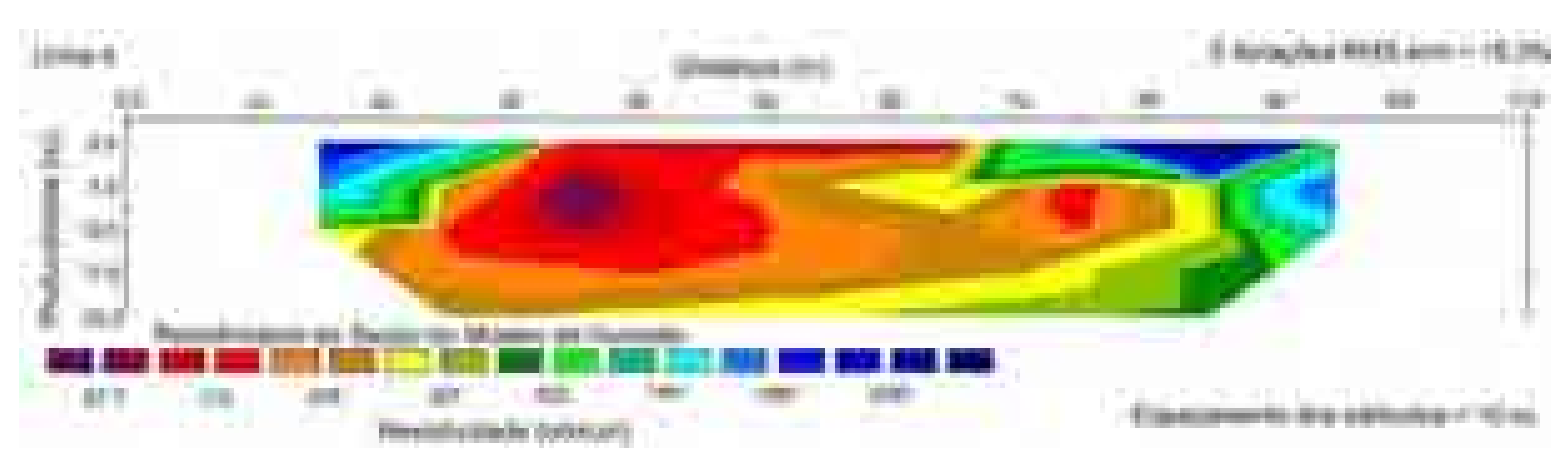

Figura 5.8 - Seção 4 interpretada com o programa RES2DINV.

Como para a seção 4, para a linha 5 não se pode mais definir a localização da zona saturada, principalmente quando se compara as Figuras 5.9 e 5.10 com os perfis das sondagens e poços (vide Apêndice B). A conclusão dos poços de monitoramento é clara em mostrar que não há água presente à profundidades superiores a 20,0 $\mathrm{m}$ (nem zona saturada, nem franja capilar). Entretanto, pode-se concluir que a superfície quase plana que atravessa a Figura 5.10 na profundidade próxima a 12,5 $\mathrm{m}$ é o contato entre o solo coluvionar superficial e o solo residual de arenito. Esta conclusão é baseada, principalmente, nos perfis do furo da sondagem 04 e dos poços de monitoramento 06 e 07.

Linha 5

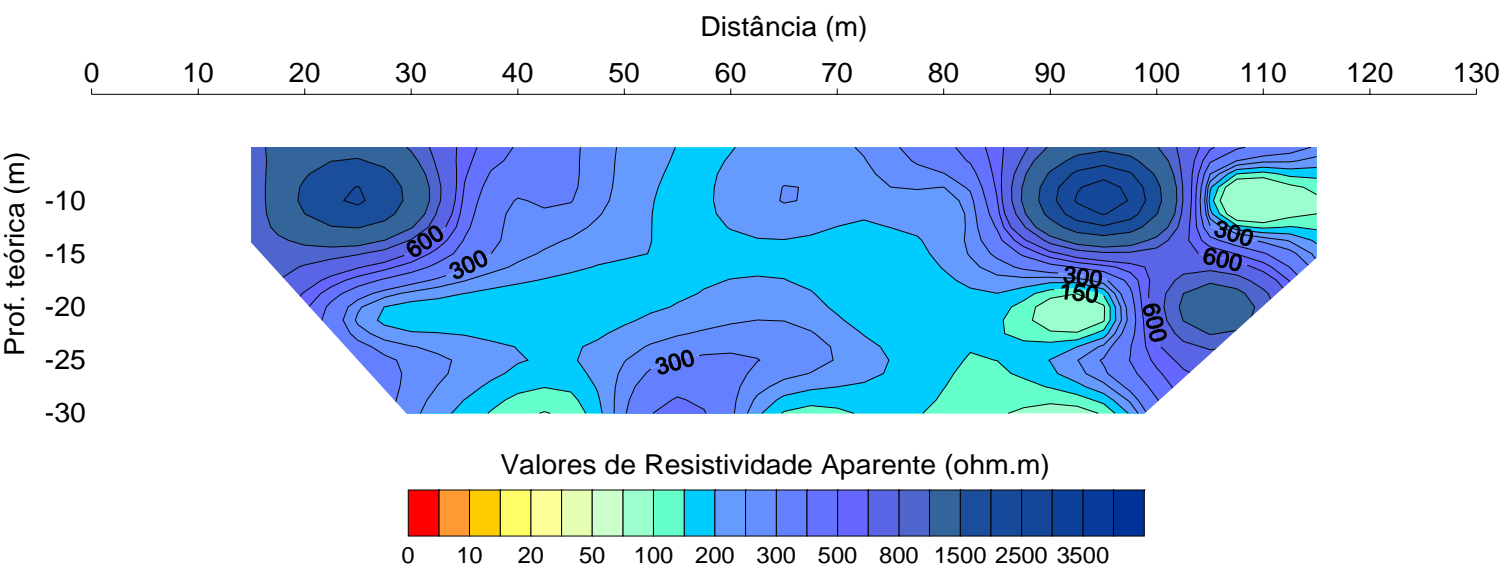

Figura 5.9 - Seção 5 interpretada com o programa SURFER 6.0.

Como na seção anterior, infere-se que esteja havendo movimento descente e lateral (do centro para esquerda) no sentido da região mais condutora eletricamente. A região altamente resistiva, delineada no canto 
direito inferior pelos valores de resistividade elétrica superiores a $2.000 \mathrm{ohmm}$ na Figura 5.10, sugere a presença de arenito seco.

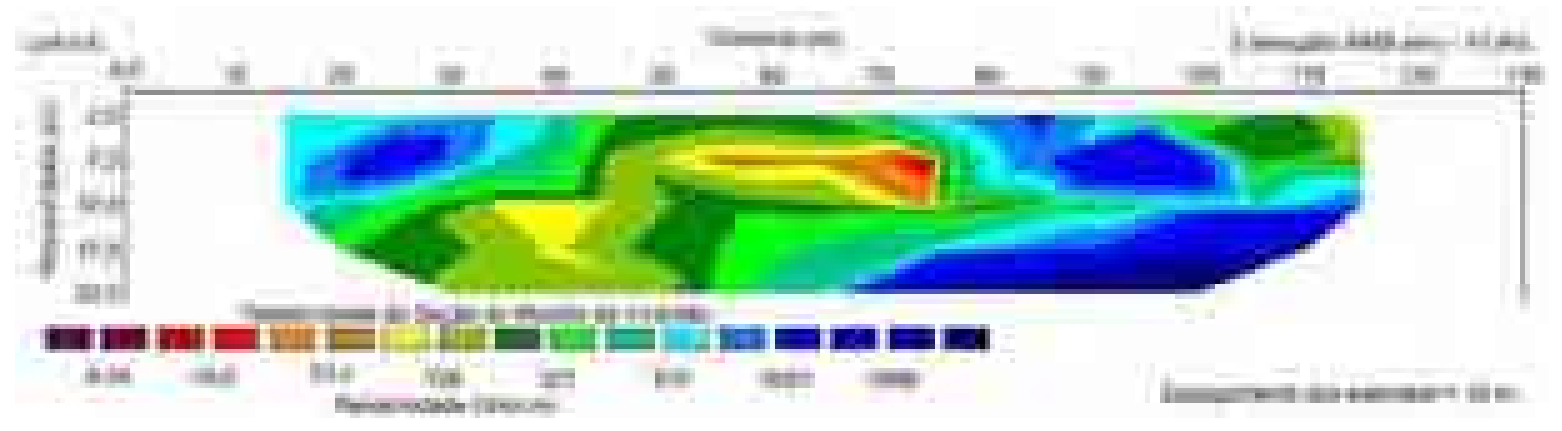

Figura 5.10 - Seção 5 interpretada com o programa RES2DINV.

A seção de investigação 6 atravessou a cava 4 (mais recente cronologicamente). Houve problemas de leitura (polarização), principalmente na região entre 80 e 110 metros das Figuras 5.11 e 5.12. Crê-se que as dificuldades nas medidas de resistividade foram provocadas pelo fato de 0 resíduo estar mais plástico e liberando líquido ácido $(\mathrm{pH} \cong 0,1)$. Como nas seções 4 e 5, não se identificou a presença da zona saturada. Pelas Figuras 5.11 e 5.12, infere-se estar havendo movimento descendente de líquidos percolados (deslocamento vertical da mancha). Como na seção 5, no canto direito das Figuras 5.11 e 5.12 há uma região mais resistiva eletricamente, sugerindo que haja a presença de arenito seco.

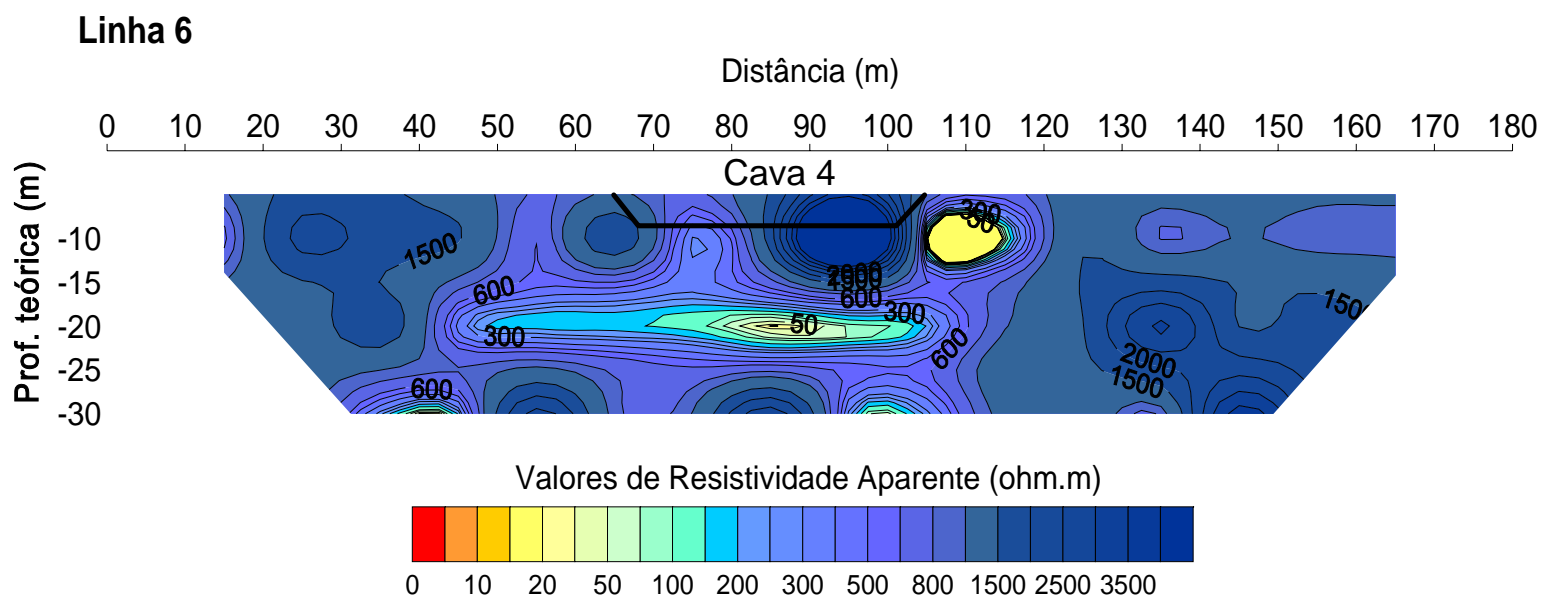

Figura 5.11 - Seção 6 interpretada com o programa SURFER 6.0. 


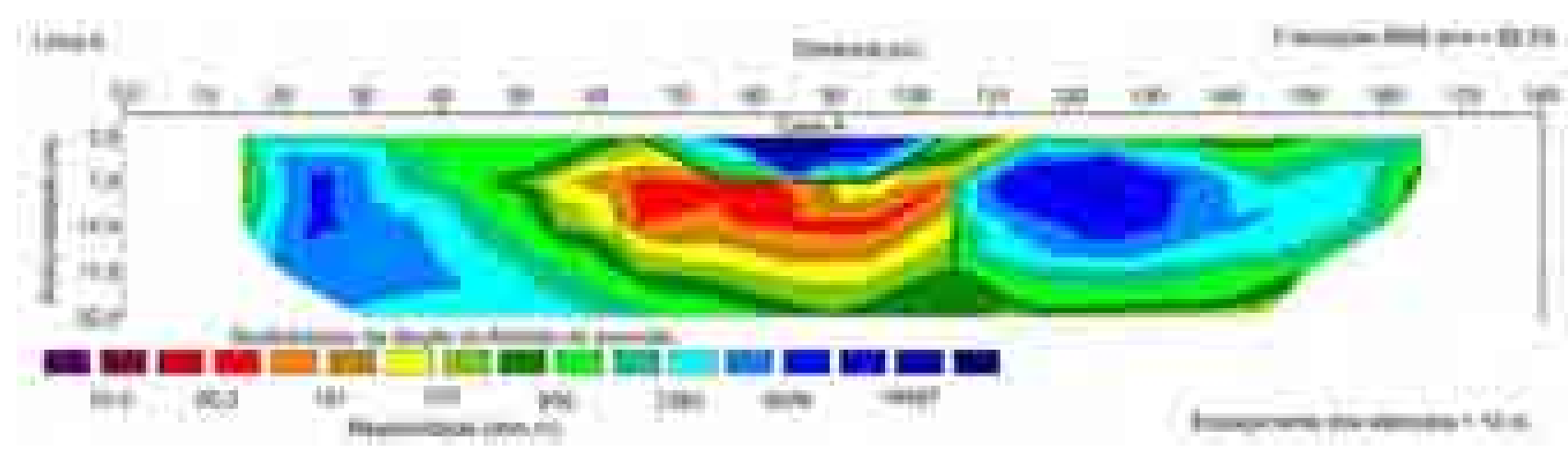

Figura 5.12 - Seção 6 interpretada com o programa RES2DINV.

Não se identificou a presença de zona saturada nas seções interpretadas para a linha de investigação geofísica 7. Pela análise das Figuras 5.13 e 5.14 acredita-se que possa haver influência, principalmente, do resíduo depositado na cava 4, nas distâncias 70 a 120 metros, devido as alterações na resistividade elétrica do solo. Vale acrescentar que a cava 4 está a aproximadamente 20 metros da seção 7. Infere-se que ainda esteja havendo movimento descendente e em menor escala lateral, principalmente pela observação da Figura 5.14. A região de elevada resistiva elétrica no canto direito das Figuras 5.13 e 5.14 sugere a presença de arenito seco.

\section{Linha 7}

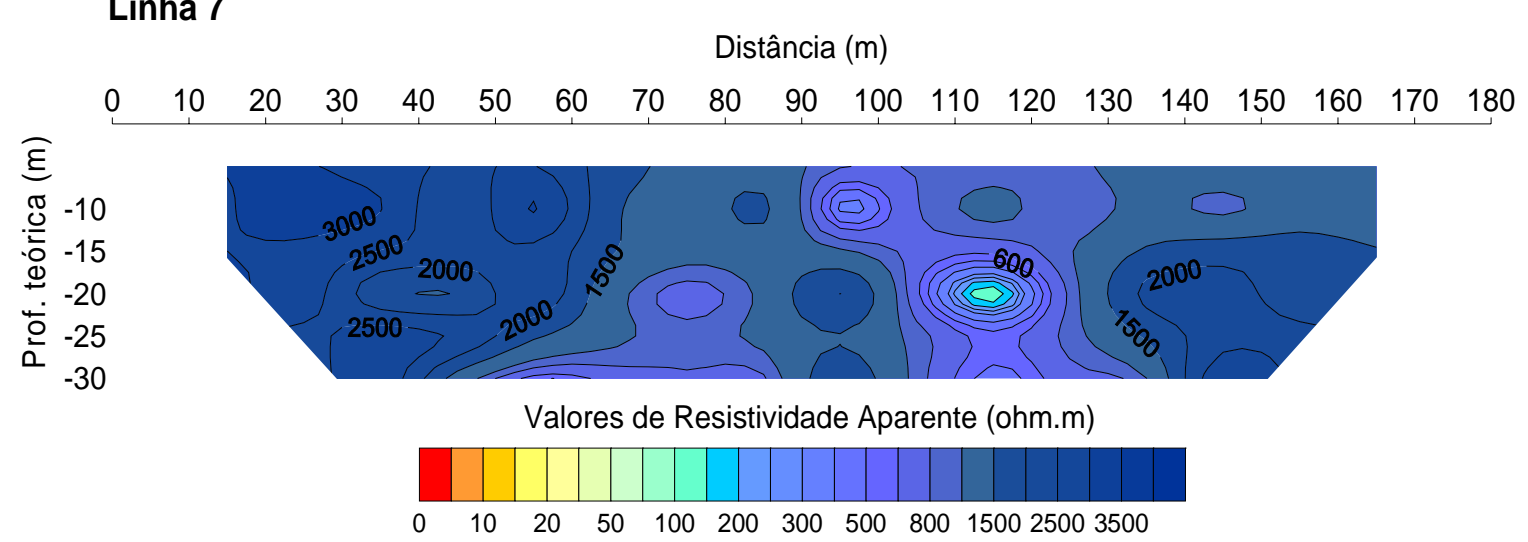

Figura 5.13 - Seção 7 interpretada com o programa SURFER 6.0.

Nas Figuras 5.15 e 5.16, seção 8, não foi observada alteração na resistividade elétrica do solo que possa está relacionada com os resíduos descartados neste sítio. Sugere-se que a região de resistividade elétrica elevada à direita das Figuras 5.15 e 5.16 advenha da presença de arenito seco. A elevada resistividade elétrica nas demais regiões das Figuras 5.15 e 5.16 muito provavelmente é provocada pela presença de solo natural não alterado. 
A diferença entre o solo natural e o arenito seco evidencia-se ao longo da profundidade.

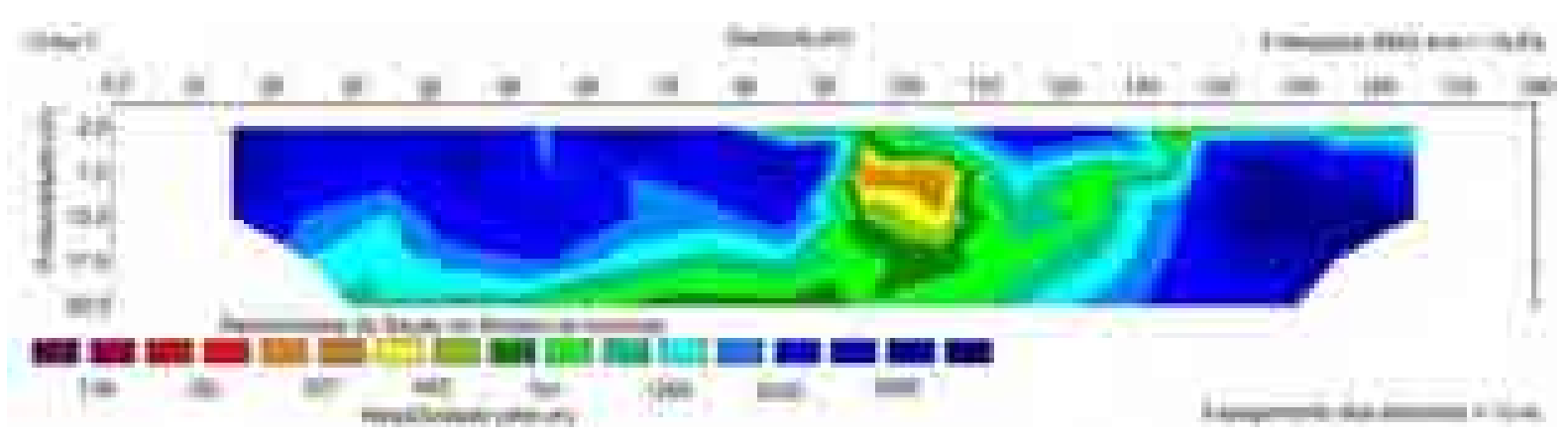

Figura 5.14 - Seção 7 interpretada com o programa RES2DINV.

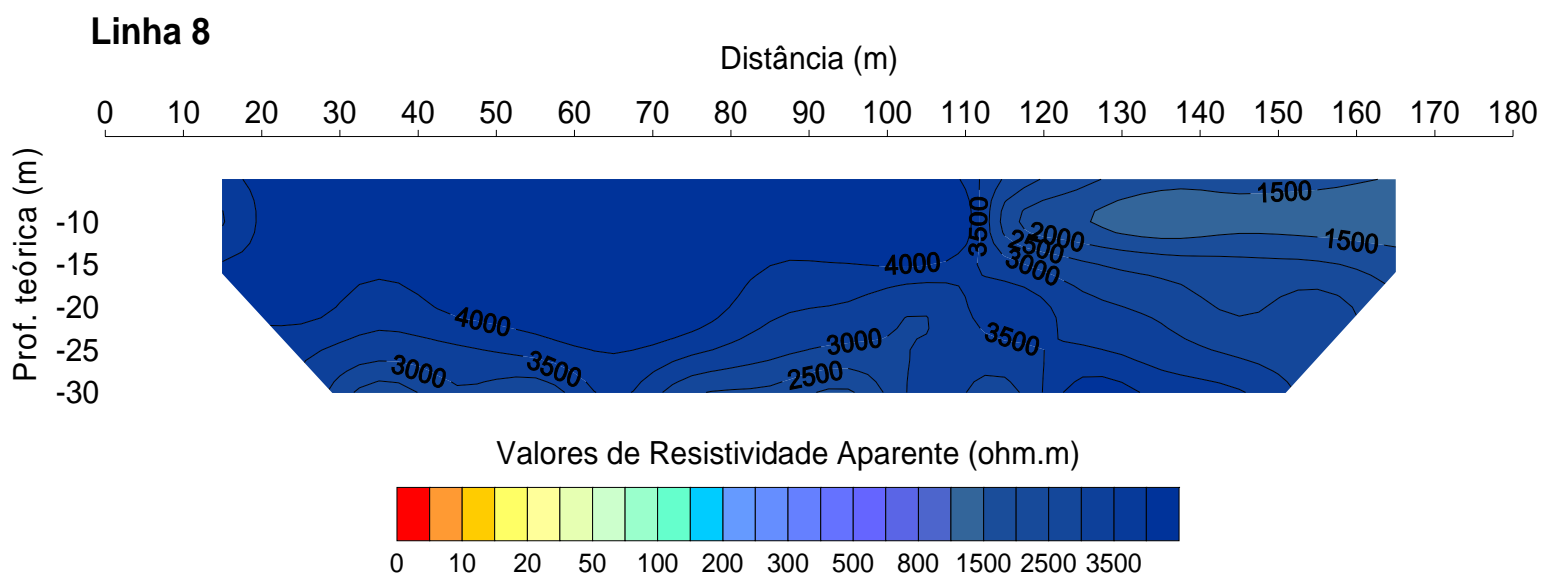

Figura 5.15 - Seção 8 interpretada com o programa SURFER 6.0.

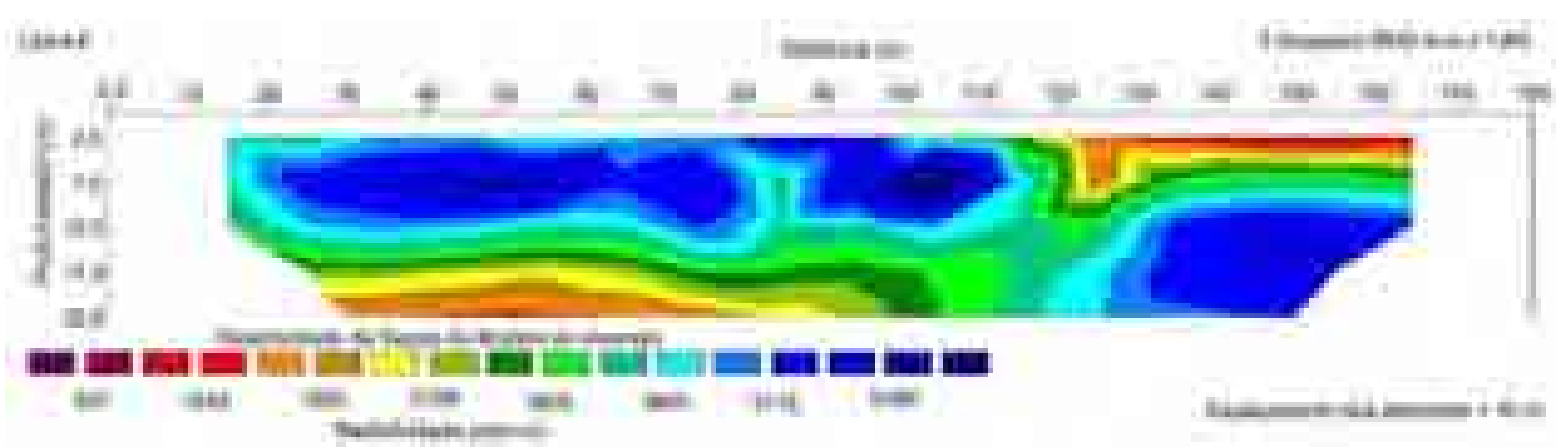

Figura 5.16 - Seção 8 interpretada com o programa RES2DINV.

A seção 9, indicada nas Figuras 5.17 e 5.18, é um corte transversal em relação às seções já descritas e numeradas de 1 a 8 . Interessantemente, a interpretação mostra concordância com relação à zona saturada das seções de 1, 2 e 3. Isto indica que a interpretação inicial do limite dessa zona estar de fato 
entre 12 e 15 metros é correta. Também se verificou concordância com relação às seções de 4 a 8 , nas quais há impossibilidade de identificação da zona saturada.

A região de baixa resistividade elétrica, parte inferior das Figuras 5.17 e 5.18 (tendendo ao vermelho), parece ser provocada pela presença de contaminantes. Infere-se ainda que esteja havendo movimento frontal de contaminantes em direção a esta seção (saindo do plano do papel).

Linha 9

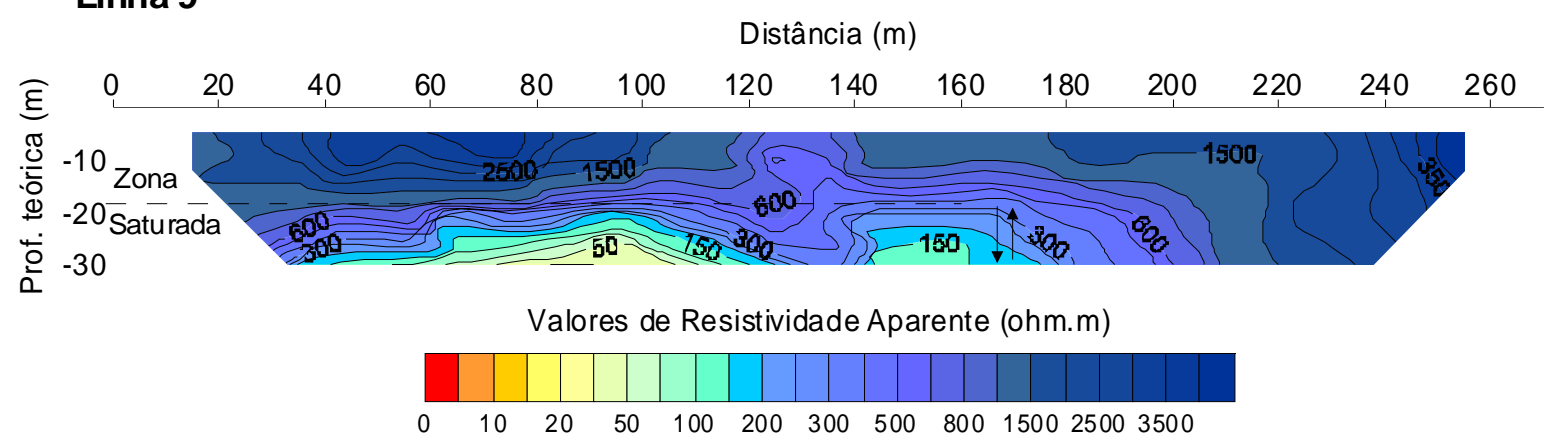

Figura 5.17 - Seção 9 interpretada com o programa SURFER 6.0.

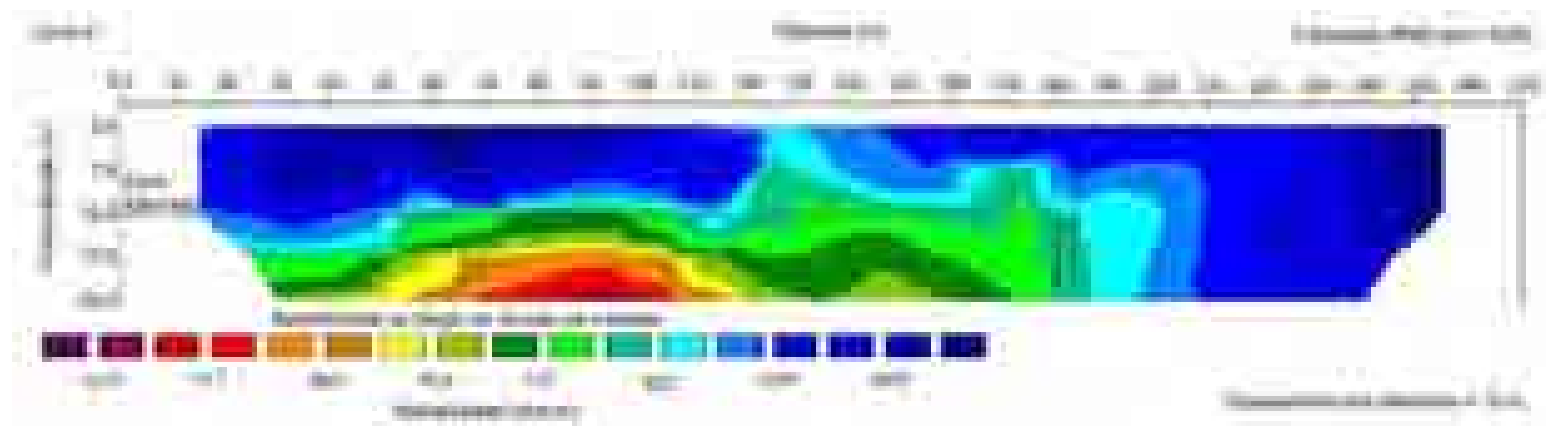

Figura 5.18 - Seção 9 interpretada com o programa RES2DINV.

Para a seção 10 (Figuras 5.19 e 5.20), que intercepta o prolongamento das linhas 1 a 5 e as próprias linhas 6 a 8, a interpretação mostra mais uma vez concordância com relação à zona saturada das seções de 1, 2 e 3. Inferese novamente que esta está entre 12 e 15 metros (o que é também condizente com o nível da água no poço vizinho, medido no mesmo dia, que apresentavase em 14 metros). Também se verificou concordância com relação às seções de 4 a 8, onde há impossibilidade de identificação da zona saturada.

A depleção na região central das Figuras 5.19 e 5.20, distância de 110 metros, pode ser provocada pelo poço, que estava em operação no período desse levantamento. Como ocorreu na seção 9 , a região de baixa resistividade 
elétrica, parte inferior das Figuras 5.19 e 5.20, pode ser provocada pela presença de contaminantes e sua evolução ao se deslocar na zona saturada. Outras hipóteses para a região mais condutora eletricamente podem ser: uma fossa mantida sem qualquer controle que será abordada com mais detalhe no subitem seguinte e característica da própria formação geológica. Ainda semelhantemente à seção 9, infere-se que esteja havendo movimento frontal (perpendicular ao plano da figura).

\section{Linha 10}

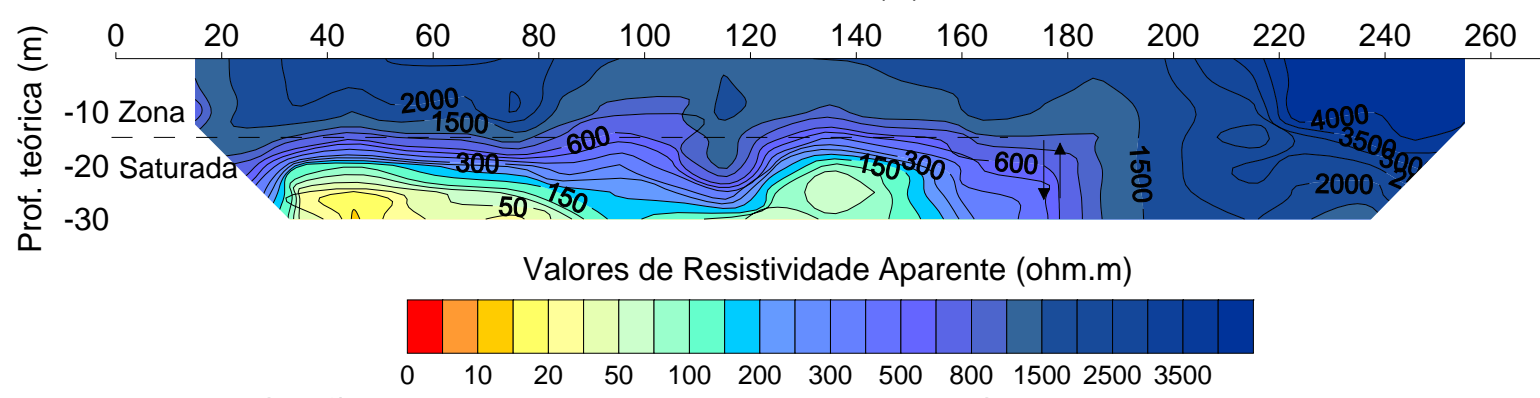

Figura 5.19 - Seção 10 interpretada com o programa SURFER 6.0.

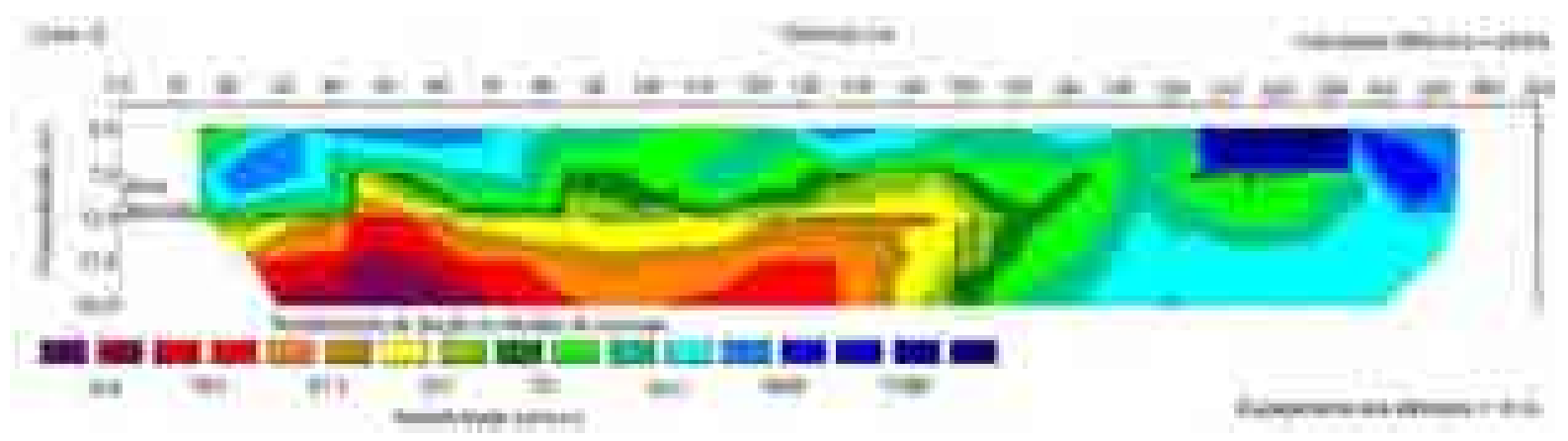

Figura 5.20 - Seção 10 interpretada com o programa RES2DINV.

A seguir são apresentados os mapas de resistividade aparente em função das profundidades de investigação. As linhas em vermelho nas Figuras 5.21 a 5.25 representam as curvas de nível e contornos das cavas, cercas, estruturas e cavas do sítio estudado (conforme informação gerada pelo levantamento topográfico realizado na área e sobreposta à figura).

A análise da Figura 5.21 mostra que, para a profundidade de investigação de 10 metros, não há interferência da zona saturada. Para as cavas 1 e 2 nas zonas de maior aeração e provável direção da drenagem das chuvas quando precipitadas, houve redução na resistividade elétrica (meio condutor), sendo que para as cavas 3 e 4 esta constatação não é válida. 
Conclui-se neste caso que a idade das cavas (cava 1 mais antiga e cava 4 mais recente) e a geologia deve ser, também, considerada na análise.

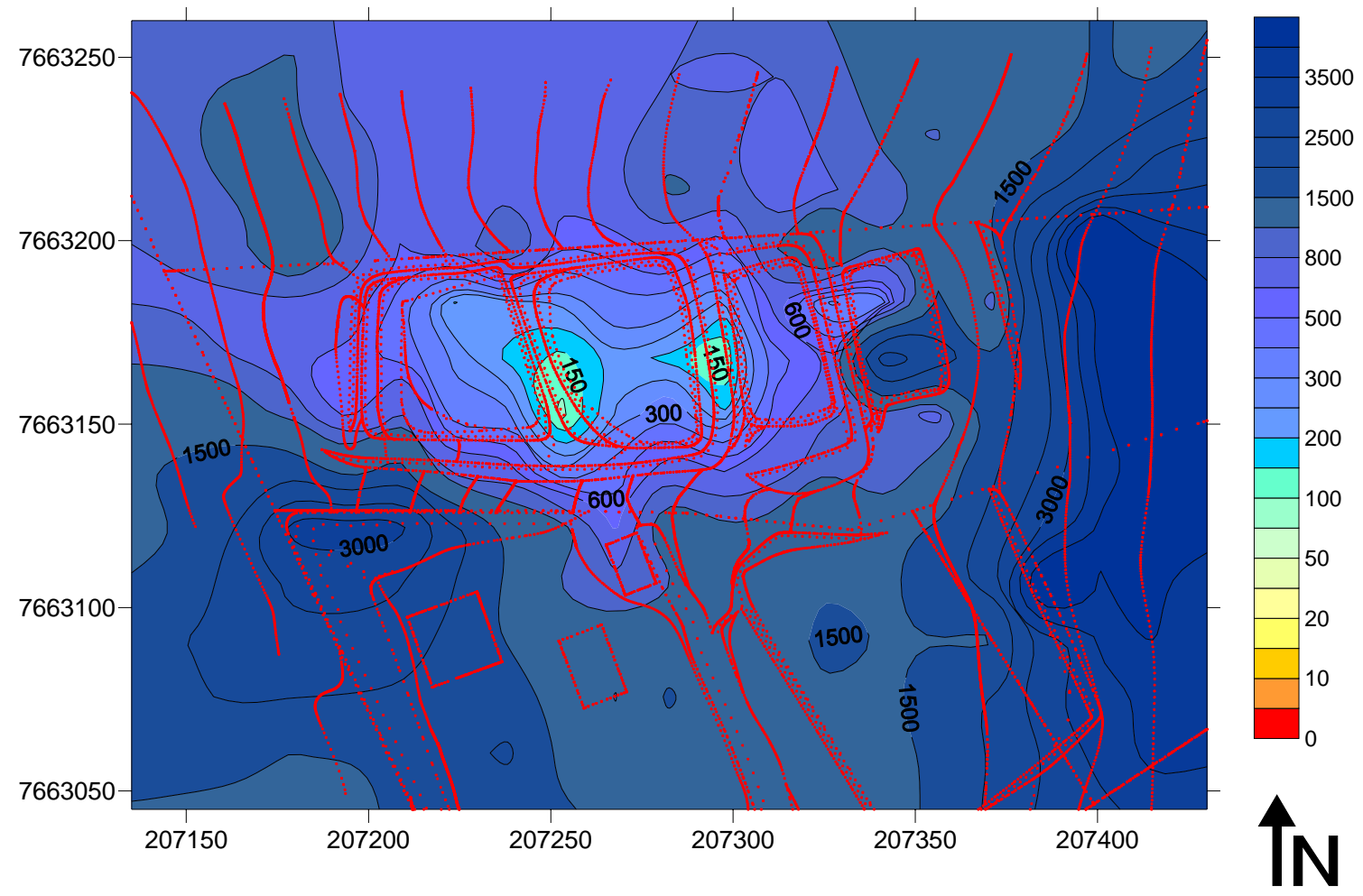

Figura 5.21 - Mapa de resistividade aparente - Nível 1 (profundidade teórica 10 metros) - Interpretado com o programa SURFER 6.0.

A interpretação da Figura 5.22, para profundidade de 15 metros, em conjunto com as informações dos perfis dos furos de sondagem e poços, sugere que esteja havendo escoamento de água subterrânea na direção normal à superfície do terreno (direção das curvas de nível). Contudo, não é perceptível a presença de contaminação atingindo a zona saturada, salvo as alterações de resistividade elétrica no centro das cavas.

A avaliação da Figura 5.23 para a profundidade de 20 metros reafirma o que foi dito para Figura 5.22 e sugere evolução da alteração de resistividade elétrica na direção normal à superfície do terreno, supostamente a mesma do escoamento da água subterrânea. A evolução do escoamento subterrâneo na direção normal à superfície do terreno pode ser compreendida quando se observa os perfis de sondagens e poços de monitoramento no Apêndice B e o perfil geológico-geotécnico no Apêndice I. A mudança brusca de litologia (solo residual de basalto para solo residual de arenito) provavelmente causa a mudança de inclinação do topo da zona saturada. 
Sugere-se que a cava 1, mais antiga cronologicamente, está liberando (ou liberou) quantidade maior de soluto (o líquido "exsudado" do material das cavas).

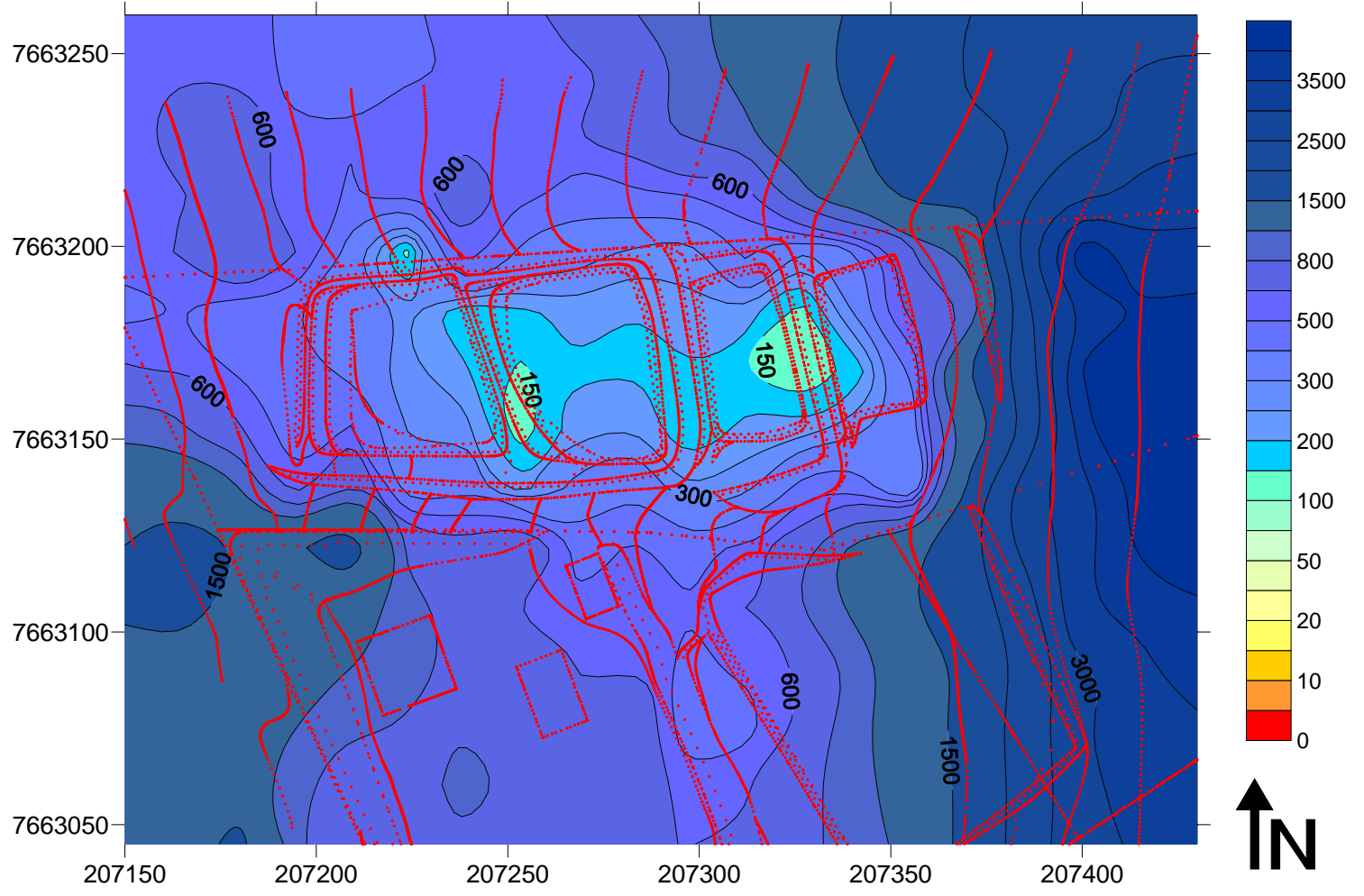

Figura 5.22 - Mapa de resistividade aparente - Nível 2 (profundidade teórica 15 metros) - Interpretado com o programa SURFER 6.0.

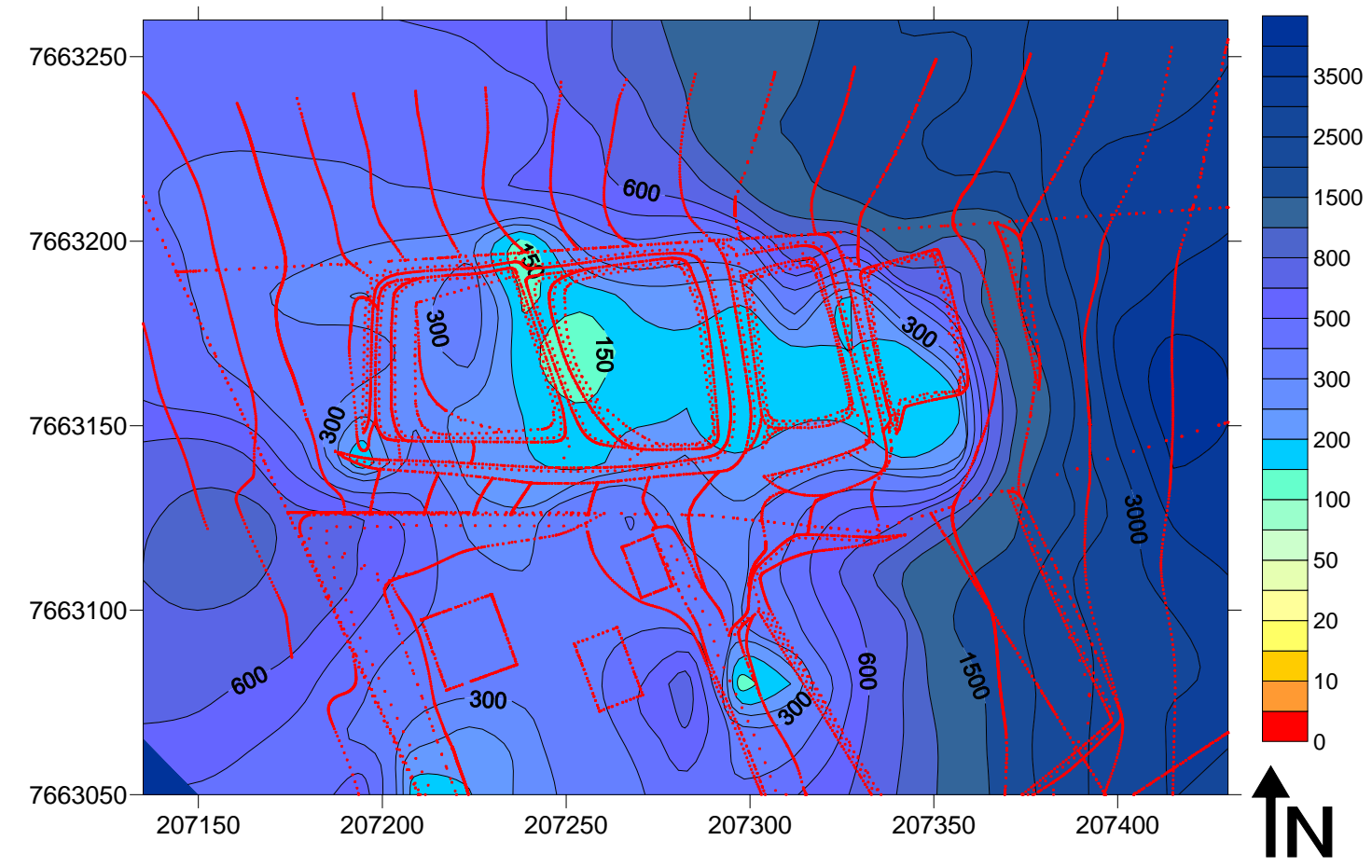

Figura 5.23 - Mapa de resistividade aparente - Nível 3 (profundidade teórica 20 metros) - Interpretado com o programa SURFER 6.0. 
A análise da Figura 5.24 para a profundidade de 25 metros indica maior espalhamento lateral. Sugere-se que os valores de baixa resistividade elétrica (meio condutor) a montante foram provocados pela proximidade das cavas e que houve contato com líquidos percolados. Todavia, por se tratar de uma geologia complexa deve-se ter cautela neste tipo de afirmação.

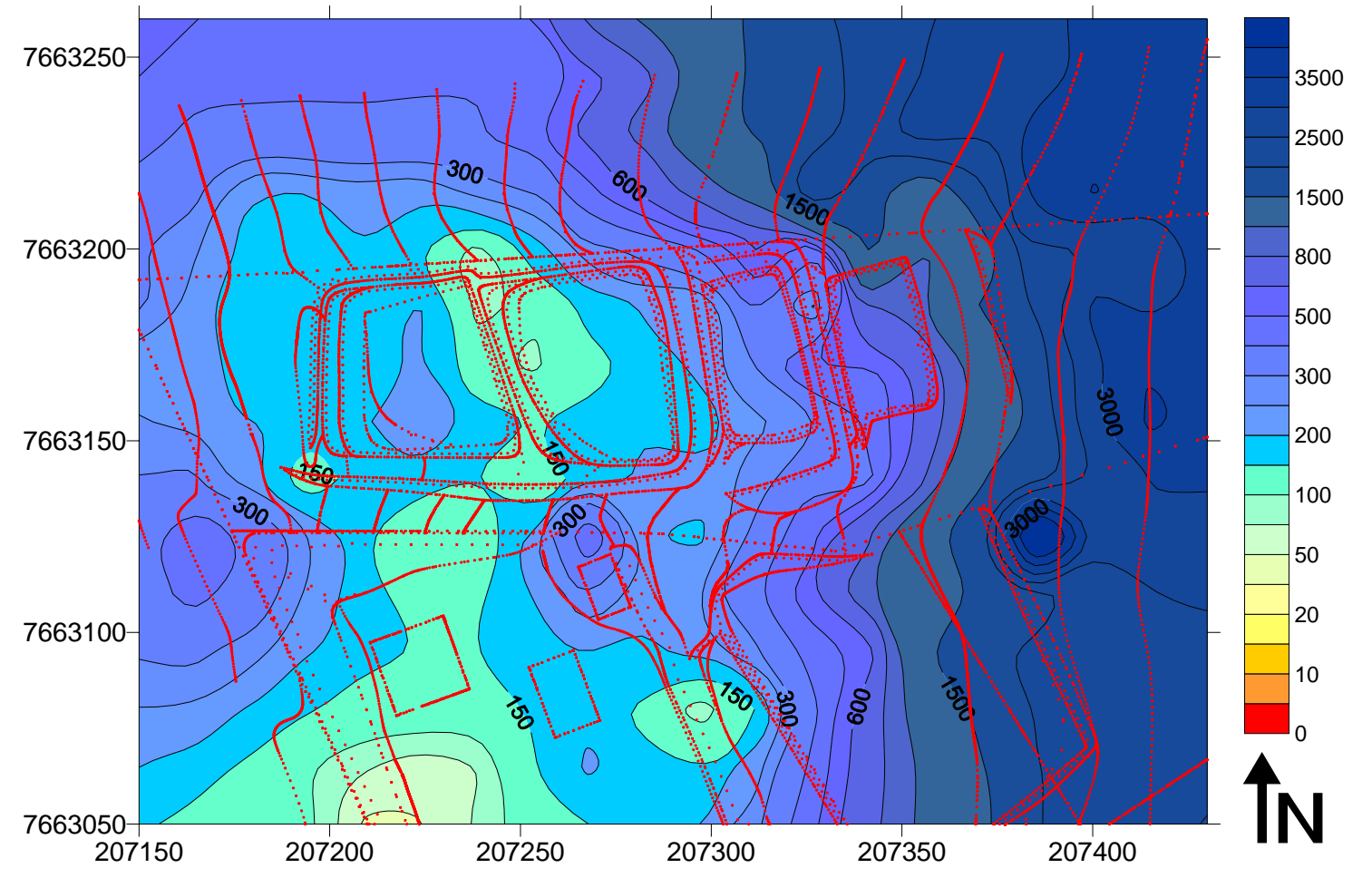

Figura 5.24 - Mapa de resistividade aparente - Nível 4 (profundidade teórica 25 metros) - Interpretado com o programa SURFER 6.0.

Como para o nível anterior, a interpretação da Figura 5.25 mostra que mesmo para uma profundidade teórica de 30 metros são visualizados indícios de alteração, provavelmente, decorrente do material lançado nas cavas.

Ainda com relação a Figura 5.25, acredita-se que o tracejado, próximo a linha com resistividade elétrica aparente de $200 \mathrm{ohm} \cdot \mathrm{m}$, defina o contato do solo residual de basalto com o solo residual de arenito. 


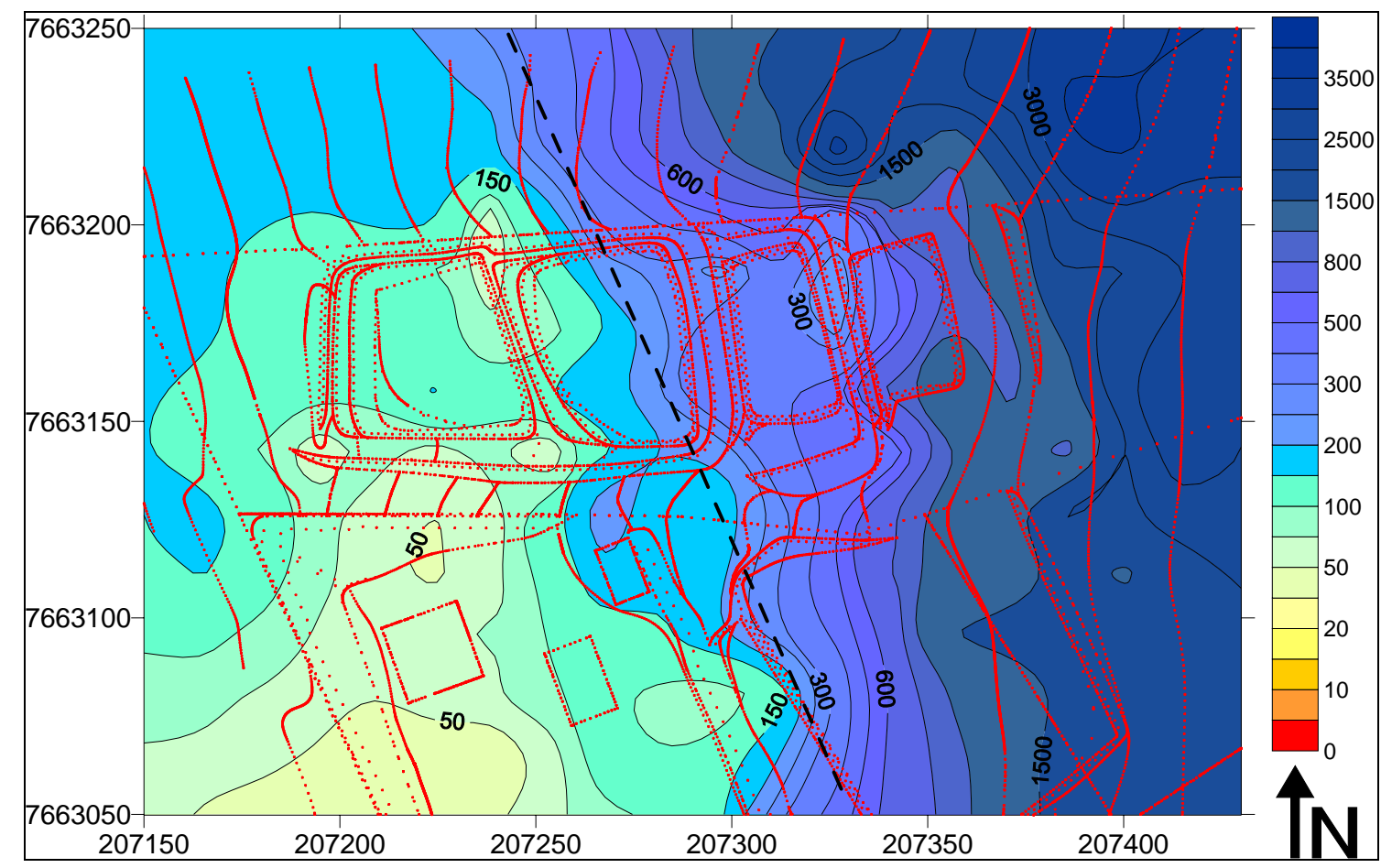

Figura 5.25 - Mapa de resistividade aparente - Nível 5 (profundidade teórica 30 metros) - Interpretado com o programa SURFER 6.0.

\subsubsection{Sondagem Elétrica Vertical}

Devido ao desconhecimento inicial da profundidade do topo da zona saturada em várias partes do sítio em questão, foram realizadas duas sondagens elétricas verticais (ver localização no Apêndice A), com o objetivo de ter uma referência da profundidade da zona saturada para as fases seguintes deste trabalho.

As Figuras 5.26 e 5.27 descrevem os perfis das sondagens elétricas interpretadas. Nas Figuras 5.26 e 5.27 os pontos representam os valores de resistividade elétrica aparente obtidos em campo, as cruzes representam os valores de cargabilidade aparente e as linhas contínuas são as curvas do modelo obtido pelo programa de interpretação. Observa-se que as sondagens são em grande parte auto-explicativas, tornando mais fácil a argumentação e discussão. Tais sondagens elétricas foram realizadas após a execução das sondagens a trado mecanizado (coleta de amostras deformadas) que foram descritas no item 4.9.1. 
$\mathrm{Na}$ Figura 5.26 nota-se cinco níveis de contrastes no perfil da sondagem. O primeiro, muito resistivo eletricamente, representa o aterro usado na borda da cava 3. O segundo, também bastante resistivo, refere-se à cobertura coluvionar do solo da região. O terceiro, condutor, está relacionado ao solo residual de basalto seco e pode também sugerir indícios de alteração por contaminantes. O quarto, resistivo, foi correlacionado ao arenito seco. Finalmente o quinto, mais condutor, foi vinculado ao arenito saturado e pode também ser usado como indício de alteração provocada por contaminantes.

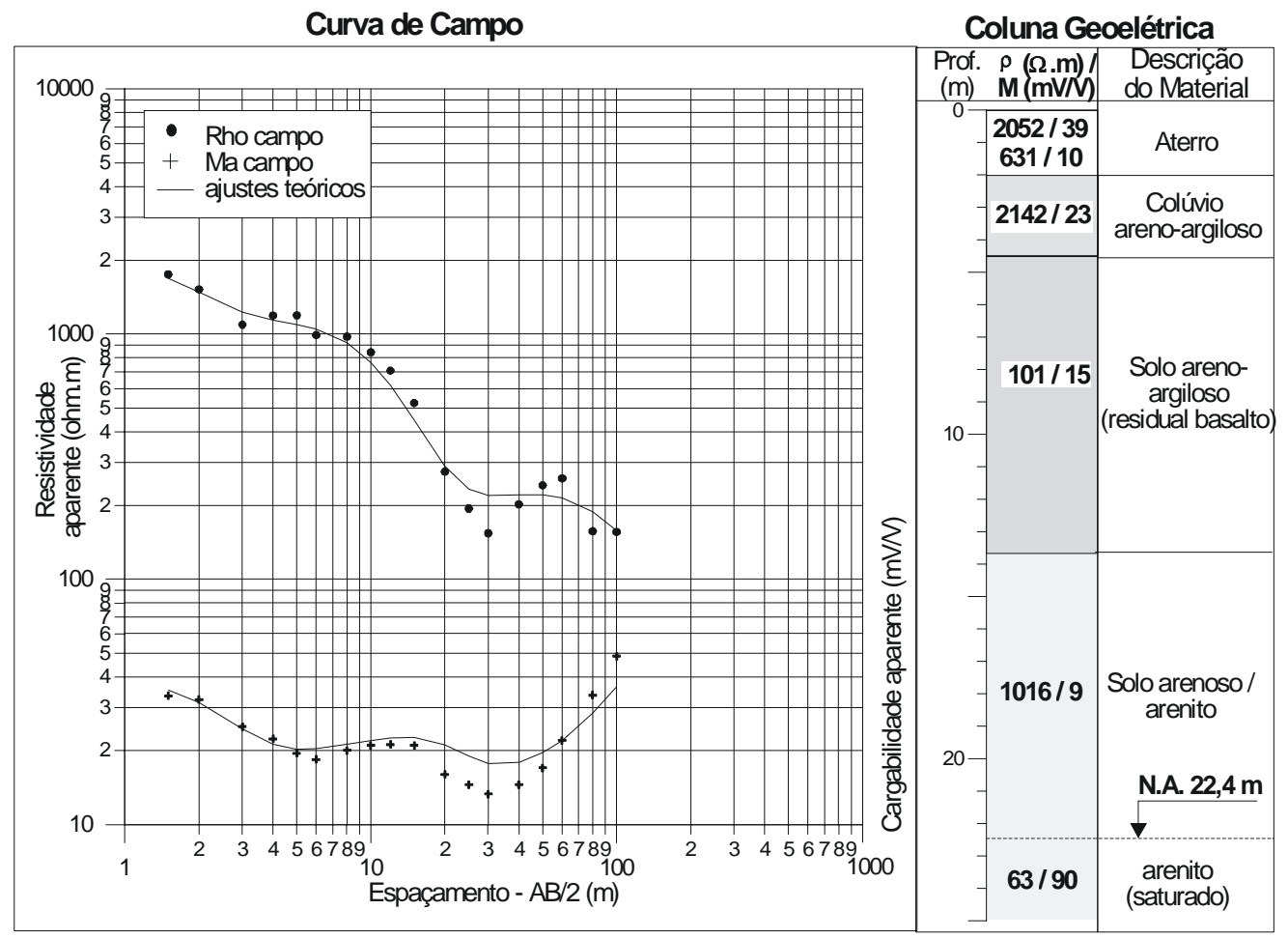

Figura 5.26 - Sondagem elétrica vertical 1 - Curva de campo e perfil geológico interpretado.

$\mathrm{Na}$ Figura 5.27 nota-se quatro níveis de contrastes no perfil da sondagem. O primeiro pode ser comparado ao segundo da Figura 5.26, bastante resistivo eletricamente, tratando-se da cobertura coluvionar do solo da região. O segundo, resistivo, está vinculado a solo arenoso. O terceiro pode ser correlacionado ao quarto da Figura 5.26, bastante resistivo, provavelmente referindo-se ao arenito seco. Finalmente o quarto, condutor, foi vinculado ao arenito saturado. 


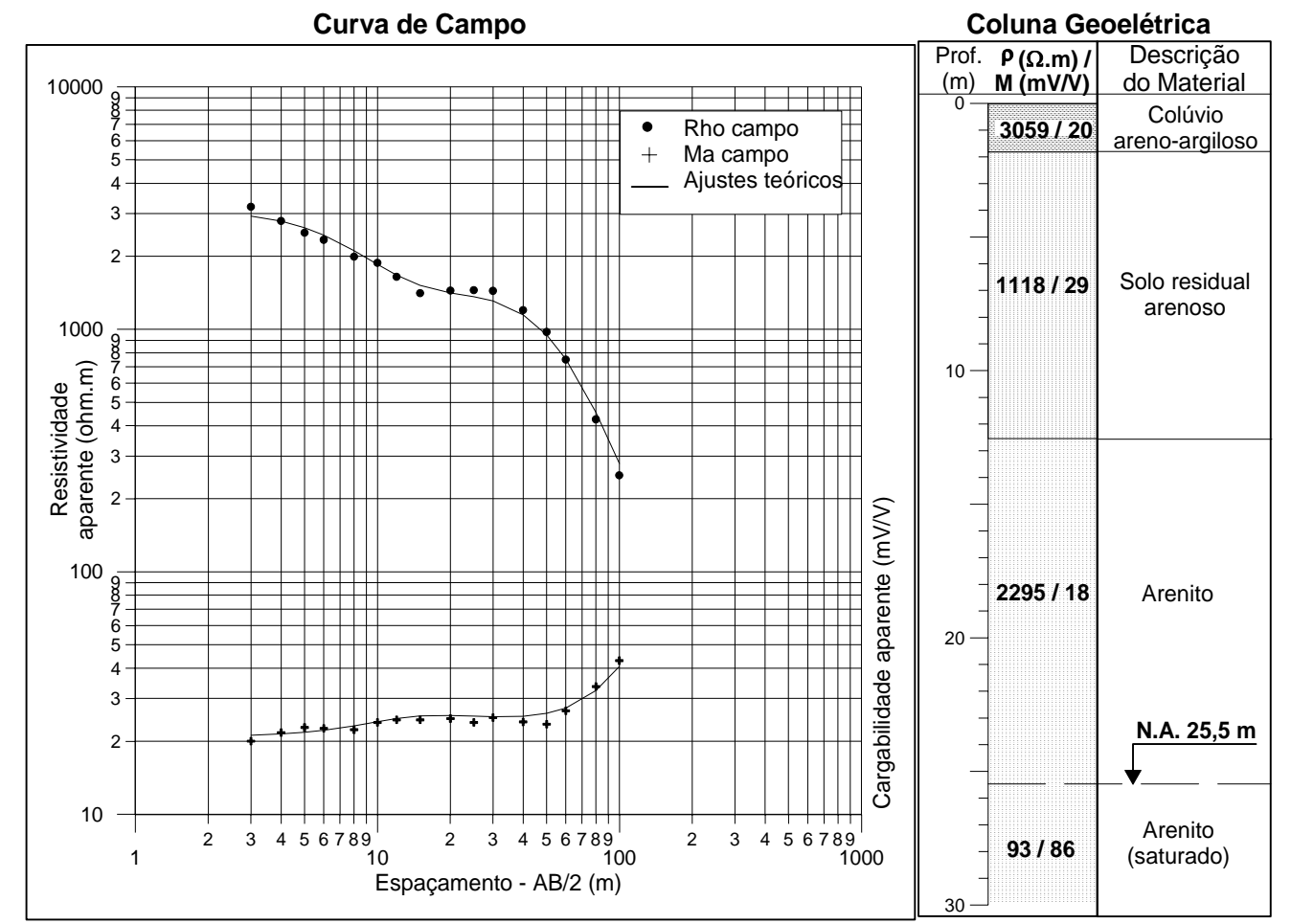

Figura 5.27 - Sondagem elétrica vertical 2. Curva de campo e perfil geológico interpretado.

\subsection{Qualidade da Água do Poço Vizinho}

Ainda que este item não tenha sido descrito na metodologia aplicada nesta pesquisa, por medida de proteção à saúde dos moradores das casas vizinhas às cavas de resíduos, bem como para tentar identificar alguma indicação de contaminação, no dia 19/11/2002 foram coletadas amostras da água do poço que abastece esses moradores (um assim denominado "poço caipira" ou "cisterna"). Foram determinados os seguintes parâmetros em campo: pH, oxigênio dissolvido (OD), potencial redox (Eh), temperatura e condutividade elétrica. Posteriormente foram realizadas as seguintes análises em laboratório: alcalinidade, coliformes, dureza, cloreto, metais, fosfato, nitrogênio e sólidos totais.

$\mathrm{Na}$ Tabela 5.1 podem ser observados os resultados dos parâmetros analisados em campo. Para tal determinação foram feitas quatro medidas, das quais computou-se a média e os respectivos desvios.

Com relação aos resultados obtidos em campo, apenas o pH de 5,92 \pm 0,12 pode ser considerado um indicativo, mostrando que o meio está 
levemente ácido. Entretanto, se considerarmos o $\mathrm{pH}$ do solo local, que apresenta uma ordem de grandeza de 5,8, pode-se inferir que esta acidez advém da formação geológica que suporta o aqüífero.

Tabela 5.1 - Parâmetros de qualidade da água do poço vizinho ao sítio em estudo, medidos em campo.

\begin{tabular}{lrrrrrr}
\hline \multicolumn{1}{c}{ Parâmetro } & Medida & Medida & Medida & Medida & \multirow{2}{*}{ Média } & Unidade \\
& \multicolumn{1}{c}{01} & \multicolumn{1}{c}{02} & \multicolumn{1}{c}{03} & \multicolumn{1}{c}{04} & & \\
\hline Temperatura & 25,44 & 25,49 & 25,44 & 25,41 & $25,45 \pm 0,04$ & ${ }^{\circ} \mathrm{C}$ \\
$\begin{array}{l}\text { Condutividade } \\
\text { Percentual de }\end{array}$ & 51 & 49 & 53 & 50 & $51 \pm 2$ & $\mu \mathrm{S} / \mathrm{cm}$ \\
Oxigênio Dissolvido & 82,3 & 68,8 & 69,6 & 51,6 & $68,1 \pm 16,5$ & $\%$ \\
Oxigênio Dissolvido & 6,67 & 5,62 & 5,71 & 4,23 & $5,56 \pm 1,33$ & $\mathrm{mg}_{\mathrm{O}_{2}} / \mathrm{L}$ \\
pH & 6,00 & 5,80 & 6,00 & 5,88 & $5,92 \pm 0,12$ & - \\
Potencial Redox & 246,6 & 251,1 & 255,0 & 256,0 & $252,2 \pm 5,6$ & $\mathrm{mV}$ \\
\hline \hline
\end{tabular}

Para as medidas de laboratório, todas as determinações foram realizadas em duplicata. Os resultados são apresentados na Tabela 5.2.

Com relação aos parâmetros medidos em laboratório, não se pode concluir pela contaminação oriunda dos resíduos depositados nas cavas. Entretanto, os coliformes totais e fecais ficaram acima dos valores recomendados como padrão de potabilidade pelo Ministério da Saúde (BRASIL, 2004). Assim, em conversa com os moradores vizinhos recomendouse, como boa conduta para sua saúde, a imediata interrupção do uso da água do poço, devido à localização inadequada (cerca de $35 \mathrm{~m}$ da fossa ou tanque séptico em uso), não permitir a presença de animais e não depositar lixos nas imediações do poço, prováveis vias de contaminação fecal. Evidentemente, a disposição para seguir essas recomendações é pessoal, e qualquer providência também é pessoal, não tendo sido objeto desse estudo verificar se as recomendações foram seguidas.

Com relação aos metais (ver Tabela 5.3), as concentrações de ferro podem ser explicadas pela elevada concentração de óxidos de ferro no solo local. A dureza identificada na Tabela 5.2 pode advir, também, da presença de óxidos de cálcio e magnésio. Entretanto, a identificação de zinco 
(supostamente ausente) pode ser correlacionada com o resíduo depositado nas cavas, devido a sua elevada concentração no resíduo. É importante frisar que a concentração de zinco medida em amostras de água subterrânea coletadas nos poços de monitoramento (ver item 5.7) também não ultrapassa os limites de potabilidade estabelecidos pelo Ministério da Saúde, que é de 5,0 $\mathrm{mg} / \mathrm{L}$ (BRASIL, 2004). Já as concentrações de ferro, considerando o maior valor medido 0,60 $\mathrm{mg} / \mathrm{L}$, excedem por vezes este limite, que é de $0,30 \mathrm{mg} / \mathrm{L}$ (BRASIL, 2004). É importante citar que foram investigados apenas os metais presentes na Tabela 5.3 (comumente medidos no Laboratório de Saneamento da EESC-USP) e que o limite de detecção do método analítico empregado (absorção atômica) pode ser considerado alto (ou seja, não apropriado para medir concentrações muito baixas ou traços, da ordem de partes por bilhão $\mathrm{ppb})$.

Tabela 5.2 - Parâmetros de qualidade da água do poço vizinho ao sítio em estudo, medidos em laboratório.

\begin{tabular}{lrrrr}
\hline \hline \multicolumn{1}{c}{ Parâmetro } & Medida 01 & Medida 02 & \multicolumn{1}{c}{ Média } & \multicolumn{1}{c}{ Unidade } \\
\hline Alcalinidade & 25,3 & 27,6 & $26,45 \pm 1,15$ & $\mathrm{mg}_{\mathrm{CaCO}_{3}} / L$ \\
Coliformes Totais & 1732,9 & 2419,2 & $2076,05 \pm 343,15$ & Coliformes totais/10OmL \\
Coliformes Fecais & 12,0 & 17,3 & $14,65 \pm 2,65$ & Coliformes fecais/10OmL \\
Dureza & 24,72 & 14,42 & $19,57 \pm 5,15$ & $\mathrm{mg}_{\mathrm{CaCO}_{3}} / \mathrm{L}$ \\
Fosfato & 0,1596 & 0,0878 & $0,1237 \pm 0,0359$ & $\mathrm{mg}_{\mathrm{PO}^{-3} / L}$ \\
Nitrogênio Amoniacal & $\mathrm{ND}$ & $\mathrm{ND}$ & - & $\mathrm{mg}_{\mathrm{N}} / \mathrm{L}$ \\
Nitrogênio Total & $\mathrm{ND}$ & $\mathrm{ND}$ & - & $\mathrm{mg}_{N} / \mathrm{L}$ \\
Sólidos Totais & 0,0041 & 0,0107 & $0,0074 \pm 0,0033$ & $\mathrm{~g}$ \\
\hline \hline
\end{tabular}

ND - Não detectado.

Tabela 5.3 - Metais presentes na água do poço vizinho a área de estudo.

\begin{tabular}{lrrrrrrrr}
\hline \hline Metais & $\begin{array}{l}\mathrm{Zn} \\
(m g / L)\end{array}$ & $\begin{array}{l}\mathrm{Pb} \\
(m g / L)\end{array}$ & $\begin{array}{l}\mathrm{Cd} \\
(m g / L)\end{array}$ & $\begin{array}{l}\mathrm{Ni} \\
(m g / L)\end{array}$ & $\begin{array}{l}\mathrm{Fe} \\
(m g / L)\end{array}$ & $\begin{array}{l}\mathrm{Mg} \\
(m g / L)\end{array}$ & $\begin{array}{l}\mathrm{Cu} \\
(m g / L)\end{array}$ & $\begin{array}{l}\mathrm{Cr} \\
(m g / L)\end{array}$ \\
\hline Medida 1 & 0,19 & $\mathrm{ND}$ & $\mathrm{ND}$ & $\mathrm{ND}$ & 0,36 & $\mathrm{ND}$ & $\mathrm{ND}$ & $\mathrm{ND}$ \\
Medida 2 & 0,03 & $\mathrm{ND}$ & $\mathrm{ND}$ & $\mathrm{ND}$ & 0,60 & 0,02 & $\mathrm{ND}$ & $\mathrm{ND}$ \\
\hline \hline
\end{tabular}

ND - Não detectado. 


\subsection{Caracterização do Resíduo}

\subsubsection{Medidas com Detector de Fotoionização}

$\mathrm{Na}$ Tabela 5.4 são apresentados os valores das concentrações de vapores de compostos orgânicos voláteis no ar, medidos com fotoionizador. Percebe-se pelos resultados que, mesmo com o forte odor emanado pelas cavas de resíduos, não se detectou concentração de voláteis mensuráveis pelo equipamento. Os valores de concentração apresentados são as médias de oito medidas armazenadas a cada 15 segundos.

As concentrações indicadas oscilam de acordo com a precisão do aparelho em torno do valor zero, sempre lembrando que o ambiente naturalmente apresenta valores desta ordem de grandeza.

\subsubsection{Densidade do Resíduo}

\subsubsection{Densidade Absoluta}

Os resultados das medidas de densidade absoluta para as amostras de resíduo das cavas são apresentados na Tabela 5.5.

Observa-se que, com exceção da amostra coletada na cava 3, na superfície, todas as amostras apresentaram densidade maior que a densidade da água. Vale acrescentar que a amostra da "cava 3 - superfície" inicialmente flutuou na superfície da água e posteriormente sedimentou, o que sugere que houve absorção de água do meio.

\subsubsection{Densidade Aparente}

Os resultados da densidade aparente determinada para cada uma das amostras de resíduo constam na Tabela 5.6. 
Também para a densidade aparente observa-se que somente a amostra coletada na cava 3 superfície apresenta densidade aparente menor do que 1 $\mathrm{kg} / \mathrm{mL}$.

Tabela 5.4 - Concentrações de orgânicos voláteis medidas com detector de fotoionização.

\begin{tabular}{lcr}
\hline \multicolumn{1}{c}{ Ponto de Amostragem } & Data & Concentração (ppm) \\
\hline Porteira (Branco) & $19 / 03 / 2002$ & 2,2 \\
\hline Cava 1 & $19 / 03 / 2002$ & 1,9 \\
\hline Cava 2 & $19 / 03 / 2002$ & 1,8 \\
\hline Cava 3 & $19 / 03 / 2002$ & 1,7 \\
\hline Cava 4 & $19 / 03 / 2002$ & 1,8 \\
\hline Cerca oposta a porteira (branco) & $19 / 03 / 2002$ & 1,9 \\
\hline Cava 1 & $19 / 03 / 2002$ & 2,1 \\
\hline Cava 2 & $19 / 03 / 2002$ & 1,8 \\
\hline Porteira (Branco) & $15 / 07 / 2002$ & 2,5 \\
\hline Cava 1 & $15 / 07 / 2002$ & 2,1 \\
\hline Cava 2 & $15 / 07 / 2002$ & 2,2 \\
\hline Cava 3 & $15 / 07 / 2002$ & 2,3 \\
\hline Cava 4 & $15 / 07 / 2002$ & 2,2 \\
\hline \hline
\end{tabular}

Tabela 5.5 - Densidade absoluta das amostras do resíduo coletado nas cavas.

\begin{tabular}{lc}
\hline \hline \multicolumn{1}{c}{ Amostra } & Densidade Absoluta $(\mathrm{kg} / \mathrm{mL})$ \\
\hline Cava 1 Superfície & 1,0584 \\
Cava 1 Fundo & 1,2616 \\
Cava 2 Superfície & 1,1286 \\
Cava 2 Fundo & 1,1340 \\
Cava 3 Superfície & 0,9907 \\
Cava 3 Fundo & 1,1312 \\
Cava 4 Superfície & 1,1045 \\
Cava 4 Fundo & 1,0670 \\
\hline \hline
\end{tabular}


Tabela 5.6 - Densidade aparente das amostras de resíduo.

\begin{tabular}{lc}
\hline \hline \multicolumn{1}{c}{ Amostra } & Densidade Aparente $(\mathrm{kg} / \mathrm{mL})$ \\
\hline Cava 1 Superfície & 1,2674 \\
Cava 1 Fundo & 1,3941 \\
Cava 2 Superfície & 1,1807 \\
Cava 2 Fundo & 1,4105 \\
Cava 3 Superfície & 0,9989 \\
Cava 3 Fundo & 1,1807 \\
Cava 4 Superfície & 1,2161 \\
Cava 4 Fundo & 1,1915 \\
\hline \hline
\end{tabular}

\subsubsection{Fração Orgânica}

As análises das frações orgânicas foram conduzidas no Instituto de Química da UNESP/Araraquara. Os extratos obtidos apresentam coloração negra e todos os métodos de limpeza (do inglês, cleanup) mostraram-se ineficientes. Em uma tentativa de avaliar o comportamento de um dos extratos negros no sistema CG-MS, o sistema foi contaminado pela amostra e a coluna cromatográfica foi perdida. Como alternativa, aventa-se a possibilidade de que os extratos podem ser medidos em HPLC (cromatografia líquida) por se tratar de um sistema que funciona à temperatura ambiente. Este aspecto do trabalho deverá ter continuidade além dos prazos previstos para a presente pesquisa.

\subsubsection{Fração Inorgânica}

Como descrito na metodologia, as amostras foram analisadas por Difração de Raios-X por Energia Dispersiva, método este que fornece resultados semiquantitativos. Os resultados das frações de espécie inorgânicas nas amostras de resíduo estão dispostos na Tabela do Apêndice F.

Em todas as amostras foram encontrados percentuais (20 a 56\%) muito elevados de enxofre (S), que provavelmente advêm do processo de re-refino com ácido e argila, que utiliza o ácido sulfúrico. Salienta-se que também foram 
encontradas percentuais (23 a 35\%) muito elevados de cálcio (Ca) em todas as amostras. Ainda foram obtidos elevados percentuais de silício (Si) ou talvez de silicatos nas cavas 1 e 4, muito provavelmente vinculados à mistura dos resíduos com solo e, em menor proporção, pela presença da argila clarificante usada no processo industrial.

Com relação às mesmas amostras de resíduo, foram encontrados valores considerados não desprezíveis de titânio (Ti), ressaltando-se que as amostras de superfície possuem porções maiores que as amostras do fundo. A mesma constatação é válida para o chumbo $(\mathrm{Pb})$. Já para o zinco $(\mathrm{Zn})$ e para o ferro $(\mathrm{Fe})$ observa-se o comportamento inverso. Por estas observações podese sugerir que o ferro e o zinco possuem mais afinidade com a água das chuvas que "lavam" as cavas de resíduo do que o titânio e o chumbo (partindose do pressuposto que cada uma das cavas foi preenchida resíduos com a mesma composição). Segundo Freeman (1998), o chumbo presente nos óleos lubrificantes usados tem origem no contato com a gasolina (no tempo de rodagem do veículo) que continha chumbo, sendo que o zinco está vinculado aos aditivos do próprio óleo.

Foram identificados ainda baixos percentuais de estrôncio ( $\mathrm{Sr}$ ) e de cobre $(\mathrm{Cu})$ em todas as amostras. Adicionalmente, foram identificados, em algumas amostras, percentuais de manganês (Mn) e alumínio (Al).

\subsection{Caracterização do Solo}

Os resultados da caracterização do solo serão apresentados segundo a seqüência descrita na metodologia.

\subsubsection{Caracterização Física}

Os resultados da caracterização física das amostras de solo podem ser observados na Tabela "resultados gerais resumidos para as amostras de solo" no Apêndice G. 
Pela observação dos resultados da análise granulométrica conjunta, verificou-se nas amostras mais superficiais de toda a região estudada a predominância de solo argilo-siltoso, argilo-silto-arenoso e silto-argiloso (o maior percentual de argila caracteriza o solo argiloso). Entende-se por amostras superficiais aquelas obtidas até a profundidade de $9 \mathrm{~m}$. Por um lado, na porção inicial do sítio (região abrangida pelas sondagens 1 , 2 e 6 e poços de monitoramento 1, 2A e B, 3 e 4) abaixo dos $9 \mathrm{~m}$ e até a profundidade de aproximadamente $19 \mathrm{~m}$, os resultados sugerem predominância de solo arenosiltoso e silto-arenoso. Por outro lado, na porção final da área de estudo (região que compreende as sondagens 3, 4, 5 e 7 e PMs 5, 6, 7 e 8), abaixo da cobertura superficial, predominam solos arenosos (residual de arenito). Ressaltar-se que os ensaios de análise granulométrica conjunta modificados (sem a adição de defloculante), em todas as amostras, sugerem a não existência de argila nas amostras, transferindo para o silte e areia o percentual referente à argila.

Com relação aos resultados de massa específica dos sólidos, as constatações feitas para a análise granulométrica conjunta são confirmadas. Em geral, as amostras do solo superficial (profundidade aproximada de $9 \mathrm{~m}$ ) apresentam valores de massa específica dos sólidos $\left(\rho_{\mathrm{s}}\right)$ na faixa de 3,15 a $3,01 \mathrm{~g} / \mathrm{cm}^{3}$. Mais uma vez, para a porção inicial do sítio, abaixo da cobertura superficial foram encontrados valores de " $\rho_{s}$ " na ordem de 3,00 a $2,91 \mathrm{~g} / \mathrm{cm}^{3}$. $\mathrm{Na}$ porção final da área de estudo, abaixo do solo superficial, observa-se valores de " $\rho_{\mathrm{s}}$ " variando entre 2,68 e $2,64 \mathrm{~g} / \mathrm{cm}^{3}$.

\subsubsection{Caracterização Físico-Química}

Os resultados da caracterização físico-química das amostras de solo estão descritos na Tabela "resultados gerais resumidos para as amostras de solo" no Apêndice G.

Pela avaliação dos resultados do pH em água do solo nota-se que os solos amostrados são, em geral, levemente ácidos. Os valores do $\mathrm{pH}$ para todas as amostras oscilaram entre 6,6 e 4,4. Já os valores de $\Delta \mathrm{pH}$ evidenciam 
predomínio de cargas negativas, pois em geral os resultados são negativos (foram obtidos somente dois valores positivos). Leite (2001) obteve resultados de $\Delta \mathrm{pH}$ positivos para solos das formações Serra Geral e Botucatu, as mesmas estudadas nesta pesquisa.

Os resultados de potencial redox (Eh) giraram em torno de 616 e 503 $m V$. Estes valores sugerem reações de oxidação (perda de elétrons), portanto pouca atividade eletrônica.

Para a condutividade elétrica (CE) os resultados, de uma forma geral, forneceram valores baixos, da ordem de $20 \mathrm{mS} / \mathrm{m}$ (exceto em três amostras), valores estes típicos para solos naturais. Menciona-se que Leite (2001) obteve resultados semelhantes para solos das mesmas formações estudas nesta pesquisa.

Em geral, os resultados da capacidade de troca catiônica (CTC) dos solos e das argilas estudados nesta pesquisa mostram baixa capacidade em reter e trocar íons positivos. Esta reduzida CTC é ainda mais evidente nas amostras referente aos solos arenosos. Para a superfície específica (SE) os resultados mostram as mesmas evidências observadas para a CTC. Mais uma vez os resultados obtidos por Leite (2001) conduzem às mesmas constatações para solos das mesmas formações.

\subsubsection{Mineralogia}

Para a análise mineralógica foram obtidos difratogramas, que foram interpretados pela identificação dos picos. Como mencionado na metodologia, foram selecionadas sete amostras dentre as 29 coletadas durante as sondagens. As sete amostras escolhidas representam de uma forma geral os diferentes solos estudados nesta pesquisa. Na Tabela 5.7 são apresentados, de maneira suscinta, a mineralogia identificada. Verifica-se, nesta análise, que os minerais encontrados correspondem a solos tropicais em estágio geoquímico evoluído. É importante ressaltar que as amostras que apresentaram Smectita estão ligadas aos valores mais elevados da CTC. 
Tabela 5.7 - Composição mineralógica identificada na fração fina (menor que $0,037 \mathrm{~mm}$ ) das amostras analisadas.

\begin{tabular}{ll}
\hline \hline \multicolumn{1}{c}{ Amostra } & \multicolumn{1}{c}{ Composição Mineralógica } \\
\hline SD - 01-3,0 m & Caulinita, quartzo, goethita, hematita \\
\hline SD - 01-16,2 m & Caulinita, gibsita, magnetita, goethita, hematita, quartzo \\
\hline SD - 02-15,0 m & Smectita, caulinita, quartzo, boehmita \\
\hline SD - 03-7,0 m & Caulinita, quartzo, hematita \\
\hline $\mathrm{SD}-03-10,0 \mathrm{~m}$ & Caulinita, goethita, magnetita, anatasio \\
\hline $\mathrm{SD}-04-9,0 \mathrm{~m}$ & Smectita, caulinita, goethita, hematita, anatasio \\
\hline $\mathrm{SD}-05-3,5 \mathrm{~m}$ & Caulinita, gibsita, magnetita, goethita, hematita, anatasio \\
\hline \hline
\end{tabular}

\subsubsection{Caracterização Química}

\subsubsection{Carbono Orgânico Total}

Para a determinação frações de carbono orgânico total $\left(f_{o c}\right)$ em amostras de solo seguiu-se a metodologia descrita no item 4.9.5.1 e os resultados obtidos podem ser observados, também, na Tabela "resultados gerais resumidos para as amostras de solo", no Apêndice G.

Em todas as amostras analisadas observa-se a redução do $f_{o c}$ com o aumento da profundidade. Esta constatação também é perceptível no estudo de Cotta (2003). Nota-se considerável percentual (acima de 0,25\%) de $f_{o c}$ nas amostras até 3,5 $\mathrm{m}$ de profundidade. Convém, entretanto, mencionar que o estudo de Cotta (2003) considerou os primeiros $30 \mathrm{~cm}$ a partir da superfície, enquanto que, no presente trabalho, foi considerado toda a profundidade estudada. Não obstante esta diferença, os resultados apontam para comportamentos similares. Para as amostras coletadas abaixo da zona saturada observa-se percentuais menores do que $0,1 \%$, principalmente para as amostras arenosas vinculadas ao solo residual de arenito, cujos resultados ficaram abaixo de $0,06 \%$. Neste caso, como mencionado no item "Partição Controlada pelo Carbono Orgânico", acredita-se que o carbono orgânico total não controla o processo sorcivo. 


\subsubsection{HPAs}

Os resultados das concentrações de HPAs em amostras de solo estão descritos na Tabela "Resultados de HPAs em Amostras de Solo" (valores em ppb - partes por bilhão), presente no Apêndice G.

Todos os compostos quantificados apresentam concentração da ordem de $p p b(n g / g)$ ou ppt (partes por trilhão). Como pode ser observado no Apêndice G, as amostras foram analisadas em duplicata, sendo arrolados os resultados das duas alíquotas.

Os HPAs identificados foram: acenafteno, antraceno, benzo[a]antraceno, fluoranteno, fluoreno, naftaleno, fenantreno e pireno. Destes, o fluoreno e o benzo[a]antraceno foram identificados somente em quatro alíquotas de amostras diferentes e em concentrações muito baixas. Dentre os compostos identificados, somente o naftaleno consta no relatório de valores orientadores para solos no Estado de São Paulo (CETESB, 2001b). Segundo CETESB (2001b), o valor de referência para o naftaleno é de $0,2 \mathrm{ppm}(\mathrm{mg} / \mathrm{kg})$. A maior concentração identificada para o naftaleno (SD 01 a $13 \quad \mathrm{~m}$ ) foi de aproximadamente $0,004 \mathrm{ppm}$, portanto muito abaixo do valor de referência. $\mathrm{O}$ HPA mais encontrado foi o fenantreno e também foi o que apresentou as maiores concentrações, entretanto praticamente todas abaixo de 0,004 ppm.

Os resultados ora apresentados sugerem pouca ou nenhuma alteração na qualidade do solo por HPAs supostamente advindos das cavas de resíduos.

\subsubsection{3. Óxidos}

Os resultados dos percentuais de óxidos nas amostras de solo são apresentados na Tabela "resultados dos óxidos presentes em amostras de solo", no Apêndice G. Estes resultados podem ser correlacionados, direta ou indiretamente, com os resultados da análise granulométrica conjunta discutidos no item 5.4.1. Observa-se que onde há percentuais elevados de areia foram obtidos percentuais elevados de óxido de silício. Nas amostras mais superficiais nota-se percentuais mais elevados de óxidos de ferro e alumínio. Verifica-se maiores percentuais de óxidos de titânio nos pontos de coleta (SDs 
1 e 2 e PMs 3 e 4), porção inicial do sítio e menores percentuais nos pontos de coleta (PMs 6 e 8), porção final do sítio.

\subsubsection{Interpretação dos Perfis das Sondagens e dos Poços de Monitoramento}

Os dados dos perfis tátil-visuais e dos níveis de água dos poços de monitoramento e sondagens foram interpretados e resumidos na Tabela "interpretação dos perfis dos furos sondagens e poços", do Apêndice H. Para permitir melhor visualização das variações espaciais dos dados e possibilitar a elaboração de hipóteses sobre o cenário geológico e hidrogeológico da área, foi elaborada uma seção vertical a partir dos resultados de todos os poços de monitoramento e sondagens, seção esta apresentada no Apêndice I. Os dados indicam que a área toda é coberta por uma camada de solo coluvionar, argilosiltoso, de coloração vermelho escura, com espessura variando de 3 a 6 metros. Em seguida ocorre, também em toda a área, solo constituído por silte argilo-arenoso, muitas vezes contendo concreções de limonita e apresentando coloração variegada e espessura variando de 4 a 8 metros. Nos PMs de 1 a $4 \mathrm{e}$ SDs 1, 2 e 6 verifica-se que, abaixo dessas camadas, ocorre outra camada de solo, com provável origem eluvial, apresentando textura mais siltosa, com coloração marrom a cinza e espessura de 4 a $5 \mathrm{~m}$. Segue-se uma camada de argila plástica, de coloração castanha, com espessura bastante variável e ocorrência generalizada na área, que se supõe ser equivalente ao solo residual de basalto. Nos PMs 1 a 4 e SDs 1, 2 e 6 essa camada de argila não foi atravessada e apresenta-se, a partir da profundidade de aproximadamente 19 metros, bastante compacta e com fragmentos de basalto intemperizado (estes fragmentos de basalto intemperizado foram observados próximo a 32 metros, próximo a PM - 03, no local onde pretendia-se construir o poço de bombeamento).

A camada de argila apresenta menor espessura na parte mais baixa da área de estudo, sendo que, nos PMs de 5 a 8 e SDs 3 a 5 e 7, abaixo dela 
ocorre arenito friável de textura fina a média, pouco a não argiloso, com coloração bege e rosada.

Os níveis da água medidos indicam que o escoamento subterrâneo ocorre nas direções W-E e N-S, com uma declividade média da ordem de 6\%. No entanto, o nível da água também apresenta uma notável descontinuidade, sendo que nos PMs 1 a 4 se encontra a profundidades variando entre 10 e 15 $m$ e nos PMs 5 a 8 , a profundidade do nível da água é mais constante, ficando entre 27 e $28 \mathrm{~m}$. Salienta-se que o nível de água no PM - 07 variou de 27,7 m, no momento da construção dos poços de monitoramento, para $30,8 \mathrm{~m}$ em 29/11/2003 e 31,6 m em 29/06/2004.

Segundo Perroni (2003), os dados obtidos indicam a existência de uma descontinuidade sub-vertical, com possível direção N-S, sendo que a Leste desta suposta estrutura as rochas basálticas (e seu respectivo solo residual) têm pequena espessura, com provável soerguimento da camada subjacente de arenito. Essa afirmação é corroborada em parte pelas interpretações feita por T. Alves Engenharia Ambiental S/C LTDA (2001) para seção que se estende da Rodovia Anhanguera até a destilaria Galo Bravo. Todavia T. Alves Engenharia Ambiental S/C LTDA (2001) sugeriu que esta descontinuidade ocorre na calha do Ribeirão Preto.

\subsection{Direção do Escoamento, Gradiente Hidráulico e Superfície Potenciométrica}

$\mathrm{Na}$ avaliação, em nível de sítio, da direção do escoamento da água subterrânea e do gradiente hidráulico, foram usadas as medidas de nível de água dos poços de monitoramento. Para tanto, foi acessada a ferramenta desenvolvida por Weaver (2004) na página da USEPA (para o endereço verificar o item 4.10.4), para a determinação de ambos os parâmetros. Como dados de entrada foram fornecidas as coordenadas UTM (direção " $x$ " oesteleste e direção "y" sul-norte) de cada poço e os níveis de água medidos em datas diferentes. 
Para compreender os diferentes comportamentos dentro do sítio foram criadas três combinações:

- $\quad \mathrm{Na}$ primeira tentou-se avaliar o comportamento do aqüífero suspenso. Nesta combinação foram usadas as informações referentes aos poços de monitoramento 1, 2A, 3 e 4, porção inicial do sítio em estudo. Os resultados podem ser observados na Figura 5.28 e estão resumidos na Tabela 5.8;

- Na segunda quis-se observar o comportamento do aqüífero da formação arenito. Neste caso foram usadas as informações referentes aos poços 5, 6, 7 e 8, porção final do sítio. Os resultados são apresentados na Figura 5.29 e resumidos na Tabela 5.9;

- Por fim, a terceira buscou-se observar a hidrogeologia do sítio como um todo. Para esta combinação foram utilizados os dados referentes aos poços de monitoramento 1, 2A, 6, 7 e 8. Os resultados podem ser observados na Figura 5.30 e na Tabela 5.10.

Com relação à primeira combinação observa-se que a direção do escoamento variou entre $110^{\circ}$ e $135^{\circ}$ em relação ao norte (eixo "y" positivo), ou seja, deslocando-se do PM-01 para o PM-02A (ver localização dos poços de monitoramento no Apêndice A) e o gradiente variou entre 0,011 e 0,016. Já para a segunda combinação nota-se que a direção do escoamento variou entre $88^{\circ}$ e $92^{\circ}$, e o gradiente variou entre 0,076 e 0,090. Finalmente para a terceira combinação, a qual considera as informações gerais do sítio, a direção do escoamento variou entre $57^{\circ}$ e $59^{\circ}$, e o gradiente girou na ordem de 0,16 a 0,17 .

Pelo descrito acima, verifica-se que mesmo em um sítio de pequena dimensão como este estudado nesta pesquisa podem ser encontradas grandes variações na direção e no gradiente hidráulico do escoamento. O presente procedimento foi seguido para balizar as buscas mais detalhadas efetuadas posteriormente com o modelo MODFLOW. Os resultados deixam evidente que se deve ter bastante cautela na hora de se determinar parâmetros como direção e gradiente hidráulico de escoamentos, pois dependendo do número de observações usadas, conclusões errôneas podem ser elaboradas. As informações referentes à direção e ao gradiente hidráulico do escoamento são 
de extrema importância no planejamento de redes de monitoramento da qualidade da água subterrânea, quando se procura determinar para onde ocorrerá a migração dos contaminantes.

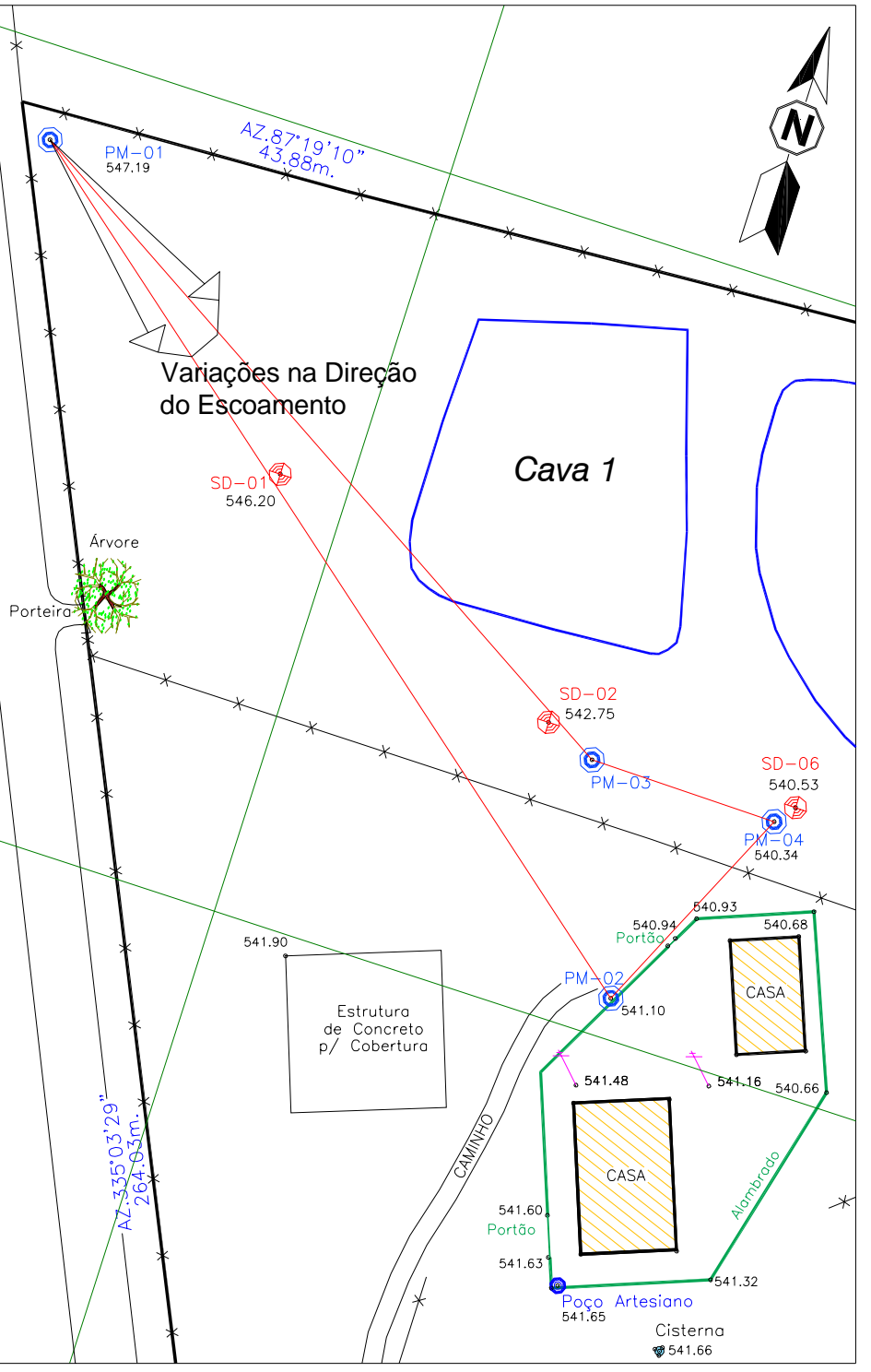

Figura 5.28 - Variações na direção do escoamento subterrâneo com base nos PMs 1, 2A, 3 e 4.

Tabela 5.8 - Resultados de direção e gradiente para os poços de monitoramento 1, 2A, 3 e 4.

\begin{tabular}{crrr}
\hline \hline Data & Gradiente Hidráulico (i) & Graus em relação ao Norte $(+y)$ & $\mathrm{R}^{2}$ (coef. de ajuste) \\
\hline $29 / 11 / 2003$ & 0,0161 & 134,9 & 0,998 \\
$31 / 03 / 2004$ & 0,0116 & 114,7 & 1,000 \\
$29 / 06 / 2004$ & 0,0155 & 127,6 & 0,999 \\
\hline \hline
\end{tabular}




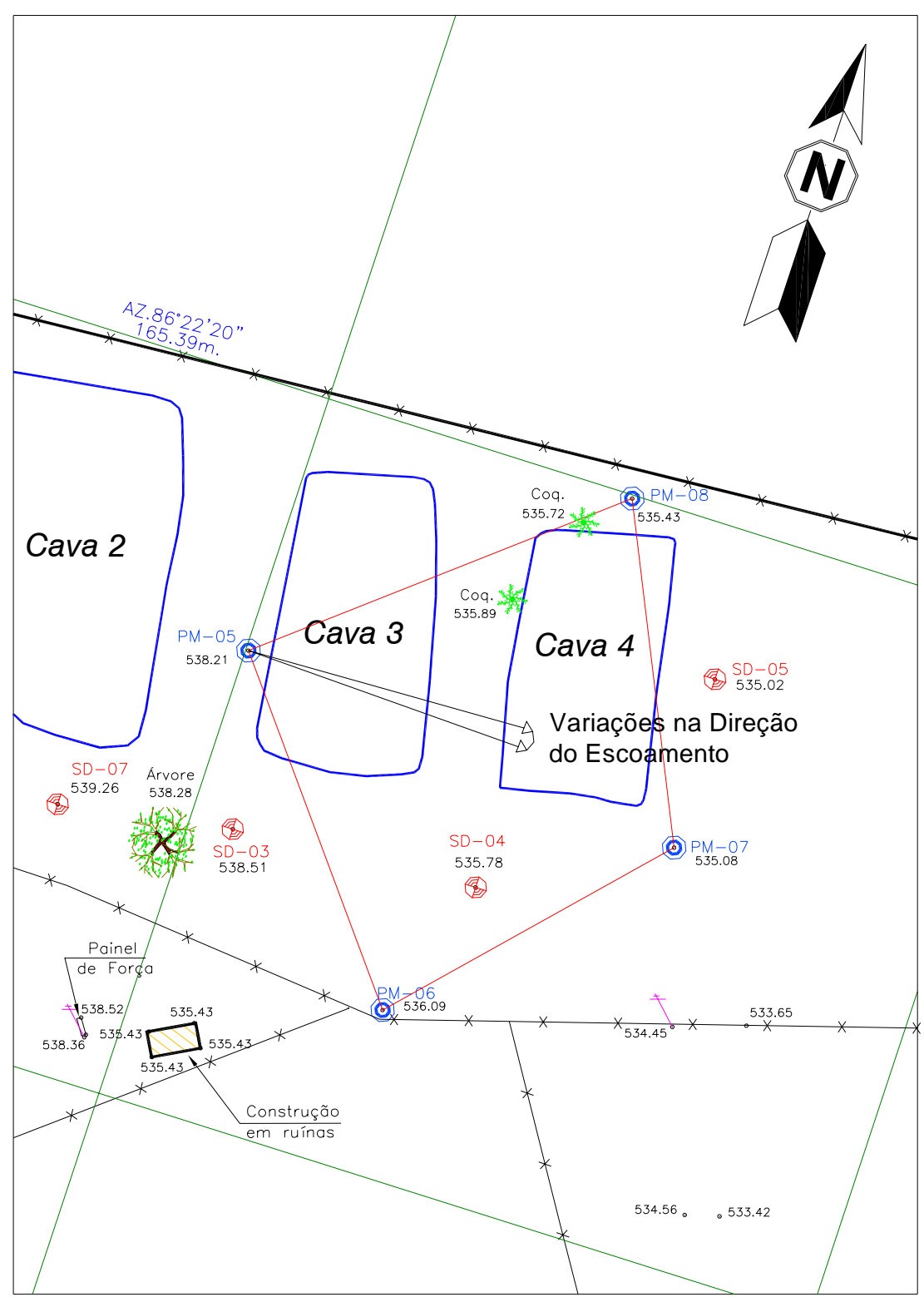

Figura 5.29 - Variações na direção do escoamento subterrâneo com base nos PMs 5, 6, 7 e 8.

Tabela 5.9 - Resultados de direção e gradiente para os poços de monitoramento 5, 6, 7 e 8.

\begin{tabular}{crrr}
\hline \hline Data & Gradiente Hidráulico (i) & Graus em relação ao Norte (+y) & $\mathrm{R}^{2}$ (coef. de ajuste) \\
\hline $29 / 11 / 2003$ & 0,0765 & 88,3 & 0,749 \\
$31 / 03 / 2004$ & 0,0846 & 88,1 & 0,750 \\
$29 / 06 / 2004$ & 0,0909 & 92,1 & 0,685 \\
\hline \hline
\end{tabular}




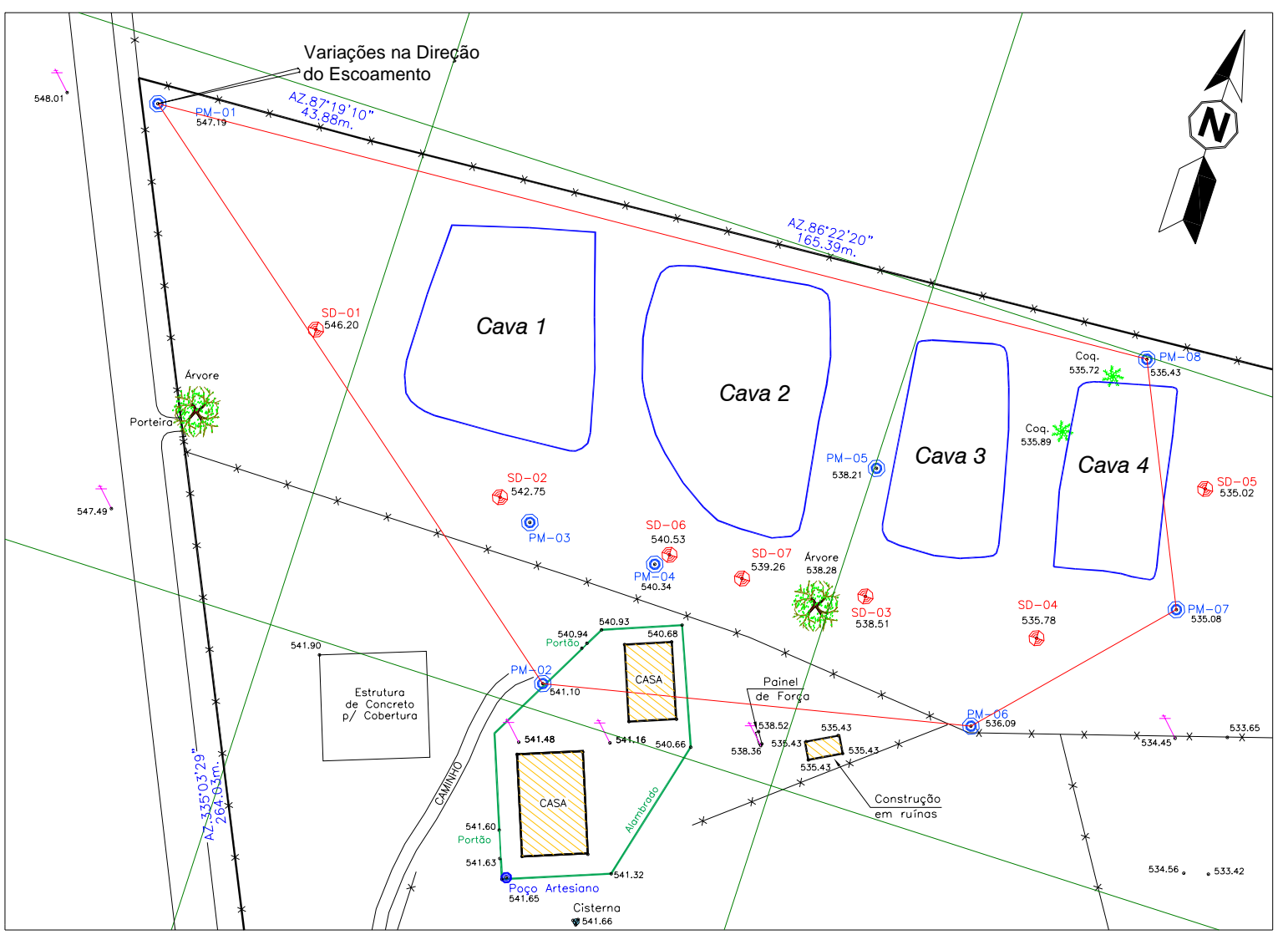

Figura 5.30 - Variações na direção do escoamento subterrâneo com base nos PMs 1, 2A, 6, 7 e 8.

Tabela 5.10 - Resultados de direção e gradiente para os poços de monitoramento 1, 2A, 6, 7 e 8 .

\begin{tabular}{crrr}
\hline \hline Data & Gradiente Hidráulico (i) & Graus em relação ao Norte (+y) & $\mathrm{R}^{2}$ (coef. de ajuste) \\
\hline $29 / 11 / 2003$ & 0,1644 & 59,2 & 0,936 \\
$31 / 03 / 2004$ & 0,1744 & 57,7 & 0,931 \\
$29 / 06 / 2004$ & 0,1695 & 59,6 & 0,930 \\
\hline \hline
\end{tabular}

Pela interpolação da média dos valores de nível de água medido nos poços de monitoramento e poços no terreno vizinho foi elaborada uma hipótese para a representação da superfície potenciométrica da área de estudo. $\mathrm{Na}$ Figura 5.31 pode ser observado mapa potenciométrico com os respectivos vetores de direção do escoamento. Acredita-se que o aqüífero suspenso, localizado na região azul da Figura 5.31, verte suas águas para o aqüífero mais profundo, situado na formação arenito, localizado na região verde da Figura 5.31. Adicionalmente, os vetores de direção do escoamento presentes na Figura 5.31 corroboram as informações de direção do escoamento presentes nas Tabelas 5.8 a 5.10 . 


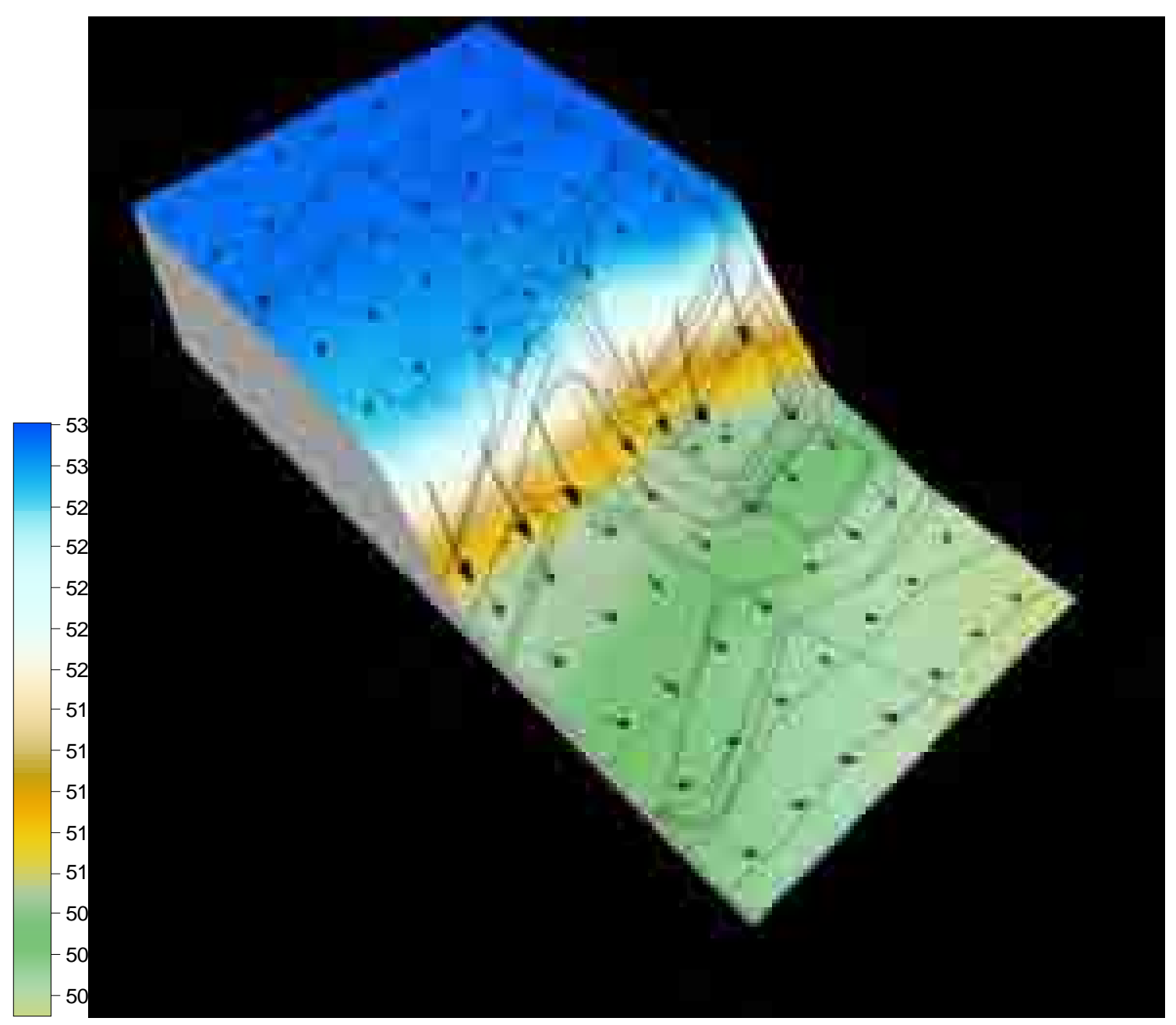

Figura 5.31 - Mapa potenciométrico mostrando a comunicação entre o aqüífero suspenso e o localizado na formação arenito.

\subsection{Interpretação dos Resultados de Slug Test}

USGS (1998) sugeriu um método simples para testar os resultados obtidos em campo no próprio campo. Este método consiste em lançar em gráfico os resultados do deslocamento do nível de água na forma adimensional $\left(\left(H_{0}-H_{t}\right) / \Delta H\right)$, neste caso rebaixamento, em escala logarítmica, em função do tempo, considerando-se o início do teste $\left(t-t_{0}\right)$, onde: $H_{0}$ é o nível de água inicial, $H_{t}$ é o nível de água em um tempo " $t$ " qualquer, $\Delta H$ é o deslocamento inicial do nível de água (elevação ou rebaixamento do nível de água) e $t_{0}$ é o tempo que o nível de água começa a se recuperar. Os resultados gráficos de testes sucessivos para um mesmo poço são sobrepostos para se ter certeza de 
que a resposta do aqüífero é a mesma. USGS (1998) menciona ainda que problemas no desenvolvimento do poço (redução da permeabilidade do préfiltro ou passagem de silte pelo filtro) podem ser evidenciados pelo aumento na inclinação dos primeiros pontos da curva de recuperação versus tempo para testes seqüenciais. Adicionalmente, se estes problemas forem observados, o primeiro resultado pode ser considerado o mais correto. Entretanto se houver uma diferença considerável na inclinação das curvas, os poços devem ser novamente desenvolvidos e ensaiados e só devem ser usados os resultados do primeiro ensaio.

Para uma melhor compreensão e interpretação inicial do comportamento dos ensaios de slug test seguiu-se o método proposto pela USGS (1998). Como apresentado no parágrafo anterior, os resultados foram lançados em gráfico relacionando-se as variações adimensionais dos níveis de água em função dos tempos de ensaio. Nas Figuras 5.32 a 5.35 pode ser observado o comportamento de cada ensaio. Percebe-se que não há gráfico para o PM-07, o que se deve à pouca quantidade de dados obtidos nos dois ensaios realizados neste poço. Para os demais poços de monitoramento foi armazenada uma variação de nível de água a cada segundo. Para o PM-07 a capacidade de armazenamento de dados do sistema de aquisição foi atingida, além do fato de se ter poucas variações, conforme já mencionado.

Em cronograma complementar (não vinculado à proposta inicial), propôs-se uma nova campanha de campo, que seria realizada no final de novembro ou início de dezembro de 2004, para certificar a qualidade do desenvolvimento nos poços mais suscetíveis de desvios neste item e, em seguida, realizar novos slug tests. A realidade social local, entretanto, restringiu essa nova ação, uma vez que houve violação e quebra das tampas de proteção dos poços. Assim, essa campanha de campo foi postergada para um tempo posterior àquele previsto para o trabalho ora apresentado.

Pela Figura 5.32 observa-se que, para o PM-01, o comportamento dos dois ensaios foi próximo. Esse critério visual de "aderência" das duas curvas, quando lineares, foi utilizado para justificar o estabelecimento do valor de $\mathrm{K}$ característico para o poço, correspondente ao valor médio dos dois resultados de condutividade hidráulica "K" obtidos. No caso de curvas não coincidentes, considerou-se válido o resultado do ensaio que apresentava maior linearidade. 
Ainda na Figura 5.32, tem-se para o PM-02 que o comportamento foi semelhante até os quatro últimos resultados e os resultados de "K" devem ser comparados antes que seja atribuído um valor médio.

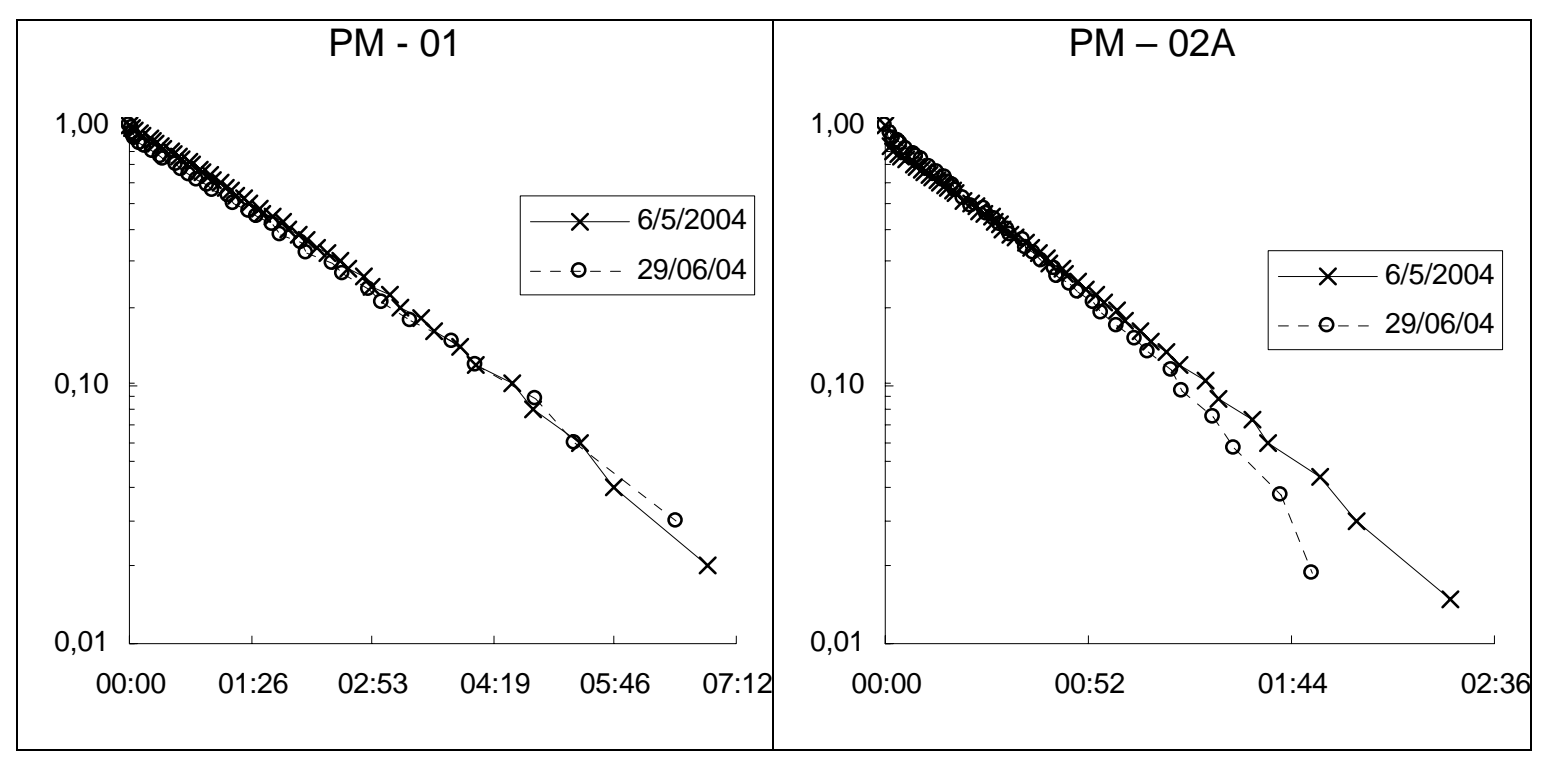

Figura 5.32 - Rebaixamento adimensional versus tempo de ensaio, para os PMs 1 e $2 A$.

$\mathrm{Na}$ Figura 5.33 pode se verificar comportamentos semelhantes nos ensaios para ambos os poços. Para o PM-02B percebe-se uma curvatura nos últimos resultados, principalmente para o ensaio realizado no dia 06/05/04. Essa curvatura pode estar vinculada à necessidade de mais desenvolvimento neste poço (eventual limpeza). Já para o PM-03 observa-se uma pequena oscilação apenas nos três últimos pontos do segundo ensaio realizado no dia 29/06/04, mas o comportamento geral nos três ensaios é similar.

Observando-se a Figura 5.34, constata-se comportamentos bem diferentes para os PMs 4 e 5. Para o PM-04, o primeiro e o terceiro ensaios apresentaram comportamento linear, mas o segundo apresentou uma curvatura (este resultado foi desprezado pelo critério aqui colocado). No PM-05 os ensaios apresentam comportamento distinto. Foi tomado como referência o resultado de condutividade hidráulica obtida no segundo ensaio, novamente seguindo os critérios aqui adotados. 


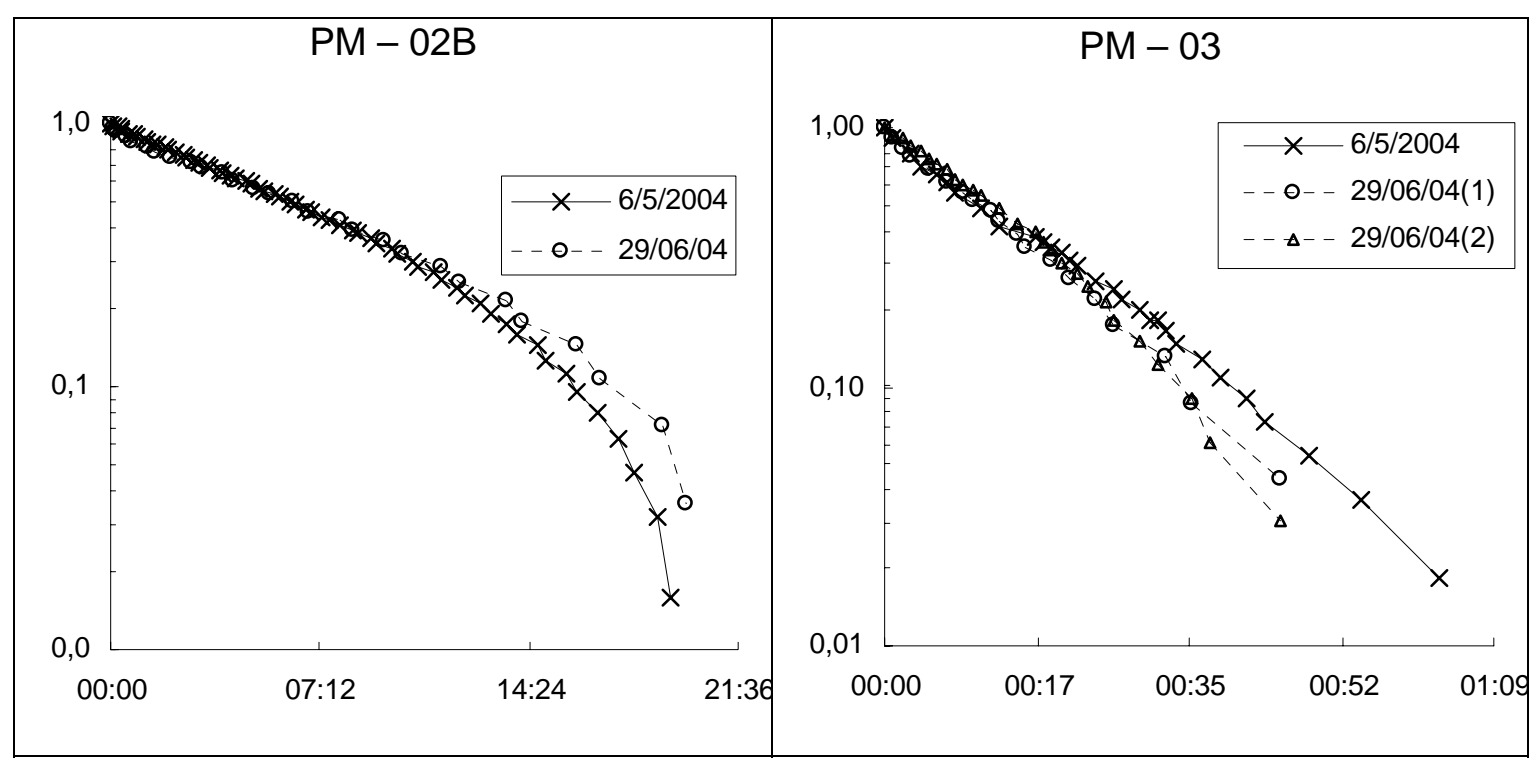

Figura 5.33 - Rebaixamento adimensional versus tempo de ensaio, para os PMs 2B e 3.

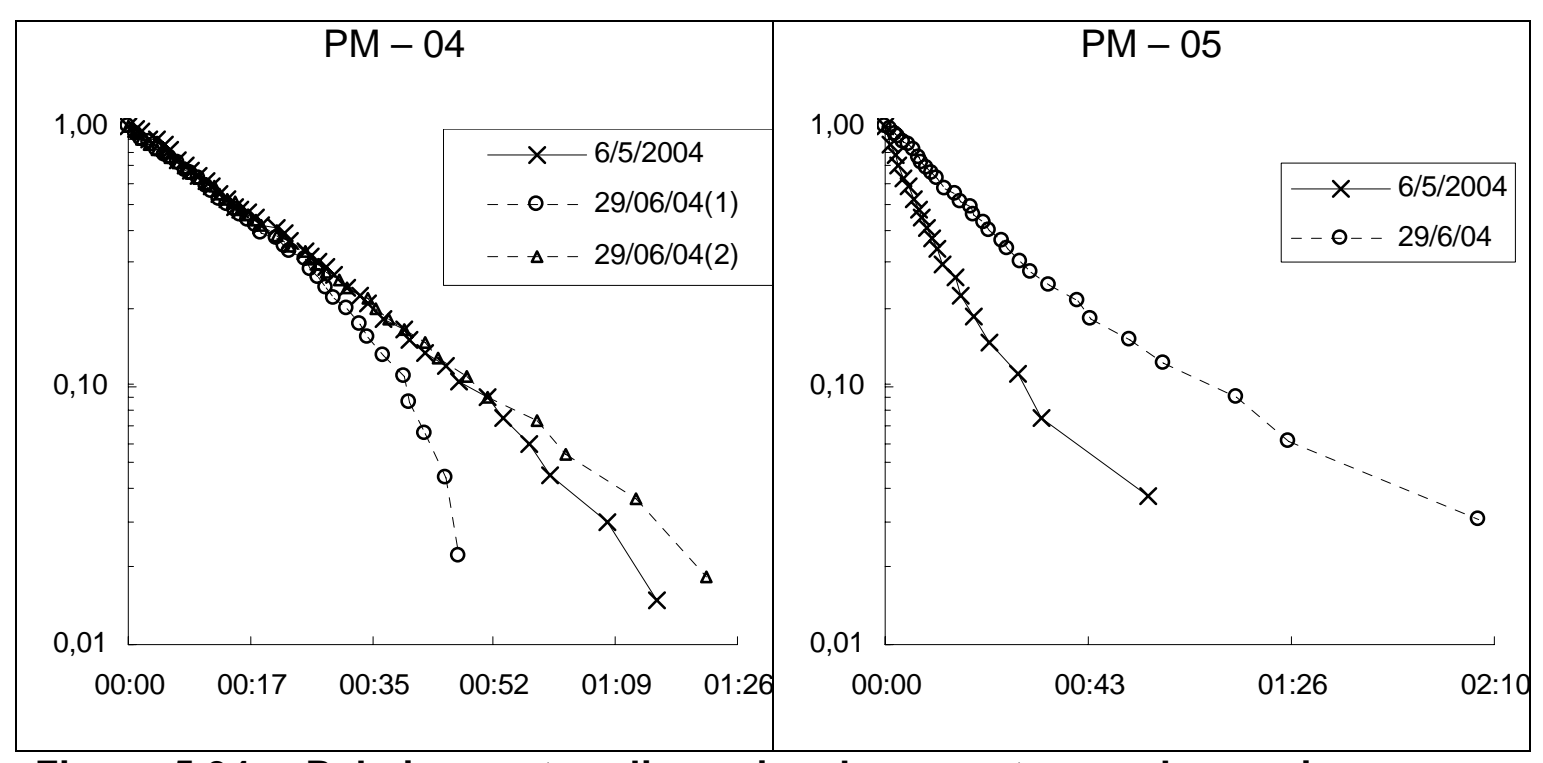

Figura 5.34 - Rebaixamento adimensional versus tempo de ensaio, para os PMs 4 e 5.

Na Figura 5.35 são apresentadas as curvas de variação para os PMs 6 e 8. Apesar de se tratar da mesma formação, os comportamentos são bem diferentes. Para o PM-06, o primeiro ensaio mostra uma inflexão inicial, sugerindo dois estágios de variação. No segundo ensaio observa-se variação significativa somente no último ponto. Nesse caso, segundo o critério adotado, considerou-se que o resultado obtido na segunda campanha representa melhor a condutividade hidráulica neste poço. Finalmente para o PM-08 nota-se curvatura em ambos os resultados (curvas dos ensaios), sugerindo que houve eventual colmatação do filtro pelas variações entre as duas tendências. Pelo 
critério já mencionado, o resultado que mantém a linearidade por um tempo maior foi o ensaio de 29/06/2004, sendo que este ensaio determinou o valor de $\mathrm{K}$ para este poço.

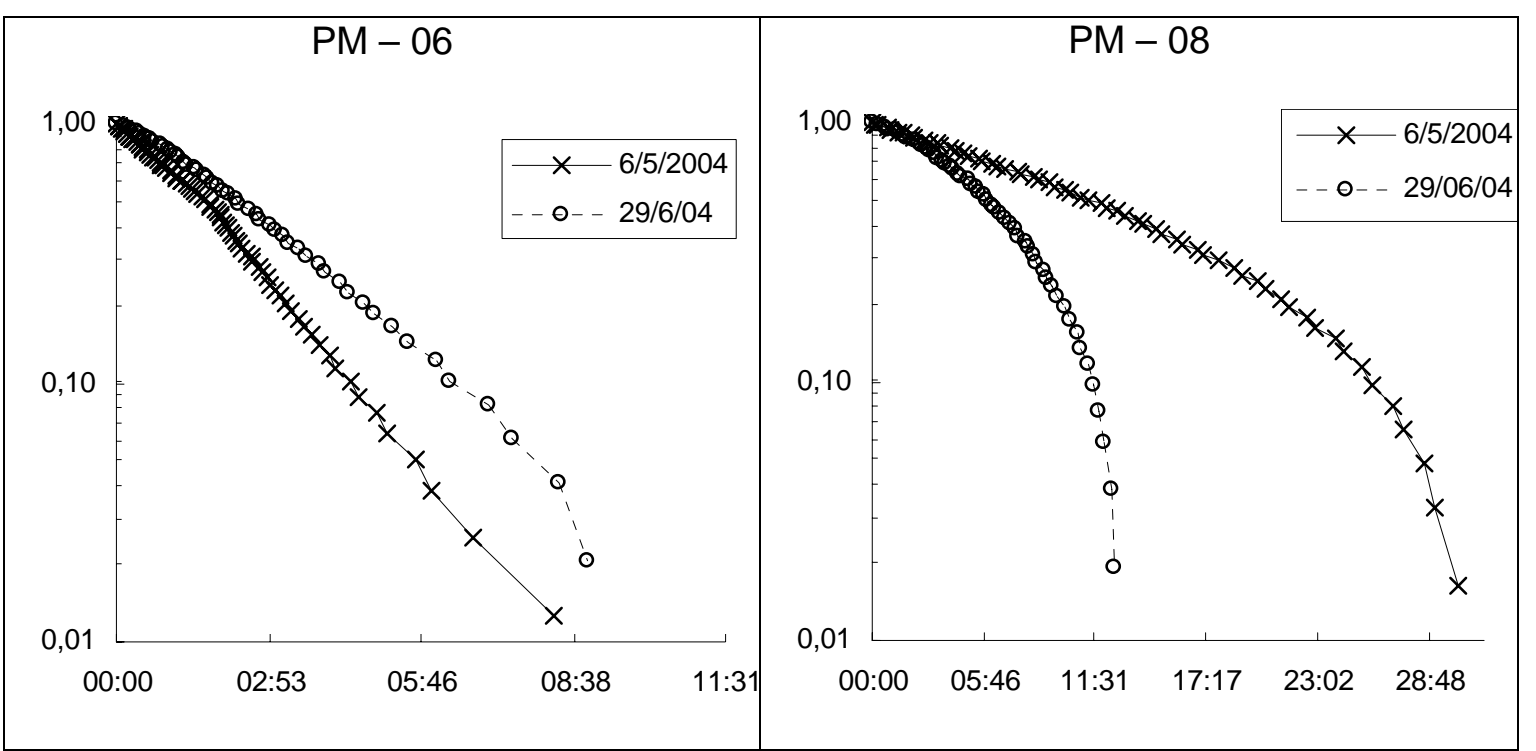

Figura 5.35 - Rebaixamento adimensional versus tempo de ensaio, para os PMs 6 e 8.

Os dados obtidos em campo também foram interpretados utilizando-se o método proposto por Bouwer e Rice, utilizando as planilhas desenvolvidas por Halford e Kuniansky (2002) para a Agência Geológica dos Estados Unidos (USGS).

$\mathrm{Na}$ Tabela 5.11 são apresentados os resultados das condutividades hidráulicas obtidas nos poços de monitoramento considerando as observações das Figuras 5.32, 5.33, 5.34 e 5.35. No Apêndice J é apresentada a Tabela "resultados dos ensaios de slug test" com todos os resultados dos testes e a descrição do método usado para deslocar o nível de água.

Pelos resultados apresentados na Tabela 5.11 observa-se que os PMs 1 e 2B possuem valores da mesma ordem de grandeza para as profundidades e formação geológica nas quais os mesmos estão posicionados. A mesma constatação pode ser feita para os PMs $2 \mathrm{~A}$, 3 e 4. Para os PMs 5, 6, 7 e 8, apesar de estarem inseridos na mesma formação geológica (arenito), os resultados são variáveis. Os valores obtidos para os PMs 5 e 6 são representativos da formação arenito. A condutividade hidráulica obtida no segundo ensaio do PM-08 é aceitável, mas as tendências apresentadas na 
Figura 5.34 mostram ser desejáveis um desenvolvimento maior e uma nova determinação de "K". O PM-07 é um caso especial. Em todas as fases de trabalho observou-se a presença de sólidos e um rebaixamento acentuado no nível de água desde a perfuração até a última medida de nível. Para o PM-07, também são desejáveis um desenvolvimento maior e uma nova determinação de "K".

Tabela 5.11 - Condutividades hidráulicas dos poços de monitoramento, determinadas por slug tests.

\begin{tabular}{lrr}
\hline \hline \multicolumn{1}{c}{ IDENTIFICAÇÃO } & \multicolumn{1}{c}{$\mathrm{K}(\mathrm{cm} / \mathrm{s})$} & \multicolumn{1}{c}{ Formação } \\
\hline PM - 01 & $4,53 \mathrm{E}-04$ & Residual de Basalto \\
$\mathrm{PM}-02 \mathrm{~A}$ & $1,97 \mathrm{E}-03$ & Colúvio \\
$\mathrm{PM}-02 \mathrm{~B}$ & $1,03 \mathrm{E}-04$ & Residual de Basalto \\
$\mathrm{PM}-03$ & $3,55 \mathrm{E}-03$ & Colúvio \\
$\mathrm{PM}-04$ & $3,26 \mathrm{E}-03$ & Colúvio \\
$\mathrm{PM}-05$ & $3,70 \mathrm{E}-03$ & Arenito \\
$\mathrm{PM}-06$ & 4,43E-04 & Arenito \\
$\mathrm{PM}-07$ & $5,31 \mathrm{E}-05$ & Arenito \\
PM - 08 & $1,57 \mathrm{E}-04$ & Arenito \\
\hline \hline
\end{tabular}

\subsection{Qualidade da Água Subterrânea}

Como descrito na metodologia, em toda campanha de campo para coleta de amostras de água subterrânea devem ser medidos em campo: temperatura, condutividade, oxigênio dissolvido, $\mathrm{pH}$ e potencial redox, porque estas determinações funcionam como indicativo da qualidade da água amostrada.

$\mathrm{Na}$ Tabela 5.12 estão descritos os resultados obtidos para os parâmetros determinados em campo. As variações na temperatura das amostras são explicáveis pelas variações na temperatura ao longo do dia. A condutividade elétrica mostrou ser um parâmetro eficiente no indicativo de contaminação ou alteração do meio, como já mencionado por USEPA (1994a), Gadotti (1998) e Clean Environment Brasil (2003), entre outros. Os valores de 
condutividade elétrica para águas naturais sem contaminação variam entre 50 e $65 \mathrm{mS} / \mathrm{cm}$; valores acima de 100,0 $\mathrm{mS} / \mathrm{cm}$ sugerem contaminação, por outro lado valores abaixo de $35,0 \mathrm{mS} / \mathrm{cm}$ podem ser usados como indício de alteração do meio. $\mathrm{O}$ pH e potencial redox (Eh) também são parâmetros que sugerem indícios de contaminação ou pelo menos alteração do meio. Como foi observado para as amostras de solo, o pH levemente ácido é característico do solo local. Entretanto, no presente trabalho considera-se que valores próximos a 4,0 sugerem contaminação do meio, considerando a existência do percolado ácido. A mesma argumentação (percolado ácido) sugere que valores de Eh acima de $125 \mathrm{mV}$ indicam contaminação.

As informações das concentrações de oxigênio dissolvido não foram discutidas por se tratar de uma informação que varia bastante de poço para poço, dependendo de vários fatores como: velocidade de inserção e remoção do amostrador, modo como a amostra foi coletada e vertida no recipiente para análise, temperatura ambiente, etc.

Tabela 5.12 - Resultados de parâmetros de qualidade de água, medidos em campo.

\begin{tabular}{lrrrrr}
\hline \hline Amostra & $\begin{array}{r}\text { Temperatura } \\
\left({ }^{\circ} \mathrm{C}\right)\end{array}$ & $\begin{array}{r}\text { Condutividade } \\
\text { elétrica }(\mathrm{mS} / \mathrm{cm})\end{array}$ & $\begin{array}{r}\text { Conc. de OD } \\
(\mathrm{mg} / \mathrm{L})\end{array}$ & $\mathrm{pH}$ & Eh $(\mathrm{mV})$ \\
\hline PB & 27,1 & 49,0 & 4,4 & 5,8 & 122,5 \\
Cisterna & 25,8 & 54,0 & 5,8 & 5,9 & 118,5 \\
PM - 01 & 26,2 & 60,0 & 4,9 & 6,3 & 105,7 \\
PM - 02 A & 26,4 & 55,0 & 5,6 & 6,2 & 90,7 \\
PM - 02 B & 26,7 & 138,0 & 4,5 & 6,4 & 86,2 \\
PM - 03 & 26,3 & 37,0 & 3,9 & 5,9 & 127,8 \\
PM -04 & 26,7 & 44,0 & 3,0 & 5,8 & 123,4 \\
PM -05 & 27,2 & 816,0 & 4,8 & 3,9 & 217,5 \\
PM - 06 & 27,7 & 504,0 & 3,0 & 4,2 & 192,6 \\
PM -07 & 26,9 & 484,0 & 4,6 & 5,8 & 136,9 \\
PM-08 & 26,5 & 5,2 & 5,7 & 6,0 & 113,7 \\
\hline \hline
\end{tabular}

No Apêndice L são mostradas as planilhas de campo usadas no esgotamento e na coleta das amostras de água, com as informações dos níveis de água medidos, volumes coletados, aspecto das amostras coletadas, etc. Para o esgotamento, a análise dos dados mostra que os PMs 7 e 8 foram os que apresentaram maiores complicações operacionais. Por outro lado, para a coleta, a análise dos dados aponta que após o esgotamento os níveis retornaram praticamente para as condições anteriores ao esgotamento. 
Também se observou que as amostras coletadas nos PMs 1, 2A e B, 5, 7 e 8 apresentaram níveis de turbidez visual variados.

Na Tabela 5.13 são apresentados os resultados das concentrações de metais em água subterrânea. A Tabela 5.13 é composta pelos limites de detecção e quantificação para cada metal, pelos brancos usados para controle, pelas amostras de cada poço com a denominação total (sem filtração das amostras) e filtrado (com filtração das amostras) e pelos limites de potabilidade descritos na portaria 518/04, editada pelo Ministério da Saúde.

Pela avaliação dos resultados, percebe-se que as concentrações de zinco $(Z n)$ encontradas estão bem abaixo do limite de potabilidade, mas as amostras do PM-05 apresentaram concentrações bastante elevadas em relação às demais amostras. Para esta região deve-se lembrar que o teor de ferro no solo é elevado. Como conseqüência, a concentração de ferro (Fe) em um poço passa a ser dependente do desenvolvimento desse poço. Uma observação que corrobora esta conclusão é o fato de nenhuma das amostras filtradas apresentar concentrações acima do limite de quantificação. Com relação ao cobre $(\mathrm{Cu})$, obteve-se resultados semelhantes aos encontrados para o Zn, pois as concentrações ficam bem abaixo do limite de potabilidade. Todavia as amostras coletadas no PM-05 apresentaram concentrações bem acima das demais amostras. Pela observação das concentrações de chumbo $\mathrm{Pb}$ ) verifica-se que o limite de potabilidade foi ultrapassado nas amostras coletadas nos PMs 2A, 5, 7 e 8. Se forem levadas em consideração somente as amostras filtradas, ainda assim as coletas dos PMs 2A e 5 continuam acima do referencial utilizado. Para o manganês $(\mathrm{Mn})$ o limite de potabilidade foi ultrapassado nas amostras dos PMs 5 e 6, totais e filtradas. Segundo WHO (2002), a mobilidade do manganês é acentuada por baixos valores de $\mathrm{pH}$ e Eh. Desta forma, como os valores de pH e Eh medidos nos PMs 5 e 6 são extremos, acredita-se que as condições de mobilidade foram atingidas nestes pontos de coleta. Adicionalmente, talvez a mesma constatação das condições de $\mathrm{pH}$ e Eh feita para o Mn seja válida para o cobre, pois as concentrações mais elevadas coincidem com os mesmos pontos de coleta (PMs 5 e 6). O metal titânio (Ti) não possui limite de aceitação vinculado à potabilidade, mas observa-se novamente que os resultados obtidos para o PM-05 são bem mais elevados que os demais, sugerindo contaminação. 
Tabela 5.13 - Resultados das concentrações de metais em água subterrânea em $\mu g / L$.

\begin{tabular}{|c|c|c|c|c|c|c|c|c|}
\hline Amostra & $\mathrm{Zn}$ & $\mathrm{Fe}$ & $\mathrm{Cu}$ & $\mathrm{Pb}$ & $\mathrm{Mn}$ & $\mathrm{Ti}$ & $\mathrm{Sr}$ & Al \\
\hline Limite de Detecção & 1,68 & 31,0 & 1,0 & 0,15 & 21,1 & 0,05 & 0,02 & 1,91 \\
\hline Limite de Quantificação & 5,61 & 103,0 & 3,2 & 0,51 & 70,2 & 0,18 & 0,08 & 6,36 \\
\hline Branco Filtração Inicial & NQ & ND & NQ & 1,4 & ND & 1,9 & 0,4 & 58,7 \\
\hline Branco Filtração Final & NQ & ND & ND & 2,2 & NQ & 0,3 & 0,6 & 53,5 \\
\hline Branco Digestão 1 & NQ & ND & NQ & 1,5 & ND & 0,4 & ND & 30,7 \\
\hline Branco Digestão 2 & NQ & ND & NQ & 1,7 & ND & 0,3 & ND & 27,9 \\
\hline Branco Digestão 3 & NQ & ND & ND & 2,3 & NQ & ND & 0,9 & 97,6 \\
\hline Branco Digestão 4 & NQ & ND & ND & 1,9 & NQ & ND & ND & 18,1 \\
\hline Branco Coletor & NQ & ND & NQ & 1,7 & ND & 0,7 & ND & 27,9 \\
\hline Branco Armazenamento & NQ & ND & NQ & 2,0 & NQ & NQ & 0,5 & 41,8 \\
\hline PM - 01 Total & 12,9 & 2883,0 & NQ & 4,1 & NQ & 11,5 & 321,1 & 25694,5 \\
\hline PM - 01 Filtrado & NQ & NQ & NQ & 3,1 & NQ & 7,9 & 276,6 & 267,5 \\
\hline PM - 02 A Total & NQ & 278,0 & NQ & 16,8 & ND & 14,3 & 54,9 & 4336,6 \\
\hline PM - 02 A Filtrado & 8,3 & NQ & ND & 12,6 & NQ & 2,9 & 53,4 & 155,4 \\
\hline PM - 02 B Total & NQ & 213,0 & NQ & 1,6 & ND & 14,1 & 131,1 & 3457,0 \\
\hline PM - 02 B Filtrado & 6,3 & NQ & ND & 1,5 & NQ & 6,3 & 139,2 & 109,7 \\
\hline PM - 03 Total & NQ & NQ & ND & 7,4 & ND & 6,8 & 26,8 & 565,5 \\
\hline PM - 03 Filtrado & NQ & ND & NQ & 9,0 & NQ & 0,7 & 33,2 & 101,0 \\
\hline PM - 04 Total & NQ & NQ & NQ & 6,6 & NQ & 4,1 & 24,6 & 1494,9 \\
\hline PM - 04 Filtrado & 6,3 & NQ & NQ & 2,9 & NQ & 0,4 & 24,6 & 114,7 \\
\hline PM - 05 Total & 363,7 & 2657,0 & 96,0 & 23,4 & 244,0 & 154,7 & 348,8 & 63924,7 \\
\hline PM - 05 Filtrado & 362,2 & NQ & 52,0 & 10,5 & 239,0 & 28,4 & 352,1 & 352,1 \\
\hline PM - 06 Total & 63,3 & NQ & 5,0 & 6,7 & 228,0 & 26,1 & 385,6 & 8460,1 \\
\hline PM - 06 Filtrado & 62,9 & NQ & 6,0 & 2,6 & 168,0 & 16,5 & 428,6 & 428,6 \\
\hline PM - 07 Total & 32,1 & 2353,0 & 4,0 & 30,6 & 96,0 & 41,3 & 1136,6 & 20561,6 \\
\hline PM - 07 Filtrado & 7,3 & NQ & NQ & 1,3 & NQ & 15,1 & 768,9 & 225,1 \\
\hline PM - 08 Total & 10,5 & 165,0 & NQ & 17,5 & NQ & 12,5 & 78,8 & 2769,4 \\
\hline PM - 08 Filtrado & 7,3 & $\mathrm{NQ}$ & $\mathrm{NQ}$ & ND & NQ & 3,1 & 69,6 & 102,6 \\
\hline PB Total & 8,3 & ND & ND & 2,8 & NQ & 3,5 & 65,7 & 216,1 \\
\hline PB Filtrado & NQ & NQ & $\mathrm{NQ}$ & ND & NQ & 1,4 & 69,5 & 78,9 \\
\hline Cisterna Total & NQ & ND & ND & 3,2 & NQ & 1,9 & 66,4 & 216,0 \\
\hline Cisterna Filtrado & NQ & NQ & ND & ND & $\mathrm{NQ}$ & 1,1 & 58,2 & 79,5 \\
\hline $\begin{array}{l}\text { Valor Máximo Permitido } \\
(518 / 04)\end{array}$ & 5000,0 & 300,0 & 2000,0 & 10,0 & 100,0 & $\mathrm{NC}$ & NC & 200,0 \\
\hline
\end{tabular}

NQ - Não quantificado;

ND - Não detectado;

NC - Não consta.

Como para o Ti, o estrôncio (Sr) não consta na portaria 518/04 editada pelo Ministério da Saúde, contudo nota-se que concentrações para os PMs 1, 5, 6 e 7 ficaram bem mais elevadas que as demais, sugerindo contaminação. Ainda com relação ao estrôncio, como o PM-01 é um poço de controle e, pelas condições de escoamento local, não sofre influências dos resíduos estudados 
nesta pesquisa, acredita-se que as concentrações elevadas advêm de elevada concentração de sólidos na amostra (constatado por observação visual). Finalmente, as concentrações de alumínio (Al) em todas as amostras não filtradas ficaram acima do limite de potabilidade, bem como as amostras filtradas coletadas nos PMs 1, 5, 6 e 7. Como mencionado para o estrôncio, acredita-se que as elevadas concentrações de alumínio encontradas no PM-01 advêm da elevada concentração de sólidos na amostra.

Os resultados de contaminação mais evidentes são para o chumbo e para o alumínio. Entretanto, deve-se lembrar que o alumínio é naturalmente presente no solo. Assim, a simulação do escoamento e das concentrações, com base em modelos numéricos, foi dirigida para a propagação da pluma do contaminante chumbo, conforme está descrito no subitem seguinte. Ademais, no momento da construção dos modelos de escoamento e transporte não se dispunha das concentrações de Mn.

\subsection{Simulação Numérica}

O mapa sobre o qual se trabalhou na simulação numérica foi obtido através da digitalização de parte do mapa elaborado pelo IBGE para a cidade de Ribeirão Preto, em escala de 1:50.000, sendo apresentados nesses itens os resultados referenciados a posições nesse mapa (ver Apêndice $D$ ). As figuras apresentadas neste subitem foram obtidas pela cópia direta das telas de trabalho do programa Groundwater Vistas ou por digitalização em Autocad das imagens de saída do Groundwater Vistas. Em alguns casos foram utilizadas as ferramentas de aproximação para observações mais detalhadas da área de estudo.

Conforme mencionado no item 4.12.4, quando da construção do modelo de escoamento, foram definidas áreas de diferentes condutividades para as camadas 2, 3 e 4 por se tratar de uma região de contato entre os solos residuais de basalto e arenito. $O$ contato foi definido como uma seção retangular que se estende desde o sítio em estudo até o Ribeirão Preto. $\mathrm{Na}$ Figura 5.36 pode ser observada em vermelho a região de contato mencionada. 


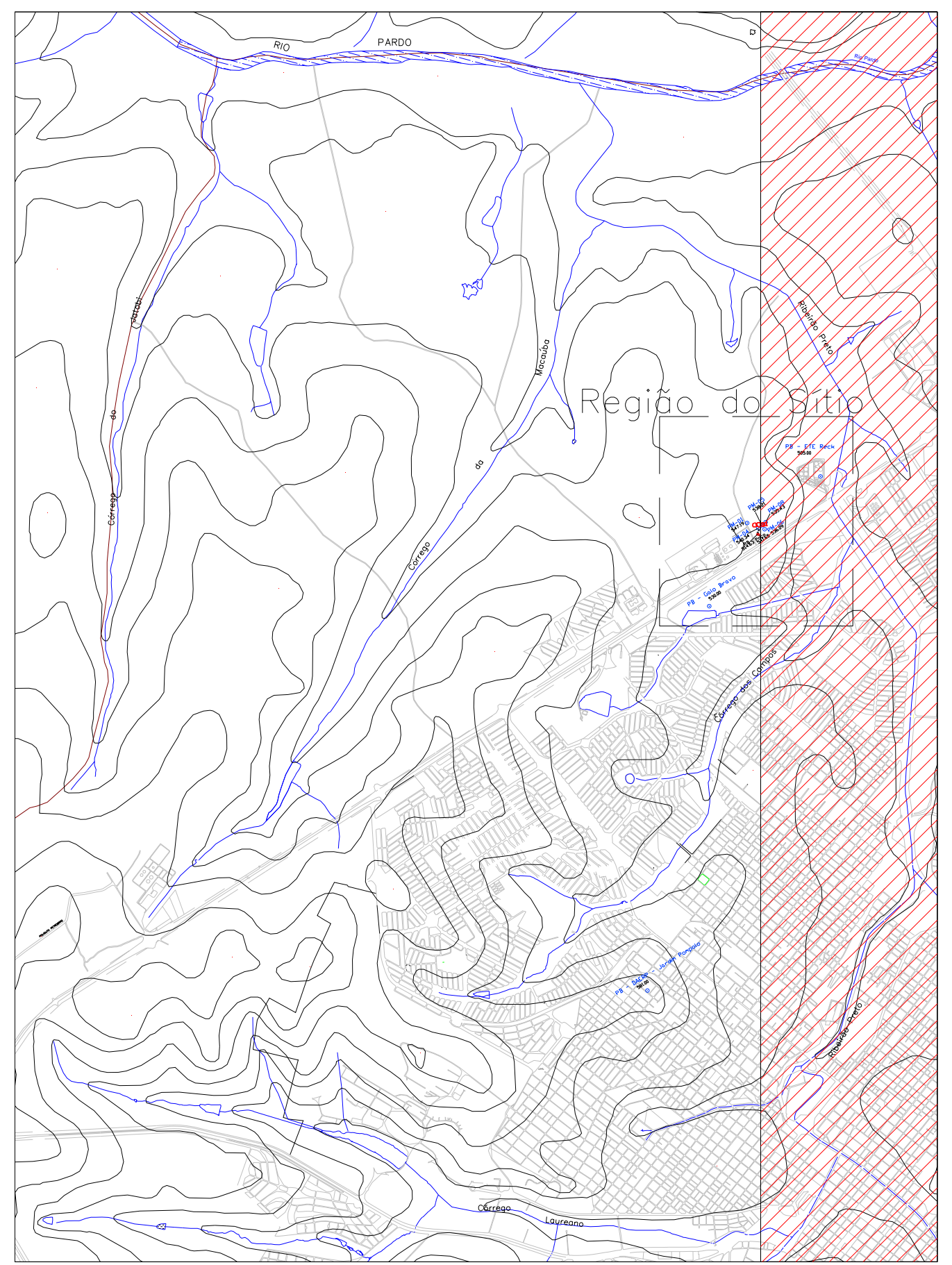

Figura 5.36 - Mapa definindo as condutividades hidráulicas (K) das camadas 2,3 e 4 do modelo numérico. A região em vermelho refere-se à zona de maior "K". Foram definidas apenas dois valores de "K" diferentes nas camadas 2, 3 e 4, sendo que nas demais camadas restringiu-se o uso a só um valor de "K".

Os valores das condutividades hidráulicas corrigidos pela análise de sensibilidade podem ser observados na Figura 5.37. É importante mencionar que a segunda análise de sensibilidade não envolveu correções na 
condutividade hidráulica, como mencionado na metodologia. Ademais, os incrementos sugeridos para as outras variáveis mostraram-se irreais, tendo sido desconsiderados.

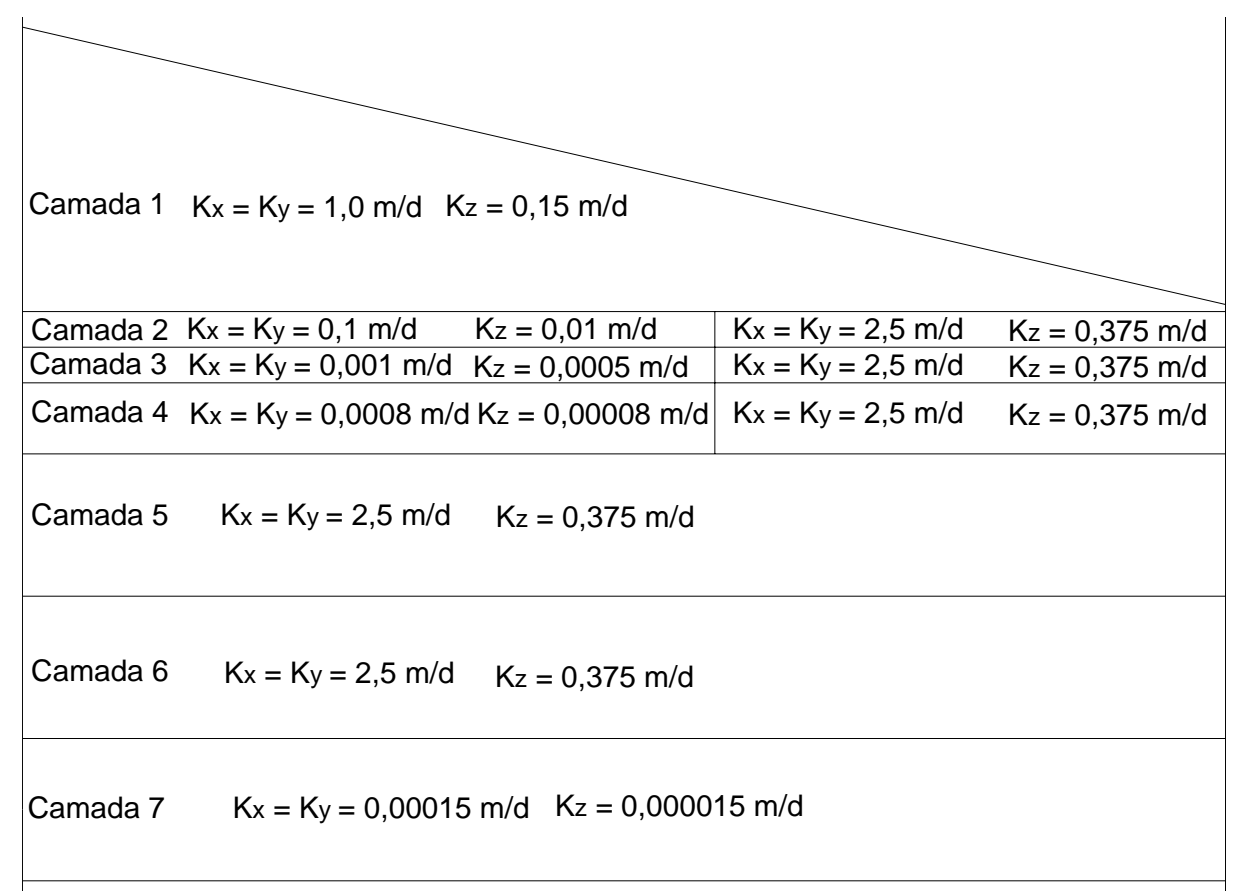

Figura 5.37 - Condutividades hidráulicas usadas no modelo de transporte.

Como já descrito na metodologia, as condições de contorno utilizadas foram os contornos físicos dos rios, ribeirões e córregos, com as cotas da água neles contida. Na Figura 5.38 pode-se observar os contornos utilizados, o comportamento das linhas equipotenciais e os vetores de direção de escoamento. O uso do MODFLOW e do MT3D mostrou-se adequado, porém considerando uma abordagem dos contornos em "escala regional", isto é, localizando os contornos distantes da região de trabalho. Vale frisar, para ilustrar esta conclusão, que este procedimento nem sempre é seguido, como pode ser observado no trabalho de Rocca (2000). A proximidade dos contornos torna uma previsão muito dependente dos mesmos, enquanto que a abordagem regional permite que a situação "real" se manifeste. 


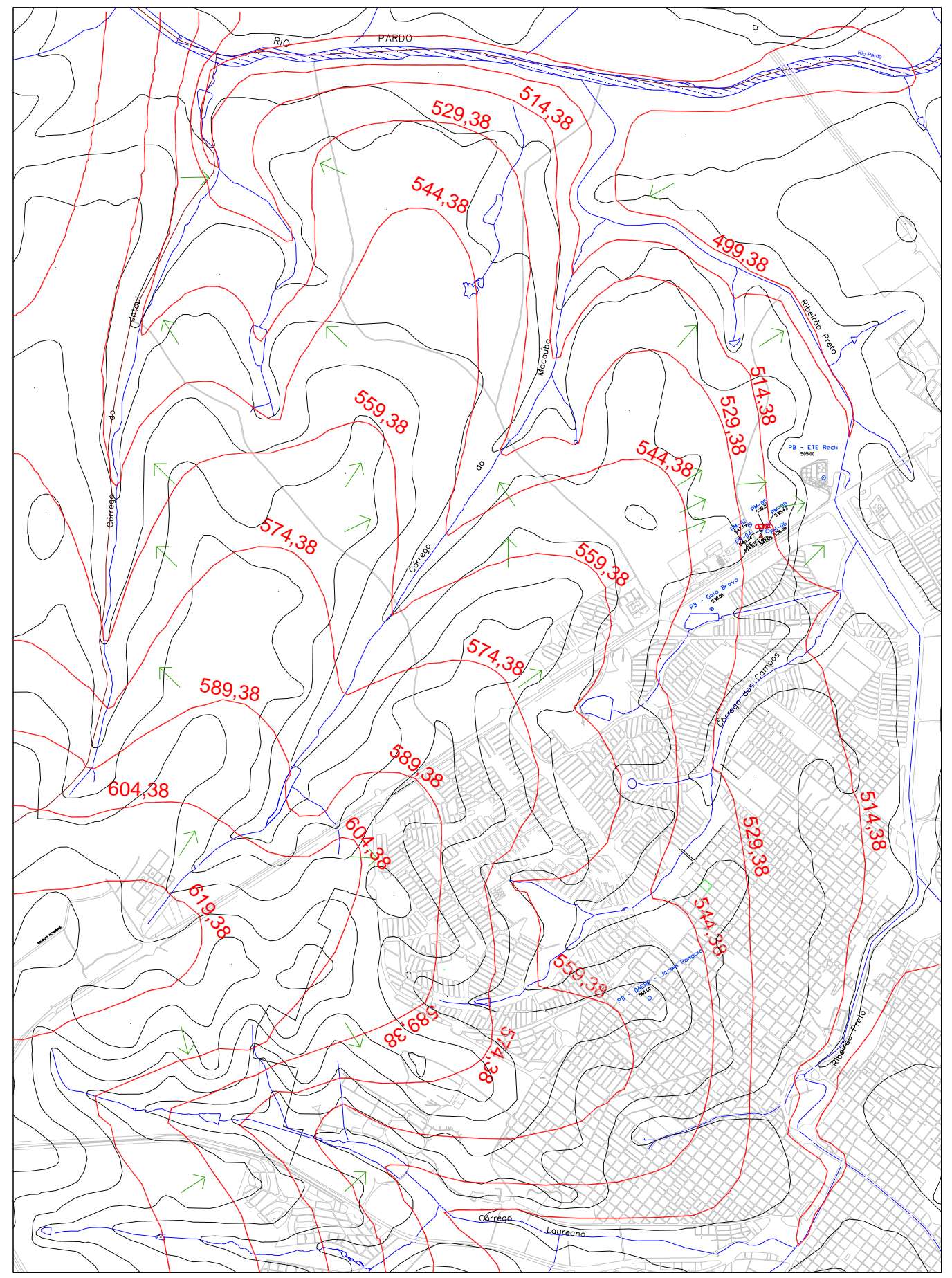

Figura 5.38 - Mapa definindo as condições de contorno, cargas hidráulicas e vetores de direção do escoamento. As flechas indicam as direções dos escoamentos para a camada superficial de solo. A cota dos rios e a topografia definem as condições de contorno. As linhas em vermelho definem as cargas hidráulicas, considerando a primeira camada de solo na simulação efetuada.

Pelas Figuras 5.39 a 5.45 podem ser observadas as direções do escoamento para as sete camadas do modelo, mostrando grande variação no padrão de escoamento ao longo da profundidade. Esta variação é decorrente 
dos diferentes materiais que compõe o perfil do solo (descritos pelos diferentes valores da condutividade hidráulica). Atente-se para a influência do contorno (rio) na primeira camada e a influência do poço existente na estação de tratamento de esgotos na sexta camada. Salienta-se que, na realidade, a distribuição dos materiais encontrados em sub-superfície, em termos de condutividade hidráulica, não é tão simplificado com representado pelo modelo, sendo a distribuição dos valores de condutividade hidráulica, em campo, muito irregular. Todavia, os resultados descrevem a maneira abordada na construção do modelo para as diferentes litologias.

$\mathrm{Na}$ Figura 5.38 podem ser observadas parcialmente as diferenças entre as cargas hidráulicas observadas em campo e geradas pelo modelo nos pontos de referência (targets) para a primeira camada. No PM-01 a diferença foi positiva de 5,70 $\mathrm{m}$, isto quer dizer que o valor simulado está $5,70 \mathrm{~m}$ abaixo do valor observado em campo. Já no poço de grande diâmetro (cisterna) a diferença foi positiva de 8,18 $\mathrm{m}$, para o PM-05 a diferença foi negativa de 8,92 $m$ e finalmente para o PM-08 foi negativa de $8,75 \mathrm{~m}$. Para o PB da ETE (próximo ao Ribeirão Preto) a diferença foi negativa de $85,47 \mathrm{~m}$ e para o PB da Destilaria Galo Bravo a diferença foi positiva de 75,16 m. As grandes diferenças observadas nos poços de bombeamento da ETE e do Galo Bravo provavelmente estão vinculadas às informações imprecisas de nível dinâmico, condição de confinamento no poço do Galo Bravo e constância de parâmetros assumidos no modelo.

Pelas estatísticas fornecidas pelo programa Groundwater Vistas, os resultados da calibração são considerados aceitáveis quando o RMS (raiz quadrada da média dos erros elevados ao quadrado) ajustado for inferior a 10\%. Nesta simulação o RMS foi de $9,8 \%$ sendo portanto um valor aceitável.

Nota-se nas Figuras 5.39 a 5.41 elevados gradientes de velocidade que estão diretamente relacionados às condições de variação das condutividades hidráulicas atribuídas na construção do modelo. 


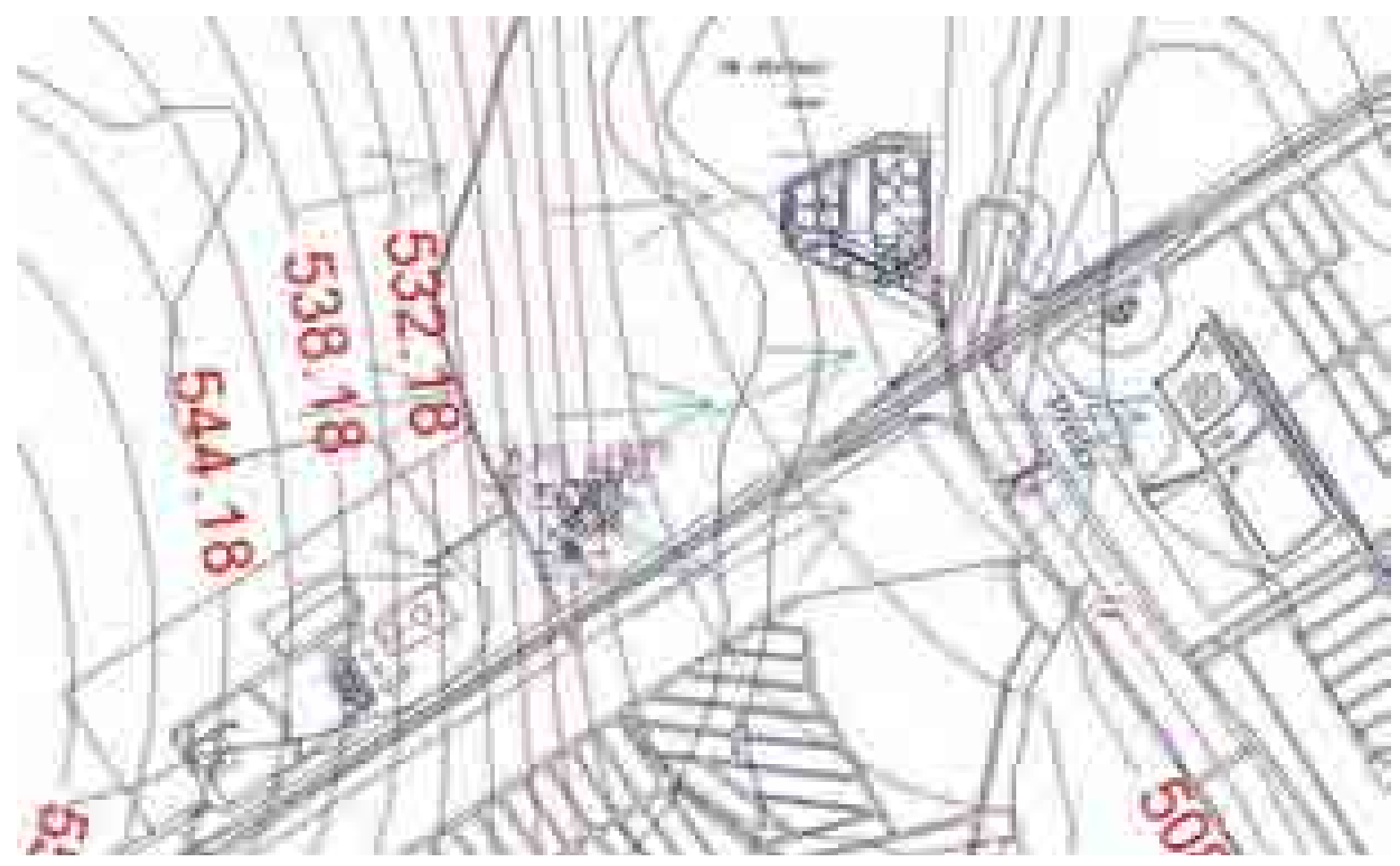

Figura 5.39 - Mapa das cargas hidráulicas na primeira camada do modelo para a região do sítio estudado e imediações.

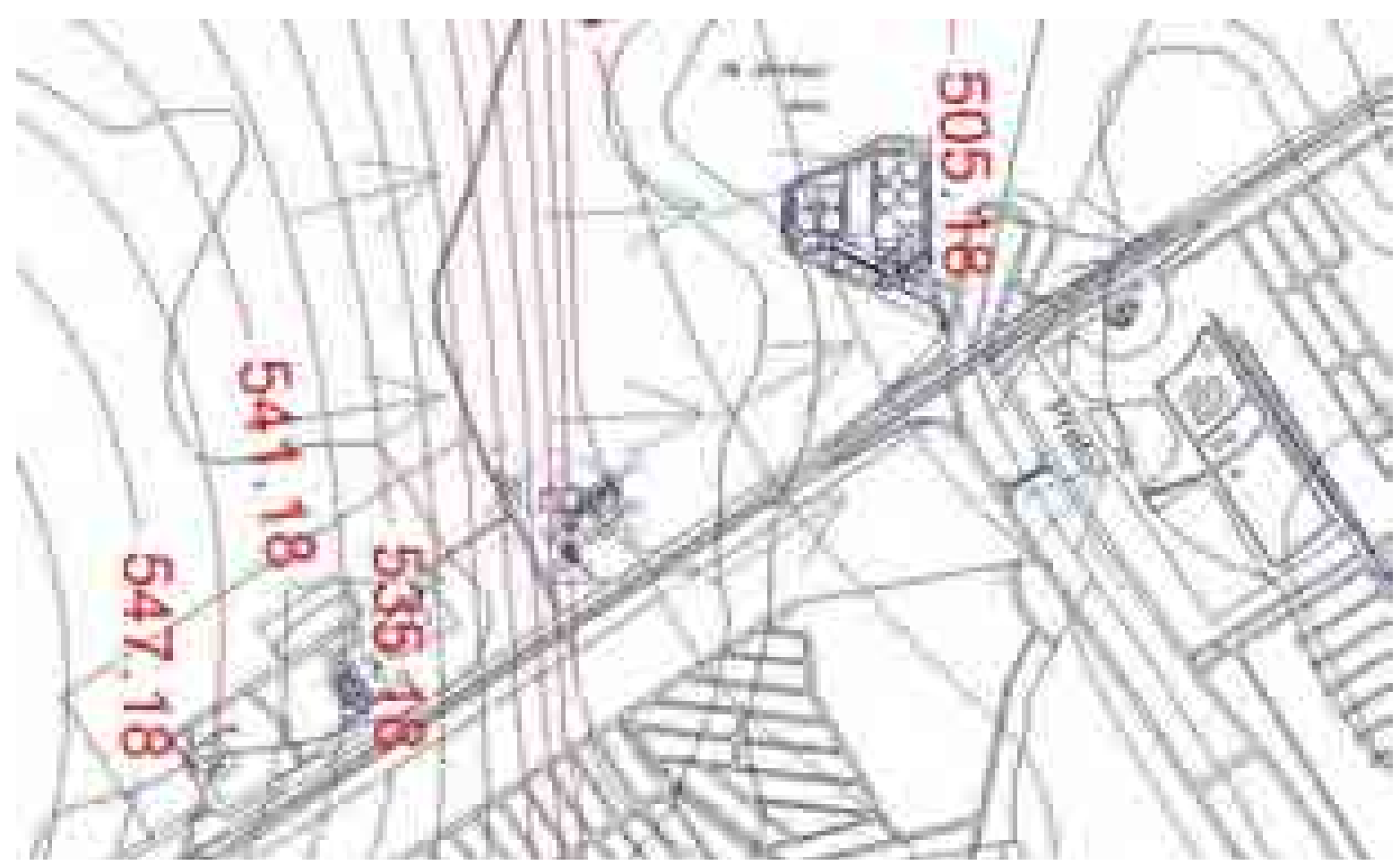

Figura 5.40 - Mapa das cargas hidráulicas na segunda camada do modelo para a região do sítio estudado e imediações. 


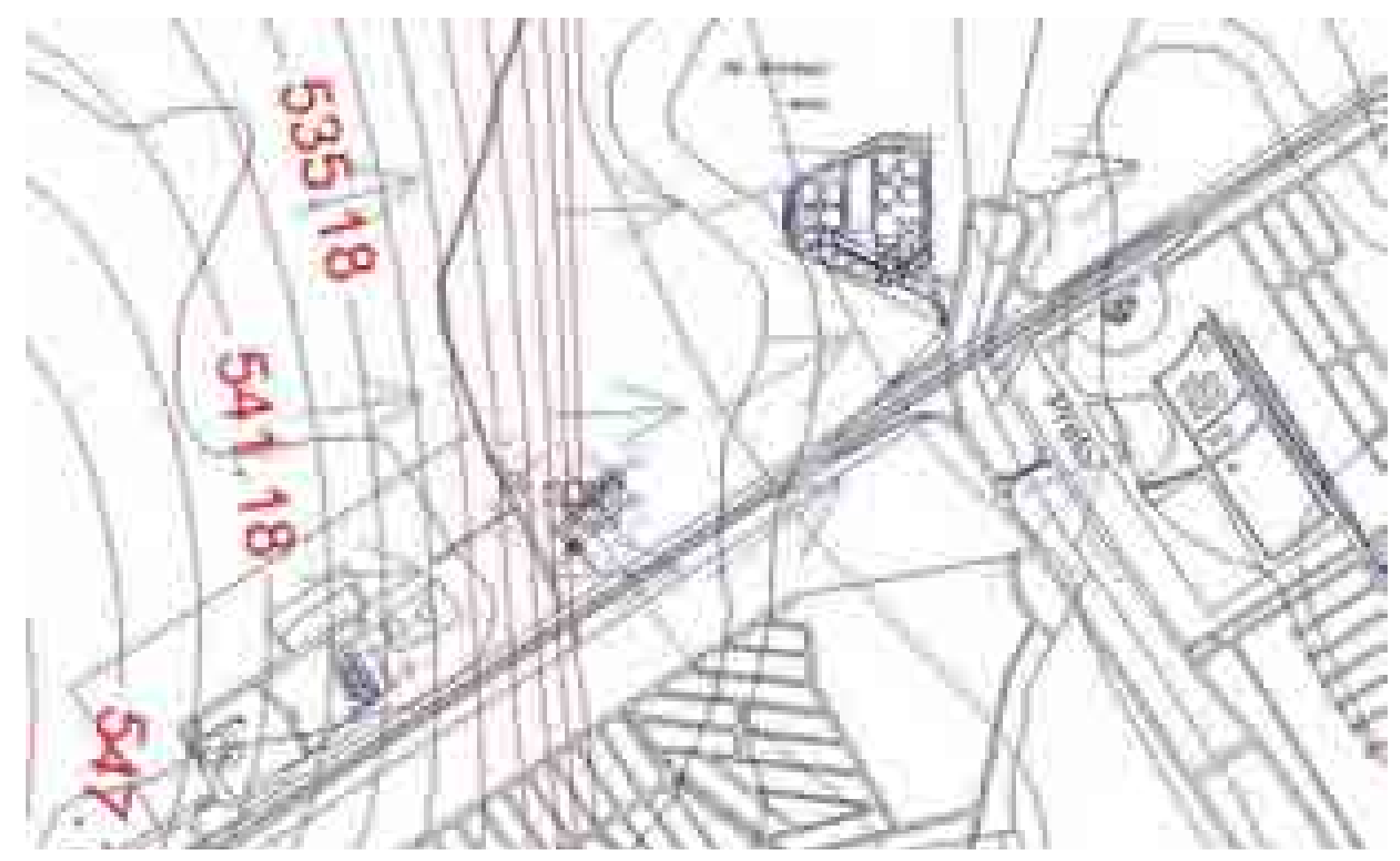

Figura 5.41 - Mapa das cargas hidráulicas na terceira camada do modelo para a região do sítio estudado e imediações.

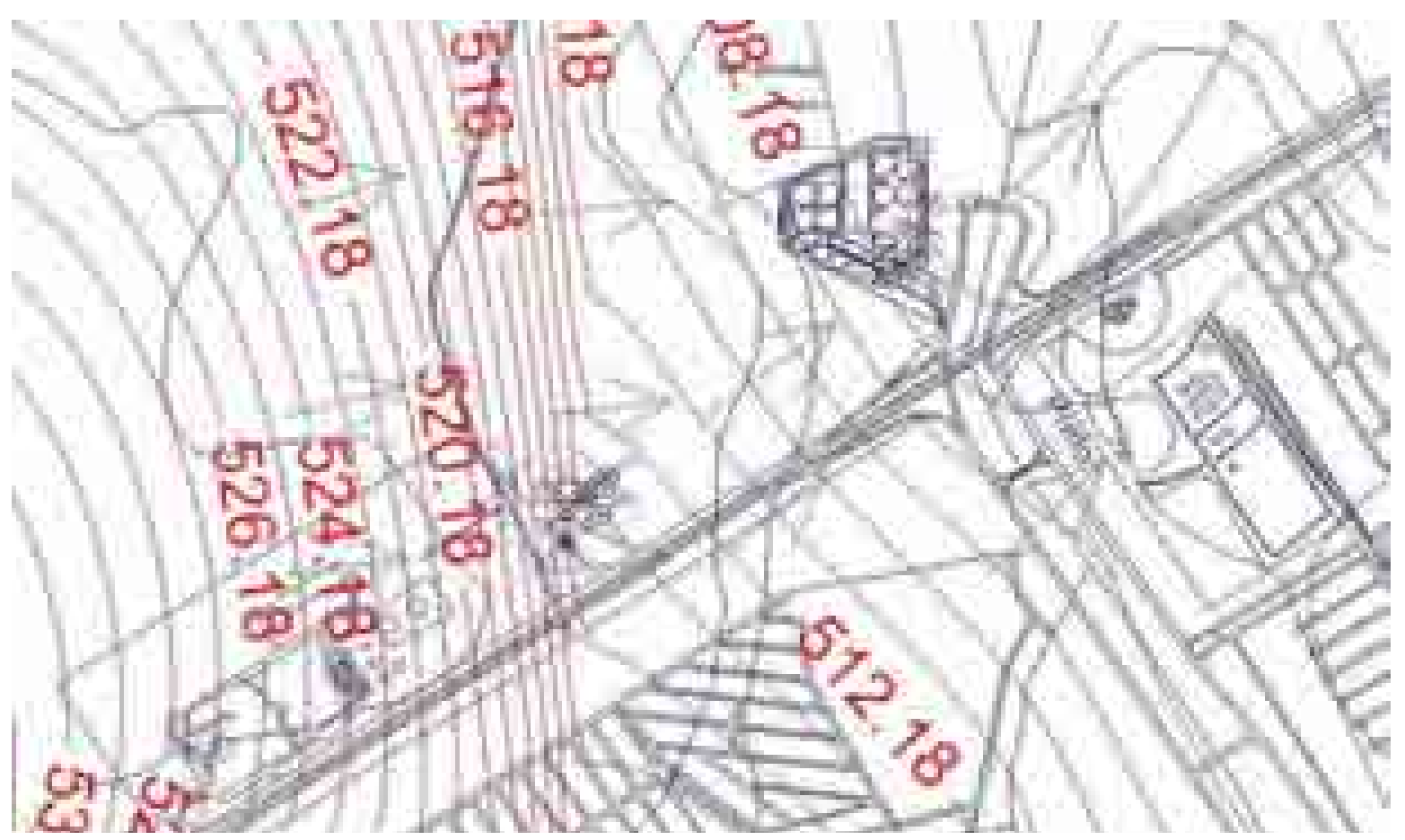

Figura 5.42 - Mapa das cargas hidráulicas na quarta camada do modelo para a região do sítio estudado e imediações. 


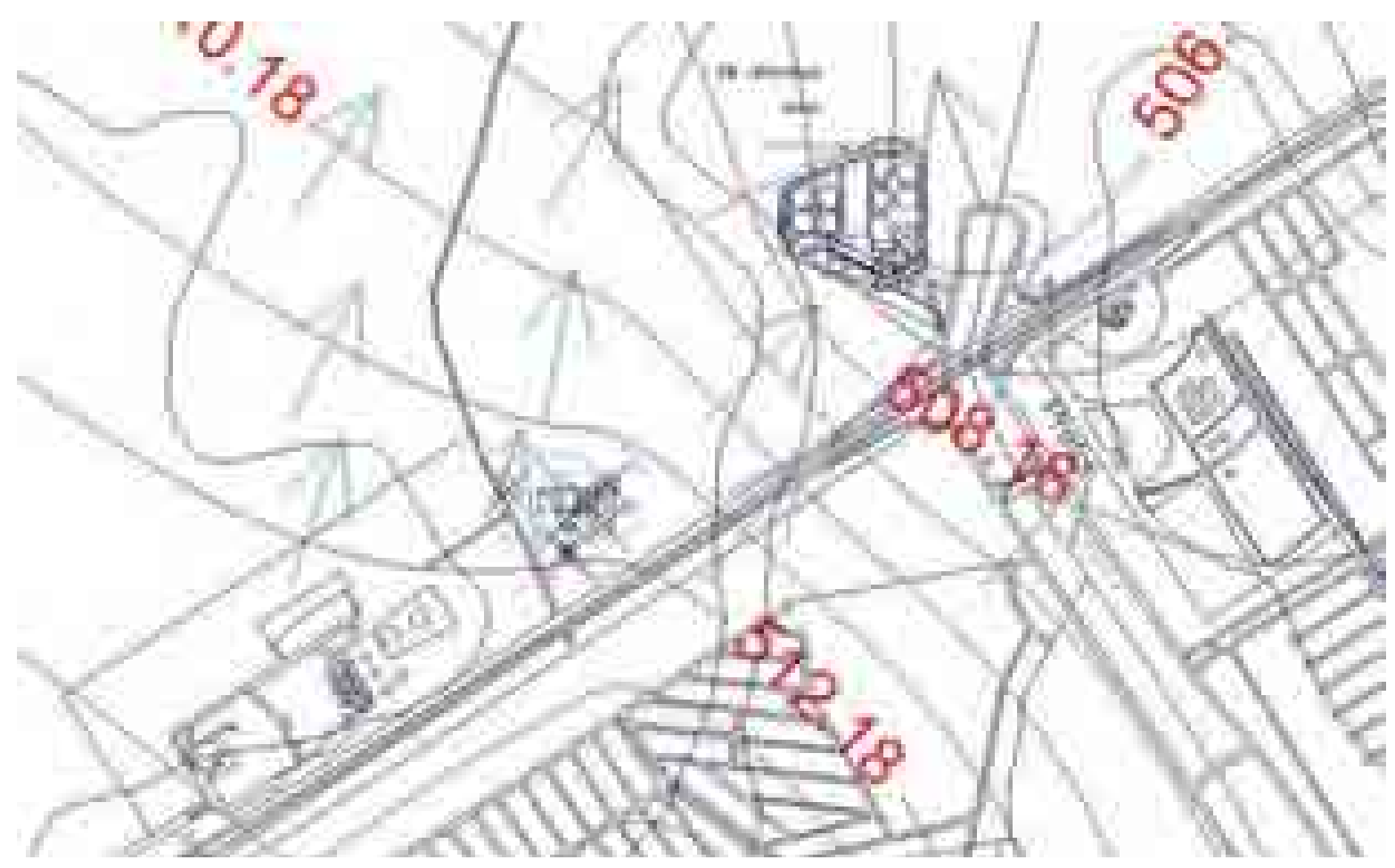

Figura 5.43 - Mapa das cargas hidráulicas na quinta camada do modelo para a região do sítio estudado e imediações.

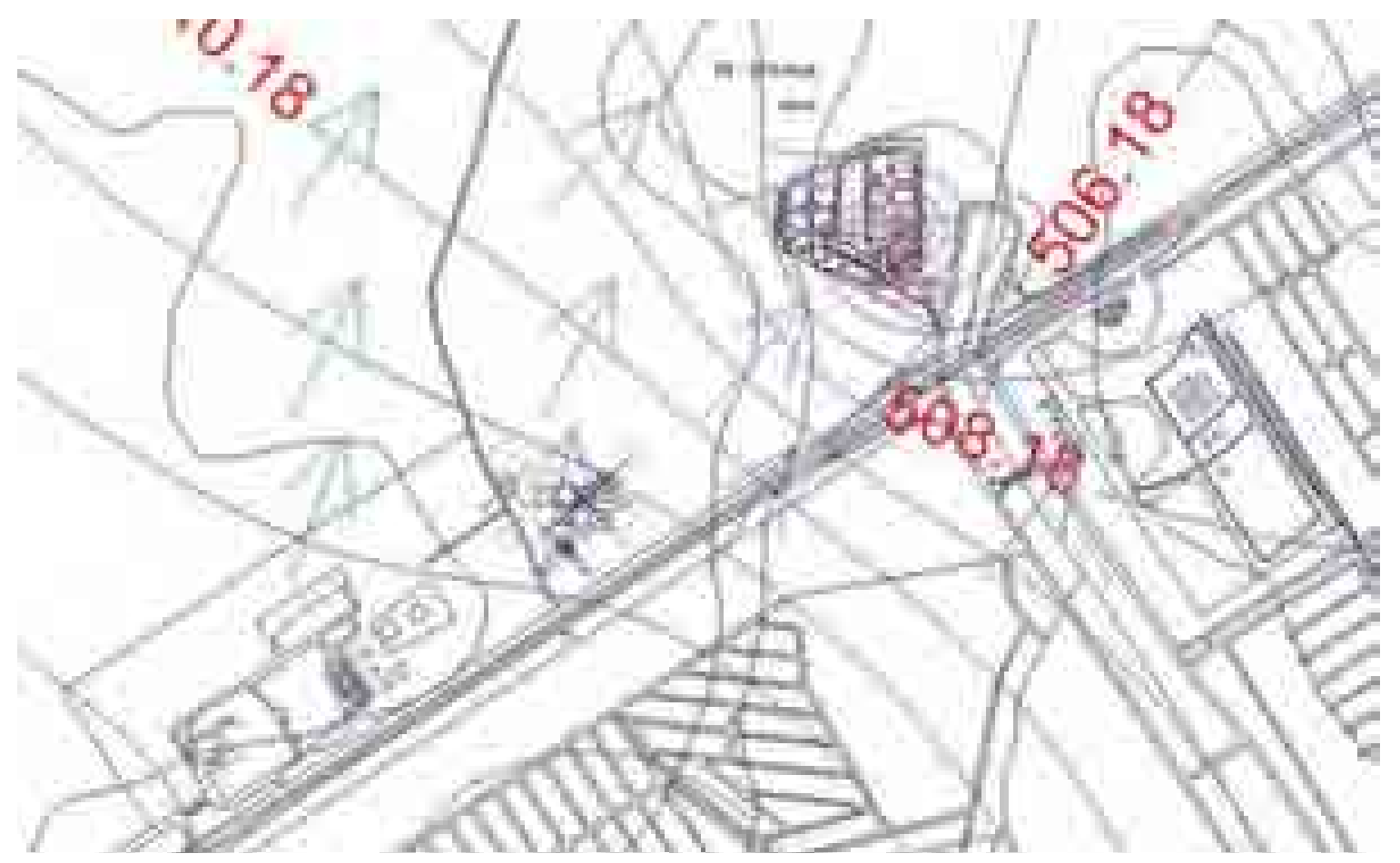

Figura 5.44 - Mapa das cargas hidráulicas na sexta camada do modelo para a região do sítio estudado e imediações. 


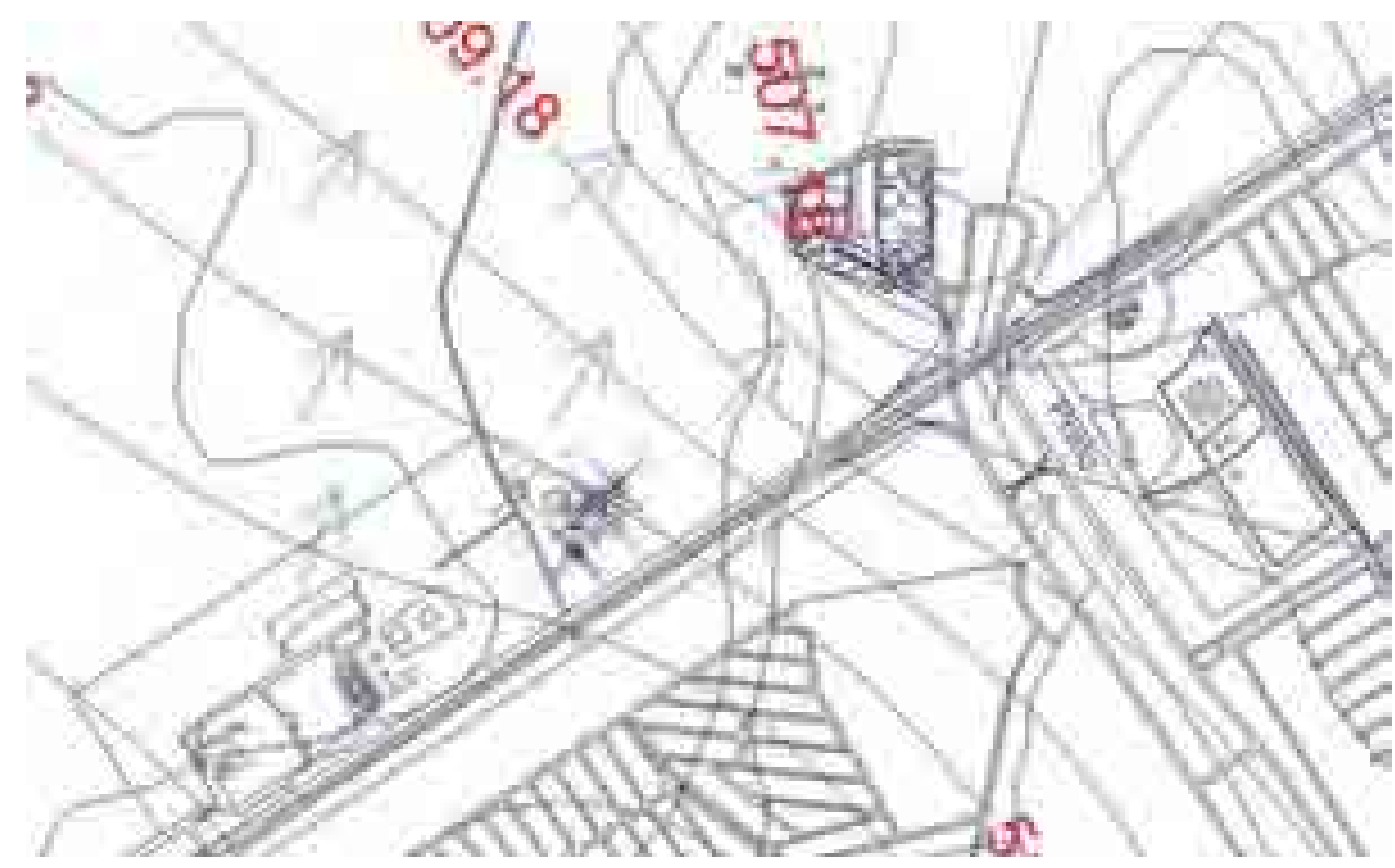

Figura 5.45 - Mapa das cargas hidráulicas na sétima camada do modelo para a região do sítio estudado e imediações.

Nas Figuras 5.46 a 5.52 pode ser observado o avanço da pluma de chumbo para um período de 10 anos a contar do preenchimento das cavas (está-se considerando uma condição inicial igual em todas as cavas, o que foge da condição que foi vivenciada nesse sítio, mas permite obter uma avaliação adequada das direções para as quais a pluma se movimenta). 0 tempo de dez anos representa a ordem de grandeza desde o término de deposição de material nas cavas (1995) até a presente época (2005).

Verifica-se que o desenvolvimento da pluma mostra valores compatíveis com as medidas efetuadas no local (PM-06). A concentração simulada nos pontos que abrange toda a área das cavas é de $25 \mu \mathrm{g} / \mathrm{L}$, que está próxima dos valores medidos nos PM-05 e PM-07. Para essas figuras, as linhas em vermelho são as curvas de isoconcentração. As variações das curvas de isoconcentração são: $10 \mu \mathrm{g} / \mathrm{L}$ para a mais interna, $1 \mu \mathrm{g} / \mathrm{L}$ para a intermediária e $0,1 \mu g / L$ para a mais externa, e para as figuras que apresentam apenas duas curvas de isoconcentração observa-se somente os dois últimos valores. Assim, embora tenha sido utilizado um tempo médio único para propagação da pluma, a metodologia seguida para este tipo de descarte de resíduos mostra-se adequada. 


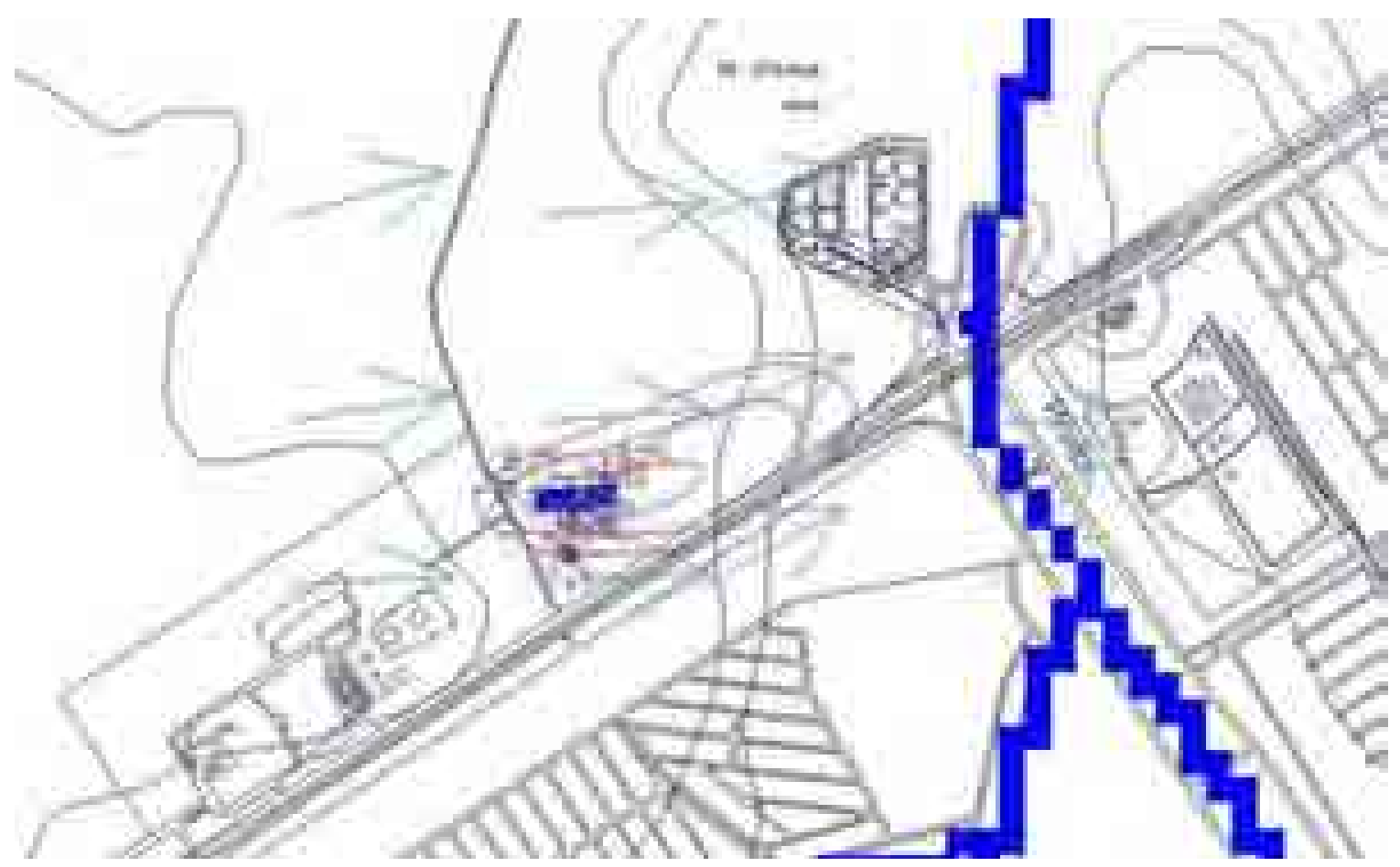

Figura 5.46 - Mapa de propagação de chumbo simulada para o um período de 10 anos. Observa-se a primeira camada do modelo para a região do sítio estudado e imediações.

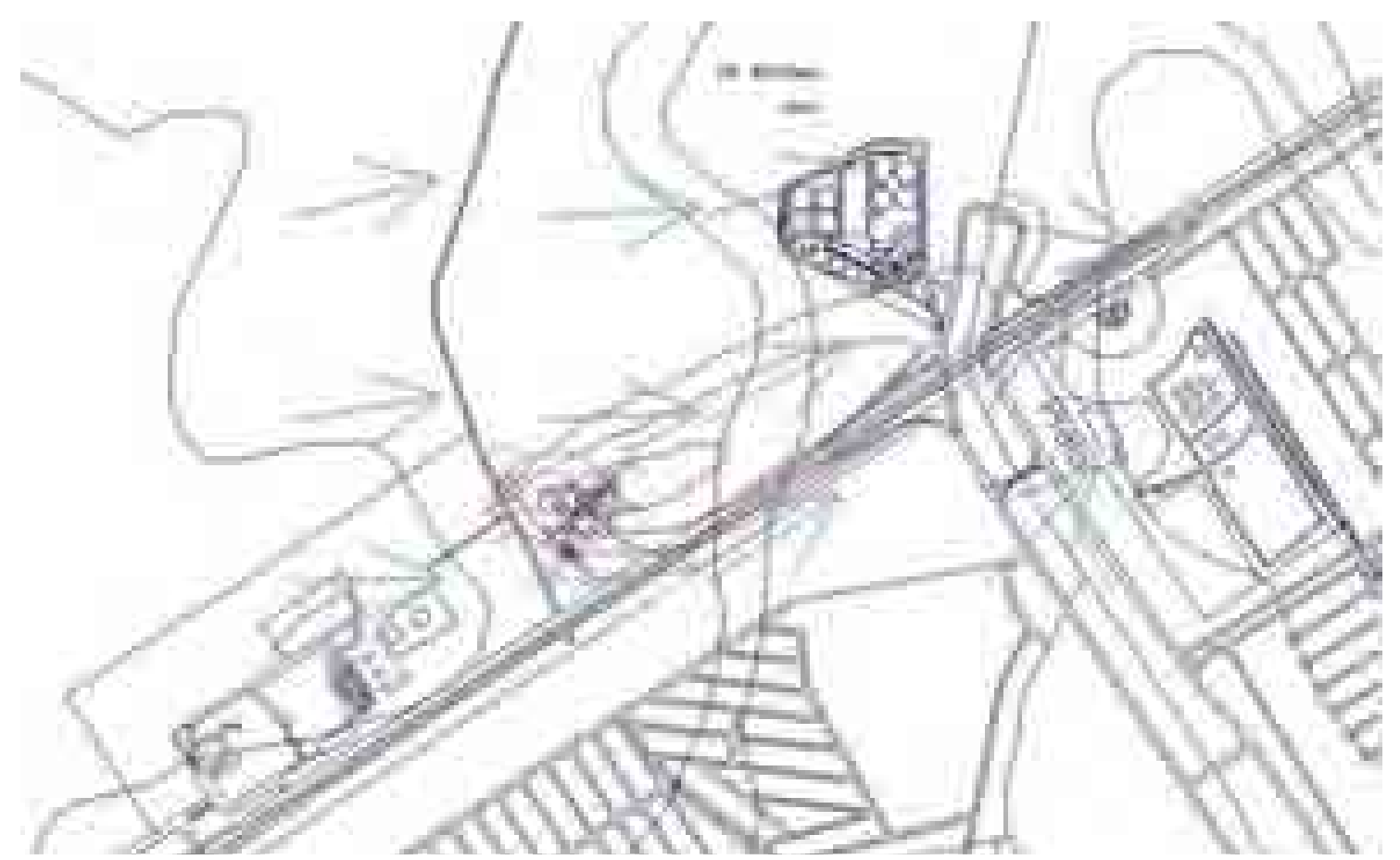

Figura 5.47 - Mapa de propagação de chumbo simulada para o um período de 10 anos. Observa-se a segunda camada do modelo para a região do sítio estudado e imediações. 


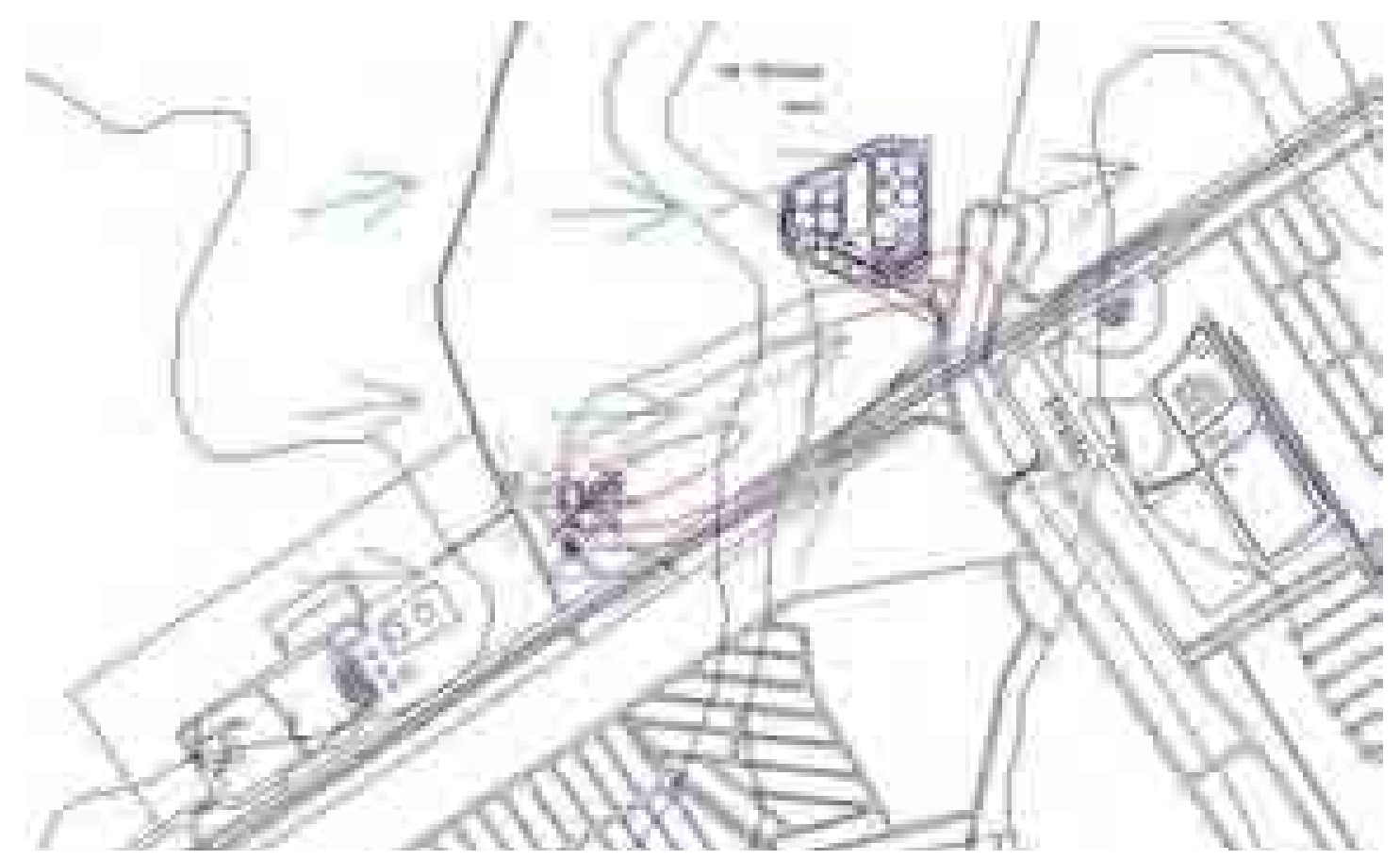

Figura 5.48 - Mapa de propagação de chumbo simulada para o um período de 10 anos. Observa-se a terceira camada do modelo para a região do sítio estudado e imediações.

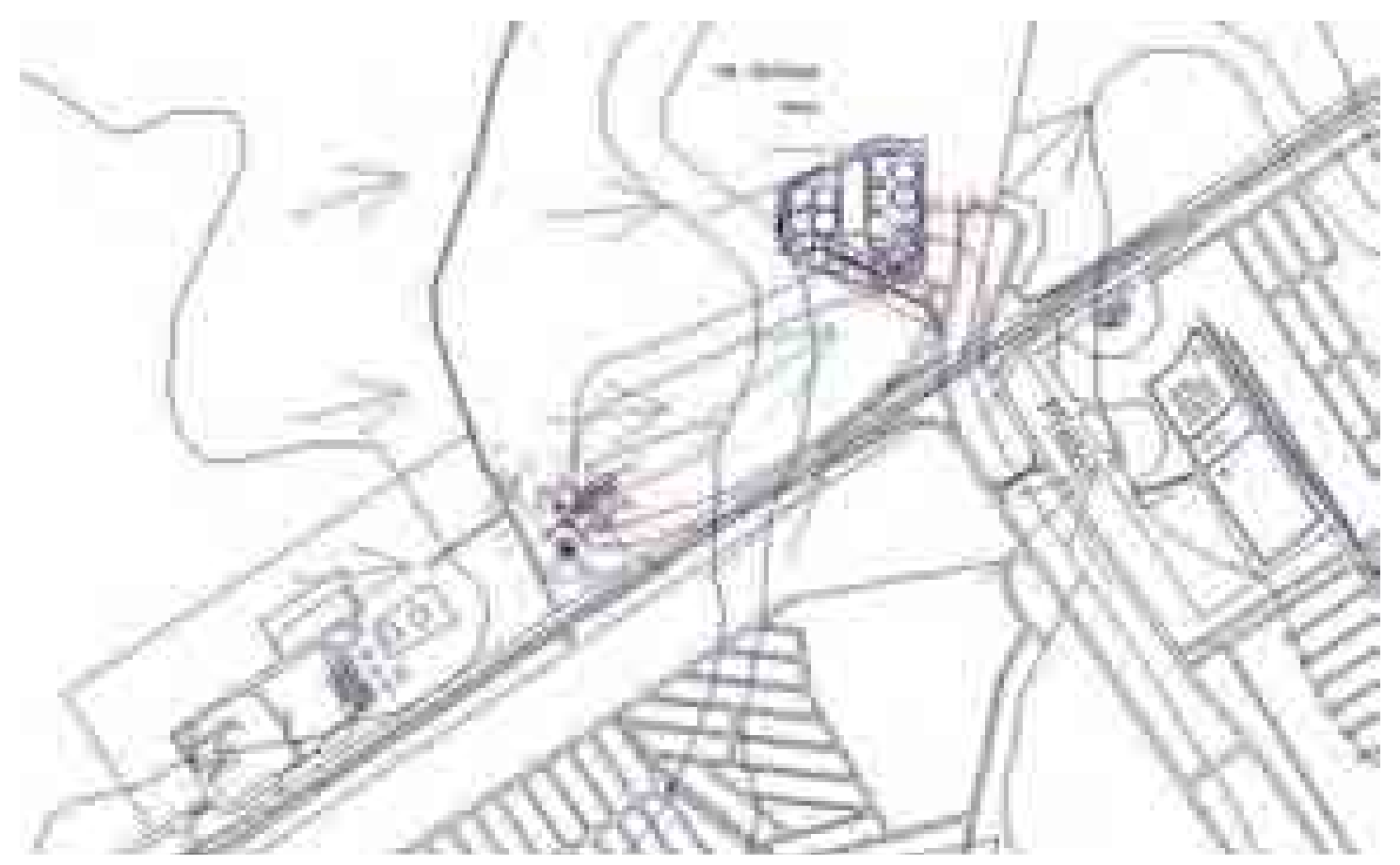

Figura 5.49 - Mapa de propagação de chumbo simulada para o um período de 10 anos. Observa-se a quarta camada do modelo para a região do sítio estudado e imediações. 


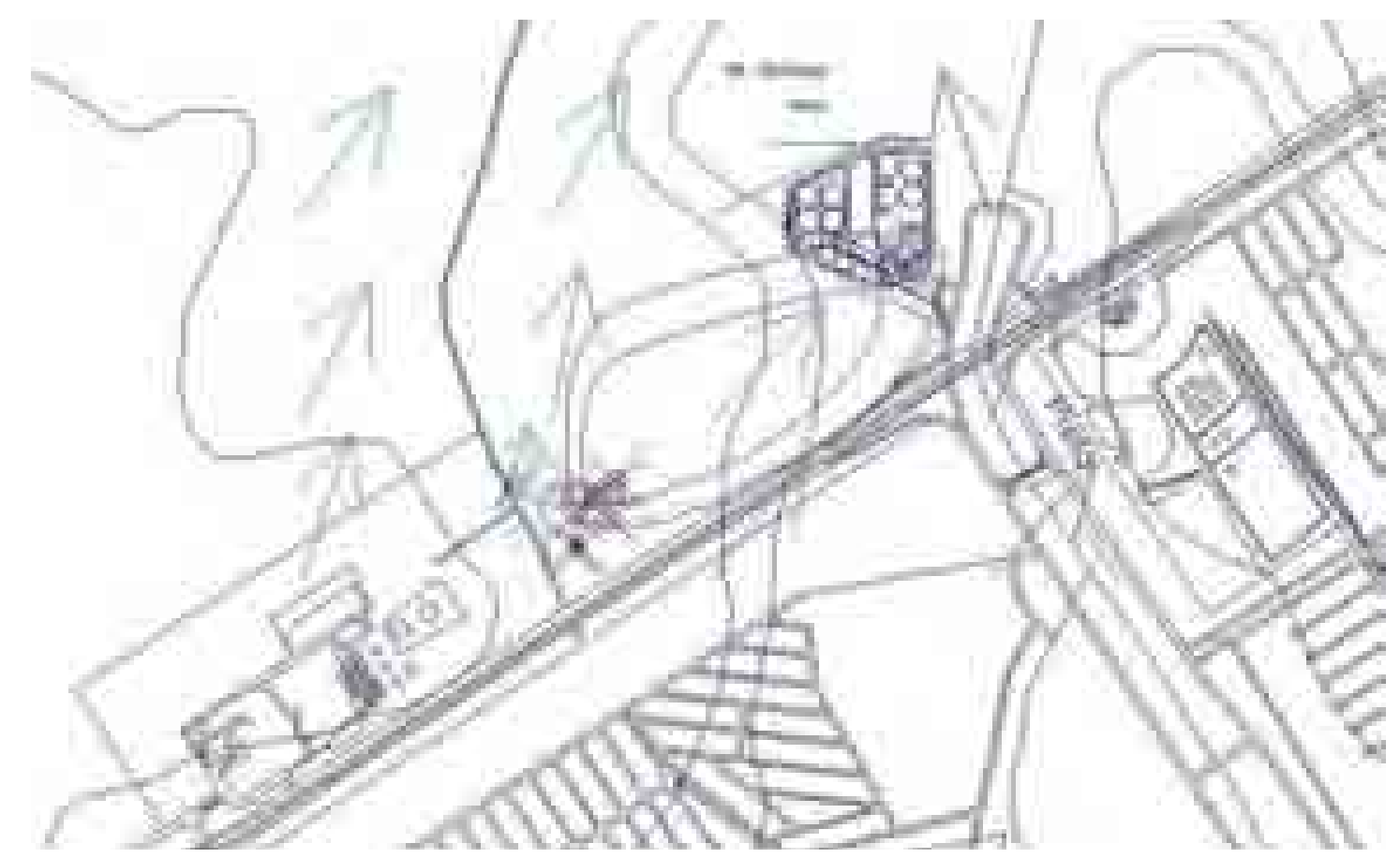

Figura 5.50 - Mapa de propagação de chumbo simulada para o um período de 10 anos. Observa-se a quinta camada do modelo para a região do sítio estudado e imediações.

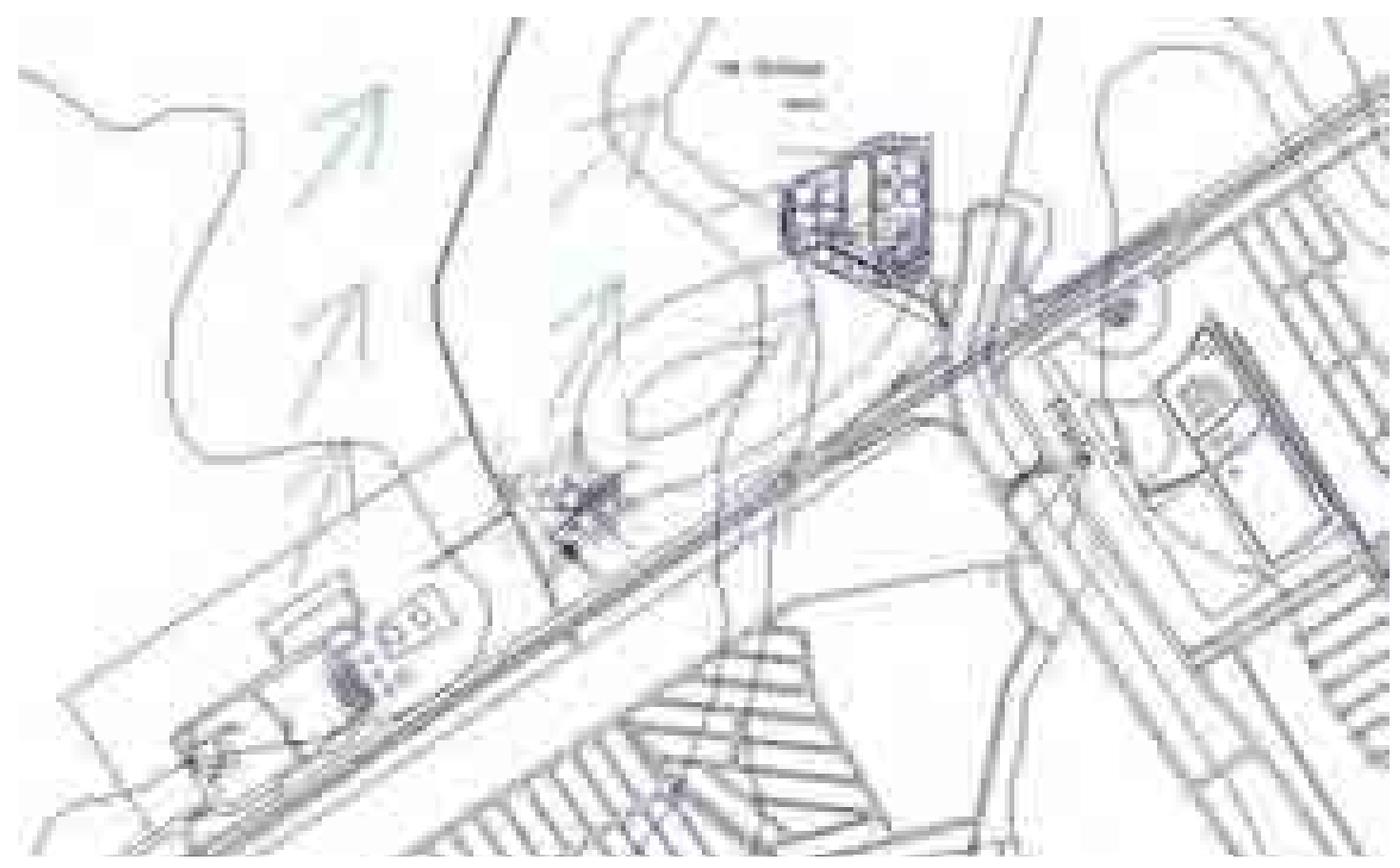

Figura 5.51 - Mapa de propagação de chumbo simulada para o um período de 10 anos. Observa-se a sexta camada do modelo para a região do sítio estudado e imediações. 


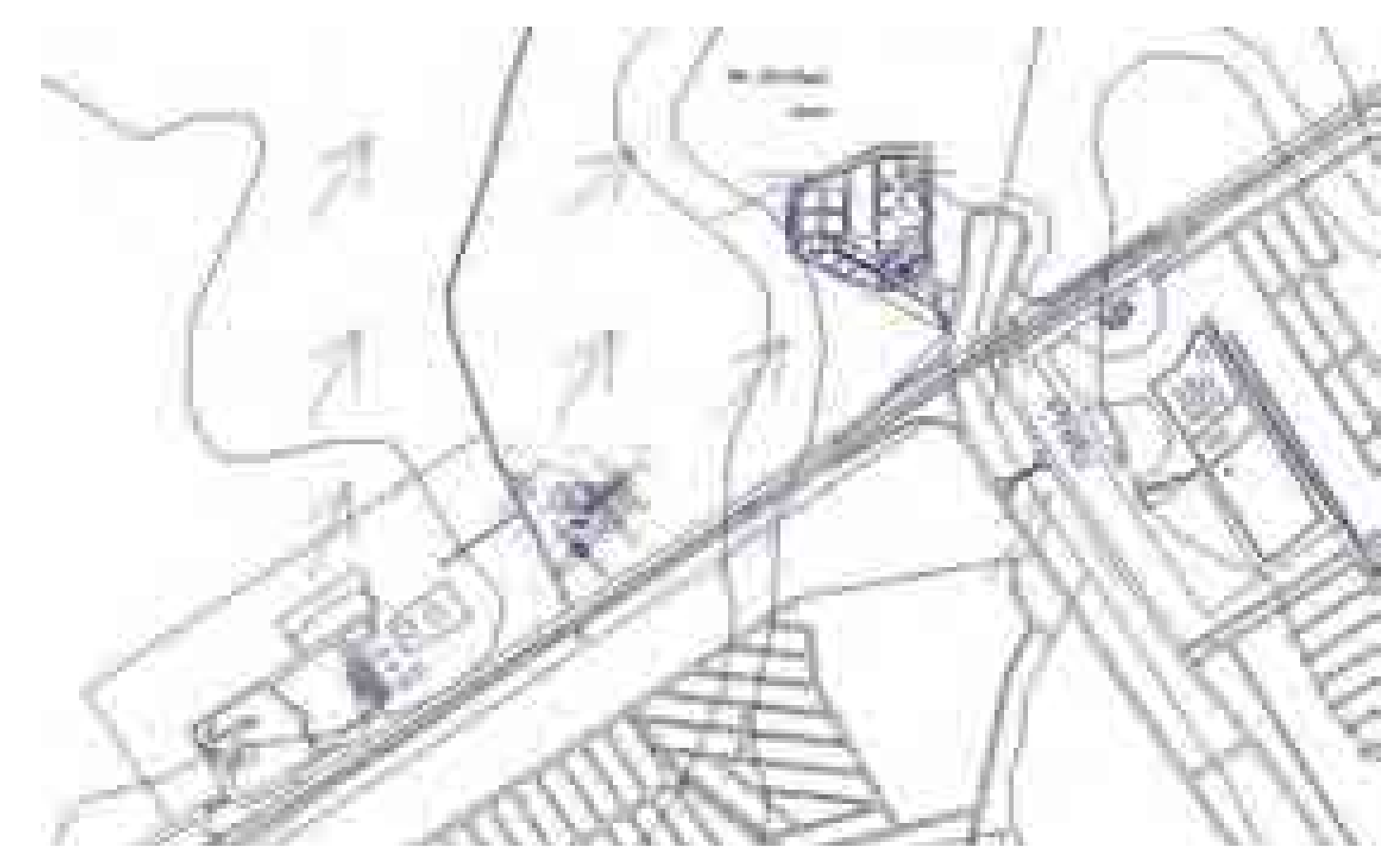

Figura 5.52 - Mapa de propagação de chumbo simulada para o um período de 10 anos. Observa-se a sétima camada do modelo para a região do sítio estudado e imediações.

Observa-se que o valor de contorno de $25 \mu \mathrm{g} / \mathrm{L}$, adotado para toda a base das cavas, torna-se o valor que se ajusta àqueles medidos no PM-06. A propagação da pluma é evidente no modelo numérico, porém os valores são muito reduzidos, sugerindo que não há comprometimento imediato nas proximidades das cavas. Isto não quer dizer que medidas de remediação não devam ser tomadas, mas que, no caso do chumbo, pode haver um planejamento mais elaborado (ações ainda não são emergenciais).

Adicionalmente, o valor do coeficiente de distribuição adotado para a espécie chumbo nesta simulação $(900 \mathrm{~L} / \mathrm{Kg})$ é menor do que os valores sugeridos por CETESB 2001b, que é de $2400 \mathrm{~L} / \mathrm{Kg}$ e Rowe et al. 1995, que é de $1900 \mathrm{~L} / \mathrm{kg}$. O significado deste menor coeficiente está relacionado a mobilidade do chumbo pois quanto menor o $K_{d}$ menor será a capacidade de retenção do solo. Assim, o valor adotado sugere a pior hipótese que é a de maior mobilidade. 


\section{Conclusões}

As conclusões aqui arroladas consideram inicialmente os objetivos fixados para este trabalho. Posteriormente, uma vez que os trabalhos e os dados extrapolaram as proposições iniciais, as conclusões adicionais são apresentadas, vinculadas ao estabelecimento de metodologia para estudo de sítios contaminados por material de re-refino de óleo.

O objetivo geral do trabalho é considerado atingido, uma vez que a metodologia foi eficiente e os resultados mostraram efetivamente o avanço da contaminação.

Os objetivos específicos são discutidos a seguir, com o detalhamento das conclusões.

- As medidas efetuadas envolveram várias fases: reconhecimento, medidas exploratórias e medidas comprobatórias. As metodologias aplicadas nem sempre redundaram em sucesso. É o caso, por exemplo, das medidas cromatográficas do extrato do resíduo, que, em sua primeira tentativa, tornaram o equipamento inoperante. Assim, embora contando com o apoio de especialistas nas diferentes áreas, as metodologias aplicáveis não eram de conhecimento geral. O presente trabalho representa uma contribuição na sistematização da análise de sítios similares. Em termos de modelo de escoamento e previsão de concentração de contaminante, procurou-se utilizar um programa comercial de manuseio suficientemente acessível, porém com boa qualidade de previsão. Nesse sentido, o uso do MODFLOW e do MT3D mostrou-se adequado, porém considerando uma abordagem dos contornos em "escala regional", isto é, localizando os contornos distantes da região de trabalho; 
- Todas as metodologias foram utilizadas, observando-se as vantagens e limitações de cada uma. No caso de solo, devido as baixas concentrações e dificuldades operacionais, não foi possível observar variações significativas de concentrações de HPAs ao longo da profundidade;

- Apesar das dificuldades encontradas com a não comprovação do modelo conceitual inicial, após o estabelecimento do novo modelo os resultados mostraram coerência e permitiram o desenrolar dos trabalhos;

- Nesse estudo não foram identificadas fases de escoamento multifásico (as peculiaridades não permitem separar as fases). Todavia, a previsão de avanço da pluma foi completada, utilizando um modelo numérico adequado, de aplicação suficientemente expedita, que mostra o escoamento principal em direção ao Ribeirão Preto e ao poço de bombeamento da estação de tratamento de esgoto, mostrando alteração na região entre o sítio contaminado e essa ETE;

- A metodologia aplicada é abrangente e pode ser aplicada e ajustada facilmente na avaliação de sítios contaminados. Nesse sentido, é importante deixar claro que a literatura brasileira trata marginalmente de sítios contaminados. Assim, a presente metodologia de trabalho representa uma abordagem original.

A extensão dos trabalhos faz com que se extrapole os objetivos iniciais, bem como as conclusões pretendidas. A seguir são apresentadas conclusões específicas.

- O levantamento geofísico mostrou ser uma ferramenta de avaliação preliminar de grande valia. Quando interpretado e confrontado com informações locais foram definidas as regiões das cavas, zona saturada, contato entre diferentes tipos de solos e indícios de contaminação;

- A caracterização do resíduo depositado nas cavas deverá ser aprimorada para uma melhor qualificação e quantificação em pesquisas futuras; 
- O comportamento hidrogeológico local apresenta dois aqüíferos distintos com diferentes direções de escoamento e gradiente hidráulico. O aqüífero suspenso tende para direção sudoeste e o aqüífero da formação arenito varia entre as direções leste e noroeste;

- Os valores de $\Delta \mathrm{pH}$, das amostras de solo, indicam um predomínio de cargas negativas em todas as amostras, com exceção da SD $02-3,30$ metros e da SD 03 - 3,00 metros. Esses resultados indicam a existência de cargas variáveis para todas as amostras, fator relevante para o transporte de contaminantes;

- As medidas de Eh, também das amostras de solo, corroboram o predomínio de cargas negativas indicado pelos valores de $\Delta \mathrm{pH}$. Deve estar havendo predomínio de substâncias oxidadas e conseqüentemente pouca atividade eletrônica, pois os valores de Eh são razoavelmente elevados;

- A mineralogia interpretada indicou solo bastante evoluído geoquímicamente condizente com os solos tropicais;

- Os valores de CTC e SE das amostras analisadas sugerem alta capacidade de retenção de cátions para as amostras silto-argilosas e pouca capacidade de retenção de cátions para as amostras arenosas;

- Os resultados de carbono orgânico total apontam, como esperado, para uma fração razoável em superfície e pequena com o aprofundamento do solo. Nos furos que atingiram a zona saturada (SD 01 e SD 02) as amostras mais profundas (mais de 10 metros) apresentam baixos percentuais de $f_{o c}$ sugerindo baixa retenção para contaminantes hidrofóbicos;

- Para as amostras de solo residual de arenito, se forem observados os percentuais de argila, $f_{o c}$, CTC e SE, conclui-se que praticamente não há capacidade de retenção ou retardamento, sugerindo que os contaminantes presente estão "livres" para contaminar a água subterrânea subjacente;

- As concentrações de HPAs, medidas em amostras de solo, levam a crer que não há contaminação do solo por estes compostos;

- Os resultados das condutividades hidráulicas, medidas nos poços de monitoramento, evidenciam que mesmo utilizando o método de perfuração mais adequado é necessário o desenvolvimento exaustivo dos poços para a coleta de amostras representativas; 
- Pelas concentrações metais medidas em amostras de água subterrânea de uma maneira geral e principalmente no PM-05 o sítio pode ser considerado contaminado;

- A simulação numérica sugeriu avanço de pluma e direção de escoamento tendendo ao poço de bombeamento da ETE localizada próximo ao Ribeirão Preto. Todavia os valores de recarga, drenança e $K_{d}$ precisam ser criteriosamente avaliados em trabalhos futuros. 


\section{Recomendações}

\section{Com relação ao sítio:}

- $\quad$ Sugere-se que a área seja isolada de maneira que impeça a entrada de pessoas estranhas, seja pela construção de muros, seja pela contração de serviço de vigilância patrimonial;

- $\quad$ Adverte-se aos responsáveis pelo sítio que sejam recuperados os poços de monitoramento danificados por terceiros, uma solicitação já feita pessoalmente e da qual depende a continuidade do monitoramento do sítio. Espera-se essa colaboração, considerando o investimento já efetuado nesta pesquisa.

Recomenda-se que as cavas e entorno sejam cobertos por material argiloso compactado para evitar que as águas de chuvas percolem pelos resíduos ou mesmo "lavem" os resíduos, provocando assim solubilização e dissociação de contaminantes. Adicionalmente, construir um sistema de drenagem superficial no sítio, evitando que as águas das chuvas fiquem retidas no sítio. Finamente, conforme frisado no parágrafo anterior, efetuar o monitoramento contínuo dos poços existentes no sítio para identificação de eventuais tendências e fornecer subsídios para decisões futuras.

\section{Com relação a pesquisas futuras:}

- $\quad$ Sugere-se que seja realizada uma avaliação de risco com relação a eventuais moradores que estejam residindo nos terrenos vizinhos e provavelmente consumindo água subterrânea;

- Recomenda-se o teste de técnicas de amostragem de água subterrânea, teoricamente, mais eficientes como amostragem a baixas vazões, para comparação com os métodos ora utilizados e como sugestão no ajuste da 
vazão de amostragem correlacionar a vazão com a condutividade hidráulica obtida no poço;

- $\quad$ Sugere-se o uso dos dados da simulação numérica realizada para o refinamento do modelo, buscando um detalhamento maior das informações inseridas e tentando comprovar as simulações com análises de amostras de água subterrânea;

- $\quad$ Recomenda-se que sejam caracterizados os vapores emanados pelas cavas, por exemplo, com o uso de campânulas em cada cava de resíduo. 


\section{Referências Bibliográficas}

AMERICAN PETROLEUM INSTITUTE, (1993). Guide for Assessing and Remediating Petroleum Hydrocarbons in Soils, Washington, D.C., EUA.

AMERICAN PUBLIC HEALTH ASSOCIATION (1998). Standard Methods for the Examination of Water and Wastewater, $20^{\text {th }}$ ed. Washington DC, American Public Health Association.

ANDERSON, M.P.; WOESSNER, W.W. (1992). Applied Groundwater Modeling: Simulation of Flow and Advective Transport. Academic Press, Inc.

ANDRADE, S.J. (2000). Otimização e validação de metodologia analítica para a determinação de hidrocarbonetos policíclicos aromáticos (HPAs) em urina. 73p. Dissertação (Mestrado) - Instituto de Química, Universidade Estadual Paulista, Araraquara. 2000.

ANDRADE, S.J. (2004). Investigação sobre a composição química e avaliação de mutagenicidade do material particulado atmosférico sob a influência da queima de cana-de-açúcar. 120p. Tese (Doutorado) - Instituto de Química, Universidade Estadual Paulista, Araraquara. 2004.

ASSOCIAÇÃO BRASILEIRA DE NORMAS TÉCNICAS, (1984). NBR 6508: Grãos de solo que passam na peneira 4,8 mm - Determinação da massa específica. Rio de Janeiro.

. (1984). NBR 7181: Solo - Análise Granulométrica. Rio de Janeiro. 
(1997). NBR 13895 - Construção de poços de monitoramento e amostragem. Rio de Janeiro.

ARISTODEMOU, E.; THOMAS-BETTS, A. (2000). DC resistivity and induced polarization investigations at a waste disposal site and its environments. Journal of Applied Geophysics. v. 44, p. 275 - 302.

BAEDECKER, M.J.; COZZARELLI, I.M.; EGANHOUSE, R.P.; SIEGEL, D.I.; BENNETT, P.C. (1993). Crude oil in a shallow sand and gravel aquifer: III. Biogeochemical reactions and mass balance modeling in anoxic groundwater. Applied Geochemistry. v. 8, p. $569-586$.

BALBA, M. T.; AL-AWADHI, N.; AL-DAHER, R. (1998). Bioremediation of oilcontaminated soil: microbiological methods for feasibility assessment and field evaluation. Journal of Microbiological Methods, v. 32, p. 155-164.

BANERJEE, S. (1984). Solubility of organic mixtures in water. Environmental Science and Technology. v. 18, n. 8, p. 587 - 591.

BARBIERE, S. (2000). Comunicação pessoal. Junho de 2000.

BARRETO, A.B. DA C. (1998). Avaliação de condições hidrogeológicas e da contaminação do subsolo por $\mathrm{HCH}$ na Cidade dos Meninos, RJ. 148p. Dissertação (Mestrado) - Departamento de Engenharia Civil, Pontifícia Universidade do Rio de Janeiro, Rio de Janeiro. 1998.

BARROS, R.M. (2000). Estudo do risco de poluição das águas subterrâneas causada por vazamentos em postos de abastecimento de combustível, no município de Ribeirão Preto - SP. 198p. Dissertação (Mestrado) - Escola de Engenharia de São Carlos, Universidade de São Paulo, São Carlos. 2000.

BEAR, J. (1972). Dynamics of Fluids in Porous Media. New York: American Elsevier Publishing Company. 
BENNETT, P.C.; SIEGEL, D.I.; BAEDECKER, M.J.; HULT, M.F. (1993). Crude oil in a shallow sand and gravel aquifer: I. Hydrogeology and inorganic geochemistry. Applied Geochemistry. v. 8, p. 529 - 549.

BENSON, A.K.; AYNE, K.L.; STUBBEN, M.A. (1997). Mapping groundwater contamination using dc resistivity and VLF geophysical methods - A case study. Geophysics. v. 62 , n. 1, p. $80-86$.

BOUWER, H. (1989). The Bouwer and Rice slug test - an update. Ground Water, vol. 27, n. 3, p. 304 - 309.

BOUWER, H.; RICE, R.C. (1976). A Slug Test for Determining Hydraulic Conductivity of Unconfined Aquifers with Completely or Partially Penetrating Well. Water Resources Research, vol. 12, n. 3, p. 423 - 428.

BRASIL, MINISTÉRIO DA SAÚDE, (2004). Portaria n. 518, de 25 de março. Estabelece os procedimentos e responsabilidades relativos ao controle e a vigilância da qualidade da água para consumo humano e seu padrão de potabilidade, e dá outras providências.

BRASIL, LEIS, etc. (1998). Decreto n. 2.607 de 28 de maio de 1998. Dispõe sobre a adição de álcool etílico anidro combustível à gasolina. Lex: Coletânea de Legislação e Jurisprudência, São Paulo, v. 62, p. 1.965.

BROWN, G.; BRINDLEY, G.W. (1984). X-ray diffraction procedures for clay mineral identification. In: BRINDLEY, G. W.; BROWN, G. edits. Crystal Structures of Clay Minerals and Their X-ray Identification. London Mineralogical Society, p. 305-359.

BROWN, D.L.; NARASIMHAN, T.N.; DEMIR, Z. (1995). An evaluation of the Bouwer and Rice method of slug test analysis. Water Resources Research, vol. 31, n. 5, p. 1239 - 1246. 
CAMARGO, O.A.; MONIZ, A.C.; JORGE, J.A.; VALADARES, J.M.A.S. (1986). Métodos de Análise Química, Mineralógica e Física de Solos do Instituto Agronômico de Campinas - Boletim Técnico. Campinas, 95p.

CHANG, H.K.; SILVA, F. DE P. (2004). Estudo de viabilidade técnicoeconômica de abastecimento de água da região metropolitana de São Paulo (RMSP) pelo aqüífero Guarani. Instituto de Geociências, Universidade Estadual Paulista. Rio Claro.

CHATZIS, I. (1983). Visualization of oil displacement mechanisms and enhanced oil recovery. In: $22^{\text {nd }}$ Annual Conference of Ontario Petroleum Institute, 1983, London, Ontario Canada. 20p.

CHIRLIN, G.R. (1989).A critique of the Hvorslev method for slug test analysis: The fully penetrating well. Ground Water. v. 40, n. 3, p. 303 - 307.

CLEAN ENVIRONMENT BRASIL, (2003). III Seminário Internacional de Amostragem de Águas Subterrâneas. Apostila de Curso.

CLEARY, R.W. (1991). Qualidade da Água Subterrânea. Capítulo 3, Hidrologia Ambiental, v. III, Coleção ABRH de Recursos Hídricos, Rio de Janeiro, Brasil, Editora da UFRJ.

COHEN, R.M.; MERCER, J.W. (1993). DNAPL Site Evaluation. Boca Raton, Florida: C. S. SMOLEY.

COMPANHIA DE TECNOLOGIA DE SANEAMENTO AMBIENTAL, (2001a). Prevenção e Controle da Poluição do Solo e das Águas Subterrâneas. Apostila de Curso.

COMPANHIA DE TECNOLOGIA DE SANEAMENTO AMBIENTAL, (2001b). Relatório de estabelecimento de valores orientadores para solos e águas subterrâneas. 
CONSELHO NACIONAL DO MEIO AMBIENTE (2005). Resolução n. 357 de 17 de março de 2005. Dispõe sobre a classificação dos corpos de água e diretrizes ambientais para o seu enquadramento, bem como estabelece as condições e padrões de lançamento de efluentes, e dá outras providências.

CORDAZZO, J.; MALISKA, C.R.; CORSEUIL, H.X. (2000). Modelagem e simulação numérica de derramamento de gasolina acrescida de álcool em águas subterrâneas. In: VIII Congresso Brasileiro de Engenharia e Ciências Térmicas, 2000, Porto Alegre - RS. Anais do VIII Congresso Brasileiro de Engenharia e Ciências Térmicas, Porto Alegre - RS, 2000. 10p.

COTTA, J.A. DE O. (2003). Diagnóstico ambiental do solo e sedimento do Parque Estadual Turístico do Alto Ribeira (PETAR). 115p. Dissertação (Mestrado) - Instituto de Química de São Carlos, Universidade de São Paulo, São Carlos. 2003.

CURTIS, P.G.; ROBERTS, P.V.; REINHARD, M. (1986). A Natural Gradient Experiment on Solute Transport in a Sand Aquifer. 4. Sorption of Organic Solutes and its Influence on Mobility. Water Resources Research. v. 22, n. 13, p. 2059 - 2067.

DEHAINI, J. (2001). Detecção da pluma de contaminação de hidrocarbonetos em subsuperfície pelo método de radar de penetração. 100p. Tese (Doutorado) - Instituto de Geociências, Universidade de São Paulo, São Paulo. 2001.

EL-FADEL, M.; KHOURY, R. (2001). Strategies for vehicle waste-oil management: a case study. Resources, conservation and recycling. v. 33, p. 75 $-91$.

ELIS, V.R. (2001). III Escola de Verão de Geofísica. Geofísica Aplicada ao Estudo da Poluição de Solos e Águas Subterrâneas. IAG-USP. São Paulo, $194 p$. 
FAUST, C.R.; GUSWA, J.H.; MERCER, J.W. (1989). Simulation of threedimensional flow of immiscible fluids within and below the unsaturated zone. Water Resources Research. v. 25, n. 12, p. 2449 - 2464.

FERNANDES, M. (2002). Atenuação natural da contaminação de aqüífero submetido a derramamento de gasolina. 212p. Tese (Doutorado) Departamento de Química, Universidade Federal de Santa Catarina, Florianópolis. 2002.

FERNANDES, M.; CORSEUIL, H.X. (1997). Contaminação de Águas Subterrâneas por Derramamento de Gasolina - Efeito Cossolvência. In: CONGRESSO BRASILEIRO DE ENGENHARIA SANITÁRIA E AMBIENTAL, 19., Foz do Iguaçu, 1997. Anais. CD-ROM.

FERREIRA, S. DE T. (1992). Estudo da vulnerabilidade à contaminação das águas subterrâneas na região de Ribeirão Preto - SP. 69p. Dissertação (Mestrado) - Instituto de Geociências e Ciências Exatas, Universidade Estadual Paulista, Rio Claro. 1992.

FERREIRA, S.B. (2000). Estudos laboratoriais para avaliação do potencial de contaminação de água e de solo por gasolina oxigenada. 216p. Tese (Doutorado) - Escola de Engenharia de São Carlos, Universidade de São Paulo, São Carlos. 2000.

FETTER, C.W. (1998). Contaminant Hydrogeology. New York: Macmillan Publishing Company.

FETTER, C.W. (2001). Applied Hydrogeology. Third edition. Englewood Cliffs N.J.: Prentice Hall.

FREEMAN, H.M. (1998). Standard handbook of hazardous waste treatment and disposal. New York: McGraw-Hill, $2^{\text {nd }}$ ed. 
FREEZE, R.; CHERRY, J. (1979). Groundwater. First edition. Englewood Cliffs N.J.: Prentice Hall.

GRUBB, D.G.; PALOMINO, A.M. (1998). Review of technologies for management of NAPL contaminated sites. In: Simpósio Brasileiro de Geotecnia Ambiental, 1998, São Paulo. Anais do Simpósio Brasileiro de Geotecnia Ambiental, São Paulo. 47p.

GADOTTI, R.F. (1998). Avaliação da contaminação das águas superficiais e subterrâneas adjacentes ao 'lixão' da cidade de São Carlos. 150p. Dissertação (Mestrado) - Escola de Engenharia de São Carlos, Universidade de São Paulo, São Carlos. 1998.

GELHAR, L.W.; WELTY, C.; REHFELDT, K.R. (1992). A Critical Review of Data on Field-Scale Dispersion in Aquifers. Water Resources Research. v. 28, n. 7 , p. 1955 - 1974.

GUIGUER, N. (1996). Poluição das Águas Subterrâneas e do Solo Causada por Vazamentos em Postos de Abastecimento. Waterloo Hydrogeologic. 356p.

HALFORD, K.J.; KUNIANSKY, E.L. (2002). Documentation of spreadsheets for the analysis of aquifer-test and slug-test data. U. S. Geological Survey, Openfile Report 02 - 197, Carson City, Nev., 2002.

HIRATA, R.C.A. (1990). Amostragem de vapores do solo (AVS): desenvolvimento de uma técnica para a detecção de águas subterrâneas contaminadas por solventes orgânicos voláteis. Estudo de caso de Porto Feliz - São Paulo. São Paulo. 113p. Dissertação (Mestrado) - Instituto de Geociências, Universidade de São Paulo.

HVORSLEV, J.M. (1951). Time lag and soil permeability in ground-water observations, Bull. 36, 50pp., U. S. Corps of Eng., Waterways Experiment Station, Vicksburg, Miss., Apr. 1994. 
HYDER, Z.; BUTLER JR, J.J. (1995). Slug tests in unconfined formations: An assessment of the Bouwer and Rice technique. Ground Water. v. 33, n. 1, p. 16 $-22$.

HYDER, Z.; BUTLER JR, J.J.; MCELWEE, C.D.; LIU, W. (1994). Slug tests in penetrating wells. Water Resources Research. v. 30, n. 11, p. 2945 - 2957.

INMAN, J. R. (1975). Resistivity inversion with ridge regression. Geophysics, v. 40, n. 5, p. 798-817.

INTERPEX (1993). RESIX IP v. 2.0. DC resistivity and induced polarization data interpretation software. USA. Manual.

JURY, W.A.; RUSSO, D.; STREILE, G.; EL ABD, H. (1990). Evaluation of Volatilization by Organic Chemicals Residing Below the Soil Surface. Water Resources Research, v. 26, n. 1, p. 13 - 20.

KEMBLOWSKI, M.W.; KLEIN, C.L. (1988). An automated numerical evaluation of slug test data. Ground Water. v. 26, n. 4, p. $435-438$.

KUEPER, B.H.; FRIND, E.O. (1991). Two-phase flow in heterogeneous porous media, 2. Model application. Water Resources Research. v. 27, n. 6, p. 1059 1070.

LEITE, J.C. (1995). Metodologia para a elaboração da carta de susceptibilidade à contaminação e poluição das águas subsuperficiais. 192p. 2v. Dissertação (Mestrado) - Escola de Engenharia de São Carlos, Universidade de São Paulo, São Carlos. 1995.

LEITE, A.L. (2001). Migração de íons inorgânicos em alguns solos tropicais, com ênfase nos processos de sorção e difusão molecular. 254p. Tese (Doutorado) - Escola de Engenharia de São Carlos, Universidade de São Paulo, São Carlos. 2001. 
LERMAN, A. (1979). Geochemical Processes - Water and Sediment Environments. Wiley Interscience, New York.

LOKE, M.H. (1998). RES2DINV version 3.3 for Windows 3.1 and 95. Rapid 2D resistivity and IP inversion using the least-squares method. Penang: M.H. Loke Software User's Manual, 35p.

LONG, L.G.; WINWFORDER, J.D. (1983). Limit of detection: a closer at the IUPAC definition. Analytical Chemistry. v. 55, n.7, p. 712 - 724.

LYMAN, W.J.; REEHL, W.F.; ROSENBLATT, D.H. (1982). Handbook of Chemicals Property Estimation Methods, Environmental Behavior of Organic Compounds. McGraw-Hill Book Co., New York.

MACKAY, D.M.; FREYBERG, D.L.; ROBERTS, P.V.; CHERRY, J.A. (1986). A Natural Gradient Experiment on Solute Transport in a Sand Aquifer. 1. Approach and Overview of Plume Movement. Water Resources Research. v. 22, n. 13, p. 2017 - 2029.

MACKAY, D.M.; ROBERTS, P.V.; CHERRY, J.A. (1985). Transport of organic contaminants in groundwater: Distribution and fate of chemicals in sand and gravel aquifers. Environmental Science and Technology. v. 19, n. 5, p. 384 392.

MIRANDA NETO, M.I. (2002). Investigação geoambiental em área de mangue na baia de Guanabara contaminada com resíduos industriais. 158p. Tese (Mestrado) - Coordenação dos Programas de Pós-Graduação em Engenharia, Universidade Federal do Rio de Janeiro, Rio de Janeiro. 2002.

NADIM, F.; HOAG, G.E.; LIU, S.; CARLEY, R.J.; ZACK, P. (2000). Detection and remediation of soil and aquifer systems contaminated with petroleum products: an overview. Journal of Petroleum Science and Engineering. v. 26, $p$ 169-178. 
NATIONAL INSTITUTE FOR OCCUPATIONAL SAFETY HEALTH (1998). Polynuclear Aromatic Hydrocarbons by HPLC. Manual of Analytical Methods. Forth Ed. Jan. 1998.

NOBRE, M. DE M.M.; NOBRE, R.C.M. (1998). Contaminação de solos e águas subterrâneas decorrentes da estocagem inadequada de compostos orgânicos e de metais pesados. In: Simpósio Brasileiro de Geotecnia Ambiental, 1998, São Paulo. Anais do Simpósio Brasileiro de Geotecnia Ambiental, São Paulo, Universidade de São Paulo. p.1-6.

NOGUEIRA, J.B. (1995). Mecânica dos Solos - Ensaios de Laboratório. São Carlos, publ. 094/95.

OGIHARA, S.H. (2000). Avaliação de investigação ambiental e de tecnologia de intervenção aplicadas em uma área industrial com elevadas concentrações de hidrocarbonetos. 126p. Dissertação (Mestrado) - Instituto de Geociências, Universidade de São Paulo, São Paulo. 2000.

OLIVEIRA, E. (1992). Contaminação de aqüíferos por hidrocarbonetos provenientes de vazamentos de tanques de armazenamento subterrâneo. 112p. Dissertação (Mestrado) - Instituto de Geociências, Universidade de São Paulo, São Paulo. 1992.

OLIVEIRA, E. (2000). Transferência de fases. Boletim da Associação Brasileira de Águas Subterrâneas, n. 100, p. 8, Mar.

OLIVEIRA, E. (2002). Comportamento de Contaminantes Orgânicos em Subsuperfície. Universidade de São Paulo. São Paulo. Notas de aula.

OLSEN, R.L.; DAVIS, A. (1990). Predicting the Fate and Transport of Organic Compounds in Groundwater: Part 1. Hazardous Materials Control. v. 3, n. 3, p. $38-64$. 
ORRELLANA, E. (1982). Prospección geoeléctrica en corriente continua. Editora Paraninfo. Madrid.

PEJON, O.J. (2000). Estudo dos fenômenos de expansão de rochas sedimentares de granulometria fina. Identificação, caracterização e mapeamento. Tese (livre docência), Escola de Engenharia de São Carlos, Universidade de São Paulo, São Carlos. 2000.

PEJON, O.J. (1992). Mapeamento Geotécnico da Folha de Piracicaba - SP (escala 1:100.000): Estudo de aspectos metodológicos, de caracterização e de apresentação de atributos. 2v. Tese (doutorado), Escola de Engenharia de São Carlos, Universidade de São Paulo, São Carlos. 1992.

PERRONI, J. C. A. (2003). Instalação de oito poços de monitoramento em área experimental em Ribeirão Preto-SP. Araraquara, GeoWater. Relatório GRT 080301.

PETERS, C.A.; LUTHY, R.G. (1993). Coal tar dissolution in water-miscible solvents: experimental evaluation. Environmental Science and Technology. v. 27, p. $2831-2843$.

PINAL, R.; RAO, S. C.; LEE, L. S.; CLINE, P.V. (1990). Cosolvency of Partially Miscible Organic Solvents on the Solubility of Hydrophobic Organic Chemicals. Environmental Science and Technology. v. 24, p. 639 - 647.

POWERS, S.E.; LOUREIRO, C.O.; ABRIOLA, L.M.; WEBER JR, W.J. (1991). Theoretical study of the significance of nonequilibrium dissolution of nonaqueous phase liquids in subsurface systems. Water Resources Research. v. 27, n. 4, p. $463-477$.

REGGIANI, L. (1999). Postos têm dívida ambiental de R\$ 3 bi. Folha de São Paulo, 2ํㅜㄹ caderno, p. 1, São Paulo, 29 de agosto de 1999. 
ROBERTS, P.V.; GOLTZ, M.N.; MACKAY, D.M. (1986). A Natural Gradient Experiment on Solute Transport in a Sand Aquifer. 3. Retardation Estimates and Mass Balances for Organic Solutes. Water Resources Research. v. 22, n. 13, p. $2047-2058$.

ROCCA, A.C.C. (2000). Simulação matemática do escoamento e transporte de massa no aqüífero freático em uma área industrial contaminada. 88p. Dissertação (Mestrado) - Escola Politécnica, Universidade de São Paulo, São Paulo. 2000.

ROSELI, M.L. (1995). Avaliação Hidrogeológicas e Programa de Monitoramento da Água Subterrânea. Relatório Técnico.

ROWE, R.K.; QUIGLEY, R.M.; BOOKER, J.R. (1995). Clayey Barrier Systems for Waste Disposal Facilities. E \& FN SPON.

RUMBAUGU, J.O.; RUMBAUGU, D.B. (2004). Groundwater Vistas Version 4: Guide to Using. Environmental Simulations, Inc.

SALLES, F.A.F. (1999). Avaliação de área contaminada por compostos orgânicos às margens da represa de Gurapiranga, no município de São Paulo - SP. 107p. Dissertação (Mestrado) - Instituto de Geociências, Universidade de São Paulo, São Paulo. 1999.

SAUCK, W.A.; ATEKWANA, E.A.; NASH, M.S. (1998). Elevated conductivities associated with an LNAPL plume imaged by integrated geophysical techniques. Journal environmental and engineering geophysics. v. 2, p. 203 - 212.

SÁNCHEZ, L.E. (2001). Desengenharia: O Passivo Ambiental na Desativação Empreendimentos Industriais. Editora da Universidade de São Paulo.

SAUCK, W.A. (2000). A model for the resistivity structure of LNAPL plumes and their environs in sandy sediments. Journal of applied geophysics. v. 44, p. 151 - 165. 
SAUCK, W.A.; ATEKWANA, E.A.; WERKEMA JR, D.D. (2000). Investigations of geoelectrical signatures at a hydrocarbon contaminated site. Journal of applied geophysics. v. 44, p. 167 - 180.

SCHWILLE, F. (1988). Dense chlorinated solvents in porous and fractured media: model experiments. Chelsea, MI: Lewis Publishers.

SCHWARZENBACH, R.P.; GSCHWEND, P.M.; IMBODEM, D.M. (1993). Environmental Organic Chemistry. John Wiley \& Sons, Inc.

SRACEK, O. (2002). Modelagem hidrogeoquímica aplicada à atenuação natural de aqüíferos. ABAS-CEPAS-IGc. IGc-USP. São Paulo, 64p.

STONE, H.L. (1973). Estimation of three-phase relative permeability and residual oil data. Journal of Canadian Petroleum Technology. v. 12, n. 4, p. 53 61.

T. ALVES ENGENHARIA AMBIENTAL S/C LTDA (2001). Relatório Ambiental Preliminar. Distrito Industrial de Ribeirão Preto - DIRP - 1aㅡ Etapa. Prefeitura Municipal de Ribeirão Preto.

TELFORD, W.M.; GELDART, L.P.; SHERRIF, R.E. (1990). Applied geophysics. Cambridge University Press. Cambridge.

TESTA, S.M.; PACZKOWSKI, M.T. (1989). Volume Determination and Recoverability of Free Hydrocarbon. Groundwater Monitoring Review. p. 120128.

THIEM, G. (1906). Hydrologische methodern: Leipzig, Geghardt, 56p.

UNITED STATE ENVIRONMENTAL PROTECTION AGENCY, (1994a). Evaluation of sampling and field-filtration methods for the analysis of trace metals in ground water, EPA-600-R94-119, July, 1994. 
UNITED STATE ENVIRONMENTAL PROTECTION AGENCY, (1994b). Evaluation of technologies for in-situ cleanup of DNAPL contaminated sites, EPA-600-R94-120, Aug. 1994.

UNITED STATE ENVIRONMENTAL PROTECTION AGENCY, (1996a). How to Effectively Recover Free Product at Leaking Underground Storage Tank Sites: A Guide for State Regulators, EPA-510-R96-001, Sept. 1996.

UNITED STATE ENVIRONMENTAL PROTECTION AGENCY, (1996b). EPA Superfund Record of Decision: Petrochem Recycling Corporation - Ekotek Plant, EPA/ROD/R08-96/901, Sept. 1996.

UNITED STATE ENVIRONMENTAL PROTECTION AGENCY, (1996c). Test Methods for Evaluating Solid Waste, SW-846. CD-ROM. Dec. 1996.

UNITED STATE ENVIRONMENTAL PROTECTION AGENCY, (1997). Office of Underground Storage Tanks, Expedited Site Assessment Tools for USTs: A Guide for Regulators, EPA-510-B97-001, Mar. 1997.

UNITED STATE ENVIRONMENTAL PROTECTION AGENCY, (1999a). Partition coefficients for metals in surface water, soil, and waste. Draft, Jun. 1999.

UNITED STATE ENVIRONMENTAL PROTECTION AGENCY, (1999b). Understanding Variation in Partition Coefficient, $\mathrm{K}_{\mathrm{d}}$, Values. Volume II: Review of geochemistry and available $K_{d}$ values for cadmium, cesium, chromium, lead, plutonium, radon, strontium, thorium, tritium, and uranium. EPA-402-R99-004B, Aug. 1999.

UNITED STATE GEOLOGICAL SURVEY, (1998). Spatial variation in hydraulic conductivity determined by slug tests in the Canadian river alluvium near the Norman landfill, Norman, Oklahoma. Report 97 - 4292, Oklahoma City, Okla., 1998. 
UNITED STATE GEOLOGICAL SURVEY, (2001). System and boundary conceptualization in ground-water flow simulation, Book 3, Applications of hydraulics, Chapter B8, Reston, Virg., 2001.

UNITED STATE GEOLOGICAL SURVEY, (2002). Ground-water flow and numerical simulation of recharge from streamflow infiltration near pine nut creek, Douglas County, Nevada. Report 02 - 4145, Carson City, Nev., 2002.

UNITED STATE GEOLOGICAL SURVEY, (2002). Characterization of hydraulic conductivity of the alluvium and basin fill, pinal creek basin near Globe, Arizona. Report 02 - 4205, Tucson, Ariz., 2002.

VOGEL, A.I. (1979). Química Analítica Quantitativa. 5 ed. Longman Scientific \& Technical. London.

WALTER, T.; EDERER, H.J.; FÖRST, C.; STIEGLITZ, L. (2000). Sorption of selected polycyclic aromatic hydrocarbons on soils in oil-contaminated systems. Chemosphere. v. 41, p. 387 - 397.

WEAVER, J.W. (2004). On-line Tools for Assessing Petroleum Releases. EPA 600/R-04/101. Athens, Georgia. September 2004.

WERKEMA JR, D.D.; ATEKWANA, E.A.; SAUCK, W.A.; ROSSBACH, S.; DURIS, J. (2000). Vertical distribution of microbial abundances and apparent resistivity at an LNAPL spill site. Proceedings of the Symposium on the Application of Geophysics to Engineering and Environmental Problems (SAGEEP). v. II, p. $669-678$.

WORLD HEALTH ORGANIZATION (2002). Manganese and its compounds: environmental aspects. Geneva. 2004.

YANG, S.Y.; YEH, H.D. (2004). A Simple Approach Using Bouwer and Rice's Method for Slug Test Data Analysis. Ground Water. v. 42, n. 5, p. 781 - 784. 
ZHDANOV, M.S.; KELLER, G.V. (1994). The geoelectrical methods in geophysical exploration. Elsevier Science B.V.. The Netherlands.

ZHENG, C.; BENNETT, G.D. (1995). Applied Contaminant Transport Modeling: Theory and Practice. Van Nostrand Reinhold. 
APÊNDICE A - Levantamento Topográfico 


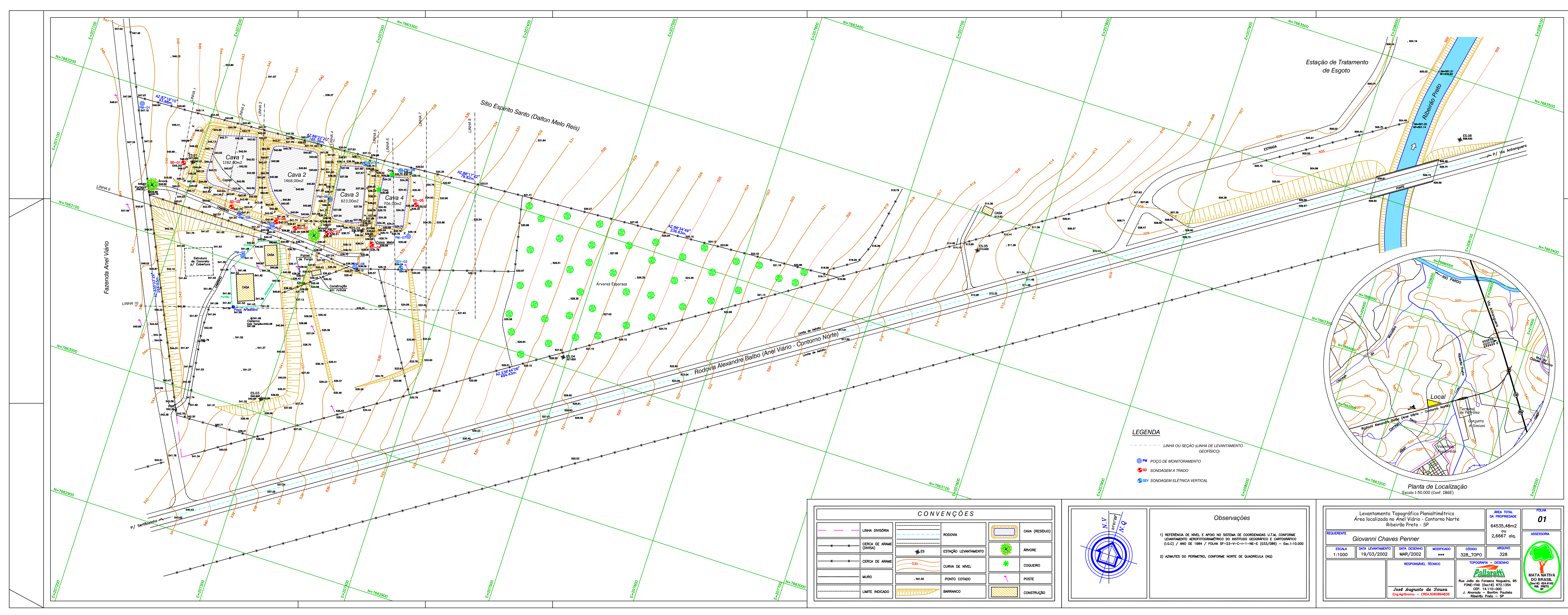







APÊNDICE B - Perfis Tátil-Visuais dos Furos 


\begin{tabular}{l|l|l}
\hline \multicolumn{3}{c}{ SONDAGEM A TRA } \\
\hline IDENTIFICAÇÃO: \\
\hline COTA (m): $\quad 546,20$ & PROFUNDIDADE (m): 16,55 \\
\hline COORDENADAS UTM: & 207190,85 EW & $7663156,29 \mathrm{NS}$ \\
\hline
\end{tabular}

DATA: 20-03-2003

ESCALA: 1:100

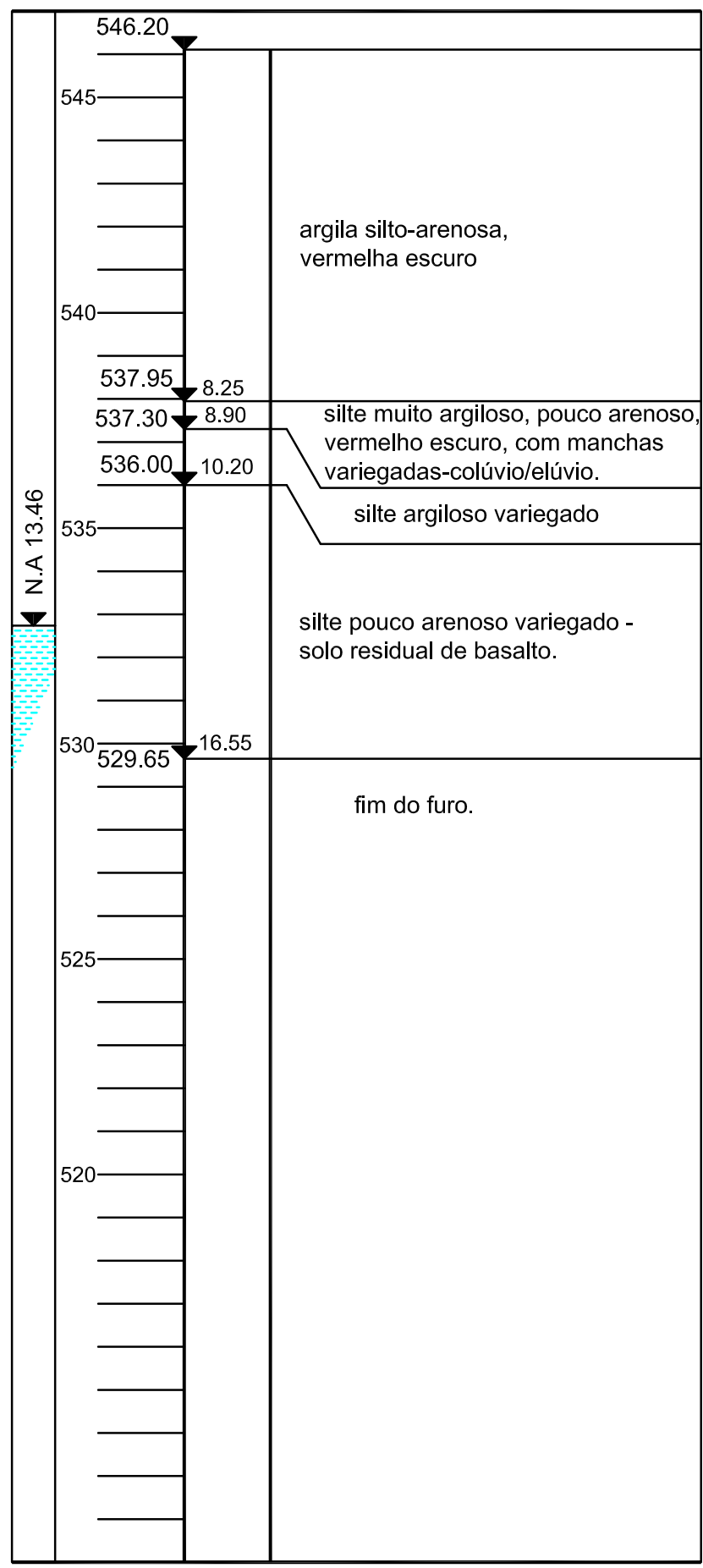

IDENTIFICAÇÃO:

SD-02

\begin{tabular}{l|l|c}
\hline COTA $(\mathrm{m}): \quad 542,75$ & \multicolumn{2}{l}{ PROFUNDIDADE $(\mathrm{m}): 15,55$} \\
\hline COORDENADAS UTM: & $207234,00 \mathrm{EW}$ & $7663136,60 \mathrm{NS}$ \\
\hline
\end{tabular}

DATA: 20-03-2003

ESCALA: 1:100

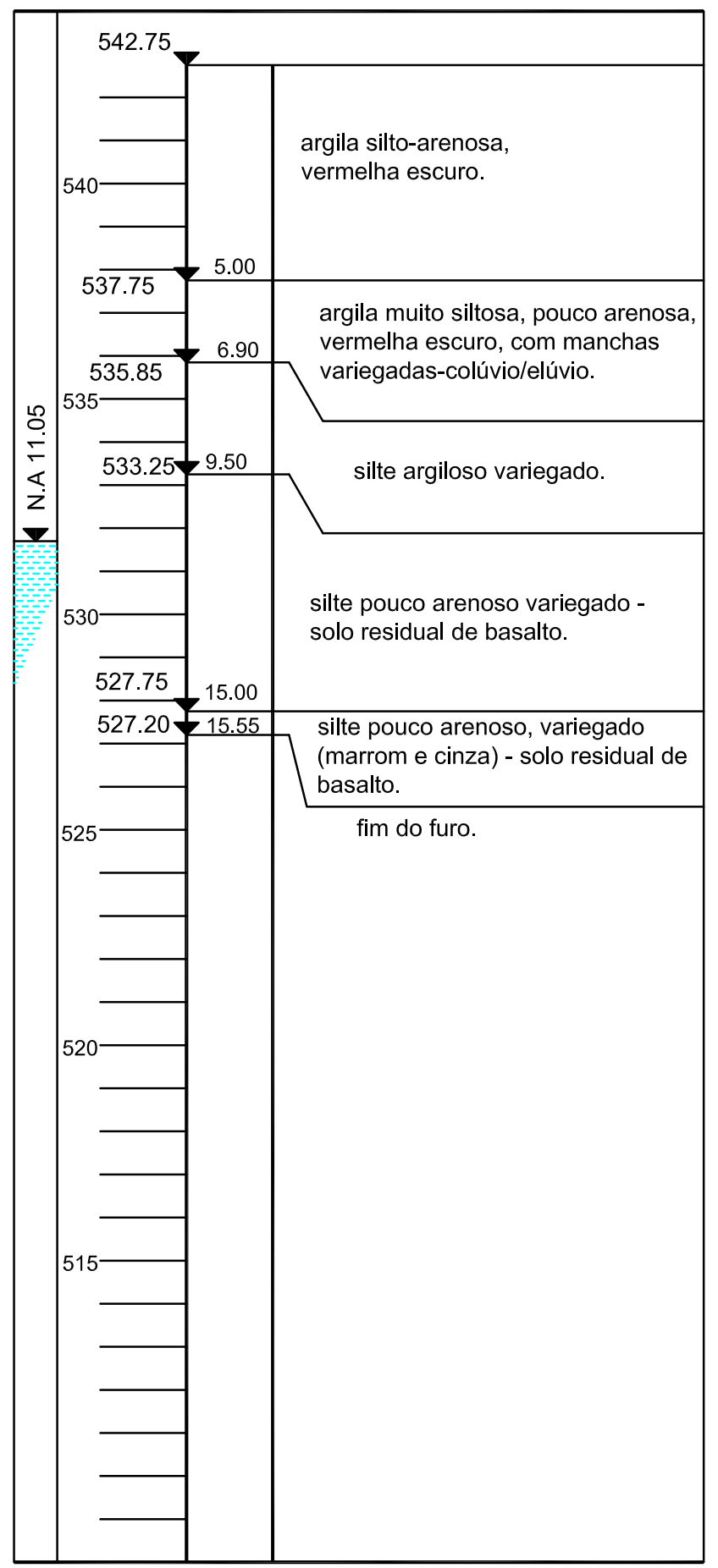


SONDAGEM A TRADO MECANIZADO

IDENTIFICAÇÃO:

SD-03

\begin{tabular}{l|l|l}
\hline COTA $(\mathrm{m}): 538,51$ & \multicolumn{1}{l}{ PROFUNDIDADE $(\mathrm{m}): 13,20$} \\
\hline COORDENADAS UTM: & $207305,90 \mathrm{EW}$ & $7663139,95 \mathrm{NS}$ \\
\hline
\end{tabular}

DATA: 20-03-2003

ESCALA: 1:100

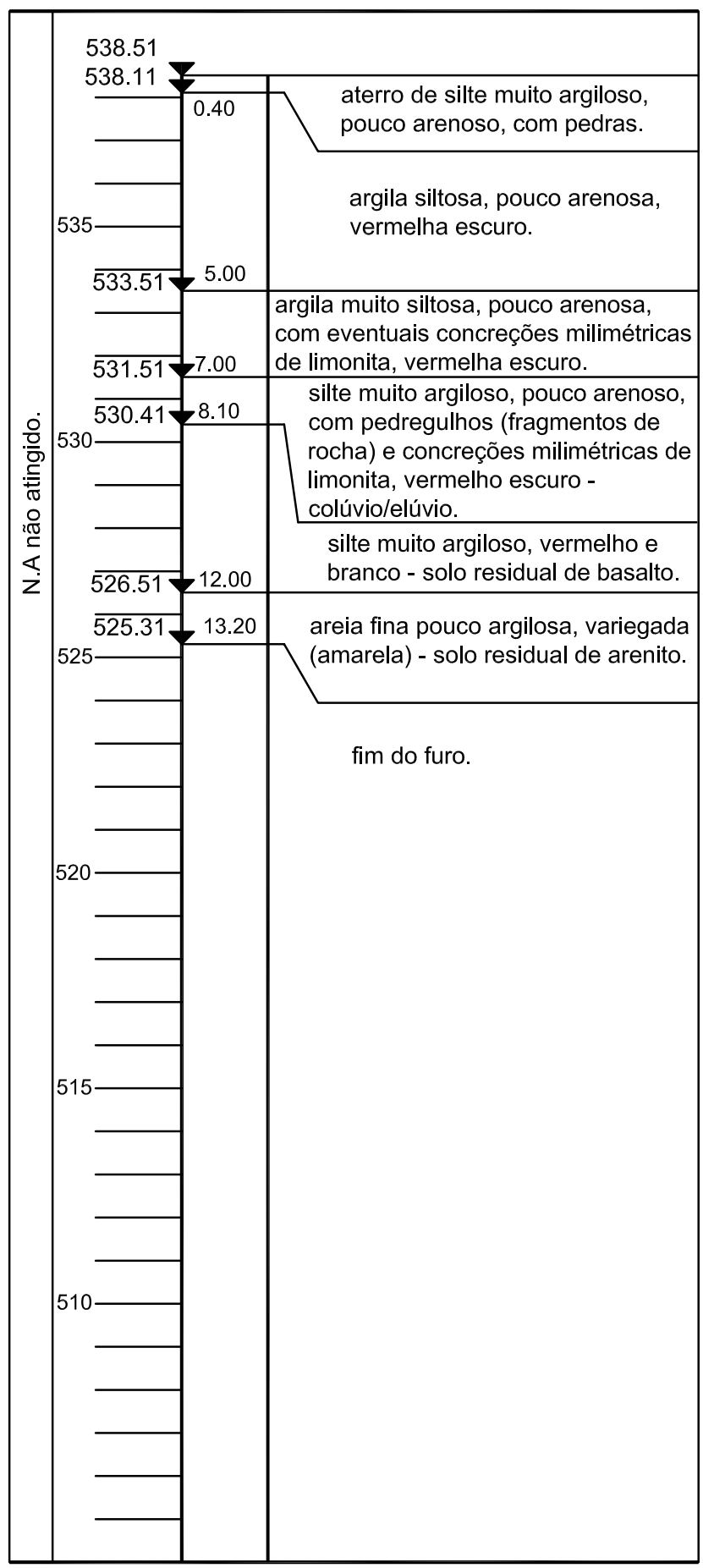

IDENTIFICAÇÃO:

SD-04

\begin{tabular}{l|l|l}
\hline COTA $(\mathrm{m}): 535,78$ & \multicolumn{2}{l}{ PROFUNDIDADE $(\mathrm{m}): 14,10$} \\
\hline COORDENADAS UTM: & $207339,31 \mathrm{EW}$ & $7663142,37 \mathrm{NS}$ \\
\hline
\end{tabular}

DATA: 20-03-2003

ESCALA: 1:100

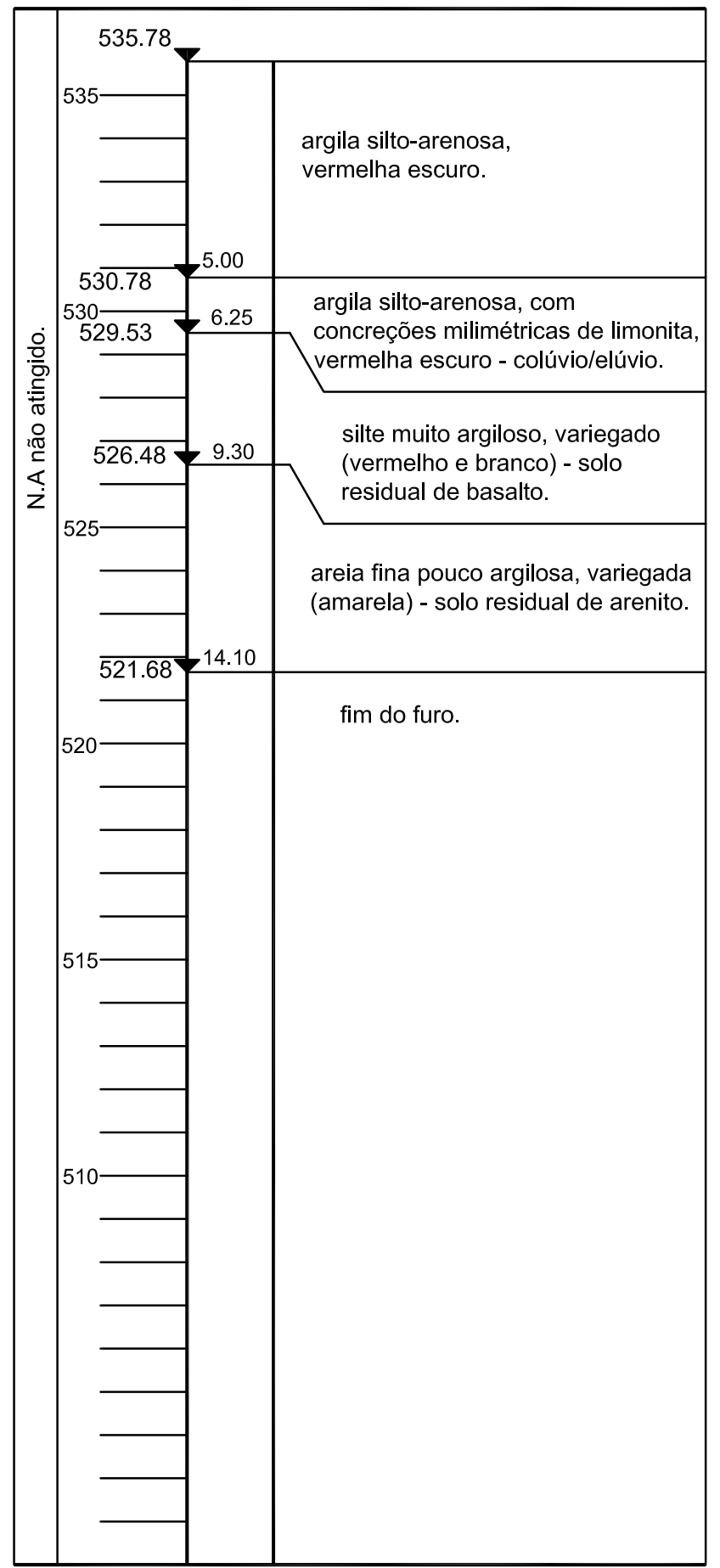


SONDAGEM A TRADO MECANIZADO

IDENTIFICAÇÃO:

SD-05

\begin{tabular}{l|l|l}
\hline COTA $(\mathrm{m}): 535,02$ & \multicolumn{2}{l}{ PROFUNDIDADE $(\mathrm{m}): 10,90$} \\
\hline COORDENADAS UTM: & $207361,03 \mathrm{EW}$ & $7663179,36 \mathrm{NS}$ \\
\hline
\end{tabular}

DATA: 20-03-2003

ESCALA: 1:100

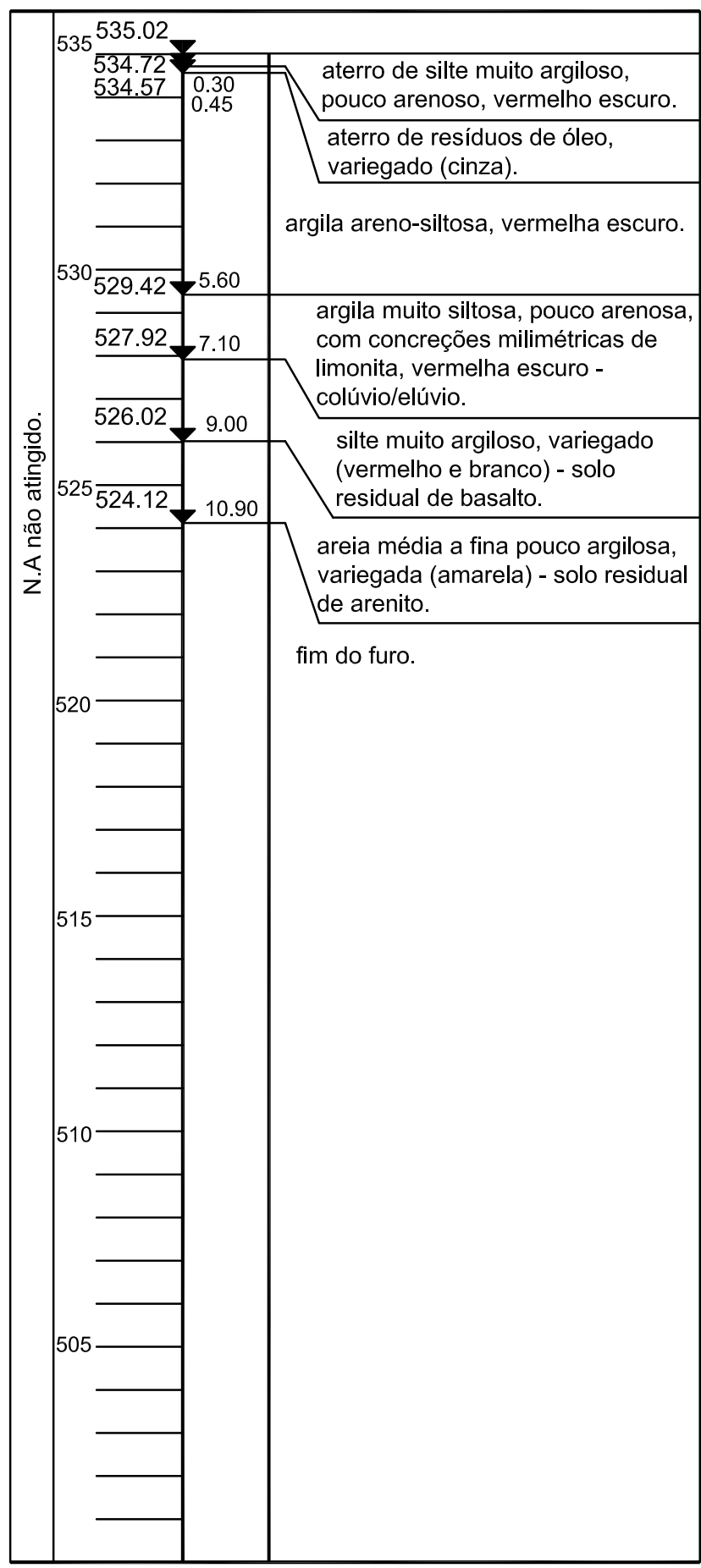

IDENTIFICAÇÃO:

SD-06

\begin{tabular}{l|l|l}
\hline COTA $(\mathrm{m}): 540,53$ & \multicolumn{2}{l}{ PROFUNDIDADE $(\mathrm{m}): 10,40$} \\
\hline COORDENADAS UTM: & $207268,03 \mathrm{EW}$ & $7663136,05 \mathrm{NS}$ \\
\hline
\end{tabular}

DATA: 20-03-2003

ESCALA: 1:100

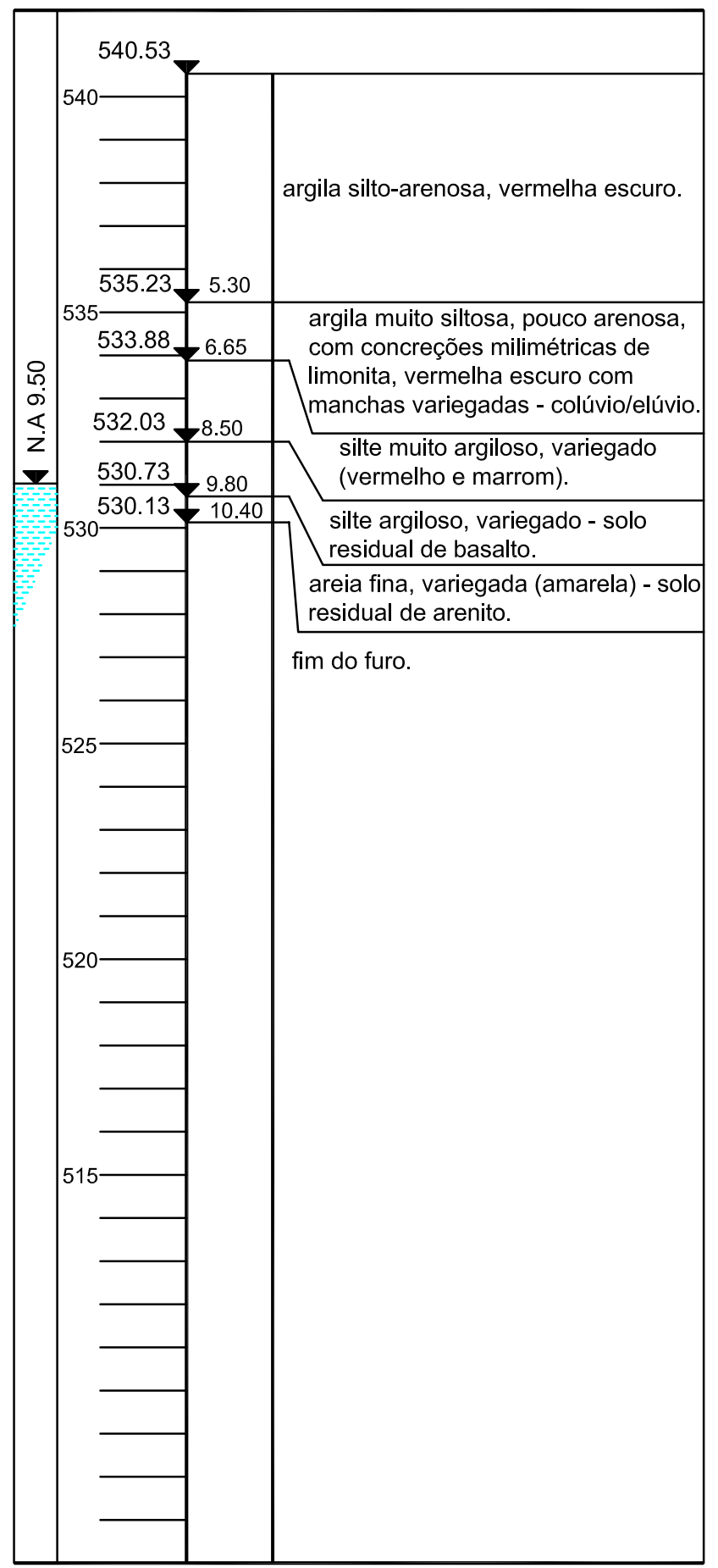


SONDAGEM A TRADO MECANIZADO

IDENTIFICAÇÃO:

\begin{tabular}{l|l|l}
\hline COTA $(\mathrm{m}):$ & \multicolumn{2}{l|}{ PROFUNDIDADE $(\mathrm{m}):$} \\
\hline COORDENADAS UTM: & & \\
\hline
\end{tabular}

DATA:

ESCALA:

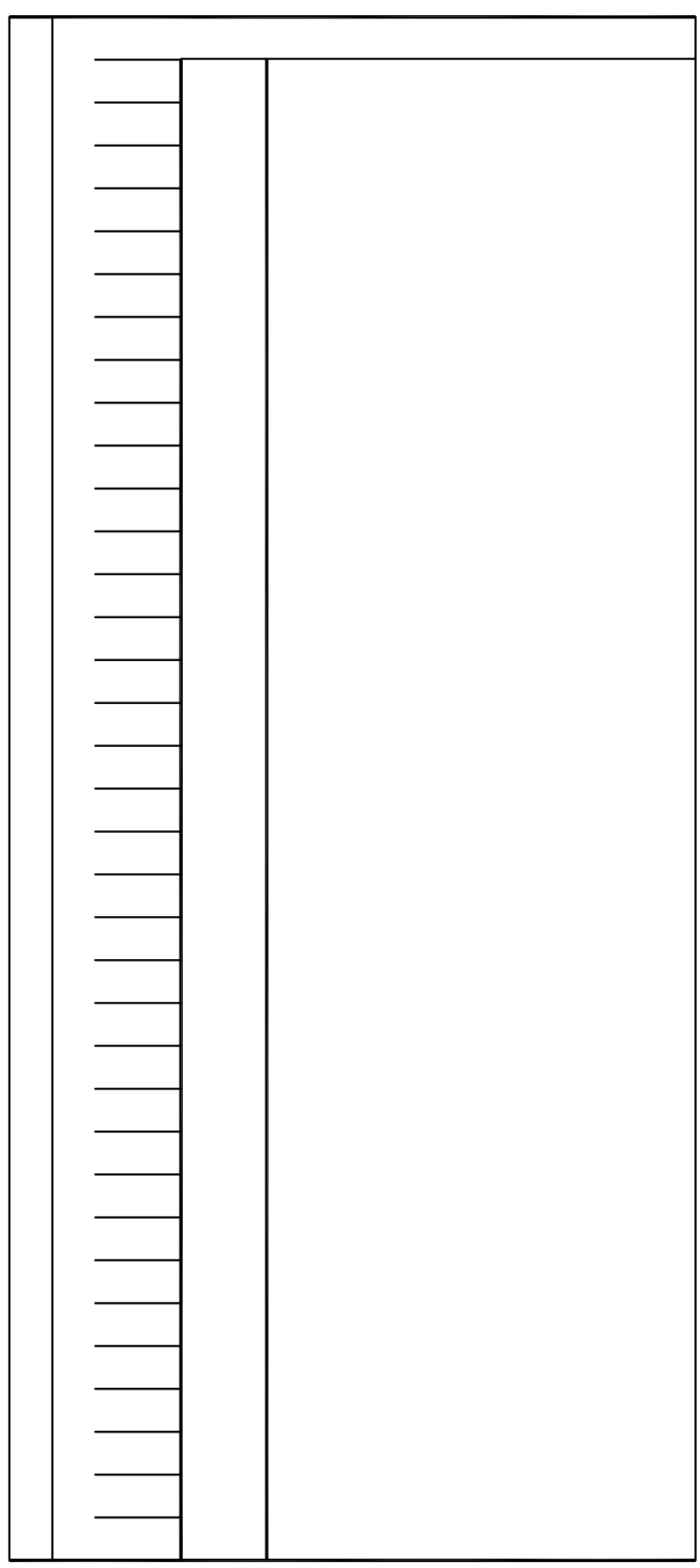

IDENTIFICAÇÃO:

SD-07

\begin{tabular}{l|l|l}
\hline COTA $(\mathrm{m}): 539,26$ & \multicolumn{2}{l}{ PROFUNDIDADE $(\mathrm{m}): 14,25$} \\
\hline COORDENADAS UTM: & $207282,54 \mathrm{EW}$ & $7663135,98 \mathrm{NS}$ \\
\hline
\end{tabular}

DATA: 20-03-2003

ESCALA: 1:100

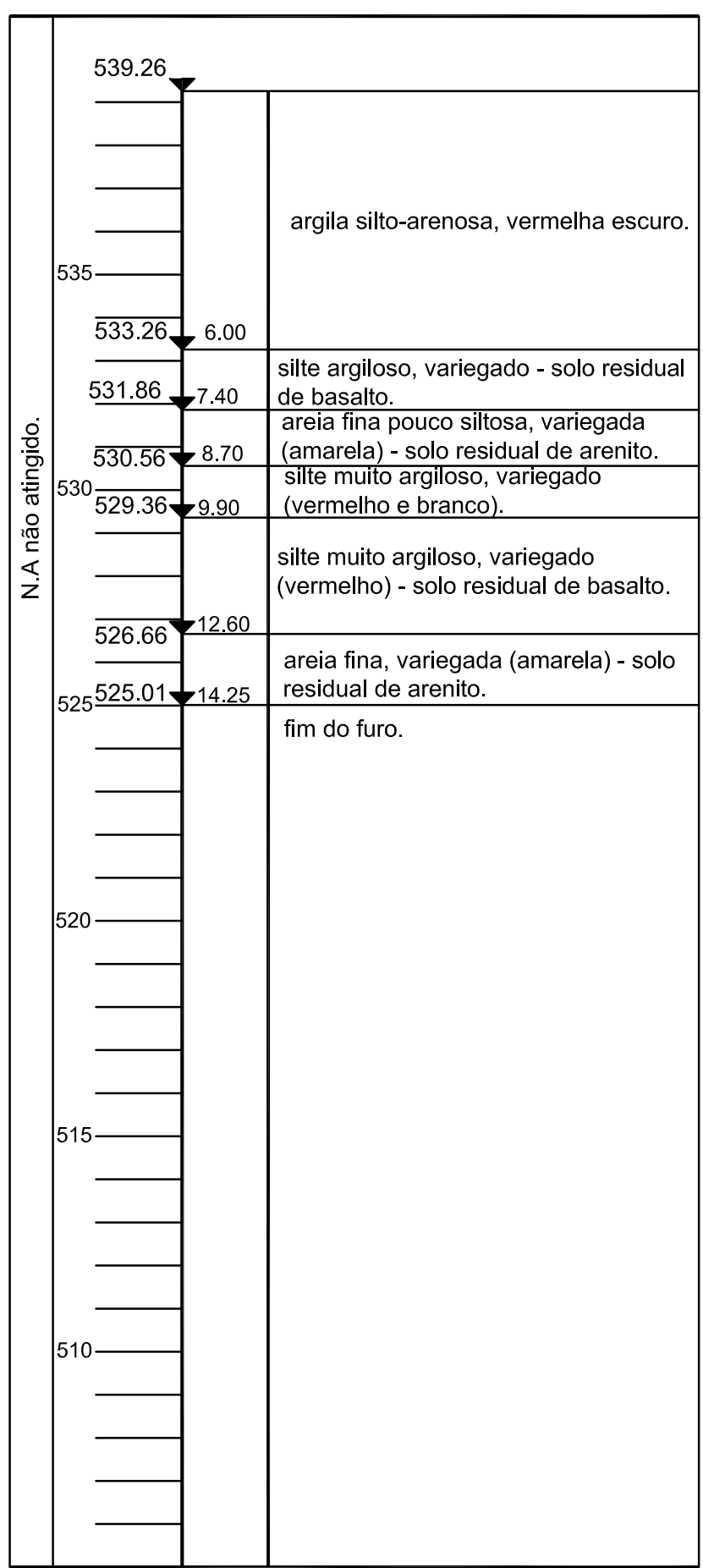




\begin{tabular}{|c|c|c|c|}
\hline \multirow[t]{5}{*}{ SONDAGEM E POÇO DE MONITORAMENTO } & \multicolumn{3}{|l|}{ COTA $(m): \quad 547.19$} \\
\hline & COORDENADAS UTM: & $207149,01 \mathrm{EW}$ & 7663188,10 NS \\
\hline & \multicolumn{3}{|l|}{ Profundidade $(m)=18.60$} \\
\hline & \multicolumn{3}{|l|}{ ESCALA: 1:200 } \\
\hline & \multicolumn{3}{|l|}{ DATA: 02-10-2003 } \\
\hline
\end{tabular}

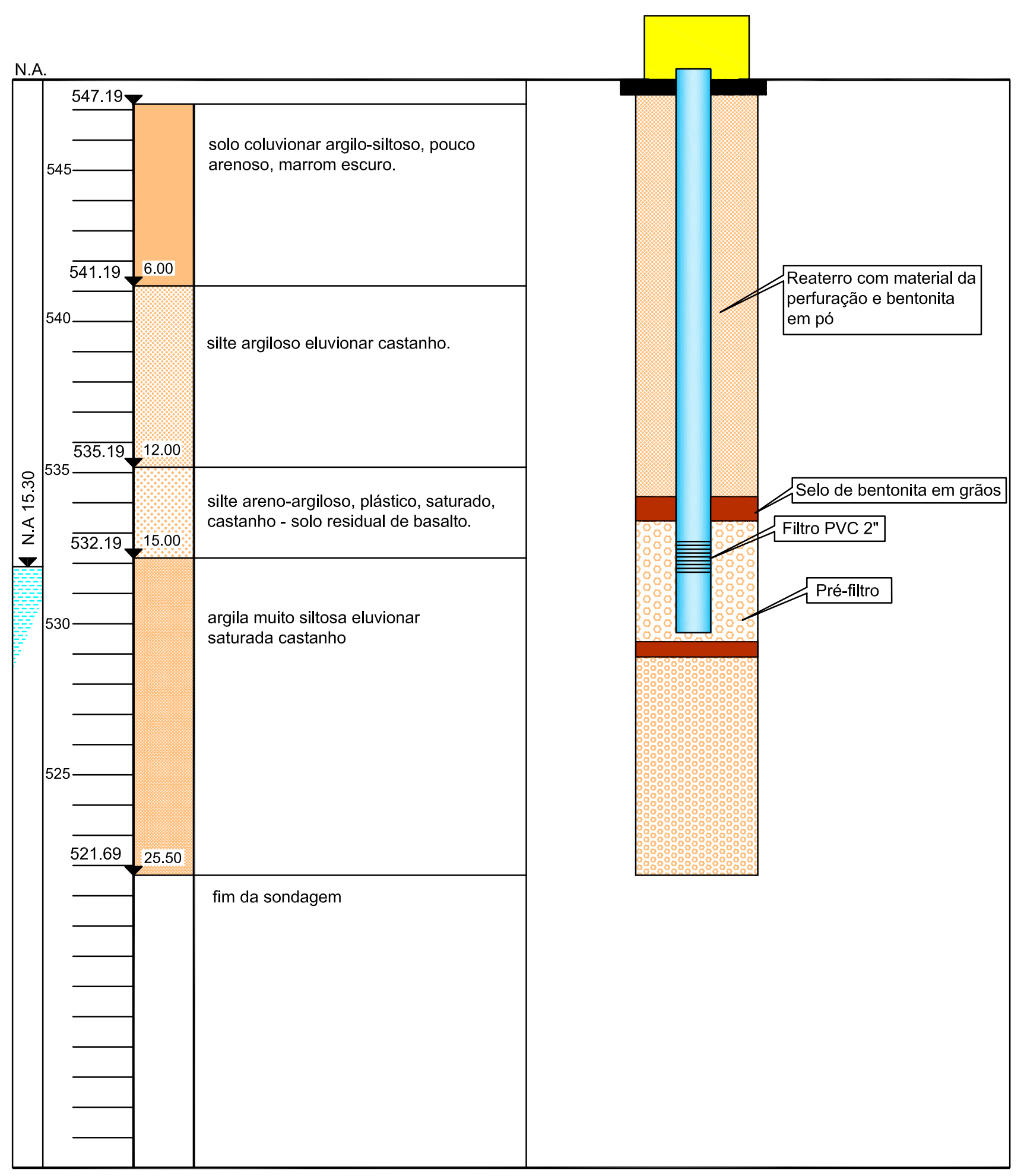




\begin{tabular}{|c|c|c|c|}
\hline \multirow[t]{5}{*}{ SONDAGEM E POÇO DE MONITORAMENTO } & \multicolumn{3}{|l|}{$\operatorname{COTA}(m): \quad 541.10$} \\
\hline & COORDENADAS UTM: & $207252,68 \mathrm{EW}$ & 7663105,22 NS \\
\hline & \multicolumn{3}{|c|}{ Profundidades $(m): A=16.40$ e $B=18.40$} \\
\hline & \multicolumn{3}{|l|}{ ESCALA: 1:200 } \\
\hline & \multicolumn{3}{|l|}{ DATA: 03-10-2003 } \\
\hline
\end{tabular}

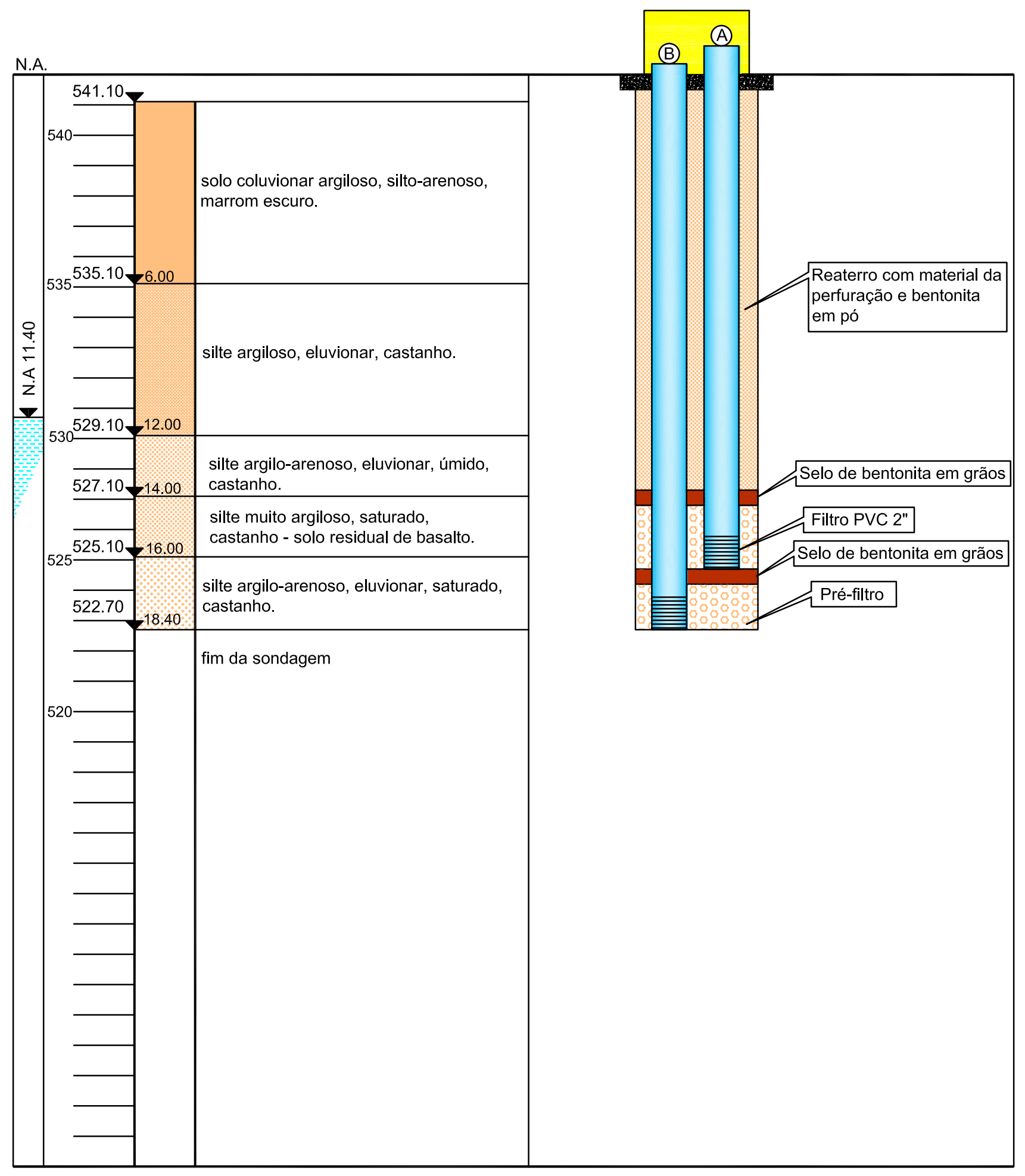




\begin{tabular}{l|l|l|l}
\hline SONDAGEM E POÇO DE MONITORAMENTO & \multicolumn{2}{|l}{ COTA $(\mathrm{m}): 541.89$} \\
\cline { 2 - 3 } & \multicolumn{2}{l}{ COORDENADAS UTM: $207240,88 \mathrm{EW}$} & $7663133,75 \mathrm{NS}$ \\
\cline { 2 - 3 } & \multicolumn{2}{|l|}{ Profundidade $(\mathrm{m})=15.45$} \\
\cline { 2 - 3 } & ESCALA: 1:200 \\
\cline { 2 - 3 } & DATA: 08-10-2003 \\
\hline
\end{tabular}

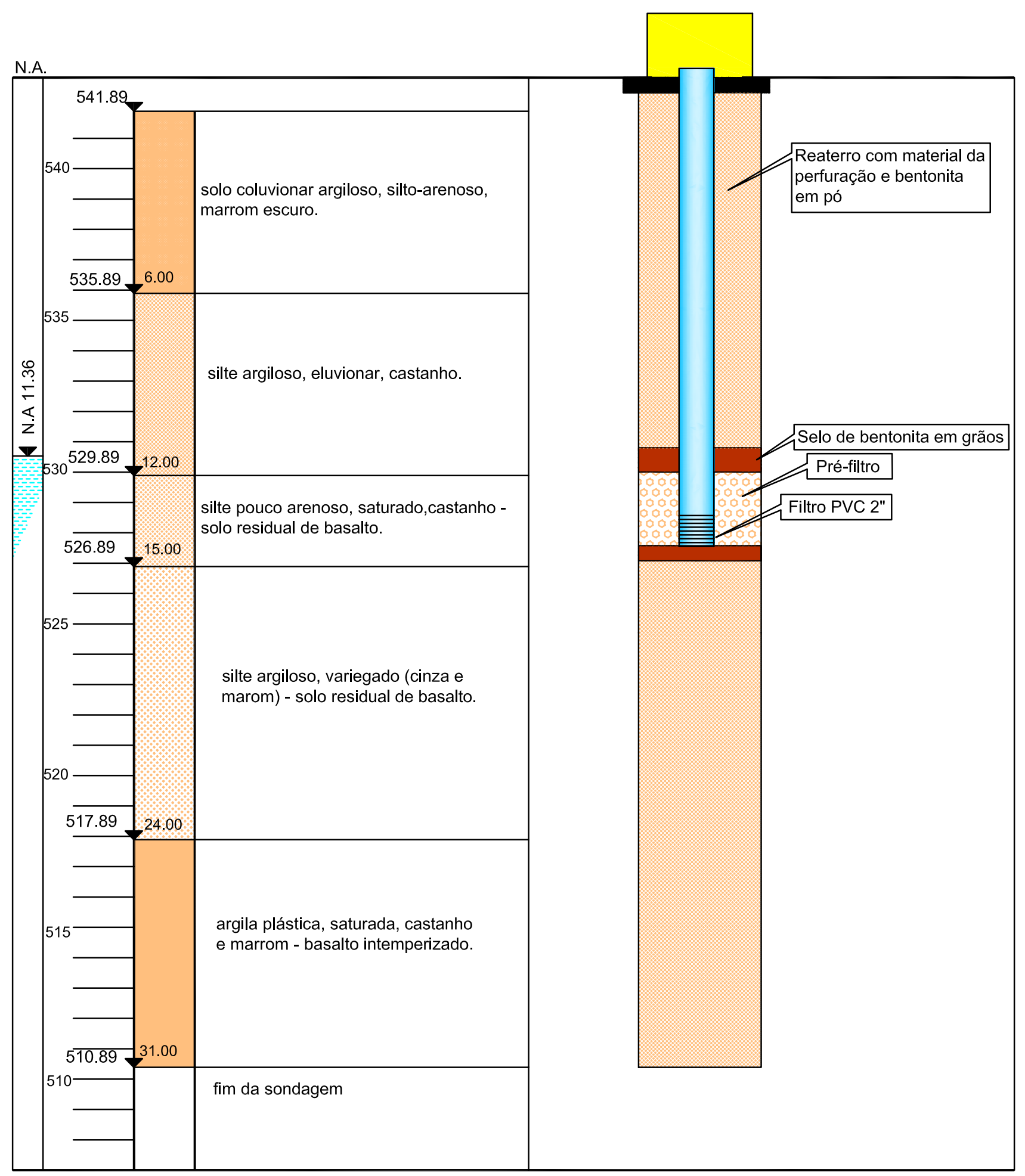




\begin{tabular}{l|l|l|l}
\hline SONDAGEM E POÇO DE MONITORAMENTO & \multicolumn{2}{|l}{ COTA $(\mathrm{m}): 540.34$} \\
\cline { 2 - 3 } & COORDENADAS UTM: & $207265,93 \mathrm{EW}$ & $7663133,47 \mathrm{NS}$ \\
\cline { 2 - 3 } & \multicolumn{2}{|l|}{ Profundidade $(\mathrm{m})=15.00$} \\
\cline { 2 - 3 } & ESCALA: 1:200 \\
\cline { 2 - 3 } & DATA: 07-10-2003 \\
\hline
\end{tabular}

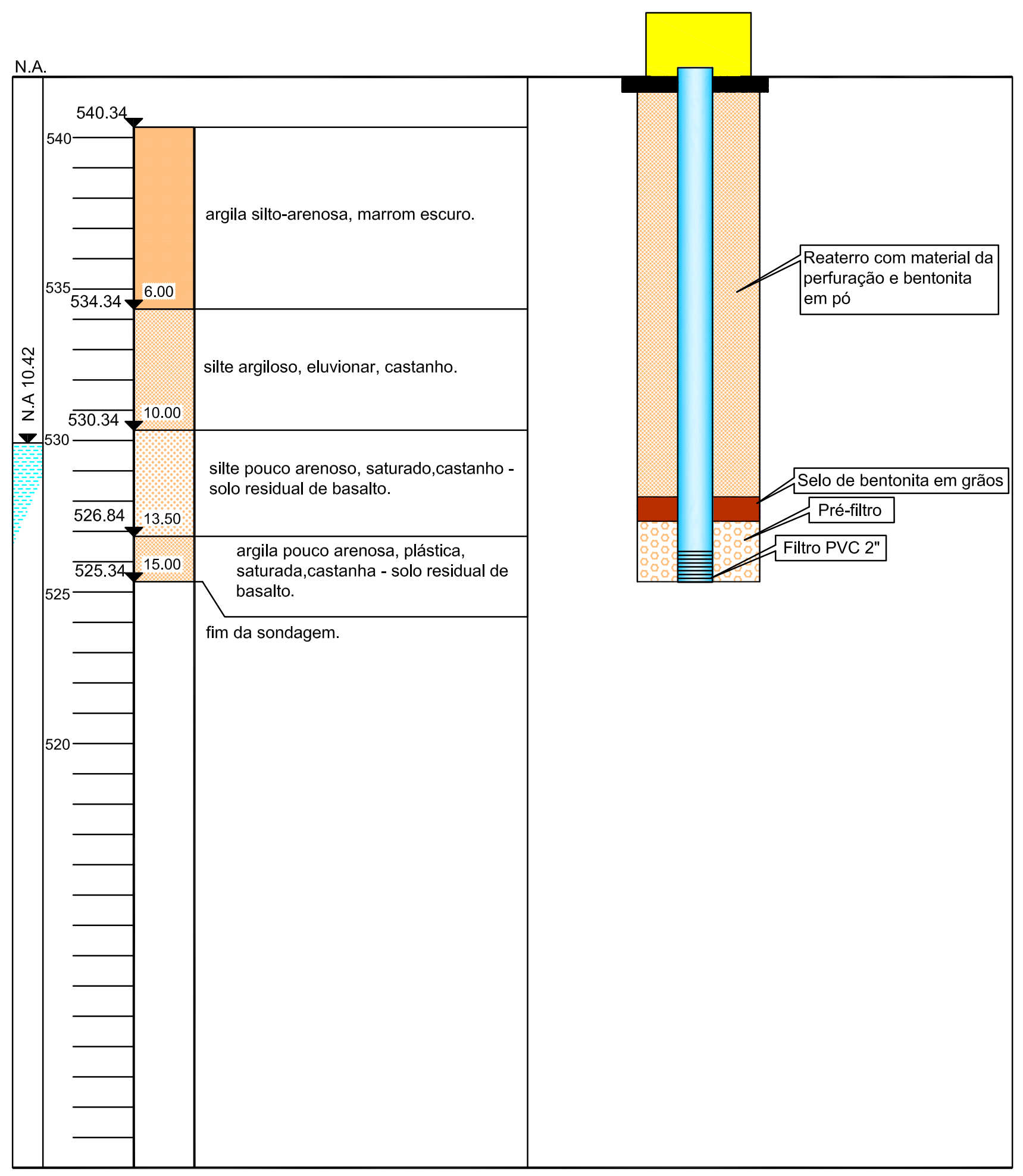




\begin{tabular}{l|l|l|l}
\hline SONDAGEM E POÇO DE MONITORAMENTO & \multicolumn{2}{|l}{ COTA $(\mathrm{m}): 538.21$} \\
\cline { 2 - 3 } & \multicolumn{2}{l}{ COORDENADAS UTM: $207300,38 \mathrm{EW}$} & $7663163,88 \mathrm{NS}$ \\
\cline { 2 - 3 } & \multicolumn{2}{|l|}{ Profundidade $(\mathrm{m})=30.50$} \\
\cline { 2 - 3 } & \multicolumn{2}{|l|}{ ESCALA: 1:200 } \\
\cline { 2 - 3 } & DATA: 04-10-2003 \\
\hline
\end{tabular}

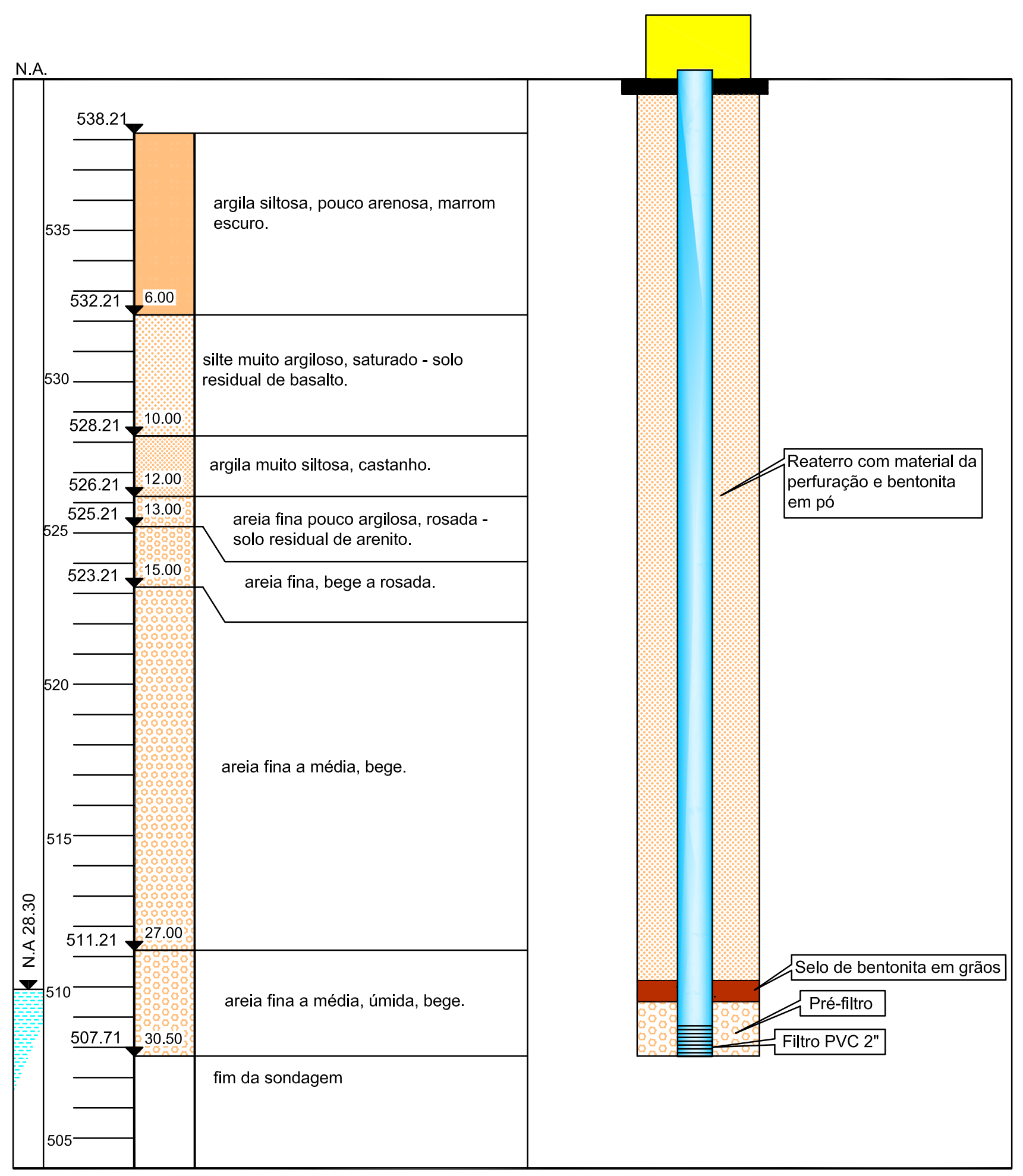




\begin{tabular}{|c|c|c|c|}
\hline \multirow[t]{5}{*}{ SONDAGEM E POÇO DE MONITORAMENTO } & \multicolumn{3}{|l|}{ COTA (m): 536.09} \\
\hline & COORDENADAS UTM: & $207332,63 \mathrm{EW}$ & 7663122,55 NS \\
\hline & \multicolumn{3}{|l|}{ Profundidade $(\mathrm{m})=31.40$} \\
\hline & \multicolumn{3}{|l|}{ ESCALA: 1:200 } \\
\hline & \multicolumn{3}{|l|}{ DATA: 02-10-2003 } \\
\hline
\end{tabular}

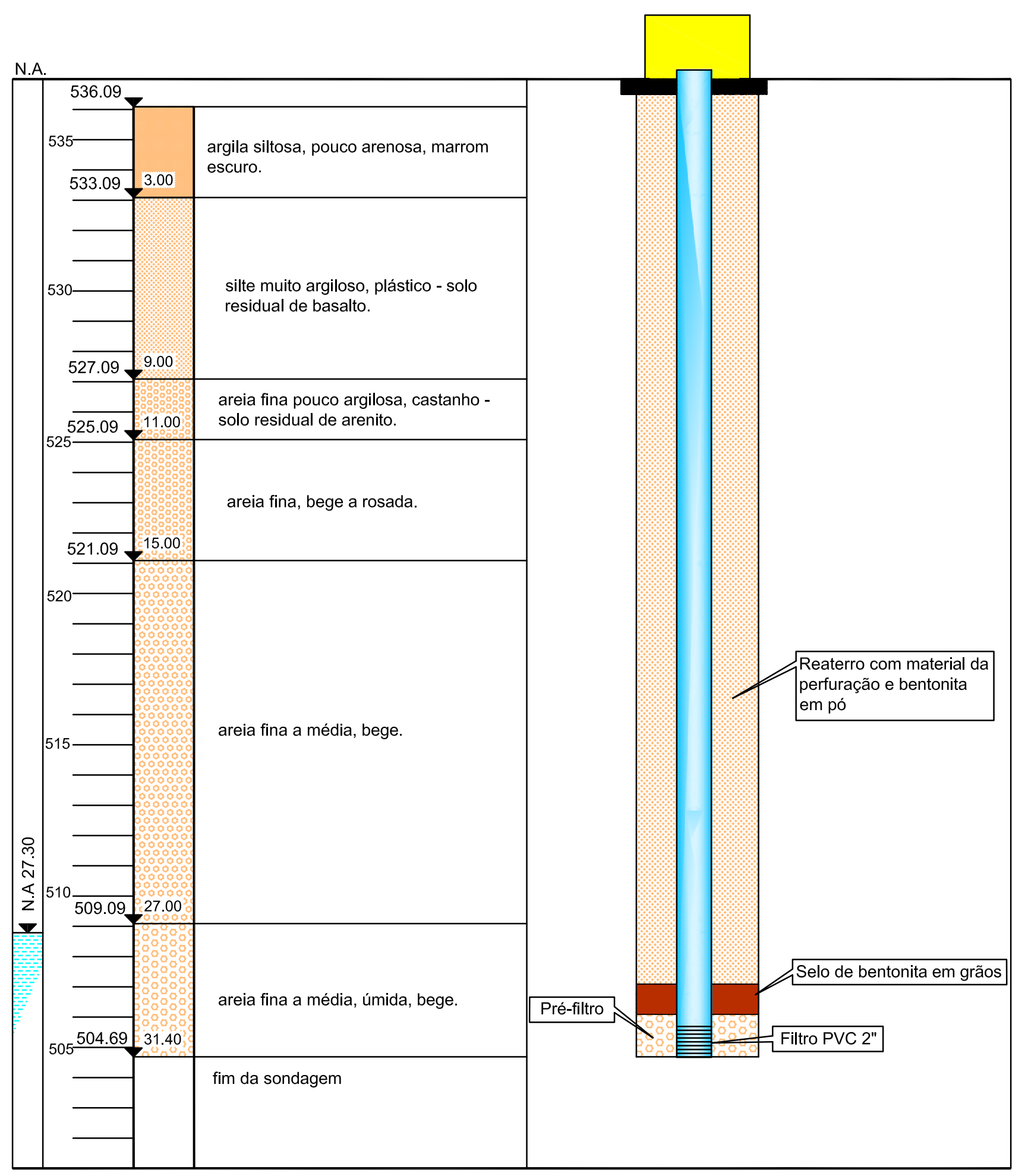




\begin{tabular}{|c|c|c|c|}
\hline \multirow[t]{5}{*}{ SONDAGEM E POÇO DE MONITORAMENTO } & \multicolumn{3}{|l|}{ COTA $(m): \quad 535.08$} \\
\hline & COORDENADAS UTM: & $207362,92 \mathrm{EW}$ & $7663155,73 \mathrm{NS}$ \\
\hline & \multicolumn{3}{|l|}{ Profundidade $(m)=32.00$} \\
\hline & \multicolumn{3}{|l|}{ ESCALA: 1:200 } \\
\hline & \multicolumn{3}{|l|}{ DATA: 01-10-2003 } \\
\hline
\end{tabular}

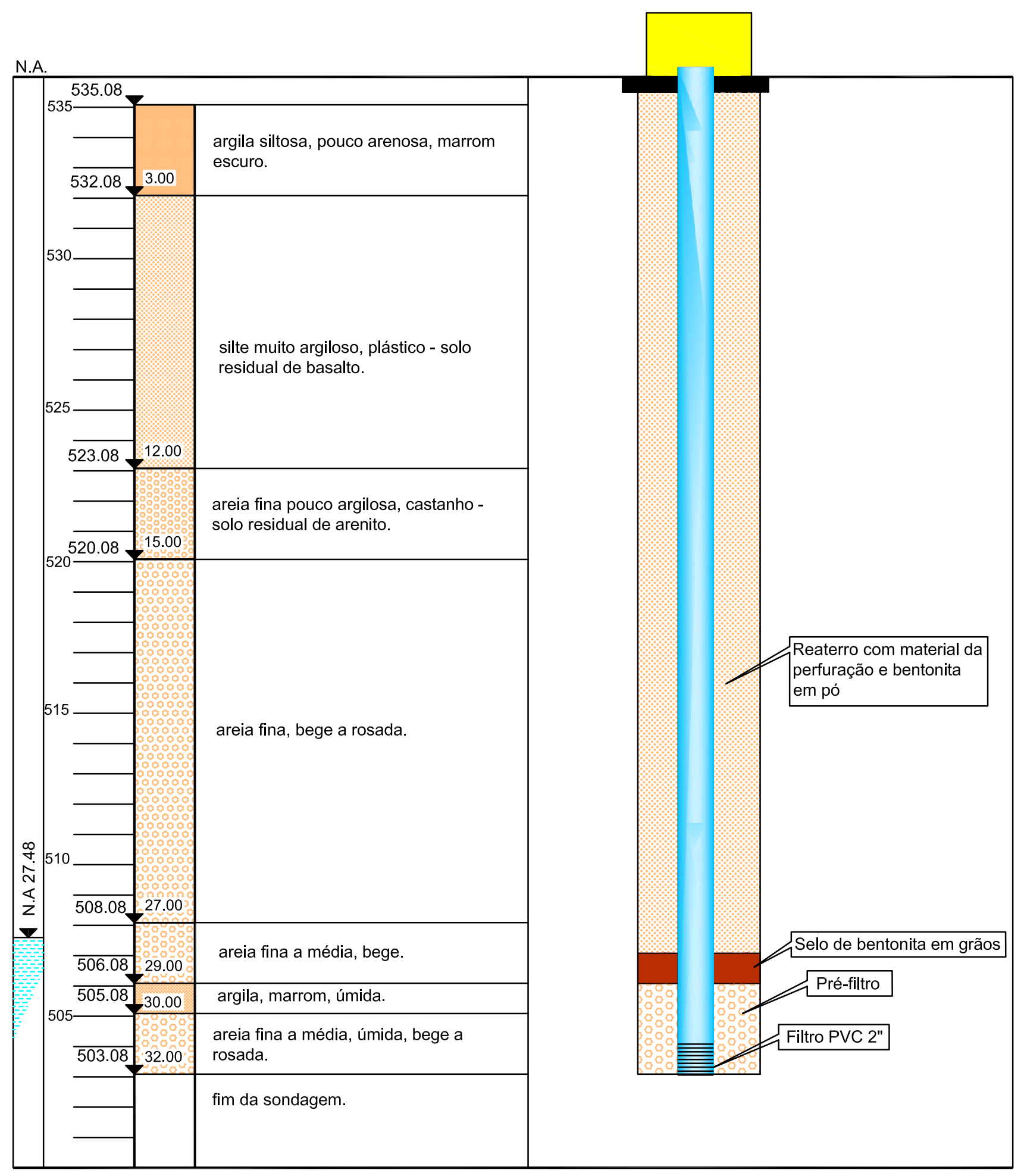




\begin{tabular}{|c|c|c|c|}
\hline \multirow[t]{5}{*}{ SONDAGEM E POÇO DE MONITORAMENTO } & \multicolumn{3}{|l|}{$\operatorname{COTA}(m):$} \\
\hline & COORDENADAS UTM: & $207342,86 \mathrm{EW}$ & $7663199,52 \mathrm{NS}$ \\
\hline & \multicolumn{3}{|l|}{ Profundidade $(m)=32.00$} \\
\hline & \multicolumn{3}{|l|}{ ESCALA: 1:200 } \\
\hline & \multicolumn{3}{|l|}{ DATA: 06-10-2003 } \\
\hline
\end{tabular}

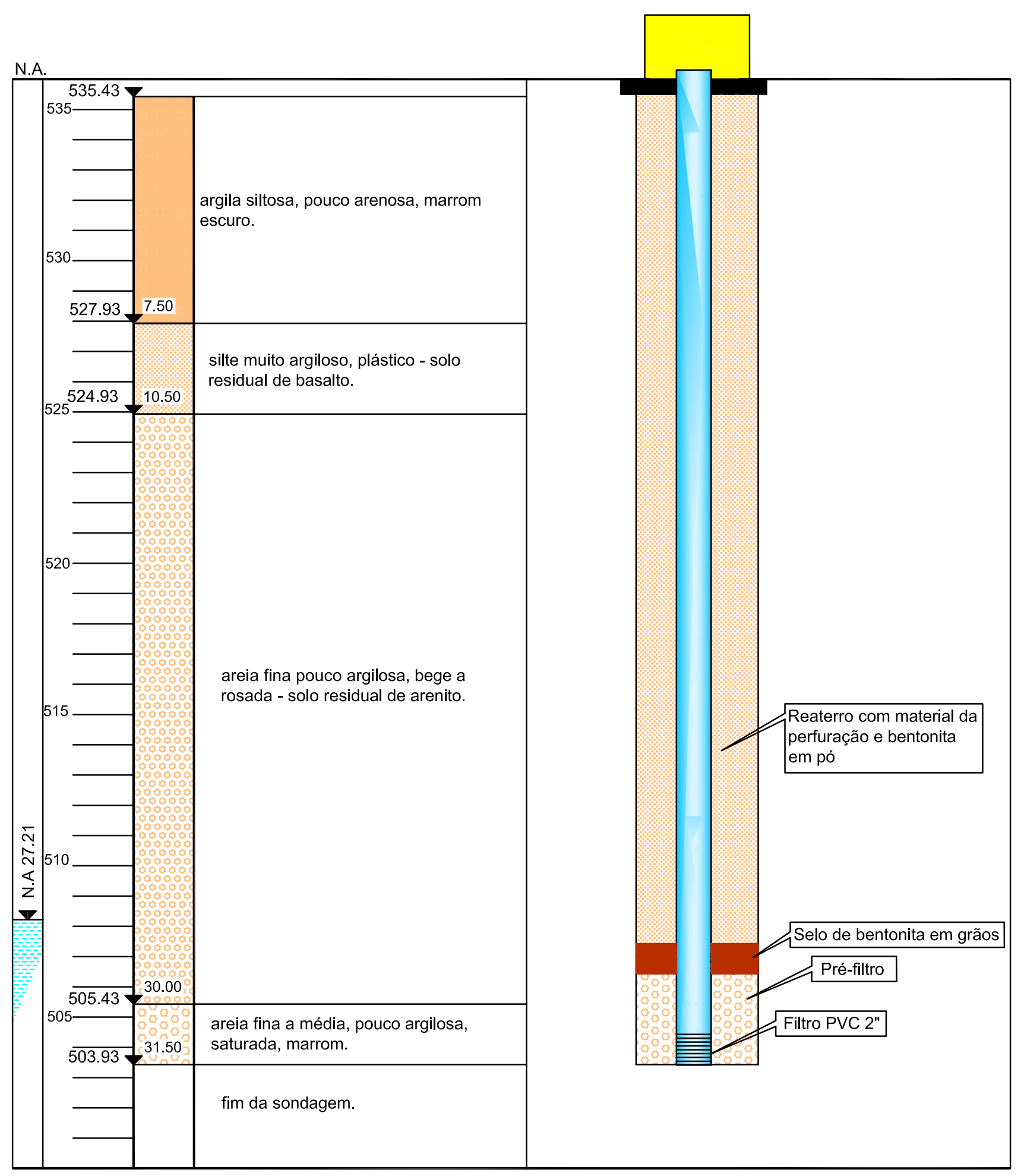




\section{APÊNDICE C:}

- Tabela com Dados Gerais dos Poços de Monitoramento;

- Tabela com Dados do Segundo Desenvolvimento. 
Tabela - Dados gerais dos poços de monitoramento.

\begin{tabular}{|c|c|c|c|c|c|c|c|c|c|c|}
\hline \multirow{3}{*}{$\begin{array}{l}\text { Identificação } \\
\text { PM } 01 \\
\end{array}$} & \multicolumn{2}{|c|}{ Início } & \multicolumn{2}{|c|}{ Término } & \multirow{2}{*}{\multicolumn{2}{|c|}{$\begin{array}{l}\text { Profundidade } \\
\text { amostragem } \\
\text { com liner }(\mathrm{m})\end{array}$}} & \multicolumn{2}{|c|}{ Profundidade (m) } & \multicolumn{2}{|c|}{$\begin{array}{l}\text { Profundidade } \\
\text { do filtro (m) }\end{array}$} \\
\hline & \multirow{2}{*}{\begin{tabular}{c|} 
Data \\
$02 / 10 / 03$
\end{tabular}} & \multirow{2}{*}{\begin{tabular}{r|} 
Hora \\
$15: 00$
\end{tabular}} & \multirow{2}{*}{$\begin{array}{c}\text { Data } \\
03 / 10 / 03\end{array}$} & \multirow{2}{*}{\begin{tabular}{|c|} 
Hora \\
$10: 45$
\end{tabular}} & & & \multirow{2}{*}{\begin{tabular}{|r|} 
Perfuração \\
25,5
\end{tabular}} & \multirow{2}{*}{\begin{tabular}{|r|} 
Revestimento \\
18,6
\end{tabular}} & \multirow{2}{*}{$\begin{array}{r}\text { Topo } \\
15,6 \\
\end{array}$} & \multirow{2}{*}{$\begin{array}{r}\text { Base } \\
16,6\end{array}$} \\
\hline & & & & & & & & & & \\
\hline $\mathrm{PM} 02 \mathrm{~B}$ & 03/10/03 & 11:00 & $03 / 10 / 03$ & $16: 18$ & 13,5 & & 18,4 & 18,4 & 17,4 & 18,4 \\
\hline PM $02 \mathrm{~A}$ & 03/10/03 & $11: 00$ & 03/10/03 & $17: 00$ & & & & 16,4 & 15,4 & 16,4 \\
\hline $\mathrm{S} 03$ & 07/10/03 & 17:05 & $08 / 10 / 03$ & $16: 00$ & & & 31,5 & 0,0 & & \\
\hline PM 03 & 07/10/03 & $14: 00$ & 07/10/03 & $16: 30$ & 15,0 & & 15,0 & 15,0 & 15,2 & 14,2 \\
\hline PM 04 & 07/10/03 & $8: 30$ & 07/10/03 & $12: 00$ & 12,0 & & 15,0 & 15,0 & 14,0 & 15,0 \\
\hline PM 05 & 04/10/03 & $8: 30$ & 04/10/03 & $16: 00$ & 30,0 & & 30,5 & 30,5 & 29,5 & 30,5 \\
\hline PM 06 & 01/10/03 & $11: 00$ & 02/10/03 & $12: 00$ & 28,5 & & 32,0 & 32,0 & 31,0 & 32,0 \\
\hline PM 07 & $30 / 09 / 03$ & 9:00 & $01 / 10 / 03$ & 9:00 & 24,0 & 31,5 & 32,5 & 32,5 & 31,5 & 32,5 \\
\hline PM 08 & 06/10/03 & $12: 30$ & 06/10/03 & $17: 30$ & 24,0 & & 31,5 & 31,5 & 30,5 & 31,5 \\
\hline
\end{tabular}


Tabela - Dados da segunda campanha de desenvolvimento dos poços de monitoramento.

\begin{tabular}{|c|c|c|c|c|c|c|c|c|}
\hline \multirow{2}{*}{ Identificação } & \multirow{2}{*}{ Data } & \multicolumn{2}{|c|}{\begin{tabular}{|c|}
$\begin{array}{c}\text { Profundidade } \\
\text { do NA }(\mathrm{m})\end{array}$ \\
\end{tabular}} & \multicolumn{2}{|c|}{$\begin{array}{l}\text { Profundidade } \\
\text { do poço }(\mathrm{m})\end{array}$} & \multirow{2}{*}{ Serviços realizados } & \multirow{2}{*}{$\begin{array}{c}\text { Volume } \\
\text { extraído } \\
\text { (litros) }\end{array}$} & \multirow{2}{*}{ Observações } \\
\hline & & Inicial & Final & Inicial & Final & & & \\
\hline PM - 01 & $08 / 01 / 04$ & 16,00 & 16,66 & & & limpeza com bailer & 22,62 & $\begin{array}{l}\text { água lamacenta, com odor } \\
\text { desagradável }\end{array}$ \\
\hline$P M-02 B$ & $08 / 01 / 04$ & 11,80 & 17,63 & & & limpeza com bailer & 22,62 & água lamacenta \\
\hline$P M-02 A$ & $15 / 12 / 03$ & 11,76 & 11,57 & 16,44 & & $\begin{array}{l}\text { bombeamento com tubo PVC 3/4" } \\
\text { com válvula }\end{array}$ & 20,00 & água barrenta \\
\hline$P M-03$ & $08 / 01 / 04$ & 12,24 & 12,29 & & & limpeza com bailer & 22,62 & água lamacenta \\
\hline$P M-04$ & $15 / 12 / 03$ & 10,85 & 10,90 & 15,10 & & $\begin{array}{l}\text { bombeamento com tubo PVC 3/4" } \\
\text { com válvula }\end{array}$ & 40,00 & $\begin{array}{l}\text { água barrenta, com areia muito } \\
\text { fina }\end{array}$ \\
\hline$P M-05$ & $15 / 12 / 03$ & 28,77 & & 30,49 & & $\begin{array}{l}\text { tentativa de bombeamento com } \\
\text { tubo PVC } 3 / 4 \text { " com válvula }\end{array}$ & & operação mal sucedida \\
\hline$P M-05$ & 08/01/04 & 28,92 & 28,94 & & & limpeza com bailer & 10,18 & $\begin{array}{l}\text { água muito suja, com areia muito } \\
\text { fina }\end{array}$ \\
\hline$P M-06$ & $15 / 12 / 03$ & 27,20 & & & & $\begin{array}{l}\text { bombeamento com tubo PVC 3/4" } \\
\text { com válvula }\end{array}$ & 20,00 & água barrenta \\
\hline$P M-07$ & $15 / 12 / 03$ & 30,96 & & & & $\begin{array}{l}\text { tentativa de bombeamento com } \\
\text { tubo PVC } 3 / 4 \text { " com válvula }\end{array}$ & 0,63 & água barrenta \\
\hline$P M-07$ & $08 / 01 / 04$ & 31,26 & 31,20 & & & limpeza com bailer & 3,39 & água barrenta \\
\hline$P M-08$ & $15 / 12 / 03$ & 27,46 & & 31,64 & & $\begin{array}{l}\text { tentativa de bombeamento com } \\
\text { tubo PVC } 3 / 4 \text { " com válvula }\end{array}$ & 8,55 & água suja, com areia fina \\
\hline$P M-08$ & $08 / 01 / 04$ & 27,78 & 28,62 & & & limpeza com bailer & 3,39 & água pouco turva \\
\hline
\end{tabular}


APÊNDICE D - Mapa Topográfico Definindo o Domínio da Modelagem 







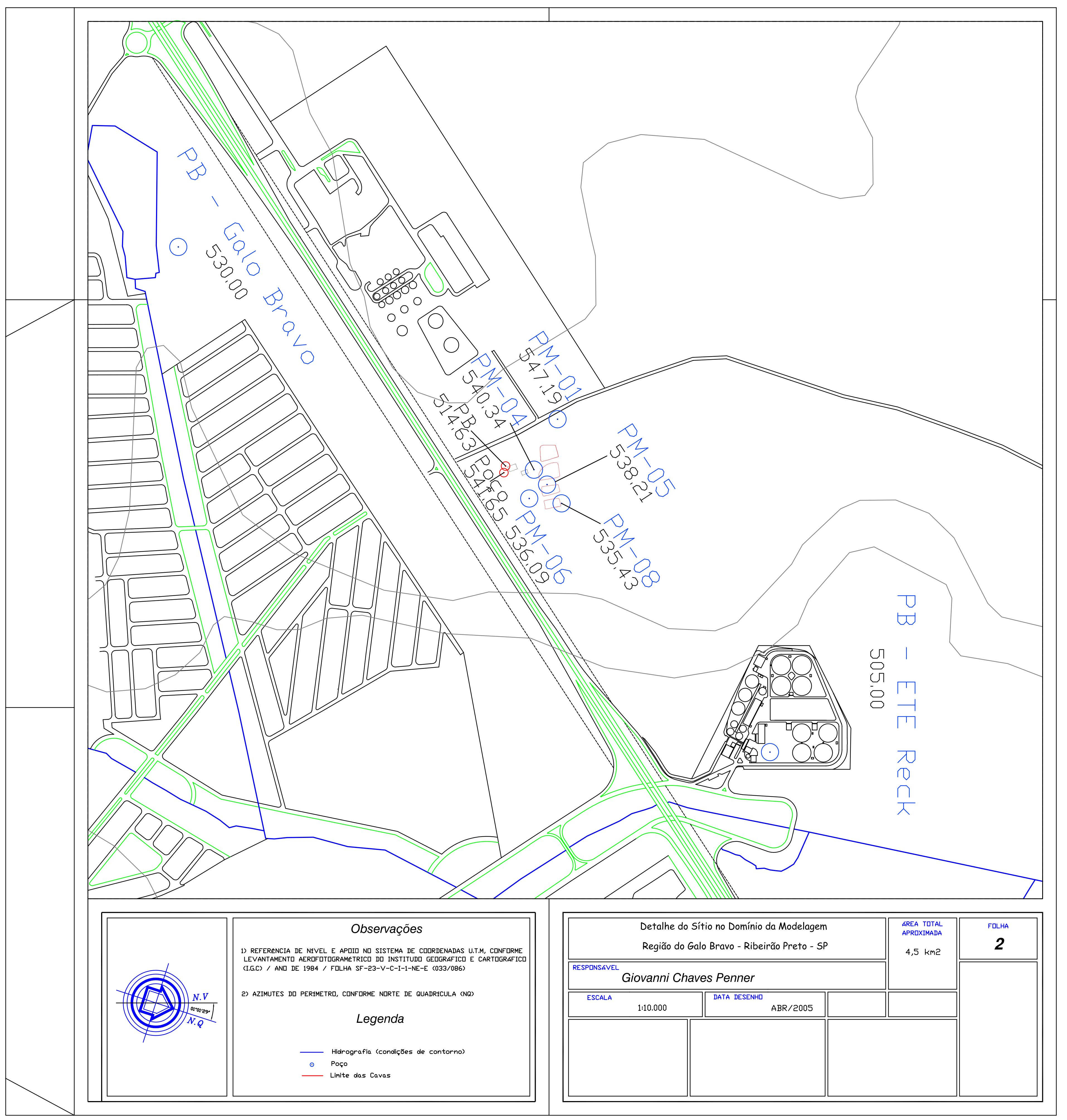


APÊNDICE E - Seção Geológica de Referência para o Modelo Numérico 


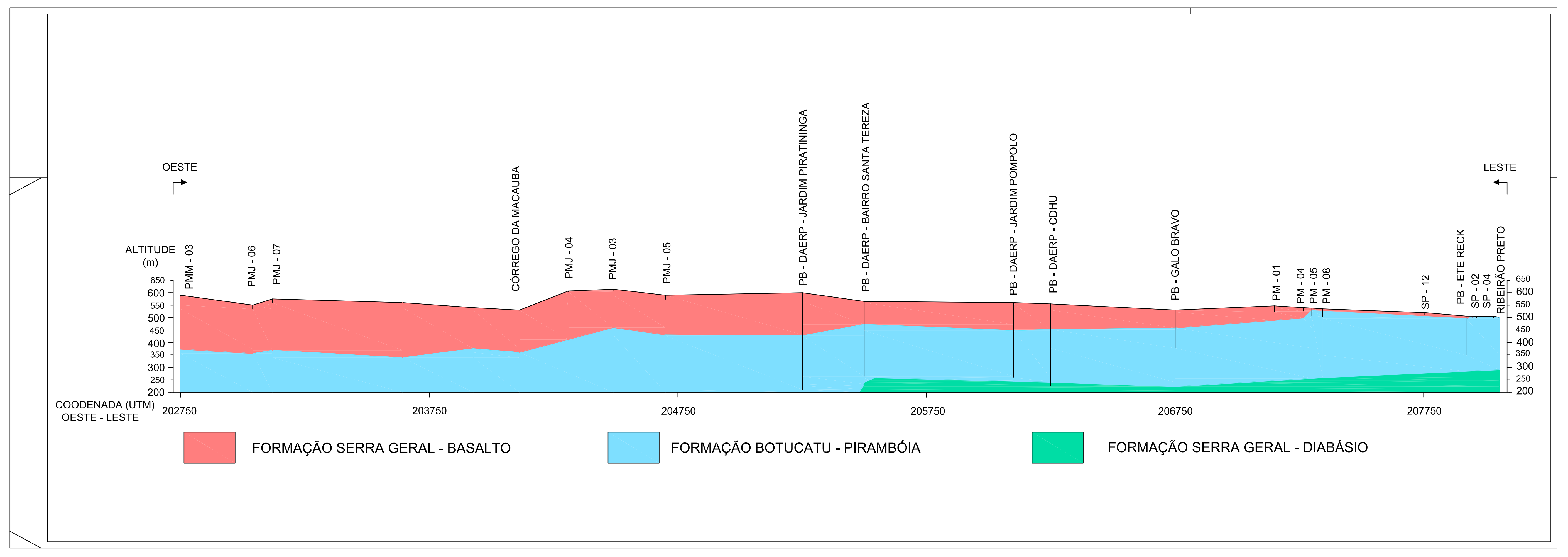


APÊNDICE F - Tabela com os Resultados da Composição Elementar das Amostras de Resíduo 


\begin{tabular}{|c|c|c|c|c|c|}
\hline \hline \multicolumn{3}{|c|}{ Cava 1 Superfície 1DUPL } & \multicolumn{3}{c|}{ Cava 1 Superfície 2DUPL } \\
\hline SUBSTÂNCIA & RESULTADO & DESVIO & SUBSTÂNCIA & RESULTADO & DESVIO \\
\hline $\mathrm{Si}$ & $23,478 \%$ & 0,138 & $\mathrm{Si}$ & $23,661 \%$ & 0,130 \\
\hline $\mathrm{S}$ & $24,251 \%$ & 0,082 & $\mathrm{~S}$ & $24,941 \%$ & 0,079 \\
\hline $\mathrm{Ca}$ & $33,519 \%$ & 0,148 & $\mathrm{Ca}$ & $35,745 \%$ & 0,147 \\
\hline $\mathrm{Fe}$ & $8,244 \%$ & 0,045 & $\mathrm{Fe}$ & $6,250 \%$ & 0,043 \\
\hline $\mathrm{K}$ & $2,335 \%$ & 0,070 & $\mathrm{~K}$ & $1,995 \%$ & 0,064 \\
\hline $\mathrm{Ti}$ & $2,330 \%$ & 0,048 & $\mathrm{Ti}$ & $2,437 \%$ & 0,056 \\
\hline $\mathrm{Pb}$ & $1,405 \%$ & 0,021 & $\mathrm{~Pb}$ & $1,395 \%$ & 0,022 \\
\hline $\mathrm{Zn}$ & $0,745 \%$ & 0,011 & $\mathrm{Zn}$ & $0,630 \%$ & 0,011 \\
\hline $\mathrm{Mn}$ & $0,096 \%$ & 0,016 & $\mathrm{Mn}$ & $0,100 \%$ & 0,017 \\
\hline $\mathrm{Al}$ & $3,279 \%$ & 0,142 & $\mathrm{Al}$ & $2,506 \%$ & 0,124 \\
\hline $\mathrm{Sr}$ & $0,121 \%$ & 0,005 & $\mathrm{Sr}$ & $0,148 \%$ & 0,005 \\
\hline $\mathrm{Cu}$ & $0,195 \%$ & 0,008 & $\mathrm{Cu}$ & $0,191 \%$ & 0,009 \\
\hline $\mathrm{P}$ & & & $\mathrm{P}$ & & \\
\hline $\mathrm{Mo}$ & & $\mathrm{Mo}$ & & \\
\hline \hline
\end{tabular}

\begin{tabular}{|c|c|c|c|c|c}
\hline \hline \multicolumn{3}{|c|}{ Cava 1 Fundo 1DUPL } & \multicolumn{3}{c}{ Cava 1 Fundo 2DUPL } \\
\hline SUBSTÂNCIA & RESULTADO & DESVIO & SUBSTÂNCIA & RESULTADO & DESVIO \\
\hline $\mathrm{Si}$ & $23,774 \%$ & 0,148 & $\mathrm{Si}$ & $24,609 \%$ & 0,143 \\
\hline $\mathrm{S}$ & $20,226 \%$ & 0,078 & $\mathrm{~S}$ & $19,800 \%$ & 0,074 \\
\hline $\mathrm{Ca}$ & $23,825 \%$ & 0,124 & $\mathrm{Ca}$ & $23,907 \%$ & 0,119 \\
\hline $\mathrm{Fe}$ & $14,019 \%$ & 0,061 & $\mathrm{Fe}$ & $13,540 \%$ & 0,061 \\
\hline $\mathrm{K}$ & $4,351 \%$ & 0,079 & $\mathrm{~K}$ & $4,297 \%$ & 0,074 \\
\hline $\mathrm{Ti}$ & $1,432 \%$ & 0,047 & $\mathrm{Ti}$ & $1,331 \%$ & 0,043 \\
\hline $\mathrm{Pb}$ & $1,029 \%$ & 0,022 & $\mathrm{~Pb}$ & $0,949 \%$ & 0,021 \\
\hline $\mathrm{Zn}$ & $0,928 \%$ & 0,013 & $\mathrm{Zn}$ & $0,917 \%$ & 0,013 \\
\hline $\mathrm{Mn}$ & $0,232 \%$ & 0,019 & $\mathrm{Mn}$ & $0,212 \%$ & 0,018 \\
\hline $\mathrm{Al}$ & $9,938 \%$ & 0,188 & $\mathrm{Al}$ & $10,193 \%$ & 0,179 \\
\hline $\mathrm{Sr}$ & $0,133 \%$ & 0,005 & $\mathrm{Sr}$ & $0,121 \%$ & 0,005 \\
\hline $\mathrm{Cu}$ & $0,113 \%$ & 0,009 & $\mathrm{Cu}$ & $0,124 \%$ & 0,009 \\
\hline $\mathrm{P}$ & & $\mathrm{P}$ & & \\
\hline $\mathrm{Mo}$ & & $\mathrm{Mo}$ & & \\
\hline \hline
\end{tabular}




\begin{tabular}{|c|c|c|c|c|c|}
\hline \hline \multicolumn{3}{|c|}{ Cava 2 Superfície 1DUPL } & \multicolumn{3}{c|}{ Cava 2 Superfície 2DUPL } \\
\hline SUBSTÂNCIA & RESULTADO & DESVIO & SUBSTÂNCIA & RESULTADO & DESVIO \\
\hline $\mathrm{Si}$ & $1,163 \%$ & 0,065 & $\mathrm{Si}$ & $1,252 \%$ & 0,068 \\
\hline $\mathrm{S}$ & $43,504 \%$ & 0,121 & $\mathrm{~S}$ & $52,304 \%$ & 0,133 \\
\hline $\mathrm{Ca}$ & $31,420 \%$ & 0,179 & $\mathrm{Ca}$ & $25,452 \%$ & 0,164 \\
\hline $\mathrm{Fe}$ & $6,539 \%$ & 0,067 & $\mathrm{Fe}$ & $6,254 \%$ & 0,062 \\
\hline $\mathrm{K}$ & & & $\mathrm{K}$ & & \\
\hline $\mathrm{Ti}$ & $1,161 \%$ & 0,092 & $\mathrm{Ti}$ & $0,972 \%$ & 0,080 \\
\hline $\mathrm{Pb}$ & $6,893 \%$ & 0,077 & $\mathrm{~Pb}$ & $4,883 \%$ & 0,063 \\
\hline $\mathrm{Zn}$ & $7,191 \%$ & 0,047 & $\mathrm{Zn}$ & $6,462 \%$ & 0,042 \\
\hline $\mathrm{Mn}$ & & & $\mathrm{Mn}$ & & \\
\hline $\mathrm{Al}$ & & & $\mathrm{Al}$ & & 0,014 \\
\hline $\mathrm{Sr}$ & $0,277 \%$ & 0,017 & $\mathrm{Sr}$ & $0,199 \%$ & 0,020 \\
\hline $\mathrm{Cu}$ & $0,558 \%$ & 0,023 & $\mathrm{Cu}$ & $0,493 \%$ & 0,063 \\
\hline $\mathrm{P}$ & $1,295 \%$ & 0,061 & $\mathrm{P}$ & $1,632 \%$ & 0,013 \\
\hline $\mathrm{Mo}$ & & & $\mathrm{Mo}$ & $0,097 \%$ & \\
\hline \hline
\end{tabular}

\begin{tabular}{|c|c|c|c|c|c|}
\hline \hline \multicolumn{3}{|c|}{ Cava 2 Fundo 1DUPL } & \multicolumn{3}{c|}{ Cava 2 Fundo 2DUPL } \\
\hline SUBSTÂNCIA & RESULTADO & DESVIO & SUBSTÂNCIA & RESULTADO & DESVIO \\
\hline $\mathrm{Si}$ & $2,760 \%$ & 0,080 & $\mathrm{Si}$ & $2,548 \%$ & 0,077 \\
\hline $\mathrm{S}$ & $45,406 \%$ & 0,124 & $\mathrm{~S}$ & $44,013 \%$ & 0,122 \\
\hline $\mathrm{Ca}$ & $29,015 \%$ & 0,170 & $\mathrm{Ca}$ & $26,983 \%$ & 0,161 \\
\hline $\mathrm{Fe}$ & $8,497 \%$ & 0,068 & $\mathrm{Fe}$ & $8,410 \%$ & 0,066 \\
\hline $\mathrm{K}$ & & & $\mathrm{K}$ & & \\
\hline $\mathrm{Ti}$ & $0,884 \%$ & 0,074 & $\mathrm{Ti}$ & $0,873 \%$ & 0,068 \\
\hline $\mathrm{Pb}$ & $3,678 \%$ & 0,056 & $\mathrm{~Pb}$ & $4,337 \%$ & 0,057 \\
\hline $\mathrm{Zn}$ & $7,707 \%$ & 0,045 & $\mathrm{Zn}$ & $8,608 \%$ & 0,046 \\
\hline $\mathrm{Mn}$ & & & $\mathrm{Mn}$ & & \\
\hline $\mathrm{Al}$ & & & $\mathrm{Al}$ & $1,706 \%$ & 0,129 \\
\hline $\mathrm{Sr}$ & $0,154 \%$ & 0,013 & $\mathrm{Sr}$ & $0,180 \%$ & 0,012 \\
\hline $\mathrm{Cu}$ & $0,405 \%$ & 0,019 & $\mathrm{Cu}$ & $0,371 \%$ & 0,018 \\
\hline $\mathrm{P}$ & $1,497 \%$ & 0,062 & $\mathrm{P}$ & $1,971 \%$ & 0,109 \\
\hline $\mathrm{Mo}$ & & & $\mathrm{Mo}$ & & \\
\hline \hline
\end{tabular}




\begin{tabular}{|c|c|c|c|c|c|}
\hline \multicolumn{3}{|c|}{ Cava 3 Superfície 1DUPL } & \multicolumn{3}{|c|}{ Cava 3 Superfície 2DUPL } \\
\hline SUBSTÂNCIA & RESULTADO & DESVIO & SUBSTÂNCIA & RESULTADO & DESVIO \\
\hline $\mathrm{Si}$ & $3,051 \%$ & 0,078 & $\mathrm{Si}$ & $1,258 \%$ & 0,062 \\
\hline $\mathrm{S}$ & $54,550 \%$ & 0,138 & $S$ & $56,816 \%$ & 0,137 \\
\hline $\mathrm{Ca}$ & $30,075 \%$ & 0,186 & $\mathrm{Ca}$ & $30,323 \%$ & 0,185 \\
\hline $\mathrm{Fe}$ & $2,507 \%$ & 0,041 & $\mathrm{Fe}$ & $3,006 \%$ & 0,043 \\
\hline $\mathrm{K}$ & & & K & & \\
\hline $\mathrm{Ti}$ & $3,374 \%$ & 0,092 & $\mathrm{Ti}$ & $1,794 \%$ & 0,076 \\
\hline $\mathrm{Pb}$ & $2,102 \%$ & 0,040 & $\mathrm{~Pb}$ & $1,712 \%$ & 0,039 \\
\hline $\mathrm{Zn}$ & $2,313 \%$ & 0,024 & $\mathrm{Zn}$ & $2,982 \%$ & 0,027 \\
\hline $\mathrm{Mn}$ & & & $\mathrm{Mn}$ & & \\
\hline $\mathrm{Al}$ & & & $\mathrm{Al}$ & & \\
\hline $\mathrm{Sr}$ & $0,141 \%$ & 0,010 & $\mathrm{Sr}$ & $0,146 \%$ & 0,010 \\
\hline $\mathrm{Cu}$ & $0,276 \%$ & 0,016 & $\mathrm{Cu}$ & $0,363 \%$ & 0,016 \\
\hline $\mathrm{P}$ & $1,540 \%$ & 0,063 & $\mathrm{P}$ & $1,540 \%$ & 0,061 \\
\hline Mo & $0,071 \%$ & 0,008 & Mo & $0,060 \%$ & 0,009 \\
\hline \multicolumn{3}{|c|}{ Cava 3 Fundo 1DUPL } & \multicolumn{3}{|c|}{ Cava 3 Fundo 2DUPL } \\
\hline SUBSTÂNCIA & RESULTADO & DESVIO & SUBSTÂNCIA & RESULTADO & DESVIO \\
\hline $\mathrm{Si}$ & & & $\mathrm{Si}$ & & \\
\hline $\mathrm{S}$ & $53,944 \%$ & 0,139 & $\mathrm{~S}$ & $48,829 \%$ & 0,129 \\
\hline $\mathrm{Ca}$ & $26,435 \%$ & 0,173 & $\mathrm{Ca}$ & $28,641 \%$ & 0,171 \\
\hline $\mathrm{Fe}$ & $5,965 \%$ & 0,054 & $\mathrm{Fe}$ & $7,030 \%$ & 0,059 \\
\hline $\mathrm{K}$ & & & $\mathrm{K}$ & & \\
\hline $\mathrm{Ti}$ & $0,633 \%$ & 0,063 & $\mathrm{Ti}$ & $0,645 \%$ & 0,061 \\
\hline $\mathrm{Pb}$ & $1,663 \%$ & 0,042 & $\mathrm{~Pb}$ & $1,919 \%$ & 0,045 \\
\hline $\mathrm{Zn}$ & $8,904 \%$ & 0,044 & $\mathrm{Zn}$ & $10,547 \%$ & 0,049 \\
\hline $\mathrm{Mn}$ & & & $\mathrm{Mn}$ & & \\
\hline $\mathrm{Al}$ & & & $\mathrm{Al}$ & & \\
\hline $\mathrm{Sr}$ & $0,136 \%$ & 0,011 & $\mathrm{Sr}$ & $0,153 \%$ & 0,012 \\
\hline $\mathrm{Cu}$ & $0,471 \%$ & 0,018 & $\mathrm{Cu}$ & $0,566 \%$ & 0,019 \\
\hline $\mathrm{P}$ & $1,850 \%$ & 0,064 & $\mathrm{P}$ & $1,670 \%$ & 0,062 \\
\hline Mo & & & Mo & & \\
\hline
\end{tabular}




\begin{tabular}{|c|c|c|c|c|c}
\hline \hline \multicolumn{3}{|c|}{ Cava 4 Superfície 1DUPL } & \multicolumn{3}{c}{ Cava 4 Superfície 2DUPL } \\
\hline SUBSTÂNCIA & RESULTADO & DESVIO & SUBSTÂNCIA & RESULTADO & DESVIO \\
\hline $\mathrm{Si}$ & $12,221 \%$ & 0,114 & $\mathrm{Si}$ & $10,681 \%$ & 0,108 \\
\hline $\mathrm{S}$ & $35,990 \%$ & 0,105 & $\mathrm{~S}$ & $39,134 \%$ & 0,106 \\
\hline $\mathrm{Ca}$ & $33,615 \%$ & 0,164 & $\mathrm{Ca}$ & $33,251 \%$ & 0,162 \\
\hline $\mathrm{Fe}$ & $5,834 \%$ & 0,048 & $\mathrm{Fe}$ & $5,389 \%$ & 0,047 \\
\hline $\mathrm{K}$ & & & $\mathrm{K}$ & & \\
\hline $\mathrm{Ti}$ & $5,574 \%$ & 0,088 & $\mathrm{Ti}$ & $4,748 \%$ & 0,085 \\
\hline $\mathrm{Pb}$ & $1,242 \%$ & 0,027 & $\mathrm{~Pb}$ & $1,288 \%$ & 0,028 \\
\hline $\mathrm{Zn}$ & $2,120 \%$ & 0,020 & $\mathrm{Zn}$ & $2,250 \%$ & 0,021 \\
\hline $\mathrm{Mn}$ & & & $\mathrm{Mn}$ & & \\
\hline $\mathrm{Al}$ & $1,363 \%$ & 0,117 & $\mathrm{Al}$ & $1,227 \%$ & 0,122 \\
\hline $\mathrm{Sr}$ & $0,112 \%$ & 0,007 & $\mathrm{Sr}$ & $0,116 \%$ & 0,007 \\
\hline $\mathrm{Cu}$ & $0,418 \%$ & 0,013 & $\mathrm{Cu}$ & $0,461 \%$ & 0,014 \\
\hline $\mathrm{P}$ & $1,449 \%$ & 0,061 & $\mathrm{P}$ & $1,378 \%$ & 0,060 \\
\hline $\mathrm{Mo}$ & $0,061 \%$ & 0,006 & $\mathrm{Mo}$ & $0,078 \%$ & 0,005 \\
\hline \hline
\end{tabular}




\section{APÊNDICE G:}

- Tabela com os resultados gerais resumidos para as amostras de solo;

- Tabela com os resultados de HPAs em amostras de solo;

- Tabela com os resultados da caracterização dos óxidos das amostras de solo. 


\begin{tabular}{|c|c|c|c|c|c|c|c|c|c|c|c|c|c|c|c|c|c|c|c|}
\hline \multirow[b]{2}{*}{ Amostra } & \multicolumn{6}{|c|}{ Granulometria } & \multirow{2}{*}{$\begin{array}{l}\text { M.E.S. } \\
\left(\mathrm{g} / \mathrm{cm}^{3}\right)\end{array}$} & \multirow{2}{*}{$\begin{array}{l}\text { C.T.C. do Solo } \\
\text { (Cmol/kg) }\end{array}$} & \multirow{2}{*}{\begin{tabular}{|c}
$\begin{array}{c}\text { C.T.C. da Argila } \\
\text { (Cmol/kg) }\end{array}$ \\
\end{tabular}} & \multirow{2}{*}{\begin{tabular}{|c|} 
S.E. do Solo \\
$\left(\mathrm{m}^{2} / \mathrm{g}\right)$
\end{tabular}} & \multirow{2}{*}{\begin{tabular}{|c} 
S.E. da Argila \\
$\left(\mathrm{m}^{2} / \mathrm{g}\right)$
\end{tabular}} & \multirow{2}{*}{$\begin{array}{c}\text { Vb } \\
\text { (g/100 g de Solo) } \\
\end{array}$} & \multirow{2}{*}{$\begin{array}{c}\text { Acb } \\
\text { (g/100 g de Argila) }\end{array}$} & \multirow{2}{*}{$\underset{(\mathrm{KCl})}{\mathrm{pH}}$} & \multirow{2}{*}{$\underset{\text { (Água) }}{\mathrm{pH}}$} & \multirow[b]{2}{*}{$\Delta \mathbf{p H}$} & \multirow{2}{*}{$\begin{array}{c}\text { Eh } \\
(\mathrm{mV})\end{array}$} & \multirow{2}{*}{\begin{tabular}{|c|} 
Condutividade \\
Elétrica $(\mathrm{mS} / \mathrm{cm})$
\end{tabular}} & \multirow{2}{*}{$\begin{array}{c}\text { (\%) Carbono } \\
\text { Orgânico Total }\end{array}$} \\
\hline & \begin{tabular}{|c|}
$\%$ de \\
Argila
\end{tabular} & $\begin{array}{l}\text { \% de } \\
\text { Silte }\end{array}$ & Fina & $\begin{array}{l}\text { \% de Ar } \\
\text { Média }\end{array}$ & reia & $\begin{array}{c}\% \text { de } \\
\text { Pedregulho }\end{array}$ & & & & & & & & & & & & & \\
\hline $\begin{array}{l}\text { SD-1-03m-Com } \\
\text { SD-1-03m-Sem }\end{array}$ & $\begin{array}{c}50 \\
0\end{array}$ & $\begin{array}{l}26 \\
37\end{array}$ & $\begin{array}{l}16 \\
32 \\
\end{array}$ & $\begin{array}{c}7 \\
24\end{array}$ & $\begin{array}{l}1 \\
5\end{array}$ & $\begin{array}{l}0 \\
2\end{array}$ & 3,12 & 2,90 & 5,80 & 22,65 & 45,29 & 0,94 & 1,88 & 5,00 & 5,41 & $-0,41$ & 553 & 265,0 & 0,35 \\
\hline $\begin{array}{l}\text { SD-1-05,70m-Com } \\
\text { SD-1-05,70m-Sem }\end{array}$ & $\begin{array}{c}40 \\
0\end{array}$ & $\begin{array}{l}25 \\
35 \\
\end{array}$ & \begin{tabular}{|l|}
21 \\
35 \\
\end{tabular} & \begin{tabular}{c|}
9 \\
24 \\
\end{tabular} & $\begin{array}{l}2 \\
3 \\
\end{array}$ & $\begin{array}{l}3 \\
3 \\
\end{array}$ & 3,03 & 3,10 & 7,75 & 24,22 & 60,54 & 1,01 & 2,52 & 6,19 & 6,37 & $-0,18$ & 557 & 393,0 & 0,29 \\
\hline $\begin{array}{l}\text { SD-1-09m-Com } \\
\text { SD-1-09m-Sem }\end{array}$ & $\begin{array}{c}35 \\
0\end{array}$ & $\begin{array}{l}34 \\
49\end{array}$ & 22 & $\begin{array}{c}8 \\
14\end{array}$ & $\begin{array}{l}0 \\
2\end{array}$ & $\frac{5}{2}$ & 3,07 & 6,41 & 18,32 & 50,07 & 143,04 & 2,11 & 6,03 & 4,51 & 5,75 & $-1,24$ & 525 & 13,4 & 0,11 \\
\hline $\begin{array}{l}\text { SD-1-10,50m-Com } \\
\text { SD-1-10,50m-Sem }\end{array}$ & $\begin{array}{c}31 \\
0\end{array}$ & $\begin{array}{l}34 \\
50\end{array}$ & $\begin{array}{l}26 \\
29 \\
\end{array}$ & $\begin{array}{c}8 \\
16 \\
\end{array}$ & $\begin{array}{l}0 \\
2\end{array}$ & $\begin{array}{l}1 \\
3 \\
\end{array}$ & 2,96 & 9,23 & 29,78 & 72,10 & 232,57 & 3,08 & 9,93 & 4,07 & 6,04 & $-1,97$ & 519 & 10,6 & 0,09 \\
\hline $\begin{array}{l}\text { SD-1-13m-Com } \\
\text { SD-1-13m-Sem }\end{array}$ & $\frac{26}{0}$ & $\begin{array}{l}36 \\
53\end{array}$ & $\begin{array}{l}26 \\
31\end{array}$ & $\begin{array}{l}10 \\
13\end{array}$ & $\frac{1}{2}$ & $\begin{array}{l}1 \\
1\end{array}$ & 3,04 & 9,99 & 38,40 & 77,97 & 299,88 & 3,37 & 12,97 & 3,88 & 5,37 & $-1,49$ & 510 & 15,7 & 0,05 \\
\hline $\begin{array}{l}\text { SD-1-15,00m-Com } \\
\text { SD-1-15,00m-Sem }\end{array}$ & $\begin{array}{c}18 \\
0\end{array}$ & $\begin{array}{l}38 \\
56\end{array}$ & $\begin{array}{l}28 \\
28\end{array}$ & $\begin{array}{l}13 \\
15\end{array}$ & $\begin{array}{l}2 \\
1\end{array}$ & $\begin{array}{l}1 \\
0\end{array}$ & 2,94 & 9,94 & 55,24 & 77,65 & 431,37 & 3,35 & 18,64 & 3,98 & 6,24 & $-2,26$ & 526 & 15,4 & 0,05 \\
\hline $\begin{array}{l}\text { SD-1-16,20m-Com } \\
\text { SD-1-16,20m-Sem }\end{array}$ & $\frac{22}{0}$ & $\begin{array}{l}40 \\
55\end{array}$ & $\begin{array}{l}27 \\
31\end{array}$ & $\begin{array}{c}9 \\
11\end{array}$ & $\frac{1}{2}$ & $\frac{1}{1}$ & 2,91 & 18,29 & 83,13 & 142,81 & 649,14 & 6,27 & 28,49 & 4,68 & 6,59 & $-1,91$ & 512 & 39,0 & 0,07 \\
\hline $\begin{array}{l}\text { SD-2-03,30m-Com } \\
\text { SD-2-03,30m-Sem }\end{array}$ & $\begin{array}{c}41 \\
0\end{array}$ & $\begin{array}{l}28 \\
43\end{array}$ & $\begin{array}{l}17 \\
29 \\
\end{array}$ & \begin{tabular}{|c|}
9 \\
16 \\
\end{tabular} & $\begin{array}{l}0 \\
4\end{array}$ & $\begin{array}{l}5 \\
8 \\
\end{array}$ & 3,13 & 2,71 & 6,61 & 21,17 & 51,64 & 0,88 & 2,14 & 6,21 & 6,17 & 0,04 & 503 & 24,6 & 0,25 \\
\hline $\begin{array}{l}\text { SD-2-05,30m-Com } \\
\text { SD-2-05,30m-Sem }\end{array}$ & $\begin{array}{c}35 \\
0\end{array}$ & $\begin{array}{l}24 \\
37\end{array}$ & $\begin{array}{l}17 \\
31\end{array}$ & $\begin{array}{c}8 \\
15 \\
\end{array}$ & $\begin{array}{l}4 \\
3\end{array}$ & $\begin{array}{l}12 \\
14\end{array}$ & 3,08 & 5,44 & 15,54 & 42,46 & 121,33 & 1,77 & 5,06 & 5,88 & 6,54 & $-0,66$ & 517 & 9,8 & 0,26 \\
\hline $\begin{array}{l}\text { SD-2-06,40m-Com } \\
\text { SD-2-06,40m-Sem }\end{array}$ & $\begin{array}{c}39 \\
0\end{array}$ & $\begin{array}{l}37 \\
56\end{array}$ & \begin{tabular}{|l|}
18 \\
29
\end{tabular} & $\begin{array}{c}6 \\
13\end{array}$ & $\begin{array}{l}0 \\
1\end{array}$ & $\frac{0}{1}$ & 2,97 & 9,28 & 23,81 & 72,49 & 185,88 & 3,06 & 7,85 & 4,20 & 6,13 & $-1,93$ & 550 & 17,9 & 0,12 \\
\hline $\begin{array}{l}\text { SD-2-09,50m-Com } \\
\text { SD-2-09,50m-Sem }\end{array}$ & $\begin{array}{c}33 \\
0 \\
\end{array}$ & $\begin{array}{l}40 \\
68\end{array}$ & $\begin{array}{l}21 \\
23 \\
\end{array}$ & $\begin{array}{l}6 \\
9\end{array}$ & $\begin{array}{l}0 \\
0\end{array}$ & $\begin{array}{l}0 \\
0\end{array}$ & 2,95 & 11,96 & 36,25 & 93,40 & 283,04 & 3,99 & 12,09 & 3,97 & 5,43 & $-1,46$ & 542 & 14,4 & 0,08 \\
\hline $\begin{array}{l}\text { SD-2-11,50m-Com } \\
\text { SD-2-11,50m-Sem }\end{array}$ & $\begin{array}{c}24 \\
0\end{array}$ & $\begin{array}{l}41 \\
65\end{array}$ & $\begin{array}{l}25 \\
26\end{array}$ & $\begin{array}{l}8 \\
9\end{array}$ & $\begin{array}{l}1 \\
0\end{array}$ & $\begin{array}{l}1 \\
0\end{array}$ & 2,93 & 13,66 & 56,93 & 106,69 & 444,55 & 4,61 & 19,20 & 3,93 & 5,93 & $-2,00$ & 515 & 18,7 & 0,05 \\
\hline $\begin{array}{l}\text { SD-2-15,00m-Com } \\
\text { SD-2-15,00m-Sem }\end{array}$ & $\frac{25}{0}$ & $\begin{array}{l}48 \\
60\end{array}$ & $\begin{array}{l}21 \\
32 \\
\end{array}$ & $\frac{5}{7}$ & $\frac{1}{1}$ & $\frac{0}{0}$ & 2,91 & 33,75 & 134,98 & 263,50 & 1054,00 & 11,70 & 46,80 & 4,34 & 6,42 & $-2,08$ & 513 & 25,5 & 0,04 \\
\hline $\begin{array}{l}\text { SD-3-03m-Com } \\
\text { SD-3-03m-Sem }\end{array}$ & $\begin{array}{c}45 \\
0\end{array}$ & $\begin{array}{l}30 \\
72\end{array}$ & $\begin{array}{l}17 \\
17\end{array}$ & $\begin{array}{c}7 \\
11 \\
\end{array}$ & $\begin{array}{l}1 \\
0\end{array}$ & $\begin{array}{l}0 \\
0\end{array}$ & 3,19 & 2,42 & 5,38 & 18,92 & 42,04 & 0,78 & 1,74 & 6,03 & 5,79 & 0,24 & 545 & 27,3 & 0,36 \\
\hline $\begin{array}{l}\text { SD-3-07m-Com } \\
\text { SD-3-07m-Sem }\end{array}$ & $\begin{array}{c}41 \\
0\end{array}$ & $\begin{array}{l}39 \\
81\end{array}$ & $\begin{array}{l}13 \\
13\end{array}$ & $\begin{array}{l}5 \\
5\end{array}$ & $\begin{array}{l}1 \\
1\end{array}$ & $\frac{1}{0}$ & 3,11 & 5,86 & 14,29 & 45,75 & 111,58 & 1,91 & 4,67 & 4,21 & 5,82 & $-1,61$ & 516 & 19,1 & 0,12 \\
\hline $\begin{array}{l}\text { SD-3-08,40m-Com } \\
\text { SD-3-08,40m-Sem }\end{array}$ & $\begin{array}{c}40 \\
0\end{array}$ & $\begin{array}{l}46 \\
87\end{array}$ & $\begin{array}{l}\frac{11}{10} \\
10\end{array}$ & $\begin{array}{l}2 \\
3\end{array}$ & $\begin{array}{l}1 \\
0\end{array}$ & $\begin{array}{l}0 \\
0\end{array}$ & 3,11 & 9,55 & 23,87 & 74,55 & 186,36 & 3,14 & 7,84 & 4,03 & 5,56 & $-1,53$ & 538 & 24,7 & 0,07 \\
\hline $\begin{array}{l}\text { SD-3-10,00m-Com } \\
\text { SD-3-10,00m-Sem }\end{array}$ & $\frac{39}{0}$ & $\begin{array}{l}45 \\
83\end{array}$ & $\begin{array}{l}11 \\
12\end{array}$ & $\begin{array}{l}5 \\
5\end{array}$ & $\begin{array}{l}0 \\
0\end{array}$ & $\begin{array}{l}0 \\
0\end{array}$ & 3,01 & 18,46 & 47,34 & 144,16 & 369,64 & 6,15 & 15,78 & 3,82 & 5,65 & $-1,83$ & 536 & 24,2 & 0,07 \\
\hline $\begin{array}{l}\text { SD-3-12,10m-Com } \\
\text { SD-3-12,10m-Sem }\end{array}$ & $\begin{array}{l}6 \\
0 \\
\end{array}$ & $\begin{array}{l}2 \\
3 \\
\end{array}$ & $\begin{array}{l}55 \\
57 \\
\end{array}$ & $\begin{array}{l}37 \\
40 \\
\end{array}$ & $\begin{array}{l}0 \\
0 \\
\end{array}$ & $\begin{array}{l}0 \\
0\end{array}$ & 2,68 & 1,66 & 27,63 & 12,95 & 215,76 & 0,53 & 8,84 & 4,25 & 5,75 & $-1,50$ & 558 & 23,8 & 0,06 \\
\hline $\begin{array}{l}\text { SD-4-03,50m-Com } \\
\text { SD-4-03,50m-Sem }\end{array}$ & $\begin{array}{c}47 \\
0\end{array}$ & $\begin{array}{l}27 \\
38\end{array}$ & $\begin{array}{l}18 \\
33\end{array}$ & \begin{tabular}{|c|}
8 \\
23
\end{tabular} & $\frac{0}{3}$ & $\begin{array}{l}0 \\
3\end{array}$ & 3,14 & 3,43 & 7,30 & 26,79 & 56,99 & 1,11 & 2,36 & 5,75 & 6,00 & $-0,25$ & 560 & 21,8 & 0,26 \\
\hline $\begin{array}{l}\text { SD-4-05,50m-Com } \\
\text { SD-4-05,50m-Sem }\end{array}$ & $\begin{array}{c}44 \\
0\end{array}$ & $\begin{array}{l}27 \\
73\end{array}$ & $\begin{array}{l}18 \\
15\end{array}$ & $\begin{array}{l}7 \\
8\end{array}$ & $\begin{array}{l}0 \\
1\end{array}$ & $\begin{array}{l}4 \\
3\end{array}$ & 3,03 & 5,09 & 11,56 & 39,71 & 90,25 & 1,65 & 3,76 & 4,43 & 5,68 & $-1,25$ & 547 & 17,6 & 0,15 \\
\hline $\begin{array}{l}\text { SD-4-07,00m-Com } \\
\text { SD-4-07,00m-Sem }\end{array}$ & $\begin{array}{c}37 \\
0\end{array}$ & $\begin{array}{l}46 \\
84\end{array}$ & $\begin{array}{l}13 \\
12\end{array}$ & $\begin{array}{l}4 \\
4\end{array}$ & $\begin{array}{l}0 \\
0\end{array}$ & $\begin{array}{l}0 \\
0\end{array}$ & 3,00 & 11,16 & 30,16 & 87,15 & 235,53 & 3,68 & 9,95 & 3,93 & 5,54 & $-1,61$ & 543 & 30,9 & 0,05 \\
\hline $\begin{array}{l}\text { SD-4-09,00m-Com } \\
\text { SD-4-09,00m-Sem }\end{array}$ & $\frac{40}{0}$ & $\begin{array}{l}30 \\
66\end{array}$ & $\begin{array}{l}16 \\
19\end{array}$ & $\frac{14}{14}$ & $\begin{array}{l}0 \\
1\end{array}$ & $\begin{array}{l}0 \\
0\end{array}$ & 3,01 & 15,01 & 37,52 & 117,19 & 292,97 & 5,00 & 12,51 & 3,79 & 5,51 & $-1,72$ & 573 & 29,0 & 0,02 \\
\hline $\begin{array}{l}\text { SD-4-09,50m-Com } \\
\text { SD-4-09,50m-Sem }\end{array}$ & $\frac{6}{0}$ & $\frac{2}{1}$ & $\begin{array}{l}55 \\
65\end{array}$ & $\begin{array}{l}37 \\
34\end{array}$ & $\begin{array}{l}0 \\
0\end{array}$ & 0 & 2,64 & 1,09 & 18,18 & 8,52 & 141,92 & 0,35 & 5,82 & 4,21 & 5,58 & $-1,37$ & 569 & 15,4 & 0,02 \\
\hline $\begin{array}{l}\text { SD-4-10,00m-Com } \\
\text { SD-4-10,00m-Sem }\end{array}$ & $\begin{array}{l}3 \\
0\end{array}$ & $\begin{array}{l}0 \\
0\end{array}$ & $\begin{array}{l}55 \\
44 \\
\end{array}$ & $\begin{array}{l}42 \\
56\end{array}$ & $\begin{array}{l}0 \\
0\end{array}$ & $\begin{array}{l}0 \\
0\end{array}$ & 2,65 & 0,43 & 14,44 & 3,38 & 112,72 & 0,14 & 4,61 & 4,41 & 5,94 & $-1,53$ & 572 & 22,7 & 0,00 \\
\hline $\begin{array}{l}\text { SD-4-11,00m-Com } \\
\text { SD-4-11,00m-Sem }\end{array}$ & $\begin{array}{l}6 \\
0\end{array}$ & $\begin{array}{l}1 \\
1\end{array}$ & $\begin{array}{l}39 \\
59\end{array}$ & $\begin{array}{l}54 \\
40\end{array}$ & $\begin{array}{l}0 \\
0\end{array}$ & $\begin{array}{l}0 \\
0\end{array}$ & 2,66 & 1,33 & 22,23 & 10,41 & 173,58 & 0,43 & 7,11 & 4,41 & 5,70 & $-1,29$ & 546 & 20,5 & 0,03 \\
\hline $\begin{array}{l}\text { SD-5-03,50m-Com } \\
\text { SD-5-03,50m-Sem }\end{array}$ & $\frac{45}{0}$ & $\begin{array}{l}22 \\
77\end{array}$ & $\begin{array}{l}23 \\
13\end{array}$ & $\begin{array}{l}10 \\
10\end{array}$ & $\begin{array}{l}0 \\
0\end{array}$ & $\begin{array}{l}0 \\
0\end{array}$ & 3,07 & 10,61 & 23,57 & 82,81 & 184,02 & 3,43 & 7,61 & 4,28 & 4,45 & $-0,17$ & 616 & 865,0 & 0,25 \\
\hline $\begin{array}{l}\text { SD-5-07,30m-Com } \\
\text { SD-5-07,30m-Sem }\end{array}$ & $\begin{array}{c}39 \\
0\end{array}$ & $\begin{array}{l}37 \\
74\end{array}$ & $\begin{array}{l}17 \\
17\end{array}$ & $\begin{array}{l}7 \\
99\end{array}$ & $\begin{array}{l}0 \\
0\end{array}$ & $\begin{array}{l}0 \\
0\end{array}$ & 2,95 & 2,79 & 7,15 & 21,77 & 55,83 & 0,91 & 2,34 & 4,00 & 5,30 & $-1,30$ & 572 & 69,2 & 0,08 \\
\hline $\begin{array}{l}\text { SD-5-09,30m-Com } \\
\text { SD-5-09,30m-Sem }\end{array}$ & $\frac{9}{0}$ & $\begin{array}{l}4 \\
5\end{array}$ & $\begin{array}{l}46 \\
65\end{array}$ & $\begin{array}{l}41 \\
30\end{array}$ & $\begin{array}{l}0 \\
0\end{array}$ & $\begin{array}{l}0 \\
0\end{array}$ & 2,67 & 2,89 & 32,09 & 22,55 & 250,54 & 0,92 & 10,27 & 4,25 & 5,37 & $-1,12$ & 563 & 23,5 & 0,02 \\
\hline SD-5-10,70m-Com & 3 & 2 & 44 & 51 & 0 & 0 & 2,68 & 0,63 & 20,96 & 4,91 & 163,64 & 0,20 & 6,70 & 4,41 & 5,87 & $-1,46$ & 556 & 25,3 & 0,02 \\
\hline SD-5-10,70m-Sem & 0 & 0 & 50 & 50 & 0 & 0 & & & & & & & & & & & & & \\
\hline
\end{tabular}


Tabela - Resultados de HPAs em amostras de solo (concentrações em ppb ou ng/g).

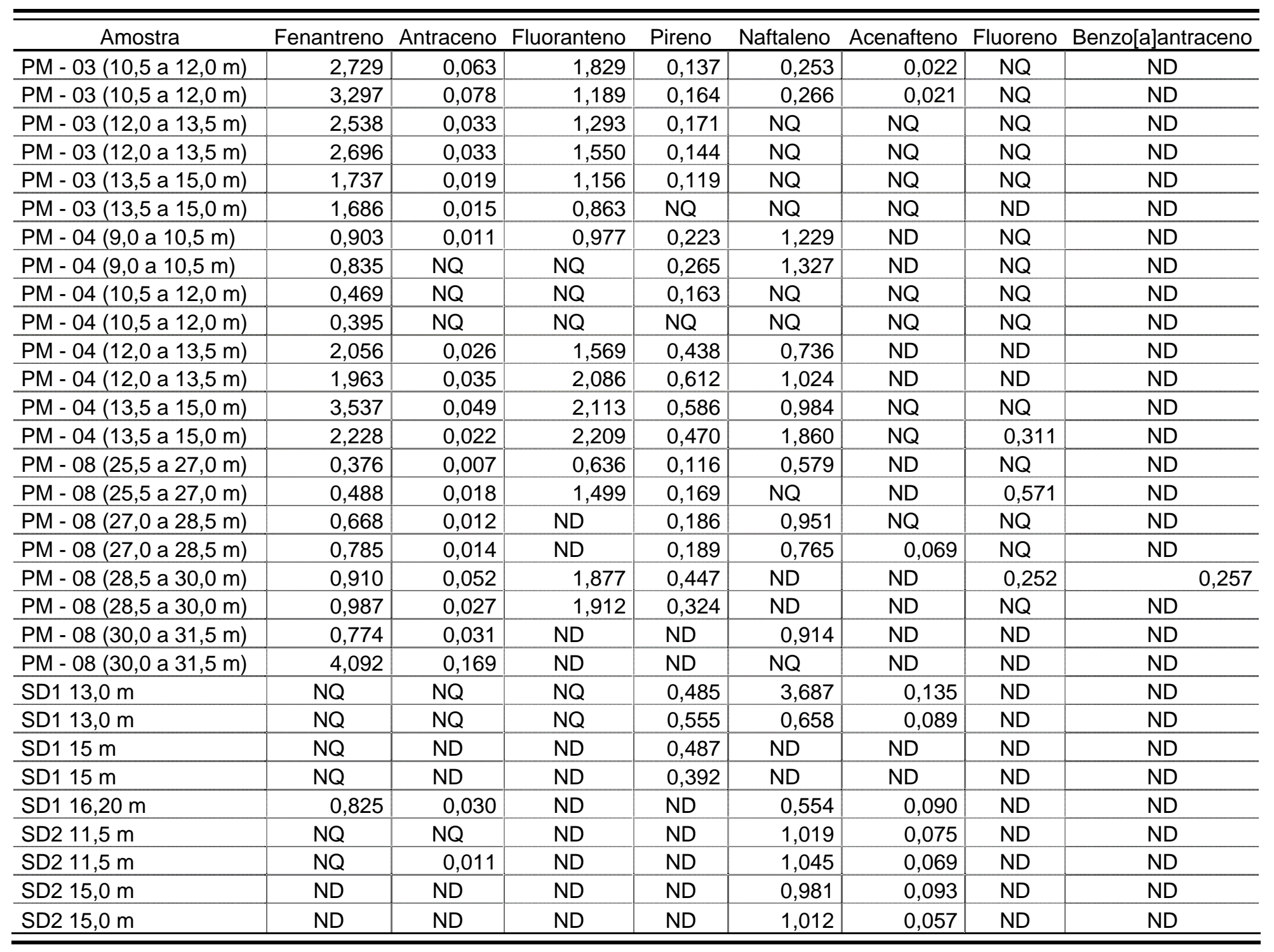


Tabela - Resultados da caracterização dos óxidos das amostras de solo

\begin{tabular}{|c|c|c|c|c|c|c|c|c|c|c|c|c|c|c|c|c|}
\hline \multicolumn{2}{|c|}{ Local e Profundidade } & $\mathrm{Al} 2 \mathrm{O} 3$ & $\overline{\mathrm{SiO} 2}$ & TiO2 & $\mathrm{Fe} 2 \mathrm{O} 3$ & $\mathrm{ZrO2}$ & $\mathrm{MgO}$ & $\mathrm{K} 2 \mathrm{O}$ & $\mathrm{ZnO}$ & $\mathrm{SO} 3$ & $\mathrm{CaO}$ & $\mathrm{V} 2 \mathrm{O5}$ & $\mathrm{MnO}$ & $\mathrm{CuO}$ & $\mathrm{Y} 2 \mathrm{O} 3$ & $\mathrm{P} 2 \mathrm{O5}$ \\
\hline \multicolumn{17}{|l|}{ PM - 03} \\
\hline & $1,5-3,0$ & $40,790 \%$ & $18,601 \%$ & $6,259 \%$ & $32,701 \%$ & $0,110 \%$ & $0,006 \%$ & $0,054 \%$ & $0,023 \%$ & $0,074 \%$ & $0,068 \%$ & $0,951 \%$ & $0,218 \%$ & $0,037 \%$ & $0,011 \%$ & $0,096 \%$ \\
\hline & $3,0-4,5$ & $41,993 \%$ & $18,212 \%$ & $5,919 \%$ & $32,366 \%$ & $0,108 \%$ & $0,000 \%$ & $0,038 \%$ & $0,023 \%$ & $0,081 \%$ & 0,039\% & $0,907 \%$ & 0,199\% & $0,036 \%$ & $0,009 \%$ & $0,071 \%$ \\
\hline & $4,5-6,0$ & $41,813 \%$ & $18,203 \%$ & $5,395 \%$ & $33,132 \%$ & $0,119 \%$ & $0,027 \%$ & $0,069 \%$ & $0,028 \%$ & 0,047\% & $0,047 \%$ & $0,803 \%$ & $0,195 \%$ & $0,049 \%$ & $0,011 \%$ & $0,063 \%$ \\
\hline & $6,0-7,5$ & $38,317 \%$ & $26,038 \%$ & $4,862 \%$ & $29,492 \%$ & $0,094 \%$ & $0,000 \%$ & $0,033 \%$ & $0,021 \%$ & $0,031 \%$ & 0,019\% & $0,734 \%$ & $0,232 \%$ & $0,043 \%$ & $0,014 \%$ & $0,069 \%$ \\
\hline & $7,5-9,0$ & $36,835 \%$ & $31,566 \%$ & $3,595 \%$ & $26,801 \%$ & $0,090 \%$ & $0,032 \%$ & $0,040 \%$ & $0,019 \%$ & $0,029 \%$ & $0,034 \%$ & $0,579 \%$ & $264 \%$ & $0,048 \%$ & $016 \%$ & $0,054 \%$ \\
\hline & $9,0-10,5$ & $36,555 \%$ & $33,090 \%$ & $3,657 \%$ & $25,380 \%$ & $0,082 \%$ & $0,094 \%$ & $0,036 \%$ & $0,025 \%$ & $0,040 \%$ & $0,034 \%$ & $0,560 \%$ & $0,291 \%$ & $0,045 \%$ & $0,016 \%$ & $0,095 \%$ \\
\hline & $10,5-12,0$ & $34,350 \%$ & $35,286 \%$ & $3,701 \%$ & $25,264 \%$ & $0,083 \%$ & $0,100 \%$ & $0,048 \%$ & $0,029 \%$ & $0,027 \%$ & $0,048 \%$ & $0,589 \%$ & $0,366 \%$ & $0,041 \%$ & $0,019 \%$ & $0,051 \%$ \\
\hline & $12,0-13,5$ & $33,188 \%$ & $36,667 \%$ & $4,027 \%$ & $24,536 \%$ & $0,077 \%$ & $0,113 \%$ & $0,087 \%$ & $0,025 \%$ & $0,035 \%$ & $0,152 \%$ & $0,637 \%$ & $0,306 \%$ & $0,040 \%$ & $0,020 \%$ & $0,094 \%$ \\
\hline & $13,5-15,0$ & $33,219 \%$ & $36,575 \%$ & $\mid 4,059 \%$ & $24,636 \%$ & $0,077 \%$ & $0,063 \%$ & $0,051 \%$ & $0,029 \%$ & $\mid 0,047 \%$ & $\mid 0,281 \%$ & $0,626 \%$ & $0,260 \%$ & $\mid 0,036 \%$ & $0,020 \%$ & $0,021 \%$ \\
\hline \multicolumn{17}{|l|}{ PM - 04} \\
\hline & $0,0-1,5$ & $41,191 \%$ & $18,859 \%$ & $5,773 \%$ & $32,437 \%$ & $0,112 \%$ & $0,046 \%$ & $0,074 \%$ & $0,027 \%$ & $0,088 \%$ & $0,103 \%$ & $0,882 \%$ & $0,201 \%$ & $0,070 \%$ & $0,010 \%$ & $0,128 \%$ \\
\hline & $1,5-3,0$ & $41,513 \%$ & $18,912 \%$ & 6,101\% & $31,916 \%$ & $0,105 \%$ & 0,007\% & 0,047\% & $0,026 \%$ & 0,077\% & 0,068\% & $0,905 \%$ & 0,186\% & $0,050 \%$ & 0,012\% & $0,074 \%$ \\
\hline & $3,0-4,5$ & $41,993 \%$ & $18,212 \%$ & $5,919 \%$ & $32,366 \%$ & $0,108 \%$ & $0,000 \%$ & $0,038 \%$ & $0,023 \%$ & $0,081 \%$ & $0,039 \%$ & $0,907 \%$ & $0,199 \%$ & $0,036 \%$ & $0,009 \%$ & $0,071 \%$ \\
\hline & $4,5-6,0$ & $42,361 \%$ & $18,949 \%$ & $5,597 \%$ & $31,640 \%$ & $0,103 \%$ & $0,090 \%$ & $0,034 \%$ & $0,021 \%$ & $0,040 \%$ & $0,027 \%$ & $0,848 \%$ & $0,190 \%$ & $0,040 \%$ & $0,013 \%$ & $0,047 \%$ \\
\hline & $6,0-7,5$ & $\begin{array}{l}37,051 \% \\
\end{array}$ & $\begin{array}{l}29,002 \% \\
\end{array}$ & $4,714 \%$ & $\begin{array}{l}27,885 \% \\
\end{array}$ & $0,090 \%$ & 0,045\% & $0,046 \%$ & 0,025\% & $0,030 \%$ & 0,035\% & $0,713 \%$ & & $0,043 \%$ & $4 \%$ & $0,086 \%$ \\
\hline & $7,5-9,0$ & $35,318 \%$ & $30,620 \%$ & $4,927 \%$ & $27,634 \%$ & $0,091 \%$ & $0,003 \%$ & $0,044 \%$ & $0,030 \%$ & 0,041\% & $0,028 \%$ & $0,771 \%$ & $0,349 \%$ & 0,051\% & $0,014 \%$ & $0,080 \%$ \\
\hline & $9,0-10,5$ & $\begin{array}{l}34,531 \% \\
\end{array}$ & $33,615 \%$ & $4,824 \%$ & $\begin{array}{l}25,604 \% \\
\end{array}$ & $0,079 \%$ & 0,065\% & $0,086 \%$ & $0,025 \%$ & 0,019\% & 0,054\% & $0,703 \%$ & \begin{tabular}{l|l|}
$0,301 \%$ \\
\end{tabular} & $0,040 \%$ & 0,013\% & $0,042 \%$ \\
\hline & $10,5-12,0$ & $27,173 \%$ & $57,344 \%$ & $2,832 \%$ & $10,801 \%$ & $0,042 \%$ & $0,373 \%$ & $0,413 \%$ & 0,026\% & $9 \%$ & (7\% & $0,405 \%$ & 0,161\% & $0,042 \%$ & $2 \%$ & $0,010 \%$ \\
\hline & $12,0-13,5$ & $32,429 \%$ & $39,229 \%$ & $4,846 \%$ & $21,892 \%$ & $0,072 \%$ & 0,083\% & $0,218 \%$ & $0,024 \%$ & \begin{tabular}{l|l}
$0,027 \%$ \\
\end{tabular} & $0,185 \%$ & $0,678 \%$ & $0,223 \%$ & $0,045 \%$ & $0,022 \%$ & $0,027 \%$ \\
\hline & $13,5-15,0$ & $32,788 \%$ & $36,467 \%$ & $5,041 \%$ & $23,756 \%$ & $0,078 \%$ & $0,204 \%$ & $0,190 \%$ & $0,026 \%$ & 0,049\% & $0,284 \%$ & $0,746 \%$ & $0,286 \%$ & $0,043 \%$ & 0,022\% & $0,019 \%$ \\
\hline
\end{tabular}

PM - 06

PM - 08

$21,0-22,5|19,857 \%| 74,733 \% \mid 1,109 \%$ | 2,881\% | 0,018\% | 0,126\% | 0,782\% | 0,022\% | 0,216\% | 0,013\% | 0,157\% | 0,061\% | 0,021\% | 0,005\% | 0,000\%

\begin{tabular}{|c|c|c|c|c|c|c|c|c|c|c|c|c|c|c|c|c|}
\hline & $12,0-13,5$ & $26,801 \%$ & 66,438\% & $\mid 1,677 \%$ & $4,395 \%$ & 0,025\% & 0,034\% & 0,086\% & 0,018\% & $0,126 \%$ & |0,031\% & $0,255 \%$ & $0,065 \%$ & 0,038\% & 0,011\% & $0,002 \%$ \\
\hline & $13,5-15,0$ & $21,966 \%$ & $74,993 \%$ & $0,625 \%$ & $1,749 \%$ & $0,014 \%$ & $0,063 \%$ & $0,083 \%$ & $0,016 \%$ & $0,309 \%$ & $0,019 \%$ & $0,104 \%$ & $0,022 \%$ & $0,027 \%$ & $0,008 \%$ & $0,003 \%$ \\
\hline & $15,0-16,5$ & $20,449 \%$ & $77,201 \%$ & $0,458 \%$ & $1,431 \%$ & $0,014 \%$ & $0,050 \%$ & $0,095 \%$ & $0,028 \%$ & $0,120 \%$ & 0,011\% & $0,074 \%$ & $0,043 \%$ & $0,020 \%$ & $0,007 \%$ & $0,000 \%$ \\
\hline & $16,5-18,0$ & $22,286 \%$ & 74,919\% & $0,538 \%$ & $1,662 \%$ & $0,017 \%$ & $\begin{array}{l}0,024 \% \\
\end{array}$ & 0,084\% & 0,014\% & $0,268 \%$ & 0,012\% & $0,076 \%$ & $\begin{array}{l}0,059 \% \\
\end{array}$ & 0,032\% & 0,007\% & $0,001 \%$ \\
\hline & $18,0-19,5$ & $21,022 \%$ & 77,489\% & $0,258 \%$ & $0,768 \%$ & $0,014 \%$ & $0,044 \%$ & $0,144 \%$ & $0,025 \%$ & $0,108 \%$ & $0,029 \%$ & $0,039 \%$ & $0,048 \%$ & $0,027 \%$ & $0,007 \%$ & $0,000 \%$ \\
\hline & $19,5-21,0$ & $19,809 \%$ & 78,770\% & 0,197\% & $0,502 \%$ & 0,011\% & $0,000 \%$ & $0,116 \%$ & $0,015 \%$ & $0,374 \%$ & $0,135 \%$ & $0,024 \%$ & $0,021 \%$ & $0,018 \%$ & $0,007 \%$ & $0,002 \%$ \\
\hline & $21,0-22,5$ & $19,121 \%$ & 79,689\% & $0,183 \%$ & $0,500 \%$ & $0,014 \%$ & $0,051 \%$ & $0,085 \%$ & $0,018 \%$ & $0,196 \%$ & $0,074 \%$ & $0,030 \%$ & $0,034 \%$ & $0,027 \%$ & $0,005 \%$ & $0,000 \%$ \\
\hline & $22,5-24,0$ & $19,600 \%$ & 78,838\% & 0,236\% & $0,693 \%$ & $0,008 \%$ & $0,052 \%$ & $0,130 \%$ & $0,042 \%$ & $0,289 \%$ & $0,018 \%$ & $0,048 \%$ & $0,018 \%$ & $0,022 \%$ & $0,005 \%$ & $0,001 \%$ \\
\hline & $24,0-25,5$ & $16,979 \%$ & $81,793 \%$ & $0,160 \%$ & $0,535 \%$ & $0,015 \%$ & $0,013 \%$ & $0,093 \%$ & 0,020\% & $0,264 \%$ & 0,012\% & $0,030 \%$ & $0,059 \%$ & $0,020 \%$ & $0,007 \%$ & $0,000 \%$ \\
\hline & $25,5-27,0$ & $18,503 \%$ & 79,594\% & $0,303 \%$ & $0,904 \%$ & $0,014 \%$ & $0,031 \%$ & $0,155 \%$ & 0,019\% & $0,095 \%$ & $0,285 \%$ & $0,053 \%$ & $0,027 \%$ & $0,012 \%$ & $0,005 \%$ & $\overline{0,000 \%}$ \\
\hline & $27,0-28,5$ & $20,968 \%$ & 75,828\% & $0,660 \%$ & $1,892 \%$ & $0,015 \%$ & $0,040 \%$ & $0,191 \%$ & 0,017\% & $0,157 \%$ & 0,041\% & $0,128 \%$ & $0,036 \%$ & $0,020 \%$ & $0,007 \%$ & $0,000 \%$ \\
\hline & $28,5-30,0$ & $20,976 \%$ & $73,548 \%$ & 0,873\% & $2,634 \%$ & $0,028 \%$ & $0,266 \%$ & $1,128 \%$ & 0,016\% & $0,105 \%$ & 0,169\% & $0,134 \%$ & $0,085 \%$ & $0,029 \%$ & $0,008 \%$ & $0,002 \%$ \\
\hline & $30,0-31,5$ & $16,161 \%$ & 77,694\% & $0,518 \%$ & $\mid 1,664 \%$ & $0,027 \%$ & $0,671 \%$ & $2,592 \%$ & $0,021 \%$ & $0,108 \%$ & $0,378 \%$ & $0,073 \%$ & $0,057 \%$ & $0,032 \%$ & $0,005 \%$ & $0,000 \%$ \\
\hline \multicolumn{17}{|l|}{ SD - 01} \\
\hline & 10,5 & $34,224 \%$ & $33,938 \%$ & $3,355 \%$ & $27,187 \%$ & 7\% & $026 \%$ & , ,048\% & 0,025\% & $7 \%$ & & $0,540 \%$ & $0,318 \%$ & $0,049 \%$ & 0,019\% & $0,139 \%$ \\
\hline & 13,0 & $33,487 \%$ & $35,185 \%$ & $3,125 \%$ & $26,918 \%$ & $0,088 \%$ & $0,010 \%$ & $0,076 \%$ & $0,025 \%$ & $0,029 \%$ & $0,029 \%$ & $0,501 \%$ & $0,314 \%$ & $0,046 \%$ & $0,016 \%$ & $0,153 \%$ \\
\hline & 15,0 & $30,836 \%$ & $36,857 \%$ & $3,480 \%$ & $27,352 \%$ & $\%$ & $0,077 \%$ & $0,031 \%$ & $0,040 \%$ & $6 \%$ & $0,108 \%$ & $3 \%$ & $0,285 \%$ & $0,053 \%$ &, $023 \%$ & $197 \%$ \\
\hline \multicolumn{17}{|l|}{ SD - 02} \\
\hline & 9,5 & $34,557 \%$ & $\%$ & $3,582 \%$ & $\%$ & $5 \%$ & 0,0 & 0,050\% & $\%$ & & $\%$ & 0,5 & & 0,0 & |0,014\% & $0,128 \%$ \\
\hline & 11,5 & $32,748 \%$ & $35,685 \%$ & $3,850 \%$ & $26,226 \%$ & $0,089 \%$ & $0,017 \%$ & $0,045 \%$ & $0,034 \%$ & $0,012 \%$ & $0,119 \%$ & $0,599 \%$ & $0,372 \%$ & $0,040 \%$ & $0,024 \%$ & $0,141 \%$ \\
\hline & 15,0 & $28,402 \%$ & $42,714 \%$ & $4,000 \%$ & $22,914 \%$ & 0,084\% & $0,186 \%$ & 0,078\% & 0,034\% & 0,039\% & $0,635 \%$ & 0,614\% & 0,219\% & $0,041 \%$ & $0,033 \%$ & $0,006 \%$ \\
\hline
\end{tabular}


APÊNDICE H - Tabela de Interpretação dos Perfis dos Furos das Sondagens e Poços de Monitoramento 
Tabela - Interpretação dos perfis dos furos sondagens e poços.

\begin{tabular}{|c|c|c|c|c|c|c|c|c|c|c|}
\hline \multirow{2}{*}{ Identificação } & \multirow{2}{*}{$\begin{array}{l}\text { Coordenada } \\
\text { Norte }(Y)\end{array}$} & \multirow{2}{*}{$\begin{array}{l}\text { Coordenada } \\
\text { Leste }(X)\end{array}$} & \multirow{2}{*}{$\begin{array}{c}\text { Distância } \\
(\mathrm{m})\end{array}$} & \multirow{2}{*}{$\begin{array}{c}\text { Cota do terreno } \\
(\mathrm{m})\end{array}$} & \multirow{2}{*}{$\begin{array}{l}\text { Profundidade } \\
\text { do NA (m) }\end{array}$} & \multirow{2}{*}{$\begin{array}{l}\text { Cota do } \\
\text { NA (m) }\end{array}$} & \multicolumn{2}{|c|}{ Topo do basalto } & \multicolumn{2}{|c|}{ Topo do arenito } \\
\hline & & & & & & & $\begin{array}{c}\text { Profundidade } \\
(\mathrm{m})\end{array}$ & $\begin{array}{l}\text { Cota } \\
(\mathrm{m})\end{array}$ & $\begin{array}{c}\text { Profundidade } \\
(\mathrm{m})\end{array}$ & $\begin{array}{c}\text { Cota } \\
(\mathrm{m})\end{array}$ \\
\hline$P M-01$ & 7663188,10 & 207149,01 & 0,00 & 547,19 & 15,29 & 531,60 & 16,5 & 530,69 & & \\
\hline SD - 01 & 7663156,29 & 207190,85 & 41,84 & 546,20 & 13,46 & 532,74 & 15,5 & 530,70 & & \\
\hline$S D-02$ & 7663136,60 & 207234,00 & 84,99 & 542,75 & 11,05 & 531,70 & 15,0 & 527,75 & & \\
\hline PM - 03 & 7663133,75 & 207240,88 & 91,87 & 541,89 & 11,20 & 530,35 & 15,0 & 526,89 & & \\
\hline$P M-02 A$ & 7663105,22 & 207252,68 & 103,67 & 541,10 & 10,67 & 530,25 & 14,0 & 527,10 & & \\
\hline$P M-02$ B & 7663105,22 & 207252,68 & 103,67 & 541,10 & 10,70 & 530,08 & 14,0 & 527,10 & & \\
\hline PM - 04 & 7663133,47 & 207265,93 & 116,92 & 540,34 & 9,95 & 530,11 & 13,5 & 526,84 & & \\
\hline SD - 06 & 7663136,05 & 207268,03 & 119,02 & 540,53 & 9,50 & 531,03 & 5,3 & 535,23 & 9,8 & 530,73 \\
\hline SD - 07 & 7663135,98 & 207282,54 & 133,53 & 539,26 & - & - & 6,0 & 533,26 & 12,6 & 526,66 \\
\hline PM - 05 & 7663163,88 & 207300,38 & 151,37 & 538,21 & 28,82 & 509,09 & 6,0 & 532,21 & 10,0 & 528,21 \\
\hline$S D-03$ & 7663139,95 & 207305,90 & 156,89 & 538,51 & - & - & 5,0 & 533,51 & 12,0 & 526,51 \\
\hline PM - 06 & 7663122,55 & 207332,63 & 183,62 & 536,09 & 27,30 & 508,49 & 3,0 & 533,09 & 9,0 & 527,09 \\
\hline SD - 04 & 7663142,37 & 207339,31 & 190,30 & 535,78 & - & - & 5,0 & 530,78 & 9,3 & 526,48 \\
\hline $\mathrm{PM}-08$ & 7663199,52 & 207342,86 & 193,85 & 535,43 & 27,73 & 507,36 & 7,5 & 527,93 & 10,5 & 524,93 \\
\hline SD - 05 & 7663179,36 & 207361,03 & 212,02 & 535,02 & - & - & 5,6 & 529,42 & 9,0 & 526,02 \\
\hline PM - 07 & 7663155,73 & 207362,92 & 213,91 & 535,08 & 31,47 & 503,41 & 3,0 & 532,08 & 12,0 & 523,08 \\
\hline
\end{tabular}


APÊNDICE I - Perfil Geológico-Geotécnico para o Sítio Estudado 


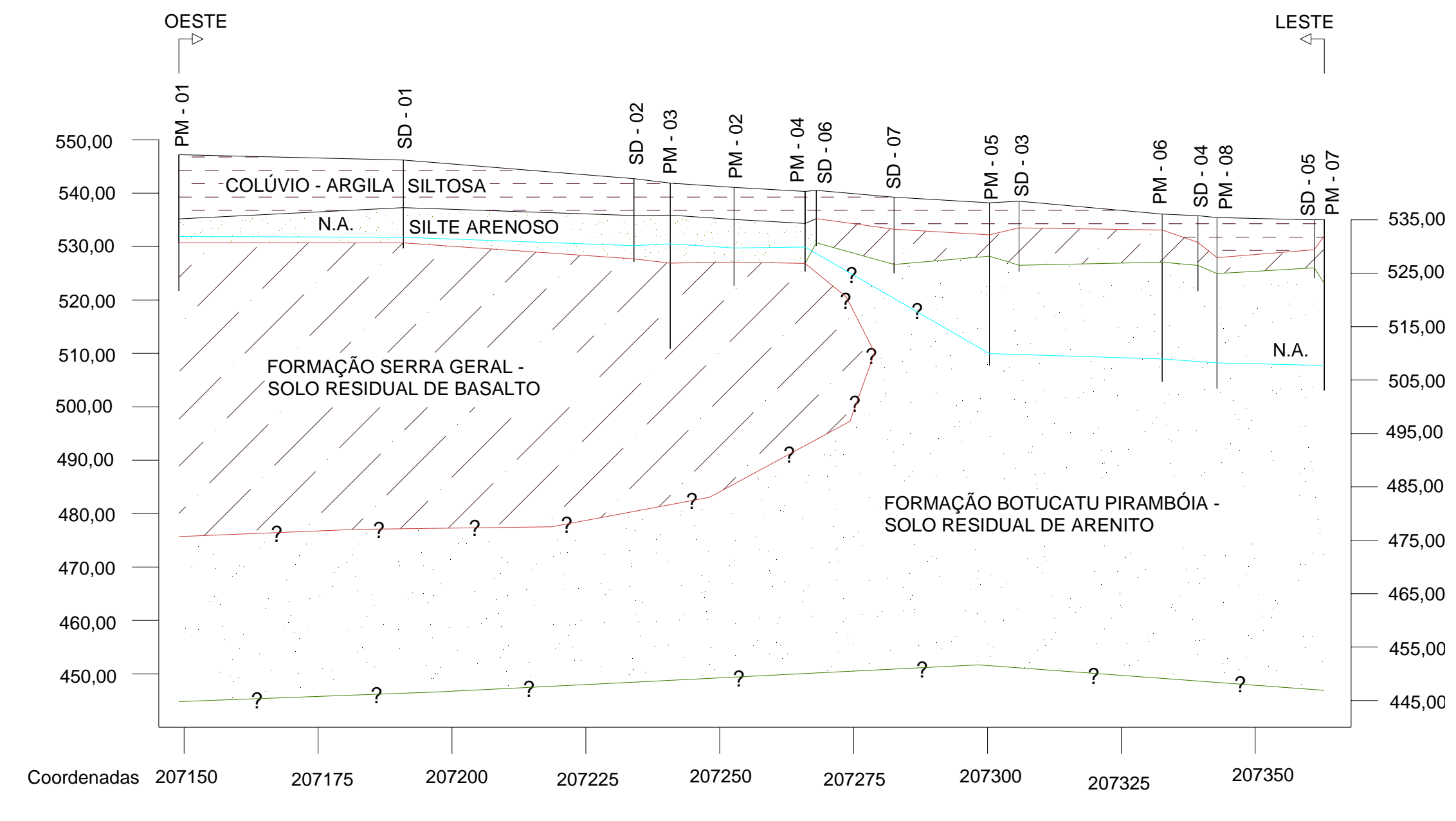

$?=$ CONTATO INDETERMINADO N.A. = NÍVEL DE ÁGUA

ESCALA APROXIMADA $=1 / 1000$ 
APÊNDICE J - Tabela com resultados obtidos em cada slug test 
Tabela - Resultados dos ensaios de slug test.

\begin{tabular}{|c|c|c|c|c|c|c|c|}
\hline \multirow{2}{*}{ Identificação } & \multicolumn{2}{|r|}{$6 / 5 / 2004$} & \multicolumn{4}{|c|}{$29 / 6 / 2004$} & \multirow{2}{*}{$\mathrm{K}_{\text {médio }}(\mathrm{cm} / \mathrm{s})$} \\
\hline & $\mathrm{K}(\mathrm{cm} / \mathrm{s})$ & Método & $\mathrm{K}(\mathrm{cm} / \mathrm{s})$ & Método & $\mathrm{K}(\mathrm{cm} / \mathrm{s})$ & Método & \\
\hline PM - 01 & 4,63E-04 & Introdução de corpo com volume de $1,75 \mathrm{~L}$ & 4,42E-04 & Retirada de $1 \mathrm{~L}$ de água & & & $4,53 \mathrm{E}-04$ \\
\hline$P M-02 A$ & 1,89E-03 & Introdução de corpo com volume de 1,75 L & 2,04E-03 & Retirada de $1 \mathrm{~L}$ de água & & & 1,97E-03 \\
\hline PM - 02 B & 1,01E-04 & Introdução de corpo com volume de 1,75 L & 1,05E-04 & Retirada de $1 \mathrm{~L}$ de água & & & 1,03E-04 \\
\hline PM - 03 & 3,41E-03 & Introdução de corpo com volume de 1,75 L & $3,68 \mathrm{E}-03$ & Retirada de $1 \mathrm{~L}$ de água & 3,56E-03 & Retirada de $1 \mathrm{~L}$ de água & $3,55 \mathrm{E}-03$ \\
\hline PM - 04 & 3,09E-03 & Introdução de corpo com volume de $1,75 \mathrm{~L}$ & 3,29E-03 & Retirada de $1 \mathrm{~L}$ de água & 3,39E-03 & Retirada de $1 \mathrm{~L}$ de água & $3,26 \mathrm{E}-03$ \\
\hline PM - 05 & 5,82E-03 & Introdução de corpo com volume de $0,88 \mathrm{~L}$ & 3,70E-03 & Introdução de $3 \mathrm{~L}$ de água & & & $4,76 \mathrm{E}-03$ \\
\hline PM - 07 & 5,57E-05 & Introdução de corpo com volume de $0,44 \mathrm{~L}$ & 5,05E-05 & Introdução de 3 L de água & & & $5,31 \mathrm{E}-05$ \\
\hline PM - 08 & 4,81E-05 & Introdução de corpo com volume de $1,75 \mathrm{~L}$ & 1,57E-04 & Introdução de 1,5 L de água & & & 1,03E-04 \\
\hline
\end{tabular}




\section{APÊNDICE L:}

- Planilha de campo usada no esgotamento;

- Planilha de campo usada na coleta. 
Tabela - Planilha de campo usada no esgotamento.

\begin{tabular}{|c|c|c|c|c|c|c|c|c|c|c|}
\hline \multirow{2}{*}{ Identificação } & \multicolumn{2}{|c|}{ Coordenadas } & \multirow{2}{*}{$\begin{array}{l}\text { Cota do } \\
\text { Terreno }\end{array}$} & \multirow{2}{*}{$\begin{array}{l}\text { (B) Base } \\
\text { do Poço } \\
\text { (m) }\end{array}$} & \multirow{2}{*}{$h(m)$} & \multirow{2}{*}{$\begin{array}{l}\text { (NA) } \\
\text { Profundidade } \\
\text { do NA. (m) }\end{array}$} & \multirow{2}{*}{$\begin{array}{l}\text { (B-NA+h) Altura } \\
\text { da Lâmina } \\
\text { d'água (m) }\end{array}$} & \multirow{2}{*}{$\begin{array}{c}\text { V=6,29*(B-NA+h) } \\
\text { Volume a esgotar } \\
\text { (litros) }\end{array}$} & \multirow{2}{*}{$\begin{array}{l}\text { Volume } \\
\text { Esgotado } \\
\text { (litros) }\end{array}$} & \multirow{2}{*}{ Observações } \\
\hline & Norte & Leste & & & & & & & & \\
\hline PM - 01 & 207148,65 & 7663188,69 & 547,56 & 18,60 & $-0,30$ & 15,29 & 3,01 & 18,9 & 19,0 & - \\
\hline PM - 02 A & 207243,55 & 7663105,03 & 541,35 & 16,40 & $-0,32$ & 10,67 & 5,41 & 34,0 & 31,0 & - \\
\hline PM - 02 B & 207243,55 & 7663105,03 & 541,35 & 18,40 & $-0,18$ & 10,70 & 7,52 & 47,3 & 35,0 & - \\
\hline PM - 04 & 207275,74 & 7663136,39 & 539,87 & 15,00 & $-0,28$ & 9,95 & 4,77 & 30,0 & 34,5 & - \\
\hline PM - 05 & 207300,54 & 7663163,36 & 538,25 & 30,50 & $-0,30$ & 28,82 & 1,38 & 8,7 & 8,5 & - \\
\hline PM - 06 & 207333,53 & 7663122,33 & 536,13 & 31,40 & $-0,30$ & 27,30 & 3,80 & 23,9 & 21,0 & - \\
\hline PM - 07 & 207362,07 & 7663157,72 & 535,18 & 32,00 & $-0,20$ & 31,47 & 0,33 & 2,1 & 2,0 & $\begin{array}{l}\text { * Esgotado após } 4 \\
\text { tentativas. }\end{array}$ \\
\hline PM - 08 & 207344,28 & 7663197,40 & 535,43 & 32,00 & $-0,34$ & 27,73 & 3,93 & 24,7 & 17,0 & *Poço praticamente seco. \\
\hline Cisterna & 207272,73 & 7663063,88 & 542,08 & - & $-0,42$ & 13,01 & - & - & - & * Em uso. \\
\hline PB & 207257,5 & 7663067,83 & 541,65 & - & - & - & - & - & - & * Em uso. \\
\hline
\end{tabular}

Data 31/03/02004

Início 08:30

Término 16:30

Dia ensolarado 
Tabela - Planilha de campo usada na coleta.

\begin{tabular}{|c|c|c|c|c|c|c|}
\hline \multirow{2}{*}{ Identificação } & \multicolumn{2}{|c|}{ Coordenadas } & \multirow{2}{*}{$\begin{array}{l}\text { Cota do } \\
\text { Terreno }\end{array}$} & \multirow{2}{*}{$\begin{array}{l}\text { Base Poco } \\
\text { (m) }\end{array}$} & \multirow{2}{*}{$\begin{array}{c}\text { Profundidade do } \\
\text { NA. }\end{array}$} & \multirow{2}{*}{ Observações } \\
\hline & Norte & Leste & & & & \\
\hline PM - 01 & 207148,65 & 7663188,69 & 547,56 & 18,60 & 15,26 & * Turva \\
\hline$P M-02 A$ & 207243,55 & 7663105,03 & 541,35 & 16,40 & 10,69 & * Pouco turva \\
\hline PM - 02 B & 207243,55 & 7663105,03 & 541,35 & 18,40 & 10,69 & ${ }^{*}$ Pouco turva \\
\hline PM - 03 & 207241,49 & 7663134,14 & 541,91 & 15,45 & 11,21 & * Limpida \\
\hline PM - 04 & 207275,74 & 7663136,39 & 539,87 & 15,00 & 9,97 & * Limpida \\
\hline PM - 05 & 207300,54 & 7663163,36 & 538,25 & 30,50 & 28,80 & * Turva \\
\hline PM - 06 & 207333,53 & 7663122,33 & 536,13 & 31,40 & 27,29 & * Limpida \\
\hline PM - 07 & 207362,07 & 7663157,72 & 535,18 & 32,00 & 31,43 & ${ }^{*}$ Muito turva \\
\hline PM - 08 & 207344,28 & 7663197,40 & 535,43 & 32,00 & 27,25 & * Turva \\
\hline Cisterna & 207272,73 & 7663063,88 & 542,08 & - & 13,01 & * Limpida \\
\hline PB & 207257,5 & 7663067,83 & 541,65 & - & - & * Limpida \\
\hline
\end{tabular}

Data 01/04/02004

Início 09:15

Término 17:10

Dia ensolarado 
ANEXO A - Seção Geológica A: Destilaria Galo Bravo ao CEASA 
SECYAO GEOLOGICA A DESTILARIA GALO BRAVO AO CEASA

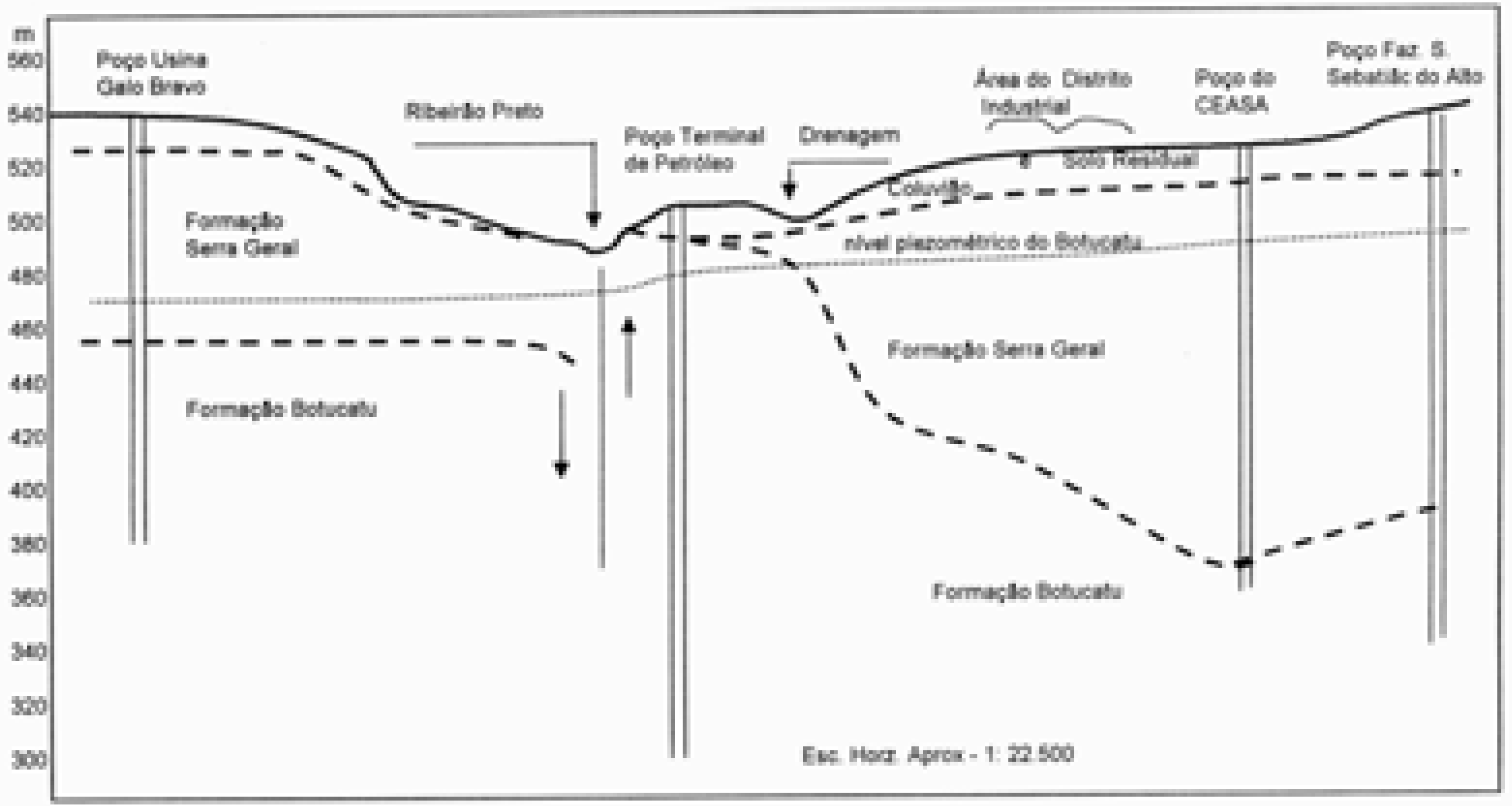


ANEXO B - Tabela com Dados de Poços Profundos

Cadastrados no Município de Ribeirão Preto 


\begin{tabular}{|c|c|c|c|c|c|c|c|c|c|c|c|c|}
\hline \multicolumn{13}{|c|}{ POÇOS PROFUNDOS CADASTRADOS NO MUNICÍPIO DE RIBEIRÃO PRETO } \\
\hline & \multirow{2}{*}{ Local } & \multicolumn{2}{|c|}{ Coordenadas } & \multirow{2}{*}{$\begin{array}{l}\text { Cota do } \\
\text { Terreno } \\
(\mathrm{m})\end{array}$} & \multirow{2}{*}{$\begin{array}{l}\text { Profundidade } \\
(\mathrm{m})\end{array}$} & \multirow{2}{*}{ Perfil Estratigráfico } & \multirow{2}{*}{$\begin{array}{l}\text { Topo } \\
\text { Arenito } \\
(\mathrm{m})\end{array}$} & \multirow{2}{*}{ NA $(m)$} & \multirow{2}{*}{$\begin{array}{l}\text { Cota do } \\
\text { NA }(m)\end{array}$} & \multirow{2}{*}{$\mathrm{ND}(\mathrm{m})$} & \multirow{2}{*}{$\left(\mathrm{m}^{3} / \mathrm{h}\right)$} & \multirow{2}{*}{$\begin{array}{c}\top \\
\left(m^{2} / d i a\right)\end{array}$} \\
\hline & & $L-O$ & $N-S$ & & & & & & & & & \\
\hline 1 & $\begin{array}{l}\text { Via } \\
\text { Anhanguera, } \\
\mathrm{Km} 20\end{array}$ & 210450,00 & 7664100,00 & 550,0 & 145,00 & $\begin{array}{l}0 \text { a } 114 \mathrm{~m}, \text { Serra Geral } \\
114 \text { a } 145 \mathrm{~m} \text {, Botucatu }\end{array}$ & 436,0 & & & & & \\
\hline 2 & Galo Bravo & 206750,00 & 7662400,00 & 530,0 & 153,00 & $\begin{array}{l}0 \text { a } 72 \mathrm{~m} \text {, Serra Geral } \\
72 \text { a } 153 \mathrm{~m} \text {, Botucatu }\end{array}$ & 458,0 & 60,0 & 470,0 & 73,0 & 30,0 & \\
\hline 3 & $\begin{array}{l}\text { Terminal de } \\
\text { Petróleo }\end{array}$ & 208550,00 & 7663100,00 & 505,0 & 200,00 & $\begin{array}{l}0 \text { a } 11.5 \mathrm{~m} \text {, Serra Geral } \\
11.5 \text { a } 200 \mathrm{~m} \text {, Botucatu/Piramboia }\end{array}$ & 493,5 & 10,8 & 494,2 & 31,0 & 150,0 & \\
\hline 4 & ETA - Reck & 207920,00 & 7663680,00 & 506,0 & 156,00 & $\begin{array}{l}0 \text { a 10m, Colúvio Superficial } \\
10 \text { a 156m, Botucatu/Piramboia }\end{array}$ & 496,0 & 18,0 & 488,0 & 64,0 & 178,0 & \\
\hline 5 & $\begin{array}{l}\text { Penha } \\
\text { Máquinas } \\
\text { Agrícolas }\end{array}$ & 210950,00 & 7660400,00 & 528,0 & 129,00 & 0 a 129m, Botucatu/Piramboia & 528,0 & 22,5 & 505,5 & 29,0 & 148,0 & \\
\hline 6 & $\begin{array}{l}\text { Jardim } \\
\text { Pompolo - } \\
\text { DAERP }\end{array}$ & 206100,00 & 7658250,00 & 560,0 & 302,00 & $\begin{array}{l}0 \text { a } 112 \mathrm{~m} \text {, Serra Geral } \\
112 \text { a 302m, Botucatu/Piramboia }\end{array}$ & 448,0 & 135,0 & 425,0 & 155,0 & 189,0 & \\
\hline 7 & $\begin{array}{l}\text { CDHU - } \\
\text { DAERP }\end{array}$ & 206250,00 & 7651350,00 & 555,0 & 330,00 & $\begin{array}{l}0 \text { a } 103 \mathrm{~m} \text {, Serra Geral } \\
103 \text { a } 315 \mathrm{~m} \text {, Botucatu/Piramboia } \\
315 \text { a } 330 \mathrm{~m} \text {, Sill de Diabasio }\end{array}$ & 452,0 & 97,0 & 458,0 & 133,0 & 214,0 & \\
\hline 8 & CEASA & 209150,00 & 7665450,00 & 530,0 & 165,00 & $\begin{array}{l}0 \text { a } 160 \mathrm{~m} \text {, Serra Geral } \\
160 \text { a } 165 \mathrm{~m} \text {, Botucatu/Piramboia }\end{array}$ & 370,0 & & & & 10,0 & \\
\hline 9 & Ciane & 208350,00 & 7658000,00 & 500,0 & 208,50 & $\begin{array}{l}0 \text { a } 30 \mathrm{~m} \text {, Serra Geral } \\
30 \text { a } 208.5 \mathrm{~m} \text {, Botucatu }\end{array}$ & 470,0 & 57,0 & 443,0 & 85,0 & 250,0 & 540,0 \\
\hline 10 & $\begin{array}{l}\text { Jardim } \\
\text { Canadá - } \\
\text { DAERP }\end{array}$ & 208750,00 & 7650900,00 & 560,0 & 284,00 & $\begin{array}{l}0 \text { a } 72 \mathrm{~m} \text {, Serra Geral } \\
72 \text { a } 284 \mathrm{~m} \text {, Botucatu/Piramboia }\end{array}$ & 488,0 & 63,8 & 496,2 & 90,0 & 320,0 & 652,0 \\
\hline 11 & $\begin{array}{l}\text { Bairro Santa } \\
\text { Tereza }\end{array}$ & 205500,00 & 7652150,00 & 565,0 & 301,75 & $\begin{array}{l}0 \text { a } 92.5 \mathrm{~m} \text {, Serra Geral } \\
92.5 \text { a } 301.75 \mathrm{~m}, \\
\text { Botucatu/Piramboia }\end{array}$ & 472,5 & 68,1 & 496,9 & 125,0 & 280,0 & 570,0 \\
\hline 12 & $\begin{array}{l}\text { Jardim } \\
\text { Piratininga }\end{array}$ & 205250,00 & 7654650,00 & 585,0 & 390,00 & $\begin{array}{l}0 \text { a } 158 m \text {, Serra Geral } \\
158 \text { a 390m, Botucatu/Piramboia }\end{array}$ & 427,0 & 137,3 & 447,7 & 184,0 & 250,0 & 417,0 \\
\hline 13 & $\begin{array}{l}\text { Fazenda } \\
\text { São } \\
\text { Sebastião do } \\
\text { Alto }\end{array}$ & 209750,00 & 7666250,00 & 540,0 & 200,00 & $\begin{array}{l}0 \text { a } 145 \mathrm{~m} \text {, Serra Geral } \\
145 \text { a } 200 \mathrm{~m} \text {, Botucatu }\end{array}$ & 386,0 & 49,0 & 491,0 & & & \\
\hline
\end{tabular}

